\title{
Coronary heart disease in the Netherlands : incidence, etiology and risk prediction
}

Citation for published version (APA):

Merry, A. H. H. (2010). Coronary heart disease in the Netherlands : incidence, etiology and risk prediction. [Doctoral Thesis, Maastricht University]. Datawyse / Universitaire Pers Maastricht.

https://doi.org/10.26481/dis.20101210am

Document status and date:

Published: 01/01/2010

DOI:

10.26481/dis.20101210am

Document Version:

Publisher's PDF, also known as Version of record

\section{Please check the document version of this publication:}

- A submitted manuscript is the version of the article upon submission and before peer-review. There can be important differences between the submitted version and the official published version of record.

People interested in the research are advised to contact the author for the final version of the publication, or visit the DOI to the publisher's website.

- The final author version and the galley proof are versions of the publication after peer review.

- The final published version features the final layout of the paper including the volume, issue and page numbers.

Link to publication

\footnotetext{
General rights rights.

- You may freely distribute the URL identifying the publication in the public portal. please follow below link for the End User Agreement:

www.umlib.nl/taverne-license

Take down policy

If you believe that this document breaches copyright please contact us at:

repository@maastrichtuniversity.nl

providing details and we will investigate your claim.
}

Copyright and moral rights for the publications made accessible in the public portal are retained by the authors and/or other copyright owners and it is a condition of accessing publications that users recognise and abide by the legal requirements associated with these

- Users may download and print one copy of any publication from the public portal for the purpose of private study or research.

- You may not further distribute the material or use it for any profit-making activity or commercial gain

If the publication is distributed under the terms of Article $25 \mathrm{fa}$ of the Dutch Copyright Act, indicated by the "Taverne" license above, 
Coronary heart disease in the Netherlands:

Incidence, etiology and risk prediction 
Coronary heart disease in the Netherlands:

Incidence, etiology and risk prediction

Audrey H.H. Merry

ISBN: $\quad$ 978-90-5278-987-3

Cover design: Bas Verhage

Lay-out: Yvonne Leenders

Printed by Datawyse - Universitaire Pers Maastricht

(C) 2010, A.H.H. Merry

All rights reserved. No part of this thesis may be reproduced or transmitted in any form or by any means, electronic or mechanical, including photocopying, recording or any information storage or retrieval system, without permission in writing from the author, or, when appropriate, from the publishers of the publications. 


\title{
Coronary heart disease in the Netherlands: Incidence, etiology and risk prediction
}

\author{
PROEFSCHRIFT \\ Ter verkrijging van de graad van doctor \\ aan de Universiteit Maastricht, \\ op gezag van de Rector Magnificus, \\ Prof. mr. G.P.M.F. Mols, \\ volgens het besluit van het College van Decanen, \\ in het openbaar te verdedigen \\ op vrijdag 10 december 2010 om 14:00 uur \\ door \\ Audrey Helena Hendrica Merry
}

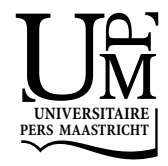




\section{Promotores}

Prof. dr. ir. P.A. van den Brandt

Prof. dr. A.P.M. Gorgels

\section{Copromotores}

Dr. L.J. Schouten

Dr. ir. J.M.A. Boer (Rijksinstituut voor Volksgezondheid en Milieu, Bilthoven)

\section{Beoordelingscommissie}

Prof. dr. J.F.M. Metsemakers (voorzitter)

Prof. dr. K.G.M. Moons (UMC Utrecht)

Prof. dr. R.J.G. Peters (Universiteit van Amsterdam)

Prof. dr. C.D.A. Stehouwer

Prof. dr. N.K. de Vries

This project was funded by CAPHRI School for Public Health and Primary Care, Maastricht University.

The studies presented in this thesis were conducted at the Department of Epidemiology, CAPHRI School for Public Health and Primary Care, Maastricht University. CAPHRI is part of the Netherlands School of Primary Care Research ( $\mathrm{CaRe}$ ), which has been acknowledged since 1995 by the Royal Netherlands Academy of Arts and Sciences (KNAW).

Financial support by the Netherlands Heart Foundation for the publication of this thesis is gratefully acknowledged.

Financial support for the printing of this thesis was kindly provided by the Department of Epidemiology (Maastricht University). 
Not everything that counts can be counted, and not everything that can be counted counts.

(Albert Einstein) 



\section{Contents}

$\begin{array}{lll}\text { Chapter } 1 & \text { General introduction } & 9\end{array}$

Chapter 2 Validity of coronary heart diseases and heart failure based on 31 hospital discharge and mortality data in the Netherlands using the cardiovascular registry Maastricht (CAREMA) cohort study

Chapter 3 Co-occurrence of metabolic factors and the risk of coronary heart disease: a prospective cohort study in the Netherlands

Chapter 4 Do smoking, alcohol consumption, physical activity, and family history have different effects on the risks of acute myocardial infarction and unstable angina pectoris? A prospective cohort study

Chapter 5 Risk prediction of incident coronary heart disease in the Netherlands: recalibration and improvement of the SCORE risk function

Chapter 6 General discussion

Summary

Samenvatting

Dankwoord 



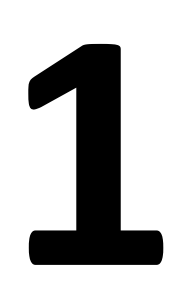

General introduction 
Heavy chest pain, shortness of breath, nausea, vomiting, palpitations, sweating, being very anxious... These complaints can be experienced by a patient suffering from an acute myocardial infarction (AMI). In the Netherlands, every day about 66 persons are being admitted to the hospital with an AMI (1). In the hospital, the diagnosis is made by an electrocardiogram (ECG) and the determination of enzyme levels. Additionally, coronary angiography is performed in more than half of the patients to detect the localisation and amount of stenosis in the coronary arteries (2). Patients may be treated with medication, coronary artery bypass grafting surgery or percutaneous coronary intervention and are mostly subjected to lifelong use of medications. Although about $11 \%$ of the patients die within 30 days after their admission to the hospital (2), most patients survive their AMI. They are, however, at increased risk of developing new ischemic events, cardiac arrhythmias, or heart failure. Furthermore, their quality of life may be considerably lower compared with healthy persons, even long after their event $(3,4)$. Coronary heart disease (CHD) including AMI also has large consequences for the Dutch population in general. In 2005, CHD was responsible for $2.8 \%$ of the total health care costs in men and $1.2 \%$ in women (5). As patients are not able to work for a certain amount of time after their event, CHD is also responsible for high costs due to productivity losses (lost working days) (6).

Because of this high disease burden of CHD in the Netherlands with large consequences for the patient as well as for society, the focus has been on the primary prevention of CHD in which it is useful to identify persons at high risk of the disease but without symptoms yet. In the last decades, several attempts have been made to predict the absolute risk of an individual to develop CHD in the next years, based on the cumulative effects of the person's risk factors. As a result, several risk scores have been developed for different cardiovascular endpoints, of which the Framingham risk score is probably the best-known $(7,8)$. Although these risk scores performed reasonably well within their own and similar populations, different levels and trends in risk factors and in disease rates in other populations diminish their performance in other settings, as was recently also found in a Dutch population (9).

Therefore, the main focus of this thesis is to study the accuracy of existing risk scores used in primary practice in the Netherlands and to develop an adjusted risk function to predict the 10-year absolute risk of CHD incidence in a Dutch population-based cohort study.

\section{Coronary heart disease}

CHD is mainly caused by atherosclerosis in one or more of the coronary arteries. The development of the disease starts already early in life. Changes in the arterial wall, including the deposition of lipids to form fatty streaks, may occur already in childhood or adolescence $(10,11)$. Although this is an unhealthy condition, it is found in most humans. In some people, however, this condition may progress to a definite athero- 
sclerotic plaque, under influence of their risk factor levels (12). When a coronary artery is largely narrowed or eventually totally occluded by the occurrence of a thrombus on an atherosclerotic plaque, the disease may become clinically evident. The natural course of CHD is characterized by a long asymptomatic phase, followed by a shorter clinical phase.

Classically, two main subtypes of CHD can be distinguished: AMI and unstable angina pectoris (UAP). The clinical presentation of patients with AMI or UAP depends on the degree of occlusion $(12,13)$. AMI is characterised by the complete and persistent occlusion of a coronary artery caused by a thrombus after plaque disruption resulting in myocardial ischemia and eventually cell death. Clinical symptoms of AMI are prolonged chest pain, ECG abnormalities such as ST elevations and Q waves, and raised levels of cardiac enzymes such as creatinine kinase (CK), aspartate aminotransferase (ASAT), and lactate dehydrogenase (LDH). In UAP, the occlusion is caused by a labile thrombus that may not completely occlude the coronary artery or may lead to an early reopening of the artery. As a result, clinical symptoms are somewhat different from those of AMI: chest pain may last shorter and responds to nitroglycerin, and ECG abnormalities are less typical with ST depression as the most specific change. Myocardial cell death, however, may also occur in patients with UAP as became evident after the introduction of more sensitive biomarkers for cell damage such as troponin $\mathrm{T}$ and $\mathrm{I}$. Consequently, a new classification of acute coronary syndromes was introduced consisting of ST elevation AMI (STEMI), non-ST elevation AMI (non-STEMI), UAP with raised troponin levels, and UAP without raised troponin levels but characterised by chest pain and ischemic EGC abnormalities (14). This new classification system became available during our study period (1987-2003) and may have influenced the clinical diagnoses of AMI and UAP, made by cardiologists, which are used in this thesis.

\section{Incidence of coronary heart disease}

In 2008, 11,387 persons died from CHD in the Netherlands, accounting for $8 \%$ of all deaths (1). CHD is also one of the major causes of death worldwide, accounting for $12 \%$ of all deaths (15). In many developed countries, the mortality rates of CHD have declined in the last decades (16-22). A considerable decrease in the number of deaths from CHD was also seen in the Netherlands between 1980 and 2004 (figure 1). The mortality rate of AMI declined by $70 \%$ for men and $63 \%$ for women in this period (23). Additionally, the number of deaths according to other coronary diseases such as old myocardial infarction and angina pectoris also declined considerably since 1996. 


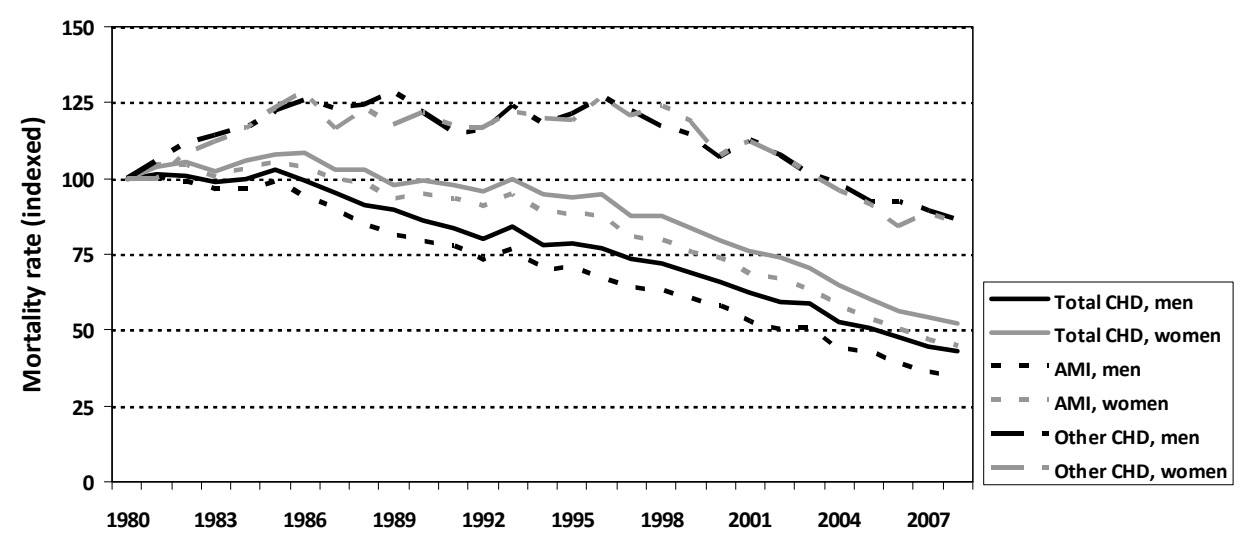

Figure 1 Trend in mortality rates in men and women for coronary heart disease (CHD) in the period 1980-2008, standardized to the Dutch population in 1990 and indexed (1980 is 100).

ICD-9 codes: acute myocardial infarction (AMI) 410; other CHD 411-414; total CHD 410-414.

Source: Statistics Netherlands.

Because national as well as regional cardiovascular registries are not available in the Netherlands and most other countries, incidence rates for CHD and other heart diseases are being estimated using data from other sources such as databases of general practitioners (GP), hospital discharge diagnoses and/or causes of death registries. The validity of incidence rates based on data from GP registries, however, depends on the completeness and precision of the registrations made by the GPs. In addition, a disadvantage of incidence estimates based on data from the Dutch national hospital discharge registry (LMR) is that these estimates do not include day care admissions and outpatients' visits, although these are less relevant for the diagnosis of acute CHD events. Nowadays, incidence rates are often estimated by record linkage of population registries to hospital discharge data in combination with causes of death registries in the Netherlands. Based on this method, the crude incidence rates of a first AMI were 293 and 174 per 100,000 in men and women, respectively, in 2000 (24).

From 1980 till 1995, the number of hospital admissions for total CHD increased considerably, which was mostly due to an increase in the number of admissions for (sub)acute (ICD-9 code 411) and chronic (ICD-9 codes 412-414) types of CHD (figure 2) (23). Thereafter, a declining trend was seen for all CHD subtypes until 2004, when the number of hospital admissions increased again for CHD, especially for chronic CHD (23). So, there seems to be a shift from acute to more chronic subtypes of CHD (16). Nevertheless, a slight increase in the number of hospital admissions was also seen for AMI in the period 2005-2008 (1), despite of the steady decrease in the previous years since 1985. 


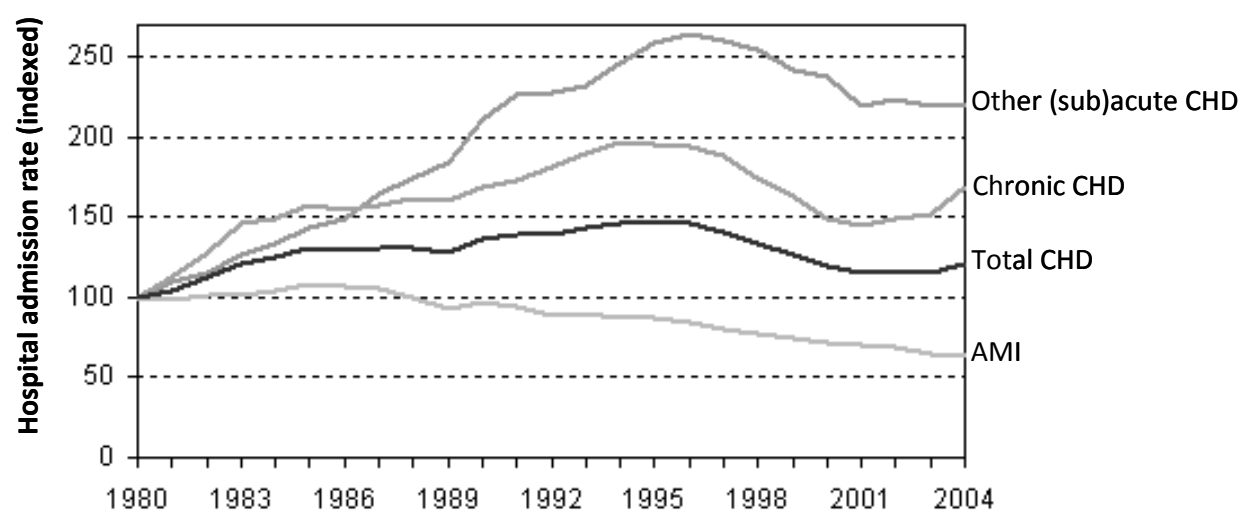

Figure 2 Trend in hospital admissions for coronary heart disease (CHD) according to subtypes in the period 1980-2004, standardized to the Dutch population in 1990 and indexed (1980 is 100).

Subtypes according to ICD-9 codes: acute myocardial infarction (AMI) 410; other acute and subacute CHD 411; chronic CHD 412-414; total CHD 410-414.

Source: www.nationaalkompas.nl/gezondheid-en-ziekte/ziekten-en-aandoeningen/hartvaatstelsel/coronaire-

hartziekten/trend, accessed in May 2010.

The decreasing trend in the mortality rate of CHD can firstly be explained by a better survival of patients with CHD. The better treatment and care of patients with CHD have resulted in a lower case-fatality rate and thus a better survival. This better survival may also have caused the shift of patients to more chronic types of CHD. As patients live longer because of their treatment of acute $\mathrm{CHD}$, they may be at higher risk to develop chronic CHD such as angina pectoris. Secondly, the decreasing trend in CHD mortality can be explained by a lower incidence rate of CHD. The declining trend in the number of hospital admissions of especially acute CHD types may be explained by the favourable changes in risk factor prevalences in the Netherlands such as a reduction in the percentage of smokers, decreasing plasma total cholesterol levels (25), a lower intake of trans-fatty acids, and an increase in the number of persons treated for hypertension $(16,23)$. In contrast, the number of persons with overweight/obesity and diabetes mellitus increased (23). As a result of the trends in CHD mortality and incidence rates, the proportion of non-fatal CHD to fatal CHD has increased during the last decades.

\section{Etiology (risk factors)}

The association between etiological factors and the risk of CHD has been thoroughly investigated. Several risk factors have been established for CHD which can be subdivided in demographic factors such as increasing age and male sex; behavioural factors such as smoking, physical inactivity, and heavy alcohol consumption; metabolic factors such as high systolic blood pressure, high serum cholesterol levels, overweight or obesity, and diabetes mellitus; and genetic factors such as familial predisposition. Addi- 
tionally, several dietary factors have been associated with the risk of CHD such as the intake of fruit and vegetables, fish consumption, and fibre intake (26). Together, the major established risk factors explain about $75 \%$ of the excess risk of CHD within populations $(27,28)$. Data from both observational studies and clinical trials have shown that changes in these factors by lifestyle modifications or pharmaceutical treatment resulted in large risk reductions of $\operatorname{CHD}(28,29)$. Although the established risk factors explain a considerable part of the excess risk of CHD, a smaller part of the excess risk is still unexplained. Therefore, a considerable amount of research has been performed on emerging risk factors, e.g. atherosclerotic markers such as homocysteine, thrombotic factors such as fibrinogen, inflammatory markers such as $\mathrm{C}$ - reactive protein, psychosocial factors such as depression and stress, and genetic markers (30-33). Many of these factors have been found to be independent risk factors for CHD.

\section{AMI versus UAP}

While many studies investigated the associations between established as well as emerging factors and the incidence of total $\mathrm{CHD}$ or $\mathrm{AMI}$, only few studies investigated associations with the incidence of UAP as separate outcome $(34,35)$. This may be explained by the difficulty of identifying cases with incident UAP as this diagnosis is not always as certain as the well-defined diagnosis of AMI. As previously described, the clinical presentation with AMI or UAP depends on the degree of occlusion of the coronary artery. Because risk factors may influence the progression of atherosclerotic and thrombotic processes $(12,13)$, the strength of the associations with these factors may be different for AMI and UAP. To my knowledge, only one study compared associations of risk factors with AMI versus associations with UAP (35). They found that family history of myocardial infarction was more strongly related to UAP compared with AMI, while this difference was not found for a history of stroke. Two studies compared the clinical characteristics between patients admitted to the hospital with AMI and patients admitted with $\operatorname{UAP}(36,37)$. Both studies found that patients with AMI were older, more often male and current smoker compared with UAP patients. Furthermore, Kennon et al. (36) reported that patients with AMI more often had a raised creatinine level, while hypertension, previous treatment with aspirin, and a history of CHD were more often present in patients with UAP. Based on the results of these studies, it may be suggested that the strength of associations with these risk factors differs between AMI and UAP.

\section{Cumulative effect of risk factors}

Although many studies found that risk factors independently increase the risk of total CHD, AMI, and to a lesser extent UAP, a single risk factor is mostly not sufficient to cause these diseases. CHD is a multifactorial disease which is caused by the combined effect of risk factors including their interactions in a complex way. A well-known example is the combined effect of the metabolic risk factors diabetes, hypertension, hypercholesterolemia, and obesity. These factors are all independent risk factors for CHD, 
but they tend to co-occur within an individual more often than expected by chance $(38,39)$. As a result, several studies have shown a dose-response relationship between these metabolic factors and the risk of CHD; the more factors present, the higher the risk (40-45). Different combinations of risk factors may cause CHD, but the level of the increased risk may vary between these different combinations. Only two studies investigated CHD risk according to specific combinations of metabolic factors $(40,45)$. These studies indeed found that different combinations of risk factors were associated with varying risks of $\mathrm{CHD}$. Because of interactions between risk factors, the combined effect on the CHD risk may also be higher than expected based on the effects of single risk factors. Synergistic effects have been found, for example, between a positive family history of CHD and other risk factors (46-48). Compared with persons without a family history, the CHD risk according to other risk factors such as smoking and diabetes was considerably higher in persons with a positive family history of CHD in these studies. Because of the cumulative effect of risk factors, several modestly increased factors may result in a much higher risk of CHD than one extremely increased risk factor (49). Therefore, the focus should not be on the single risk factor status of an individual in primary prevention of $\mathrm{CHD}$, but on the simultaneous presence of multiple risk factors within a person.

\section{Risk prediction}

Because of the high disease burden of CHD in the Netherlands and other Western countries, much attention has been given to the prevention of CHD. Primary prevention aims to prevent or postpone the age at which the disease becomes clinically evident. To achieve this goal, it would be useful to know which persons are at high risk of developing CHD. Therefore, many studies developed risk scoring tools to estimate the absolute risk of an individual to develop the disease in time taking into account the cumulative effect of the person's risk factors (table 1). As table 1 shows, the established risk factors such as age, sex, systolic blood pressure, and cholesterol levels were included in almost every risk score, while the scores differed in their number of additional risk factors. Furthermore, most risk scores were developed in populations consisting of both men and women, while some scores were restricted to men only. Other differences between the risk scores constituted of the time period for which the risk is predicted (ranging from 5-years to 30-years predicted risks) and the predicted outcomes. Although many risk scores were developed to predict the risk of CHD, including some of the first Framingham risk scores, this has changed towards the prediction of cardiovascular disease (CVD) in the more recent years. 


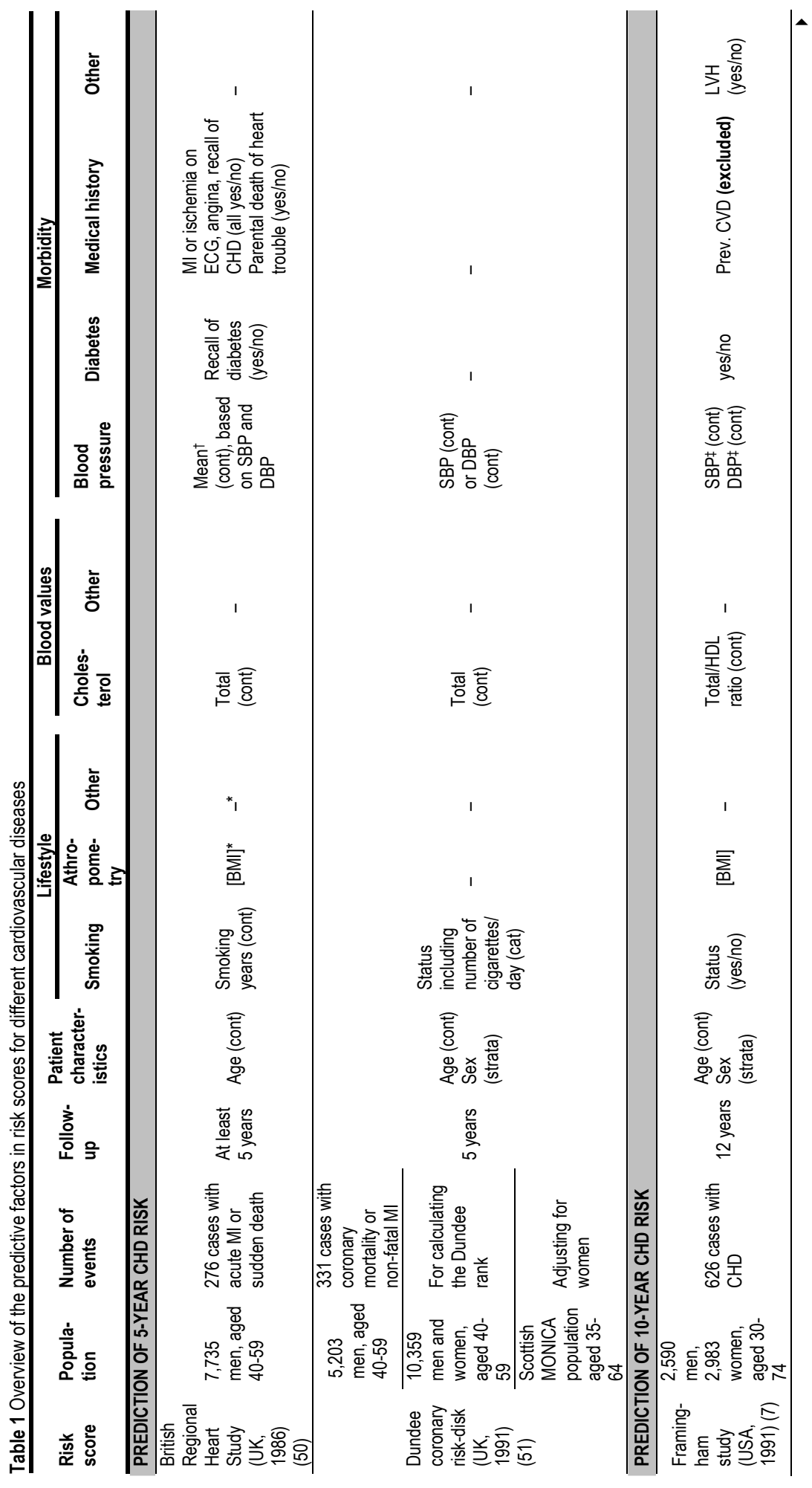




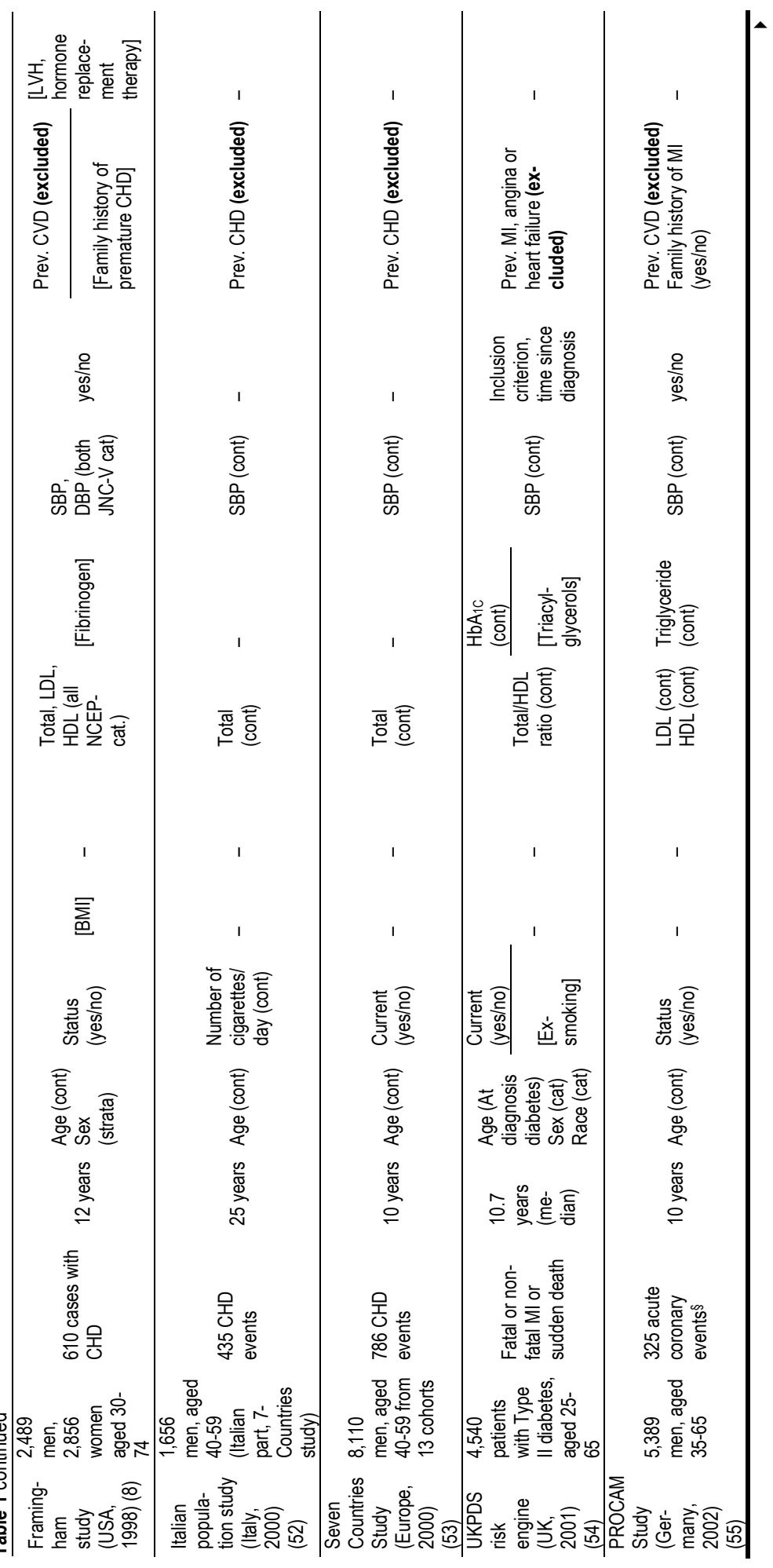




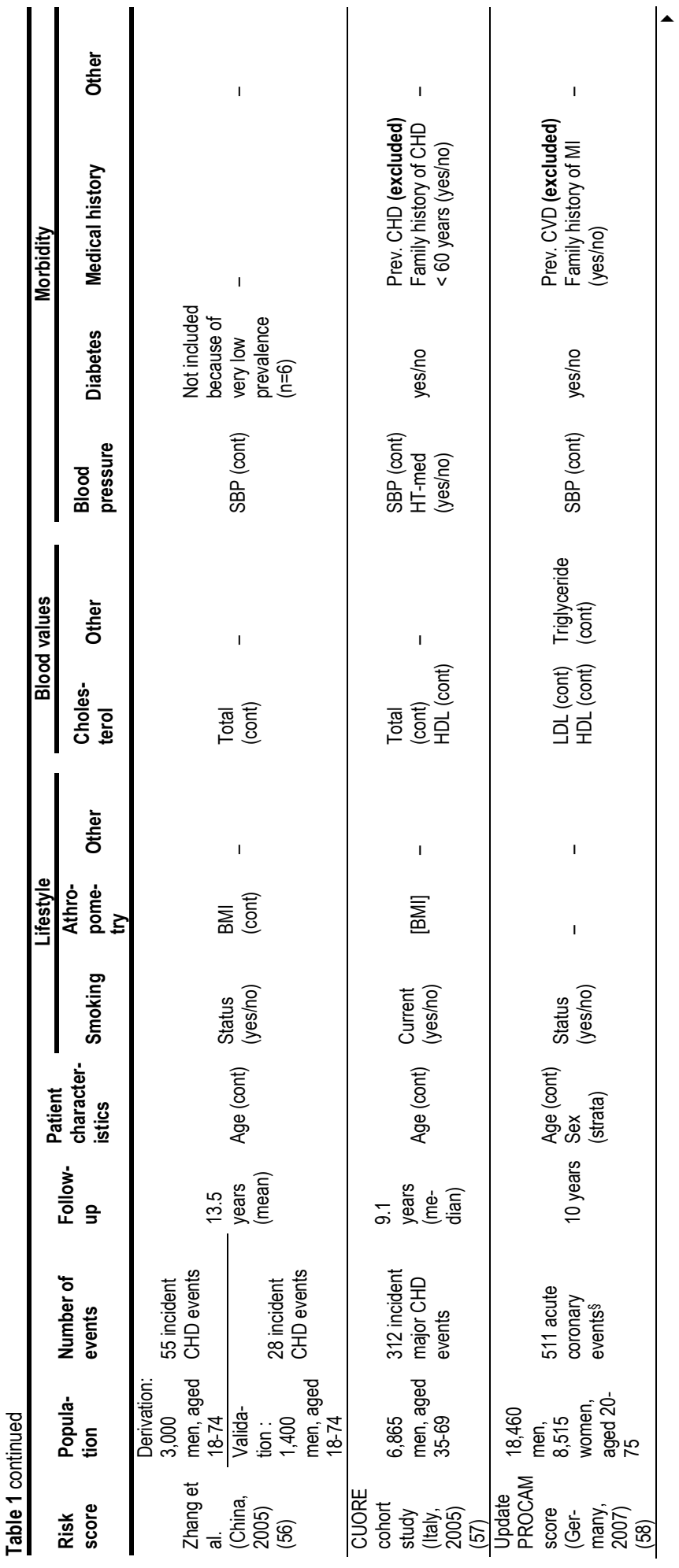




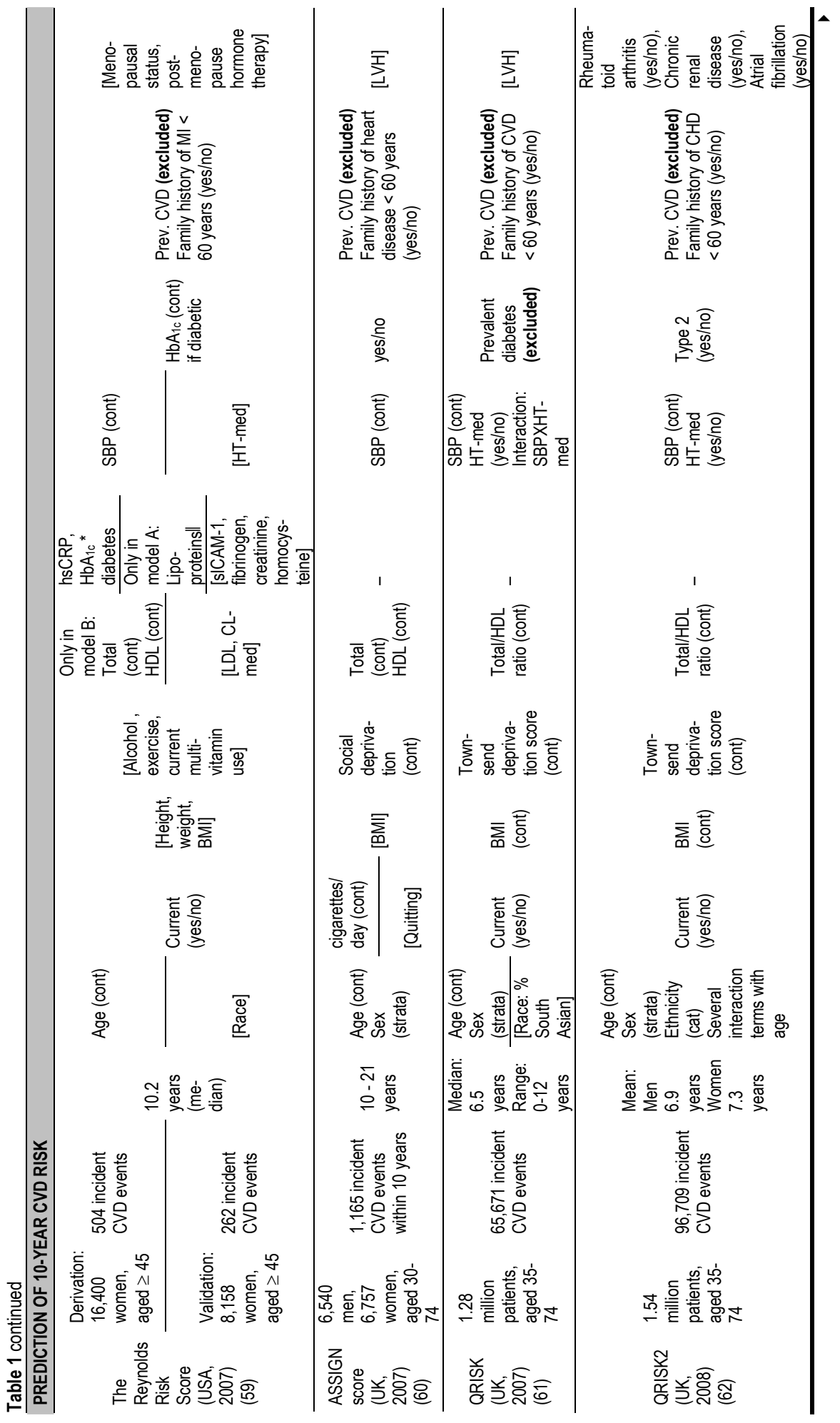




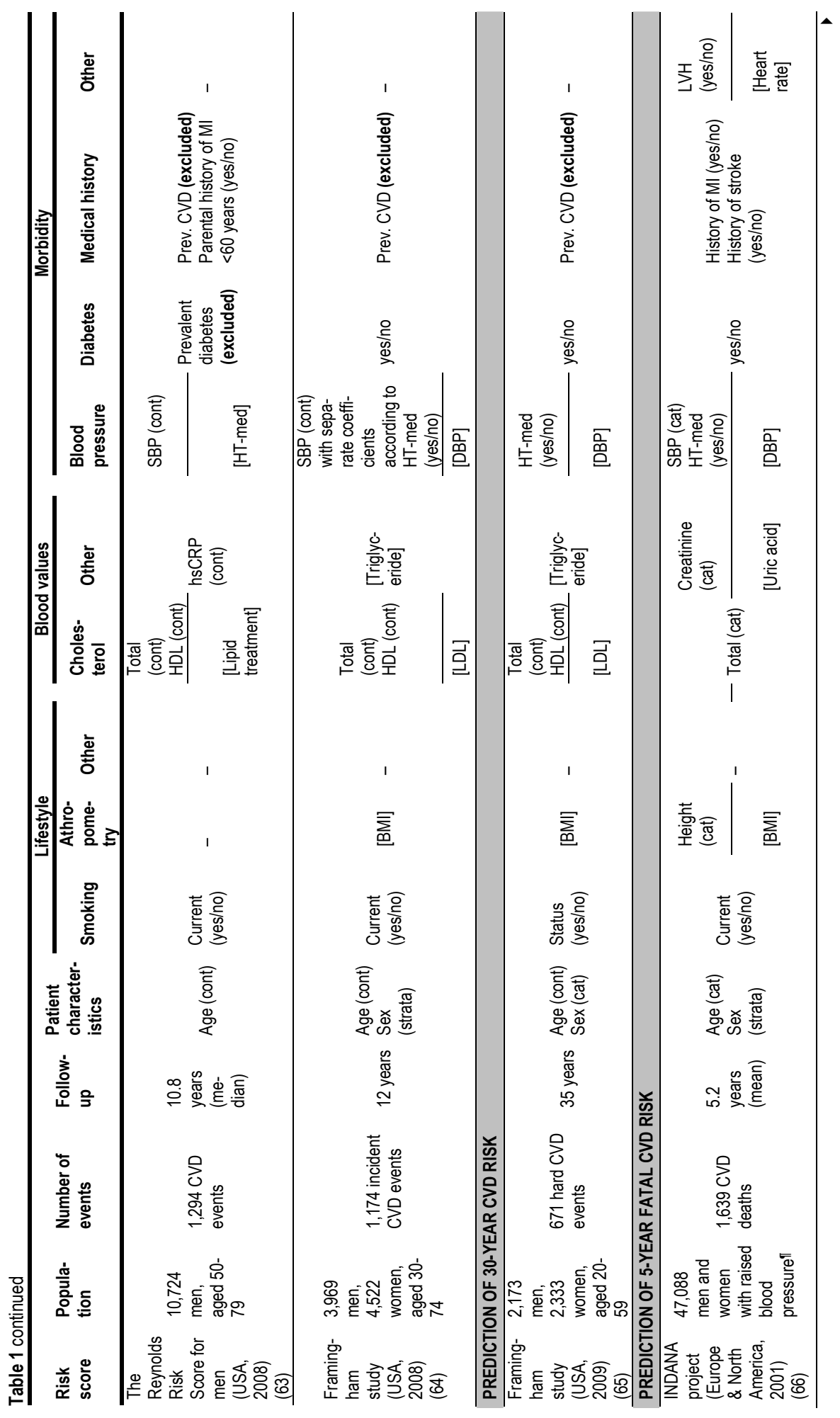




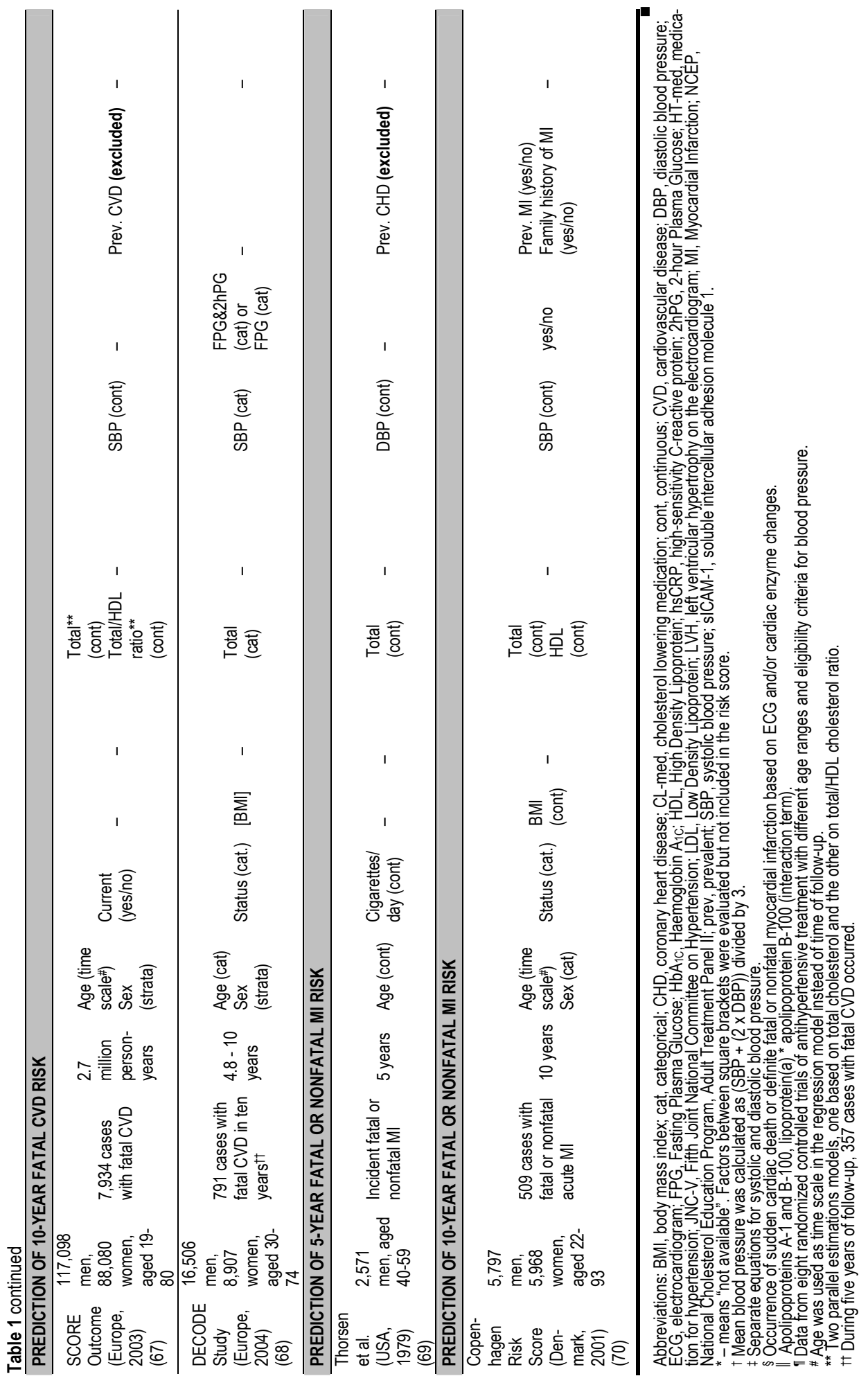


Another remarkable difference between the existing risk scores is the prediction of fatal events only against prediction of both fatal and non-fatal events. As described in the section on the incidence of $\mathrm{CHD}$, the contribution of non-fatal events to the incidence rate has increased during the last decades. Patients who survive their CHD need a lifelong treatment and care, resulting in a much higher disease burden compared with fatal events. Therefore, the prediction of both fatal and non-fatal events is more relevant than the prediction of fatal events only.

Because a risk score is a useful tool to identify people at high risk of developing CHD or CVD, many studies investigated whether the existing risk scores were applicable to their own population $(9,71-78)$. Several studies found that these risk scores over- or underestimated the absolute risks within their population. This can be explained by differences in event rates and risk factor prevalences between populations. Consequently, methods were developed to recalibrate risk functions using national data on mean risk factor levels and disease incidence. A limitation of such ecological data, however, is that it is uncertain whether the persons with the most unfavourable risk factor levels are also the ones who developed the disease. Recently, a Dutch study compared the performance of the SCORE risk functions for high- and low-risk regions, and a recalibrated SCORE function using national data on risk factor prevalences and disease rates in the Netherlands (79). The SCORE function for low-risk regions performed the best, while the SCORE function for high-risk regions and the recalibrated function overestimated the absolute risk of CVD mortality within this Dutch population. Therefore, it would be better to recalibrate the existing risk scores using individual data on risk factors and disease rates from prospective studies in which the risk factor level can be linked to the disease status in every person.

In addition to recalibration, risk prediction may be improved by adding other risk factors to existing risk scores. Although many emerging risk factors have been found to be independent risk factors for CHD, further studies should focus on their additional value over the predictive value of the established risk factors $(30,31)$. As a result, many studies evaluated whether including additional risk factors into existing scores improved risk prediction (80-88). Most studies found that these additional factors did not or only slightly improve the ability of existing scores to discriminate between persons with and without the disease. However, this method may be insensitive to detect clinically relevant changes in risk prediction as the discriminative ability of risk scores can only be slightly improved when the traditional risk factors of CHD are already included into the prediction model $(89,90)$. Some of these factors may be useful in clinical practice as they may reclassify persons to a more appropriate risk category (90). This may especially be important for persons at intermediate risk because an upgrade to a higher risk category would lead to a more optimal prevention strategy, while reclassification to a lower risk category would avoid unnecessary treatment. 


\section{Use of risk scores in the Netherlands}

In the Dutch primary practice guideline on cardiovascular risk management, the SCORE risk chart is used to identify persons at high risk of dying from CVD in the next ten years (91). Based on the level of the predicted risk, the general practitioner can recommend lifestyle modifications or to start drug treatment in order to reduce the person's risk. The SCORE risk function, however, is restricted to predict the risk of CVD mortality. As mentioned before, there is at least equal interest in predicting the risk of developing non-fatal CVD events. Therefore, a modified SCORE risk chart for CVD mortality and morbidity combined is presented in the guideline which is based on several assumptions about life expectancy and the risk of developing first and subsequent disease events (91). To my knowledge, the accuracy of these modified risk estimates has not been studied. Furthermore, individual data from prospective studies would be better to predict the risk of CVD incidence as described before.

\section{Rationale and aims of this thesis}

Because of the high disease burden of CHD, the limitations of current risk scores, the limitations of recalibrating risk scores with aggregate data instead of individual data, and the need to focus on the prediction of both fatal and non-fatal events, we aimed to develop a recalibrated and adjusted risk score for the Dutch population which predicts the risk of both fatal and non-fatal events using data from the population-based prospective Cardiovascular Registry Maastricht (CAREMA) cohort study. In order to do so, we first estimated the incidence rates of $\mathrm{CHD}$ and other cardiac diseases based on a cardiovascular disease registry in combination with the causes of death registry in this thesis. Second, the associations between several risk factors and the risk of CHD was studied, including AMI and UAP as separate outcomes. Finally, we aimed to develop an adjusted risk score to predict the 10-year risk of CHD incidence and we compared the performance of our model with that of existing scores within the CAREMA study population.

\section{Study design}

The CAREMA cohort study consisted of 21,148 participants, aged 20-59 years at baseline and living in the Maastricht region, the Netherlands. These participants were derived from two monitoring projects of the National Institute for Public Health and the Environment (RIVM): the Monitoring Project on Cardiovascular Disease Risk Factors (PPHVZ), 1987-1992, and the Monitoring Project on Chronic Disease Risk factors (MORGEN), 1993-1997. Baseline data were available on demographic characteristics, medical history, parental history of myocardial infarction, anthropometric data such as height and weight, blood pressure and cholesterol levels, and lifestyle habits such as 
smoking, alcohol consumption, physical activity, and usual dietary intake. A migration and mortality follow-up was performed by record linkage of the cohort to the Municipal Population Registries. For participants who died, the cause of death was retrieved from the causes of death registry of Statistics Netherlands. Cardiologic follow-up was performed by linkage to the Cardiology Information System (CIS) of the department of Cardiology, University Hospital Maastricht (UHM). The CIS is a unique registry that contains the cardiologic information of all persons who visited the UHM department of Cardiology. Both fatal and non-fatal incident cases of CHD were identified during follow-up until December 2003.

\section{Outline of this thesis}

Chapter 2 describes the study in which we estimated the incidence rates of several cardiologic diseases using the case identification from the CIS in combination with the causes of death registry. To see whether this method is more accurate than the currently used method, i.e. case identification based on the hospital discharge registry and causes of death registry, we compared the incidence estimates from these two methods with each other using the CIS-based method as the gold standard.

As risk factors tend to co-occur within subjects, we investigated the association between the number of metabolic factors present within an individual and the risk of total CHD, AMI and UAP (chapter 3). The metabolic factors considered were diabetes, hypertension, obesity, low HDL and high total cholesterol. In addition, we evaluated which specific combinations of these factors were associated with the highest risk.

In chapter 4, we describe the results of our study on the effects of smoking, alcohol consumption, physical activity, and parental history of myocardial infarction on the risks of AMI and UAP as separate endpoints. As persons with a positive family history of CHD may be more susceptible to other risk factors, we also compared the effects of the lifestyle factors between persons with and without a positive family history.

We recalibrated the SCORE risk function, which is currently used in the clinical practice guideline for cardiovascular risk management in the Netherlands, using individual data on risk factors and CHD incidence (chapter 5). In addition, we investigated whether including additional risk factors or current risk factors in a different manner improved risk prediction by this recalibrated model.

Chapter 6 discusses the main findings from our studies in the context of current knowledge and practice and addresses some important issues regarding risk prediction. Furthermore, recommendations for future research are given. 


\section{References}

1. Vaartjes I, Van Dis SJ, Visseren FLJ, Bots ML. Hart- en vaatziekten in Nederland. In: Visseren FL, Van Dis SJ, Bots ML, Vaartjes I (red.). Hart- en vaatziekten in Nederland 2009, cijfers over leefstijl- en risicofactoren, ziekte en sterfte. Den Haag: Nederlandse Hartstichting; 2009: p.7-23.

2. Hasdai D, Behar S, Wallentin L, Danchin N, Gitt AK, Boersma E, et al. A prospective survey of the characteristics, treatments and outcomes of patients with acute coronary syndromes in Europe and the Mediterranean basin; the Euro Heart Survey of Acute Coronary Syndromes (Euro Heart Survey ACS). Eur Heart J. 2002 Aug;23(15):1190-201.

3. Brown N, Melville M, Gray D, Young T, Munro J, Skene AM, et al. Quality of life four years after acute myocardial infarction: short form 36 scores compared with a normal population. Heart. 1999 Apr;81(4):352-8.

4. Plevier CM, Mooy JM, Marang-Van de Mheen PJ, Stouthard ME, Visser MC, Grobbee DE, et al. Persistent impaired emotional functioning in survivors of a myocardial infarction? Qual Life Res. 2001;10(2):123-32.

5. Poos M, Smit J, Groen J, Kommer G, Slobbe L. Costs of Illness in the Netherlands 2005. Bilthoven: National Institute for Public Health and the Environment; 2008. Report No.: 270751019.

6. Leal J, Luengo-Fernandez R, Gray A, Petersen S, Rayner M. Economic burden of cardiovascular diseases in the enlarged European Union. Eur Heart J. 2006 Jul;27(13):1610-9.

7. Anderson KM, Wilson PW, Odell PM, Kannel WB. An updated coronary risk profile. A statement for health professionals. Circulation. 1991 Jan;83(1):356-62.

8. Wilson PW, D'Agostino RB, Levy D, Belanger AM, Silbershatz $H$, Kannel WB. Prediction of coronary heart disease using risk factor categories. Circulation. 1998 May 12;97(18):1837-47.

9. Scheltens T, Verschuren WM, Boshuizen HC, Hoes AW, Zuithoff NP, Bots ML, et al. Estimation of cardiovascular risk: a comparison between the Framingham and the SCORE model in people under 60 years of age. Eur J Cardiovasc Prev Rehabil. 2008 Oct;15(5):562-6.

10. Willeit J, Kiechl S. Biology of arterial atheroma. Cerebrovasc Dis. 2000;10 Suppl 5:1-8.

11. Lusis AJ. Atherosclerosis. Nature. 2000 Sep 14;407(6801):233-41.

12. Fuster V, Badimon L, Badimon JJ, Chesebro JH. The pathogenesis of coronary artery disease and the acute coronary syndromes (1). N Engl J Med. 1992 Jan 23;326(4):242-50.

13. Fuster V, Badimon L, Badimon JJ, Chesebro JH. The pathogenesis of coronary artery disease and the acute coronary syndromes (2). N Engl J Med. 1992 Jan 30;326(5):310-8.

14. Alpert JS, Thygesen K, Antman E, Bassand JP. Myocardial infarction redefined--a consensus document of The Joint European Society of Cardiology/American College of Cardiology Committee for the redefinition of myocardial infarction. J Am Coll Cardiol. 2000 Sep;36(3):959-69.

15. World Health Organization. Fact sheet No 310 'Top ten causes of death'. November, 2008 [cited 2010 May 5]. Available from: http://www.who.int/mediacentre/factsheets/fs310/en/index.html

16. Reitsma JB, Dalstra JA, Bonsel GJ, van der Meulen JH, Koster RW, Gunning-Schepers LJ, et al. Cardiovascular disease in the Netherlands, 1975 to 1995: decline in mortality, but increasing numbers of patients with chronic conditions. Heart. 1999 Jul;82(1):52-6.

17. Menotti A, Lanti M, Kromhout D, Blackburn H, Nissinen A, Dontas A, et al. Forty-year coronary mortality trends and changes in major risk factors in the first 10 years of follow-up in the seven countries study. Eur J Epidemiol. 2007;22(11):747-54.

18. Kesteloot H, Sans S, Kromhout D. Dynamics of cardiovascular and all-cause mortality in Western and Eastern Europe between 1970 and 2000. Eur Heart J. 2006 Jan;27(1):107-13.

19. Levi F, Lucchini F, Negri E, La Vecchia C. Trends in mortality from cardiovascular and cerebrovascular diseases in Europe and other areas of the world. Heart. 2002 Aug;88(2):119-24.

20. McGovern PG, Jacobs DR, Jr., Shahar E, Arnett DK, Folsom AR, Blackburn H, et al. Trends in acute coronary heart disease mortality, morbidity, and medical care from 1985 through 1997: the Minnesota heart survey. Circulation. 2001 Jul 3;104(1):19-24.

21. Rosamond WD, Folsom AR, Chambless LE, Wang $\mathrm{CH}$. Coronary heart disease trends in four United States communities. The Atherosclerosis Risk in Communities (ARIC) study 1987-1996. Int J Epidemiol. 2001 Oct;30 Suppl 1:S17-22.

22. Salomaa $\mathrm{V}$, Ketonen $\mathrm{M}$, Koukkunen $\mathrm{H}$, Immonen-Raiha $\mathrm{P}$, Jerkkola $\mathrm{T}$, Karja-Koskenkari $\mathrm{P}$, et al. Trends in coronary events in Finland during 1983-1997. The FINAMI study. Eur Heart J. 2003 Feb;24(4):311-9. 
23. Feskens EJM, Merry AHH, Deckers JW, M.J.J.C. P. Coronaire hartziekten. Neemt het aantal mensen met een coronaire hartziekte toe of af? The National Public Health Compass 2006 [cited 2010 May 5]. Available from: http://www.nationaalkompas.nl/gezondheid-en-ziekte/ziekten-en-aandoeningen/hartvaat stelsel/coronaire-hartziekten/trend/

24. Koek HL, de Bruin A, Gast A, Gevers E, Kardaun JW, Reitsma JB, et al. Incidence of first acute myocardial infarction in the Netherlands. Neth J Med. 2007 Dec;65(11):434-41.

25. Houterman S, Verschuren WM, Oomen CM, Boersma-Cobbaert CM, Kromhout D. Trends in total and high density lipoprotein cholesterol and their determinants in The Netherlands between 1993 and 1997. Int J Epidemiol. 2001 Oct;30(5):1063-70.

26. Mente A, de Koning L, Shannon HS, Anand SS. A systematic review of the evidence supporting a causal link between dietary factors and coronary heart disease. Arch Intern Med. 2009 Apr 13;169(7):659-69.

27. Magnus $P$, Beaglehole $R$. The real contribution of the major risk factors to the coronary epidemics: time to end the "only-50\%" myth. Arch Intern Med. 2001 Dec 10-24;161(22):2657-60.

28. Beaglehole R, Magnus P. The search for new risk factors for coronary heart disease: occupational therapy for epidemiologists? Int J Epidemiol. 2002 Dec;31(6):1117-22; author reply 34-5.

29. Manson JE, Tosteson H, Ridker PM, Satterfield S, Hebert P, O'Connor GT, et al. The primary prevention of myocardial infarction. N Engl J Med. 1992 May 21;326(21):1406-16.

30. Helfand M, Buckley DI, Freeman M, Fu R, Rogers K, Fleming C, et al. Emerging risk factors for coronary heart disease: a summary of systematic reviews conducted for the U.S. Preventive Services Task Force. Ann Intern Med. 2009 Oct 6;151(7):496-507.

31. Ajani UA, Ford ES, McGuire LC. Distribution of lifestyle and emerging risk factors by 10-year risk for coronary heart disease. Eur J Cardiovasc Prev Rehabil. 2006 Oct;13(5):745-52.

32. Breslow JL. Genetic markers for coronary heart disease. Clin Cardiol. 2001;24(7 Suppl):II-14-7.

33. Franklin BA. Impact of psychosocial risk factors on the heart: changing paradigms and perceptions. Phys Sportsmed. 2009 Oct;37(3):35-7.

34. Sagastagoitia JD, Saez Y, Vacas M, Narvaez I, de Lafuente JP, Molinero E, et al. Acute versus chronic myocardial ischemia: a differential biological profile study. Pathophysiol Haemost Thromb. 2008;36(2):91-7.

35. Vitullo F, Marchioli R, Di Mascio R, Cavasinni L, Pasquale AD, Tognoni G. Family history and socioeconomic factors as predictors of myocardial infarction, unstable angina and stroke in an Italian population. PROGETTO 3A Investigators. Eur J Epidemiol. 1996 Apr;12(2):177-85.

36. Kennon S, Suliman A, MacCallum PK, Ranjadayalan K, Wilkinson P, Timmis AD. Clinical characteristics determining the mode of presentation in patients with acute coronary syndromes. J Am Coll Cardiol. 1998 Dec;32(7):2018-22.

37. Hoshida S, Hayashi T, Kanamasa K, Ishikawa K, Naka M, Kawarabayashi T, et al. Comparison of risk factors in acute myocardial infarction and unstable angina pectoris in patients $<$ or $=66$ versus $>66$ years of age. Am J Cardiol. 2004 Mar 1;93(5):608-10.

38. Aizawa Y, Kamimura N, Watanabe H, Aizawa Y, Makiyama Y, Usuda Y, et al. Cardiovascular risk factors are really linked in the metabolic syndrome: this phenomenon suggests clustering rather than coincidence. Int J Cardiol. 2006 May 10;109(2):213-8.

39. Eckel RH, Grundy SM, Zimmet PZ. The metabolic syndrome. Lancet. 2005 Apr 16-22;365(9468):1415-28.

40. Hong $Y$, Jin X, Mo J, Lin HM, Duan Y, Pu M, et al. Metabolic syndrome, its preeminent clusters, incident coronary heart disease and all-cause mortality--results of prospective analysis for the Atherosclerosis Risk in Communities study. J Intern Med. 2007 Jul;262(1):113-22.

41. Iso H, Sato S, Kitamura A, Imano H, Kiyama M, Yamagishi K, et al. Metabolic syndrome and the risk of ischemic heart disease and stroke among Japanese men and women. Stroke. 2007 Jun;38(6):1744-51.

42. Malik S, Wong ND, Franklin SS, Kamath TV, L'Italien GJ, Pio JR, et al. Impact of the metabolic syndrome on mortality from coronary heart disease, cardiovascular disease, and all causes in United States adults. Circulation. 2004 Sep 7;110(10):1245-50.

43. Sattar N, Gaw A, Scherbakova O, Ford I, O'Reilly DS, Haffner SM, et al. Metabolic syndrome with and without C-reactive protein as a predictor of coronary heart disease and diabetes in the West of Scotland Coronary Prevention Study. Circulation. 2003 Jul 29;108(4):414-9.

44. Wilson PW, Kannel WB, Silbershatz H, D'Agostino RB. Clustering of metabolic factors and coronary heart disease. Arch Intern Med. 1999 May 24;159(10):1104-9.

45. Wilson PW, D'Agostino RB, Parise H, Sullivan L, Meigs JB. Metabolic syndrome as a precursor of cardiovascular disease and type 2 diabetes mellitus. Circulation. 2005 Nov 15;112(20):3066-72. 
46. Leander K, Hallqvist J, Reuterwall C, Ahlbom A, de Faire U. Family history of coronary heart disease, a strong risk factor for myocardial infarction interacting with other cardiovascular risk factors: results from the Stockholm Heart Epidemiology Program (SHEEP). Epidemiology. 2001 Mar;12(2):215-21.

47. Boer JM, Feskens EJ, Verschuren WM, Seidell JC, Kromhout D. The joint impact of family history of myocardial infarction and other risk factors on 12-year coronary heart disease mortality. Epidemiology. 1999 Nov;10(6):767-70.

48. Tavani A, Augustin L, Bosetti C, Giordano L, Gallus S, Jenkins DJ, et al. Influence of selected lifestyle factors on risk of acute myocardial infarction in subjects with familial predisposition for the disease. Prev Med. 2004 Apr;38(4):468-72.

49. Cooney MT, Dudina AL, Graham IM. Value and limitations of existing scores for the assessment of cardiovascular risk: a review for clinicians. J Am Coll Cardiol. 2009 Sep 29;54(14):1209-27.

50. Shaper AG, Pocock SJ, Phillips AN, Walker M. Identifying men at high risk of heart attacks: strategy for use in general practice. Br Med J (Clin Res Ed). 1986 Aug 23;293(6545):474-9.

51. Tunstall-Pedoe $\mathrm{H}$. The Dundee coronary risk-disk for management of change in risk factors. Bmj. 1991 Sep 28;303(6805):744-7.

52. Menotti A, Puddu PE, Lanti M. Comparison of the Framingham risk function-based coronary chart with risk function from an Italian population study. Eur Heart J. 2000 Mar;21(5):365-70.

53. Menotti A, Lanti M, Puddu PE, Kromhout D. Coronary heart disease incidence in northern and southern European populations: a reanalysis of the seven countries study for a European coronary risk chart. Heart. 2000 Sep;84(3):238-44.

54. Stevens RJ, Kothari V, Adler Al, Stratton IM. The UKPDS risk engine: a model for the risk of coronary heart disease in Type II diabetes (UKPDS 56). Clin Sci (Lond). 2001 Dec;101(6):671-9.

55. Assmann G, Cullen P, Schulte H. Simple scoring scheme for calculating the risk of acute coronary events based on the 10-year follow-up of the prospective cardiovascular Munster (PROCAM) study. Circulation. 2002 Jan 22;105(3):310-5.

56. Zhang XF, Attia J, D'Este C, Yu XH, Wu XG. A risk score predicted coronary heart disease and stroke in a Chinese cohort. J Clin Epidemiol. 2005 Sep;58(9):951-8.

57. Ferrario M, Chiodini P, Chambless LE, Cesana G, Vanuzzo D, Panico S, et al. Prediction of coronary events in a low incidence population. Assessing accuracy of the CUORE Cohort Study prediction equation. Int J Epidemiol. 2005 Apr;34(2):413-21.

58. Assmann G, Schulte H, Cullen P, Seedorf U. Assessing risk of myocardial infarction and stroke: new data from the Prospective Cardiovascular Munster (PROCAM) study. Eur J Clin Invest. 2007 Dec;37(12):92532.

59. Ridker PM, Buring JE, Rifai N, Cook NR. Development and validation of improved algorithms for the assessment of global cardiovascular risk in women: the Reynolds Risk Score. Jama. 2007 Feb 14;297(6):611-9.

60. Woodward M, Brindle P, Tunstall-Pedoe H. Adding social deprivation and family history to cardiovascular risk assessment: the ASSIGN score from the Scottish Heart Health Extended Cohort (SHHEC). Heart. 2007 Feb;93(2):172-6.

61. Hippisley-Cox J, Coupland C, Vinogradova Y, Robson J, May M, Brindle P. Derivation and validation of QRISK, a new cardiovascular disease risk score for the United Kingdom: prospective open cohort study. Bmj. 2007 Jul 21;335(7611):136.

62. Hippisley-Cox J, Coupland C, Vinogradova Y, Robson J, Minhas R, Sheikh A, et al. Predicting cardiovascular risk in England and Wales: prospective derivation and validation of QRISK2. Bmj. 2008 Jun 28;336(7659):1475-82.

63. Ridker PM, Paynter NP, Rifai N, Gaziano JM, Cook NR. C-reactive protein and parental history improve global cardiovascular risk prediction: the Reynolds Risk Score for men. Circulation. 2008 Nov 25;118(22):2243-51, 4p following 51.

64. D'Agostino RB, Sr., Vasan RS, Pencina MJ, Wolf PA, Cobain M, Massaro JM, et al. General cardiovascular risk profile for use in primary care: the Framingham Heart Study. Circulation. 2008 Feb 12;117(6):74353.

65. Pencina MJ, D'Agostino RB, Sr., Larson MG, Massaro JM, Vasan RS. Predicting the 30-Year Risk of Cardiovascular Disease. The Framingham Heart Study. Circulation. 2009 Jun 8.

66. Pocock SJ, McCormack V, Gueyffier F, Boutitie F, Fagard RH, Boissel JP. A score for predicting risk of death from cardiovascular disease in adults with raised blood pressure, based on individual patient data from randomised controlled trials. Bmj. $2001 \mathrm{Jul}$ 14;323(7304):75-81.

67. Conroy RM, Pyorala K, Fitzgerald AP, Sans S, Menotti A, De Backer G, et al. Estimation of ten-year risk of fatal cardiovascular disease in Europe: the SCORE project. Eur Heart J. 2003 Jun;24(11):987-1003. 
68. Balkau B, Hu G, Qiao Q, Tuomilehto J, Borch-Johnsen K, Pyorala K. Prediction of the risk of cardiovascular mortality using a score that includes glucose as a risk factor. The DECODE Study. Diabetologia. 2004 Dec;47(12):2118-28.

69. Thorsen RD, Jacobs DR, Jr., Grimm RH, Jr., Keys A, Taylor H, Blackburn H. Preventive cardiology in practice: a device for risk estimation and counseling in coronary disease. Prev Med. 1979 Sep;8(5):54856.

70. Thomsen TF, Davidsen M, Ibsen H, Jorgensen T, Jensen G, Borch-Johnsen K. A new method for CHD prediction and prevention based on regional risk scores and randomized clinical trials; PRECARD and the Copenhagen Risk Score. J Cardiovasc Risk. 2001 Oct;8(5):291-7.

71. D'Agostino RB, Sr., Grundy S, Sullivan LM, Wilson P. Validation of the Framingham coronary heart disease prediction scores: results of a multiple ethnic groups investigation. Jama. 2001 Jul 11;286(2):180-7.

72. Hippisley-Cox J, Coupland C, Vinogradova Y, Robson J, Brindle P. Performance of the QRISK cardiovascular risk prediction algorithm in an independent UK sample of patients from general practice: a validation study. Heart. 2008 Jan;94(1):34-9.

73. Neuhauser HK, Ellert U, Kurth BM. A comparison of Framingham and SCORE-based cardiovascular risk estimates in participants of the German National Health Interview and Examination Survey 1998. Eur J Cardiovasc Prev Rehabil. 2005 Oct;12(5):442-50.

74. Empana JP, Ducimetiere P, Arveiler D, Ferrieres J, Evans A, Ruidavets JB, et al. Are the Framingham and PROCAM coronary heart disease risk functions applicable to different European populations? The PRIME Study. Eur Heart J. 2003 Nov;24(21):1903-11.

75. Thomsen TF, McGee D, Davidsen M, Jorgensen T. A cross-validation of risk-scores for coronary heart disease mortality based on data from the Glostrup Population Studies and Framingham Heart Study. Int J Epidemiol. 2002 Aug;31(4):817-22.

76. Hense HW, Schulte H, Lowel H, Assmann G, Keil U. Framingham risk function overestimates risk of coronary heart disease in men and women from Germany--results from the MONICA Augsburg and the PROCAM cohorts. Eur Heart J. 2003 May;24(10):937-45.

77. Lindman AS, Veierod MB, Pedersen JI, Tverdal A, Njolstad I, Selmer R. The ability of the SCORE high-risk model to predict 10-year cardiovascular disease mortality in Norway. Eur J Cardiovasc Prev Rehabil. 2007 Aug;14(4):501-7.

78. Ulmer H, Kollerits B, Kelleher C, Diem G, Concin H. Predictive accuracy of the SCORE risk function for cardiovascular disease in clinical practice: a prospective evaluation of 44649 Austrian men and women. Eur J Cardiovasc Prev Rehabil. 2005 Oct;12(5):433-41.

79. van Dis I, Kromhout D, Geleijnse JM, Boer JM, Verschuren WM. Evaluation of cardiovascular risk predicted by different SCORE equations: the Netherlands as an example. Eur J Cardiovasc Prev Rehabil. 2010 Apr;17(2):244-9.

80. Atsma F, van der Schouw YT, Grobbee DE, Hoes AW, Bartelink ML. No added value of age at menopause and the lifetime cumulative number of menstrual cycles for cardiovascular risk prediction in postmenopausal women. Int J Cardiol. 2007 Dec 4.

81. Bernard S, Serusclat A, Targe F, Charriere S, Roth O, Beaune J, et al. Incremental predictive value of carotid ultrasonography in the assessment of coronary risk in a cohort of asymptomatic type 2 diabetic subjects. Diabetes Care. 2005 May;28(5):1158-62.

82. Chambless LE, Folsom AR, Sharrett AR, Sorlie P, Couper D, Szklo M, et al. Coronary heart disease risk prediction in the Atherosclerosis Risk in Communities (ARIC) study. J Clin Epidemiol. 2003 Sep;56(9):880-90.

83. Cooper JA, Miller GJ, Bauer KA, Morrissey JH, Meade TW, Howarth DJ, et al. Comparison of novel hemostatic factors and conventional risk factors for prediction of coronary heart disease. Circulation. 2000 Dec 5;102(23):2816-22.

84. Lee AJ, Price JF, Russell MJ, Smith FB, van Wijk MC, Fowkes FG. Improved prediction of fatal myocardial infarction using the ankle brachial index in addition to conventional risk factors: the Edinburgh Artery Study. Circulation. 2004 Nov 9;110(19):3075-80.

85. Lloyd-Jones DM, Liu K, Tian L, Greenland P. Narrative review: Assessment of C-reactive protein in risk prediction for cardiovascular disease. Ann Intern Med. 2006 Jul 4;145(1):35-42.

86. Nawrot TS, Staessen JA, Thijs L, Fagard RH, Tikhonoff V, Wang JG, et al. Should pulse pressure become part of the Framingham risk score? J Hum Hypertens. 2004 Apr;18(4):279-86.

87. Wang TJ, Gona P, Larson MG, Tofler GH, Levy D, Newton-Cheh C, et al. Multiple biomarkers for the prediction of first major cardiovascular events and death. N Engl J Med. 2006 Dec 21;355(25):2631-9. 
88. Wilsgaard T, Arnesen E. Body mass index and coronary heart disease risk score: the Tromso study, 1979 to 2001. Ann Epidemiol. 2007 Feb;17(2):100-5.

89. Cook NR. Statistical evaluation of prognostic versus diagnostic models: beyond the ROC curve. Clin Chem. 2008 Jan;54(1):17-23.

90. Pencina MJ, D'Agostino RB, Sr., D'Agostino RB, Jr., Vasan RS. Evaluating the added predictive ability of a new marker: from area under the ROC curve to reclassification and beyond. Stat Med. 2008 Jan 30;27(2):157-72; discussion 207-12.

91. Smulders YM, Burgers JS, Scheltens T, van Hout BA, Wiersma T, Simoons ML. Clinical practice guideline for cardiovascular risk management in the Netherlands. Neth J Med. 2008 Apr;66(4):169-74. 



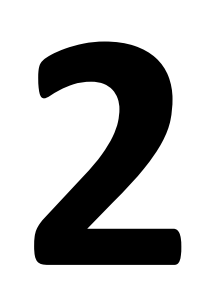

Validity of coronary heart diseases and heart failure based on hospital discharge and mortality data in the Netherlands using the cardiovascular registry Maastricht (CAREMA) cohort study

\author{
Audrey H.H. Merry \\ Jolanda M.A. Boer \\ Leo J. Schouten \\ Edith J.M. Feskens \\ W.M. Monique Verschuren \\ Anton P.M. Gorgels \\ Piet $A$. van den Brandt
}




\begin{abstract}
Incidence rates of cardiovascular diseases are often estimated by linkage to hospital discharge and mortality registries. The validity depends on the quality of the registries and the linkage. Therefore, we validated incidence rates of coronary heart disease (CHD), acute myocardial infarction, unstable angina pectoris, and heart failure, estimated by this method, against the disease registry of the cardiovascular registry Maastricht cohort study. The cohort consists of 21,148 persons, born between 1927 and 1977 , who were randomly sampled from Maastricht and surrounding communities in 1987-1997. Incident cases were identified by linkage to the Netherlands causes of death registry and either the hospital discharge registry (HDR) or the cardiology information system (CIS) of the University Hospital Maastricht. Sensitivities and positive predictive values were calculated using the CIS-based registry as gold standard. Relatively high sensitivities and positive predictive values were found for CHD (72 and 91\%, respectively) and acute myocardial infarction ( 84 and $97 \%$, respectively). These values were considerably lower for unstable angina pectoris (53 and $78 \%$, respectively) and heart failure ( 43 and $80 \%$, respectively). A substantial number of cases (14-47\%) were found only in the CIS-based registry, because they were missed or miscoded in the HDR-based registry. As a consequence, the incidence rates in the HDR-based registry were considerably lower than in the CIS-based registry, especially for unstable angina pectoris and heart failure. Incidence rates based on hospital discharge and mortality data may underestimate the true incidence rates, especially for unstable angina pectoris and heart failure.
\end{abstract}




\section{Introduction}

Coronary heart disease (CHD) is the major cause of death in developed countries. In the last decades, the mortality rate of CHD has declined in the United States and Western Europe including the Netherlands (1-4). Two possible explanations for this decreasing mortality rate are a decline in the population risk of $\mathrm{CHD}$ leading to a lower incidence, or a better survival of cases with $\mathrm{CHD}$ resulting in a lower case-fatality rate. Information about the trend in the incidence rate could be used to distinguish between these two explanations (5).

Because cardiovascular disease registries are lacking in most countries, record linkage with national hospital discharge and mortality data is often used to estimate the incidence of $\operatorname{CHD}(5,6)$. Recently, Koek et al. (7) estimated the incidence rate of a first acute myocardial infarction in 2000 by record linkage to the Dutch hospital discharge register (HDR) and causes of death registry from Statistics Netherlands. They found a crude incidence rate (per 100,000 persons per year) of 293 in men and 174 in women.

The validity of these estimates, however, depends on the completeness and accuracy of the data in the national registers and the accuracy of the linkage. Therefore, several studies have investigated the validity of data about CHD or acute myocardial infarction in national registers by comparing them with specific study registers (8-15). These studies showed a wide range in the estimated values for the validity of the data in national registers.

Less is known about the validity of incidence estimates using record linkage with national hospital discharge and mortality data for unstable angina pectoris and heart failure. These estimates may be more problematic, because the diagnoses of these diseases are more difficult to make. Only two studies investigated the validity of the diagnosis of heart failure in national HDRs $(16,17)$. Both studies indeed showed lower values for the validity of this diagnosis in national registers.

In this study, we used the disease registry of the cardiovascular registry Maastricht (CAREMA) cohort study to estimate the incidence rates of CHD, acute myocardial infarction, unstable angina pectoris, heart failure, and sudden cardiac arrest. We compared these incidence rates with the incidence rates estimated using hospital discharge data to assess the completeness and validity of the latter.

\section{Materials and methods}

\section{Study population}

The CAREMA cohort consists of participants of two large monitoring projects in the Netherlands living in the Maastricht region: the monitoring project on cardiovascular risk factors (PPHVZ) 1987-1991 (18) and the monitoring project on chronic disease risk factors (MORGEN Project) 1993-1997 (19), including the transition year (1992) between these projects. Each year, a random sample of people aged 20-59 years was 
selected from the municipal registries of Maastricht and surrounding communities: Eijsden, Margraten, Meerssen, and Valkenburg aan de Geul. Between 1987 and 1997, 21,662 men and women, born between 1927 and 1977, were included in this study, of whom 21,148 participants (97.6\%) had given informed consent to retrieve information from the municipal population registries and from their general practitioner and specialist.

\section{Follow up}

\section{Migration and mortality follow-up}

A migration and mortality follow-up was performed by record linkage of the CAREMA cohort to the municipal population registries. During follow-up until 31 December 2003, 2,106 persons (10.0\%) had migrated to a municipality outside the Maastricht region, 621 persons (2.9\%) had emigrated, and 791 persons (3.7\%) had died. Furthermore, 12 persons $(0.1 \%)$ were lost to follow-up, of whom 9 persons appeared to have migrated out of the Netherlands just before their baseline study date.

\section{Cardiologic follow-up}

Cardiologic follow-up was performed by record linkage of the CAREMA cohort to several hospital registries of the University Hospital Maastricht (UHM). In April 2004, the cohort was linked to the hospital information system (HIS) of the UHM using a combination of date of birth, gender and the first four characters of the family name (20). In the HIS, 20,632 cohort members (97.6\%) could be found. Subsequently, these subjects were linked to the cardiology information system (CIS) of the UHM department of cardiology using the personal identification number of the HIS as identifier. For all people that visited the UHM department of cardiology, the CIS contains all reports to the general practitioner and information from visits to the emergency ward or outpatient clinic for heart problems, hospital admissions for cardiologic diseases, physical examinations and treatments. Among the 20,632 persons, 4,694 (22.8\%) were known in the CIS. The cardiologic history of these persons was abstracted and coded by trained registrars under guidance of a cardiologist (AG).

Furthermore, the CAREMA cohort was linked to the Maastricht circulatory arrest registry (MCAR) (21) of the UHM department of cardiology to identify people who suffered from a sudden cardiac arrest.

For participants who died, the cause of death was obtained from Statistics Netherlands. Causes of death have been coded according to the ninth revision of the international classification of diseases (ICD-9) until 1996, and thereafter according to the tenth revision (ICD-10). Among the 791 deceased cohort members, 276 persons (34.9\%) had a cardiovascular disease as primary or secondary cause of death (ICD-9 390-459; ICD-10 I00-199). The cause of death was unknown for 24 cohort members (3.0\%) who died outside the Netherlands, while five persons $(0.6 \%)$ could not be linked to the causes of death registry from Statistics Netherlands. 
The following data was registered in the CIS-based registry: date of migration to a municipality outside the Maastricht region, date of emigration, date of death including cause of death, and the presence of a clinical diagnosis including date of diagnosis and several other characteristics of an acute or silent myocardial infarction, unstable or stable angina pectoris, heart failure, atrial fibrillation, ventricular fibrillation/tachycardia, several cardiologic treatments, and sudden cardiac arrest. All data were checked for completeness, possible errors, and inconsistencies.

In addition, the CAREMA cohort was linked to the HDR of the UHM to enlarge the completeness of the cardiologic follow-up. In the HDR, the discharge diagnoses of all admissions to the UHM have been registered using the ninth revision of the international classification of diseases (ICD-9-CM). By this linkage, only four participants were found with a discharge diagnosis of CHD (ICD-9 codes 410-414) in the HDR that were not linked to the CIS. After checking their medical history, they were no additional cases for the analyses.

Because some delay might have occurred in the registration of events in the hospital registries, the follow-up was censored at 31 December 2003 to ensure the completeness of the follow-up.

\section{Statistical analyses}

\section{Incidence estimates}

In the present study, CHD is defined as incident acute myocardial infarction, unstable angina pectoris, coronary artery bypass grafting (CABG), percutaneous transluminal coronary angioplasty (PTCA), or CHD death.

Incident cases were defined in two ways, i.e., based on causes of death and either the $\mathrm{CIS}$ or the HDR. Persons with cardiac diseases as primary or secondary cause of death according to Statistics Netherlands were defined as cases using the following ICDcodes: ICD-9 410-414 and ICD-10 I20-I25 for CHD; ICD-9 410 and ICD-10 I21-I22 for acute myocardial infarction; ICD-9 413 and ICD-10 I20 for unstable angina pectoris; ICD-9 428 and ICD-10 I50 for heart failure; and ICD-9 798 and ICD-10 I46, R96, and R98 for sudden cardiac arrest. In addition, cases were defined according to the clinical diagnosis of the disease, made by experienced cardiologists, as extracted from CIS for the CIS-based definition. This clinical diagnosis was mostly based on the diagnosis mentioned in the report to the general practitioner. Furthermore, additional information, such as enzyme levels, ECG and echo findings, was recorded in CIS and was used to check whether the patient's clinical signs and symptoms were in agreement with this diagnosis. For the HDR-based definition, cases were defined according to their hospital discharge diagnosis using the following ICD-9 codes: 410, 411.1, and 413.1 for CHD; 410 for acute myocardial infarction; 411.1 and 413.1 for unstable angina pectoris; and 428 for heart failure.

During follow-up, participants may have had multiple cardiac diseases. For each disease separately, incident cases were defined according to the first occurrence of that disease, irrespective of the occurrence of other diseases investigated in this study. For 
this reason, the sum of cases with an acute myocardial infarction and cases with unstable angina pectoris is higher than the total number of CHD cases.

For each cardiac disease separately, person-time at risk was calculated from baseline until end of follow-up i.e., clinical diagnosis of the disease in case of the CIS-based definition and date of hospital admission in case of the HDR-based definition, migration to a municipality outside the Maastricht region, emigration, death or censoring at 31 December 2003, whichever occurred first. Incidence rates were calculated as the number of incident cases divided by the disease-specific person-time at risk.

In the analyses, participants with a migration date to a municipality outside the Maastricht region before their baseline study date $(n=26)$ and participants lost to follow-up ( $n=12$ ) were excluded, leaving 21,110 cohort members. In addition, cases with CHD at baseline $(n=347)$, based on self-report or diagnosis date before baseline in the CISbased registry, were excluded in the analyses of CHD, acute myocardial infarction, and unstable angina pectoris. Cases with heart failure at baseline $(n=7)$, based on a diagnosis date before baseline in the CIS-based registry, were excluded in the analyses of heart failure. For sudden cardiac arrest, no prevalent cases were excluded.

\section{Comparison between CIS-based and HDR-based definitions}

In the analyses, the CIS-based registry was used as gold standard. A positive match between the registries was defined as a registration with the specific disease in both the CIS-based and HDR-based registry within a time frame of 6 months prior to or post diagnosis in CIS (true positives). Sensitivity was calculated as the number of cases with a positive match divided by the total number of cases in the CIS-based registry. Positive predictive value was calculated as the number of cases with a positive match divided by the total number of cases in the HDR-based registry. The $95 \%$ confidence intervals were calculated using the standard error of the estimate of the binomial distribution in the usual manner. Stratified analyses were performed for sex, age at diagnosis, and study period.

\section{Results}

\section{Incidence estimates}

During follow-up, 815 cases were registered with CHD in the CIS-based registry, 481 cases with acute myocardial infarction, and 390 cases with unstable angina pectoris (Table 1). The incidence rates per 100,000 person-years were 362.2 for CHD, 212.2 for acute myocardial infarction, and 171.8 for unstable angina pectoris (Table 2 ). In addition, 154 cases were registered with heart failure of whom 68 cases (44.2\%) selfreported CHD at baseline or had been diagnosed with CHD prior to the diagnosis of heart failure in CIS (Table 1). Among the 152 cases with sudden cardiac arrest in the CIS-based registry, 57 cases (37.5\%) self-reported CHD at baseline or had been diagnosed with CHD or heart failure prior to the diagnosis of sudden cardiac arrest in CIS. 
Table 1 Baseline characteristics of the CAREMA cohort in the Netherlands, 1987-2003

\begin{tabular}{|c|c|c|c|}
\hline & $\begin{array}{c}\text { Total } \\
(n=21,110) \\
N(\%)\end{array}$ & $\begin{array}{c}\text { Men } \\
(n=9,935) \\
N(\%)\end{array}$ & $\begin{array}{c}\text { Women } \\
(n=11,175) \\
N(\%)\end{array}$ \\
\hline $\begin{array}{l}\text { Year of inclusion in the study } \\
1987-1991 \\
1992 \\
1993-1997\end{array}$ & $\begin{array}{l}12,485(59.1) \\
2,189(10.4) \\
6,436(30.5)\end{array}$ & $\begin{array}{l}5,953(59.9) \\
1,010(10.2) \\
2,972(29.9)\end{array}$ & $\begin{array}{l}6,532(58.5) \\
1,179(10.6) \\
3,464(31.0)\end{array}$ \\
\hline $\begin{array}{l}\text { Age in years at baseline } \\
20-29 \\
30-39 \\
40-49 \\
50-60\end{array}$ & $\begin{array}{l}3,828(18.1) \\
5,287(25.0) \\
6,089(28.8) \\
5,906(28.0)\end{array}$ & $\begin{array}{l}1,724(17.4) \\
2,486(25.0) \\
2,900(29.2) \\
2,825(28.4)\end{array}$ & $\begin{array}{l}2,104(18.8) \\
2,801(25.1) \\
3,189(28.5) \\
3,081(27.6)\end{array}$ \\
\hline Mean age in years at baseline (range) & $41.7(20.1-60.9)$ & $41.9(20.1-60.2)$ & $41.5(20.1-60.9)$ \\
\hline $\begin{array}{l}\text { During follow-up (1987-2003) } \\
\text { Migration out of study area } \\
\text { Emigration to foreign country } \\
\text { Deceased }\end{array}$ & $\begin{array}{l}2,106(10.0) \\
621(2.9) \\
791(3.7)\end{array}$ & $\begin{array}{l}935(9.4) \\
313(3.2) \\
500(5.0)\end{array}$ & $\begin{array}{l}1,171(10.5) \\
308(2.8) \\
291(2.6)\end{array}$ \\
\hline $\begin{array}{l}\text { Coronary heart disease }^{\star} \\
\text { Number of incident cases } \\
\text { Mean age at diagnosis (SD) }\end{array}$ & $\begin{array}{c}815(3.9) \\
57.4(7.6)\end{array}$ & $\begin{array}{c}595(6.2) \\
57.0(7.7)\end{array}$ & $\begin{array}{l}220(2.0) \\
58.6(7.4)\end{array}$ \\
\hline $\begin{array}{l}\text { Acute myocardial infarction } \\
\text { Number of incident cases }{ }^{\dagger} \\
\text { Mean age at diagnosis (SD) }\end{array}$ & $\begin{array}{l}481(2.3) \\
56.7(7.7)\end{array}$ & $\begin{array}{c}372(3.8) \\
56.4(7.7)\end{array}$ & $\begin{array}{c}109(1.0) \\
57.7(7.5)\end{array}$ \\
\hline $\begin{array}{l}\text { Unstable angina pectoris } \\
\text { Number of incident cases } \\
\text { Mean age at diagnosis (SD) }\end{array}$ & $\begin{array}{c}390(1.9) \\
58.3(7.4)\end{array}$ & $\begin{array}{l}269(2.8) \\
58.1(7.3)\end{array}$ & $\begin{array}{c}121(1.1) \\
58.5(7.6)\end{array}$ \\
\hline $\begin{array}{l}\text { Heart failure } \\
\text { With history of coronary heart disease } \\
\text { Number of incident cases } \\
\text { Mean age at diagnosis (SD) }\end{array}$ & $\begin{array}{c}68(0.3) \\
62.4(6.4)\end{array}$ & $\begin{array}{c}47(0.5) \\
62.0(6.7)\end{array}$ & $\begin{array}{c}21(0.2) \\
63.5(5.9)\end{array}$ \\
\hline $\begin{array}{l}\text { Without history of coronary heart disease } \\
\text { Number of incident cases }{ }^{\ddagger} \\
\text { Mean age at diagnosis (SD) }\end{array}$ & $\begin{array}{c}86(0.4) \\
61.8(7.7)\end{array}$ & $\begin{array}{c}50(0.5) \\
61.7(8.1)\end{array}$ & $\begin{array}{c}36(0.3) \\
61.9(7.3)\end{array}$ \\
\hline $\begin{array}{l}\text { Sudden cardiac arrest } \\
\text { With history of cardiac disease } \\
\text { Number of incident cases } \\
\text { Mean age at diagnosis (SD) }\end{array}$ & $\begin{array}{c}57(0.3) \\
60.6(5.8)\end{array}$ & $\begin{array}{c}47(0.5) \\
60.9(5.7)\end{array}$ & $\begin{array}{c}10(0.1) \\
59.0(5.8)\end{array}$ \\
\hline $\begin{array}{l}\text { Without history of cardiac disease } \\
\text { Number of incident cases } \\
\text { Mean age at diagnosis (SD) }\end{array}$ & $\begin{array}{c}95(0.5) \\
56.7(8.8)\end{array}$ & $\begin{array}{c}67(0.7) \\
56.7(8.5)\end{array}$ & $\begin{array}{c}28(0.3) \\
56.4(9.8)\end{array}$ \\
\hline
\end{tabular}

* Defined as incident acute myocardial infarction, unstable angina pectoris, coronary artery bypass grafting (CABG), percutaneous transluminal coronary angioplasty (PTCA), or coronary heart disease as cause of death (ICD-9 codes 410414; ICD-10 codes I20-I25).

†Exclusion of persons with CHD at baseline $(n=347)$, based on self-report or a diagnosis date before baseline in the CISbased registry.

‡ Exclusion of persons with heart failure at baseline $(n=7)$, based on a diagnosis date before baseline in the CIS-based registry. 
The incidence rates per 100,000 person-years were 66.4 for heart failure and 65.4 for sudden cardiac arrest (Table 2 ).

In the HDR-based registry, 656 cases were registered with CHD during follow-up, 417 cases with acute myocardial infarction, 269 cases with unstable angina pectoris, and 84 cases with heart failure. There were no cases with sudden cardiac arrest as discharge diagnosis in the HDR. The incidence rates of these diseases derived from the HDRbased registry were lower than those derived from the CIS-based registry (Table 2). Especially in the older age categories (50-59 and 60-69 years) of both men and women, the incidence rates from the HDR-based registry were lower compared with those from the CIS-based registry, except for female cases with acute myocardial infarction. For both men and women, the estimated incidence rates per age category from the CIS-based and HDR-based registry are given in the Appendix.

Table 2 Estimated incidence rates from the HDR-based and CIS-based registry in the CAREMA cohort in 1987-2003

\begin{tabular}{|c|c|c|c|c|c|c|}
\hline & \multicolumn{3}{|c|}{ HDR-based registry } & \multicolumn{3}{|c|}{ CIS-based registry } \\
\hline & $\begin{array}{l}\text { Number of } \\
\text { registered } \\
\text { cases }\end{array}$ & $\begin{array}{c}\text { Person- } \\
\text { years at } \\
\text { risk } \\
(x 1,000)\end{array}$ & $\begin{array}{c}\text { Incidence } \\
\text { per } \\
100,000 \\
\text { person- } \\
\text { years at } \\
\text { risk }\end{array}$ & $\begin{array}{l}\text { Number of } \\
\text { registered } \\
\text { cases }\end{array}$ & $\begin{array}{c}\text { Person- } \\
\text { years at } \\
\text { risk } \\
(x 1,000)\end{array}$ & $\begin{array}{c}\text { Incidence } \\
\text { per } \\
100,000 \\
\text { person- } \\
\text { years at } \\
\text { risk }\end{array}$ \\
\hline $\begin{array}{l}\text { Coronary heart } \\
\text { disease* }^{*}\end{array}$ & $656^{\dagger}$ & 226.2 & 290.0 & $815^{\dagger}$ & 225.0 & 362.2 \\
\hline $\begin{array}{l}\text { Acute myocardial } \\
\text { infarction }\end{array}$ & $417^{\dagger}$ & 227.3 & 183.4 & $481 \dagger$ & 226.7 & 212.2 \\
\hline $\begin{array}{l}\text { Unstable angina } \\
\text { pectoris }\end{array}$ & $269+$ & 227.8 & 118.1 & $390 \dagger$ & 227.0 & 171.8 \\
\hline Heart failure & $84 \ddagger$ & 232.3 & 36.2 & $154 \ddagger$ & 232.0 & 66.4 \\
\hline $\begin{array}{l}\text { Sudden cardiac } \\
\text { arrest }\end{array}$ & - & - & $-\S$ & 152 & 232.5 & 65.4 \\
\hline
\end{tabular}

HDR, hospital discharge register; CIS, cardiology information system.

* Defined as incident acute myocardial infarction, unstable angina pectoris, coronary artery bypass grafting (CABG), percutaneous transluminal coronary angioplasty (PTCA), or coronary heart disease as cause of death (ICD-9 codes 410414; ICD-10 codes I20-I25).

† Exclusion of persons with coronary heart disease at baseline based on self-report or a diagnosis date before baseline in the registry ( $n=330$ in the HDR-based registry and $n=347$ in the CIS-based registry).

$\ddagger$ Exclusion of persons with heart failure at baseline based on a diagnosis date before baseline in the registry $(n=1$ in the HDR-based registry and $n=7$ in the CIS-based registry).

$\S$ It was not possible to estimate an incidence rate because there were no cases with sudden cardiac arrest as discharge diagnosis in the HDR.

\section{Validity of the HDR-based registry}

For the HDR-based definition of CHD, the sensitivity and positive predictive value were 72 and $91 \%$, respectively (Table 3 ). A positive match was found in $590(70.8 \%)$ of the 833 cases with CHD in one or both of the registries. For 43 persons (5.2\%), the time difference between the diagnosis in the HDR-based and CIS-based registry was longer than 6 months. Furthermore, 182 CHD cases (21.8\%) were found only in the CIS-based registry, while 18 cases (2.2\%) were found only in the HDR-based registry. 
Table 3 Sensitivity (Se) and positive predictive values (PPV) for the cardiovascular diseases in the HDR-based registry compared with the CIS-based registry in 1987-2003 within a time frame of 6 months prior to or post diagnosis in CIS

\begin{tabular}{|c|c|c|c|}
\hline & Number of incident cases* & Se $(95 \% \mathrm{Cl})$ & PPV $(95 \% \mathrm{Cl})$ \\
\hline \multicolumn{4}{|c|}{ Coronary heart disease $^{\dagger}$} \\
\hline Total & 833 & $72(69-75)$ & $91(88-93)$ \\
\hline \multicolumn{4}{|l|}{ Age group } \\
\hline$<50$ years & 151 & $78(71-85)$ & $91(86-96)$ \\
\hline$\geq 50$ years & 682 & $71(68-75)$ & $90(88-93)$ \\
\hline \multicolumn{4}{|l|}{ Study period } \\
\hline 1987-1995 & 275 & $71(65-76)$ & $82(77-87)$ \\
\hline 1996-2003 & 558 & $73(69-77)$ & $95(93-97)$ \\
\hline \multicolumn{4}{|c|}{ Acute myocardial infarction } \\
\hline Total & 485 & $84(81-87)$ & $97(96-99)$ \\
\hline \multicolumn{4}{|l|}{ Age group } \\
\hline$<50$ years & 103 & $86(80-93)$ & $99(97-100)$ \\
\hline$\geq 50$ years & 382 & $83(80-87)$ & 97 (95-99) \\
\hline \multicolumn{4}{|l|}{ Study period } \\
\hline 1987-1995 & 168 & $82(76-87)$ & $94(91-98)$ \\
\hline 1996-2003 & 317 & $85(81-89)$ & $99(97-100)$ \\
\hline \multicolumn{4}{|c|}{ Unstable angina pectoris } \\
\hline Total & 420 & $53(48-58)$ & $78(74-83)$ \\
\hline \multicolumn{4}{|l|}{ Age group } \\
\hline$<50$ years & 61 & $54(41-67)$ & $76(62-89)$ \\
\hline$\geq 50$ years & 359 & $53(48-59)$ & $79(74-84)$ \\
\hline \multicolumn{4}{|l|}{ Study period } \\
\hline 1987-1995 & 119 & $53(44-63)$ & $69(59-79)$ \\
\hline 1996-2003 & 301 & $53(48-59)$ & $83(77-88)$ \\
\hline \multicolumn{4}{|l|}{ Heart failure } \\
\hline Total & 158 & $43(35-51)$ & $80(71-88)$ \\
\hline \multicolumn{4}{|l|}{ Age group } \\
\hline$<50$ years & 11 & $30(2-58)$ & $60(17-100)$ \\
\hline$\geq 50$ years & 147 & $44(36-52)$ & 81 (72-90) \\
\hline \multicolumn{4}{|l|}{ Study period } \\
\hline 1987-1995 & 35 & $45(28-62)$ & 68 (49-88) \\
\hline 1996-2003 & 123 & $42(33-51)$ & 84 (74-93) \\
\hline
\end{tabular}

Prevalent cases based on self-report or a diagnosis date in one or both registries before baseline were excluded ( $n=349$ for coronary heart disease, acute myocardial infarction and unstable angina pectoris and $n=7$ for heart failure). * Total number of incident cases with a diagnosis in either one or both the HDR-based or the CIS-based registry. † Defined as incident acute myocardial infarction, unstable angina pectoris, coronary artery bypass grafting (CABG), percutaneous transluminal coronary angioplasty (PTCA), or coronary heart disease as cause of death (ICD-9 codes 410414; ICD-10 codes I20-I25).

Because normally CHD refers to the ICD-9 codes 410-414, the HDR-definition of CHD was extended to these ICD-9 codes in additional analyses. In doing so, the sensitivity increased from 72 to $85 \%$ while the positive predictive value decreased from 91 to $85 \%$.

For the HDR-based definition of acute myocardial infarction, the sensitivity and positive predictive value were 84 and $97 \%$, respectively (Table 3). For 404 cases (83.3\%), a positive match was found between the HDR-based and the CIS-based registry. For eight cases $(1.6 \%)$, the time difference between the diagnosis in the HDR-based and CIS-based registry was longer than 6 months. The remaining cases (15.1\%) were found in either one of the registries. 
The sensitivity and positive predictive value for the HDR-based definition of unstable angina pectoris (53 and 78\%, respectively) were substantially lower (Table 3). Only 208 out of the 420 cases with unstable angina pectoris (49.5\%) were found in both registries, while 185 cases (44.0\%) were registered only in either one of the registries. For 27 cases $(6.4 \%)$, the time between the diagnoses was more than 6 months.

The most important reasons to be only registered in the CIS-based registry for cases with CHD, acute myocardial infarction, and unstable angina pectoris were as follows: a different discharge diagnosis in the HDR-based registry $(68,59$, and $75 \%$, respectively), mostly ICD-9 codes 413.90 (other and unspecified angina pectoris) and 414.00 (coronary atherosclerosis), a diagnosis based on outpatient files $(18,6$, and $21 \%$, respectively), or a hospital admission in another Dutch hospital $(1,3$, and $0 \%$, respectively), or in a foreign hospital $(4,9$, and $1 \%$, respectively). All cases with CHD, acute myocardial infarction and unstable angina pectoris that were registered only in the HDR-based registry had a diagnosis of another $(11,100$, and $40 \%$, respectively) or no cardiovascular disease $(89,0$, and $60 \%$, respectively) according to the CIS-based registry.

For the HDR-based definition of heart failure, the sensitivity and positive predictive value were 43 and $80 \%$, respectively (Table 3). A positive match was found in 66 cases (41.8\%), while 79 cases (50.0\%) were registered only in either one of the registries. For 13 cases $(8.2 \%)$, the time between the diagnoses was more than 6 months. The most important reasons for cases with heart failure to be registered only in the CIS-based registry were a diagnosis based on outpatient files (36\%), a different discharge diagnosis in the HDR-based registry (36\%), or a diagnosis of heart failure made during hospital admission for another cardiovascular disease, but not registered as discharge diagnosis (21\%).

In the stratified analyses, slightly higher sensitivities were found in women compared with men, except for heart failure (data not shown). By contrast, the positive predictive value was slightly higher in men than in women. Furthermore, higher sensitivities were found in the age category $<50$ years compared with the age category $\geq 50$ years, except for heart failure. For CHD and acute myocardial infarction, the positive predictive values were also higher in the age category $<50$ years, while these values were higher in the age category $\geq 50$ years for unstable angina pectoris and heart failure. Both the sensitivities and positive predictive values were higher in the study period 1996-2003 than in the study period 1987-1995, except for the sensitivity of heart failure.

\section{Discussion}

In the comparison between the HDR-based and CIS-based registry, relatively high sensitivities and positive predictive values were found for CHD and acute myocardial infarction, while these values were considerably lower for unstable angina pectoris and heart failure. Furthermore, high percentages of the cases were only found in the CIS- 
based registry, varying from $14.2 \%$ for acute myocardial infarction to $47.5 \%$ for heart failure. These cases were missed or miscoded in the HDR-based registry. As a consequence, the incidence rates in the HDR-based registry were considerably lower than the incidence rates in the CIS-based registry, especially for unstable angina pectoris and heart failure.

Several reasons may have contributed to the differences found between the HDRbased and CIS-based registry. The diagnoses from CIS were abstracted and coded by trained registrars under guidance of a cardiologist (AG). Therefore, the diagnoses in the CIS-based registry are probably less susceptible to misclassification.

Furthermore, the CIS also contains information about visits to the outpatient clinic and emergency ward for heart problems. Cases diagnosed at these departments with cardiac diseases that do not warrant hospitalisation were still registered in the CIS-based registry. These cases were missed when only data from the HDR was used, leading to an underestimation of the incidence rates, especially for diagnoses that do not warrant hospitalisation, as can be seen from this study.

For the incidence estimates in this study, data were used from the University Hospital Maastricht (UHM). Because of the central and unique position of this hospital in the study region, the cardiologic follow-up is expected to be almost complete. Only a few cases will be missed, partly due to a diagnosis in another Dutch or in a foreign hospital. However, part of these cases may have visited the outpatient clinic of the UHM department of cardiology in a later stage, so that they were still registered in the CISbased registry but not in the HDR-based registry. Nonetheless, cases diagnosed in another Dutch hospital would probably be found when data is used from the national HDR, while cases diagnosed in a foreign country would still be missed. In the Netherlands, however, record linkage to the national HDR is difficult, because of the limited number of identifying variables in this register.

Because the definition of CHD in the CIS-based registry was restricted to a clinical diagnosis of acute myocardial infarction, unstable angina pectoris, CABG or PTCA, we also narrowed the definition of CHD in the HDR-based registry to cases with ICD-9 codes 410, 411.1, and 413.1 as discharge diagnosis. When the definition in the HDR-based registry was extended to ICD-9 codes 410-414, the sensitivity increased from 72 to $85 \%$, which can be explained by the larger range of ICD-9 codes used for specific CHD in the HDR. The positive predictive value, however, decreased from 91 to 85\%, which can be explained by the inclusion of all ischemic heart diseases in the HDR-based registry, including stable angina pectoris and chronic CHD that were not included in the CISbased registry.

The identification of incident cases in this study was partly performed by record linkage of the CAREMA cohort to the causes of death registry from Statistics Netherlands. Although we did not validate these cases, several studies in the Netherlands showed that the registration and coding of causes of death by Statistics Netherlands had a higher validity compared with other European countries $(22,23)$. Because the causes of death registry was used in both the CIS-based and HDR-based registry for the identi- 
fication of incident cases, this has led to an improvement of the comparison between these registries. Additional analyses, in which incident cases identified by linkage to Statistics Netherlands were excluded, showed small decreases in positive predictive values but considerable decreases in the sensitivities. This was due to a relatively large increase in the number of cases registered only in the CIS-based registry after exclusion. This means that the record linkage with the causes of death registry was especially favourable for the completeness of the HDR-based registry.

In this study, clinical diagnoses in CIS were used for the identification of cases instead of diagnostic criteria. However, 321 of the 417 cases (77.0\%) with a clinical diagnosis of acute myocardial infarction in the CIS-based registry met the diagnostic criteria of the European Society of Cardiology and the American College of Cardiology (24). The remaining $23.0 \%$ had incomplete data. Of the 321 cases that met the diagnostic criteria in the CIS-based registry, 291 cases $(90.7 \%)$ were also registered with acute myocardial infarction in the HDR. Thus, even for a diagnosis of an acute myocardial infarction based on diagnostic criteria, a considerable part of the cases was not registered with this diagnosis in the HDR. During follow-up, more sensitive screening tests became available for the diagnosis of an acute myocardial infarction. Because of these tests, clinical decision-making may have changed during the follow-up period.

The estimates of the incidence rates from the HDR-based registry are comparable to those reported by Koek et al. (7) for the Netherlands as a whole. For comparison purposes, we calculated an expected incidence rate of acute myocardial infarction using the national incidence rates of Koek et al., age and gender-standardized to the CAREMA cohort. This expected incidence rate was higher than the incidence rate in the HDR-based registry (201.9 and 183.4 per 100,000 person-years, respectively), which may be explained by a lower incidence rate in the study population (25), which is restricted to the Maastricht region, compared with the average Dutch population. Furthermore, regional differences in the coverage and validity of local hospital discharge registries may also explain this discrepancy. Conversely, the expected rate was lower than the incidence rate in the CIS-based registry (212.2 per 100,000 person-years).

Several studies have investigated the validity of hospital discharge and/or mortality data on acute myocardial infarction by comparing these data with specific study registers (8-15) or physician reviews $(5,26-28)$. In these studies, a wide range of estimated values for the sensitivity and positive predictive value was found due to differences in case identification. However, most of the studies demonstrated that hospital discharge and/or mortality data underestimate the incidence of acute myocardial infarction in the population as was found in our study.

Furthermore, three Finnish validation studies found higher sensitivities and positive predictive values in men compared with women $(9,12,15)$. In our study, the positive predictive value was also higher in men, while the sensitivity was higher in women. In the stratified analyses, we also found higher sensitivities and positive predictive values in the study period 1996-2003 compared with the period 1987-1995. This implies an improvement of the validity of the HDR in time. 
Only two studies investigated the validity of hospital discharge data on heart failure using the definition of heart failure by the European Society of Cardiology (29). Ingelsson et al. (16) found a positive predictive value of $82 \%$ which is slightly higher than the value of $80 \%$ found in our study. A considerably lower value of $65 \%$ was found in the study by Khand et al. (17). However, Khand et al. used a broader range of ICD-codes (including ICD-10 codes I25.5 and 142.9) which are probably less sensitive for a definite diagnosis of heart failure.

In many of the above mentioned studies, data from the WHO MONICA project were used $(8,9,11-15)$. This project is a multicenter study which monitors the incidence of myocardial infarction (MI) in several countries using study-specific MI registers. All events that occurred in the study population were registered according to previous defined diagnostic criteria. Although the registration in the CIS-based registry was based on a clinical diagnosis made by experienced cardiologists, a large number of cases with an acute myocardial infarction (77\%) met the diagnostic criteria of the European Society of Cardiology and the American College of Cardiology as described earlier in this discussion. In addition, none of the registered cases with complete data did not fulfil these diagnostic criteria. In the CIS-based registry, however, not only diagnoses of an acute myocardial infarction were registered but also diagnoses of silent myocardial infarctions, unstable and stable angina pectoris, and heart failure. However, the registrations in the CIS-based registry were only made for people living in the Maastricht region. In the MONICA project, the centres did also not have national coverage (8). Therefore, the estimated incidence rates of both the CIS-based registry and the $\mathrm{MI}$ registers of the MONICA project may not be generalised to a national level. Because cardiovascular disease registries are lacking in most countries, record linkage with hospital discharge and mortality data is often used to estimate the incidence rates of CHD and other cardiologic diseases. However, this study and previous studies have shown that a considerable part of the cases is missed or miscoded using hospital discharge data. Therefore, incidence rates based on these data may underestimate the true incidence rates, especially for unstable angina pectoris and heart failure.

Furthermore, an accurate identification of cases is even more important in etiological studies in which risk estimates are based on the comparison between cases and noncases. Case identification based on hospital discharge and mortality data may lead to biases in the results of these studies. Therefore, these data should be used with caution in epidemiological studies, especially in etiological studies. Although the CIS-based registry has several advantages over HDRs, some events may be still be missed. In etiologic studies, it is important to keep in mind the potential weaknesses of such registries. 


\section{Appendix}

Appendix Age- and gender-specific incidence rates from the HDR-based and CIS-based registry in the CAREMA cohort, 1987-2003

\begin{tabular}{|c|c|c|c|c|c|c|c|c|}
\hline & \multicolumn{4}{|c|}{ HDR-based registry } & \multicolumn{4}{|c|}{ CIS-based registry } \\
\hline & \multicolumn{2}{|r|}{ Men } & \multicolumn{2}{|c|}{ Women } & \multicolumn{2}{|c|}{ Men } & \multicolumn{2}{|c|}{ Women } \\
\hline & $\begin{array}{l}\text { Num- } \\
\text { ber of } \\
\text { inci- } \\
\text { dent } \\
\text { cases }\end{array}$ & $\begin{array}{c}\text { Incidence / } \\
100,000 \\
\text { person- } \\
\text { years at } \\
\text { risk }\end{array}$ & $\begin{array}{l}\text { Num- } \\
\text { ber of } \\
\text { inci- } \\
\text { dent } \\
\text { cases }\end{array}$ & $\begin{array}{c}\text { Incidence / } \\
100,000 \\
\text { person- } \\
\text { years at } \\
\text { risk }\end{array}$ & $\begin{array}{l}\text { Num- } \\
\text { ber of } \\
\text { inci- } \\
\text { dent } \\
\text { cases }\end{array}$ & $\begin{array}{c}\text { Incidence / } \\
100,000 \\
\text { person- } \\
\text { years at } \\
\text { risk }\end{array}$ & $\begin{array}{l}\text { Num- } \\
\text { ber of } \\
\text { inci- } \\
\text { dent } \\
\text { cases }\end{array}$ & $\begin{array}{c}\text { Incidence / } \\
100,000 \\
\text { person- } \\
\text { years at } \\
\text { risk }\end{array}$ \\
\hline \multicolumn{9}{|c|}{ Coronary heart disease $^{*}$} \\
\hline Total & 471 & 449.4 & 185 & 152.4 & $595^{\dagger}$ & 572.9 & $220^{\dagger}$ & 181.6 \\
\hline $20-29$ yrs & 0 & 0 & 0 & 0 & 0 & 0 & 0 & 0 \\
\hline $30-39$ yrs & 11 & 53.3 & 4 & 17.3 & 11 & 53.3 & 4 & 17.3 \\
\hline $40-49$ yrs & 84 & 280.3 & 24 & 71.5 & 106 & 354.8 & 28 & 83.4 \\
\hline $50-59$ yrs & 193 & 633.1 & 73 & 206.2 & 249 & 825.4 & 87 & 246.2 \\
\hline $60-69$ yrs & 169 & 1087.1 & 71 & 363.1 & 213 & 1413.4 & 89 & 458.4 \\
\hline \multicolumn{9}{|c|}{ Acute myocardial infarction* } \\
\hline Total & 319 & 302.2 & 98 & 80.5 & 372 & 354.4 & 109 & 89.6 \\
\hline $20-29$ yrs & 0 & 0 & 0 & 0 & 0 & 0 & 0 & 0 \\
\hline $30-39$ yrs & 10 & 48.4 & 2 & 8.6 & 10 & 48.4 & 2 & 8.6 \\
\hline $40-49$ yrs & 62 & 206.4 & 15 & 44.7 & 75 & 250.0 & 16 & 47.6 \\
\hline $50-59$ yrs & 136 & 442.4 & 42 & 118.2 & 154 & 504.7 & 49 & 138.1 \\
\hline $60-69$ yrs & 102 & 641.3 & 34 & 172.0 & 124 & 793.1 & 37 & 187.7 \\
\hline \multicolumn{9}{|c|}{ Unstable angina pectoris* } \\
\hline Total & 175 & 165.0 & 94 & 77.2 & 269 & 255.2 & 121 & 99.5 \\
\hline $20-29$ yrs & 0 & 0 & 0 & 0 & 0 & 0 & 0 & 0 \\
\hline $30-39$ yrs & 2 & 9.7 & 2 & 8.6 & 2 & 9.7 & 2 & 8.6 \\
\hline $40-49$ yrs & 24 & 79.6 & 11 & 32.8 & 37 & 122.9 & 16 & 47.7 \\
\hline $50-59$ yrs & 67 & 216.4 & 36 & 101.4 & 112 & 364.1 & 43 & 121.3 \\
\hline $60-69$ yrs & 77 & 480.0 & 37 & 187.5 & 110 & 700.8 & 52 & 264.6 \\
\hline \multicolumn{9}{|c|}{ Heart failure (with history of CHD) f $^{\ddagger}$} \\
\hline Total & 15 & 13.7 & 12 & 9.8 & 47 & 43.0 & 21 & 17.1 \\
\hline $20-29$ yrs & 0 & 0 & 0 & 0 & 0 & 0 & 0 & 0 \\
\hline $30-39$ yrs & 0 & 0 & 0 & 0 & 0 & 0 & 0 & 0 \\
\hline $40-49$ yrs & 1 & 3.3 & 0 & 0 & 2 & 6.6 & 0 & 0 \\
\hline $50-59$ yrs & 5 & 15.4 & 3 & 8.3 & 13 & 40.2 & 5 & 13.9 \\
\hline $60-69$ yrs & 8 & 45.6 & 8 & 39.6 & 25 & 143.4 & 12 & 59.5 \\
\hline \multicolumn{9}{|c|}{ Heart failure (without history of CHD) $)^{\ddagger}$} \\
\hline Total & 37 & 33.8 & 20 & 16.3 & 50 & 45.8 & 36 & 29.3 \\
\hline $20-29$ yrs & 0 & 0 & 0 & 0 & 0 & 0 & 0 & 0 \\
\hline 30-39 yrs & 1 & 4.8 & 0 & 0 & 0 & 0 & 0 & 0 \\
\hline $40-49$ yrs & 3 & 9.8 & 0 & 0 & 5 & 16.4 & 3 & 8.9 \\
\hline $50-59$ yrs & 9 & 27.8 & 6 & 16.7 & 12 & 37.1 & 11 & 30.6 \\
\hline $60-69$ yrs & 21 & 119.7 & 11 & 54.4 & 27 & 154.8 & 16 & 79.4 \\
\hline
\end{tabular}




\begin{tabular}{|c|c|c|c|c|c|c|c|c|}
\hline & \multicolumn{4}{|c|}{ HDR-based registry } & \multicolumn{4}{|c|}{ CIS-based registry } \\
\hline & \multicolumn{2}{|r|}{ Men } & \multicolumn{2}{|c|}{ Women } & \multicolumn{2}{|r|}{ Men } & \multicolumn{2}{|c|}{ Women } \\
\hline & $\begin{array}{l}\text { Num- } \\
\text { ber of } \\
\text { inci- } \\
\text { dent } \\
\text { cases }\end{array}$ & $\begin{array}{c}\text { Incidence / } \\
100,000 \\
\text { person- } \\
\text { years at } \\
\text { risk }\end{array}$ & $\begin{array}{l}\text { Num- } \\
\text { ber of } \\
\text { inci- } \\
\text { dent } \\
\text { cases }\end{array}$ & $\begin{array}{c}\text { Incidence / } \\
100,000 \\
\text { person- } \\
\text { years at } \\
\text { risk }\end{array}$ & $\begin{array}{l}\text { Num- } \\
\text { ber of } \\
\text { inci- } \\
\text { dent } \\
\text { cases }\end{array}$ & $\begin{array}{c}\text { Incidence / } \\
100,000 \\
\text { person- } \\
\text { years at } \\
\text { risk }\end{array}$ & $\begin{array}{l}\text { Num- } \\
\text { ber of } \\
\text { inci- } \\
\text { dent } \\
\text { cases }\end{array}$ & $\begin{array}{c}\text { Incidence / } \\
100,000 \\
\text { person- } \\
\text { years at } \\
\text { risk }\end{array}$ \\
\hline \multicolumn{9}{|c|}{ Sudden cardiac arrest (total) } \\
\hline Total & - & - & - & - & 114 & 104.1 & 38 & 30.9 \\
\hline $20-29$ yrs & - & - & - & - & 0 & 0 & 0 & 0 \\
\hline $30-39$ yrs & - & - & - & - & 3 & 14.5 & 2 & 8.6 \\
\hline $40-49$ yrs & - & - & - & - & 17 & 55.8 & 6 & 17.8 \\
\hline $50-59$ yrs & - & - & - & - & 36 & 111.1 & 16 & 44.5 \\
\hline $60-69$ yrs & - & - & - & - & 55 & 312.6 & 10 & 49.3 \\
\hline \multicolumn{9}{|c|}{ Sudden cardiac arrest (with history of CVD\$) } \\
\hline Total & - & - & - & - & 47 & 42.9 & 10 & 8.1 \\
\hline $20-29$ yrs & - & - & - & - & 0 & 0 & 0 & 0 \\
\hline $30-39$ yrs & - & - & - & - & 0 & 0 & 0 & 0 \\
\hline $40-49$ yrs & - & - & - & - & 3 & 9.8 & 0 & 0 \\
\hline $50-59$ yrs & - & - & - & - & 15 & 46.3 & 5 & 13.9 \\
\hline $60-69$ yrs & - & - & - & - & 28 & 159.1 & 5 & 24.7 \\
\hline \multicolumn{9}{|c|}{ Sudden cardiac arrest (without history of CVD\$) } \\
\hline Total & - & - & - & - & 67 & 61.2 & 28 & 22.8 \\
\hline $20-29$ yrs & - & - & - & - & 0 & 0 & 0 & 0 \\
\hline $30-39$ yrs & - & - & - & - & 3 & 14.5 & 2 & 8.6 \\
\hline $40-49$ yrs & - & - & - & - & 14 & 46.0 & 6 & 17.8 \\
\hline $50-59$ yrs & - & - & - & - & 21 & 64.8 & 11 & 30.6 \\
\hline $60-69$ yrs & - & - & - & - & 27 & 153.5 & 5 & 24.7 \\
\hline
\end{tabular}

HDR, hospital discharge register; CIS, cardiology information system; yrs, years; "-" means not available. The table is censored at 70 years of age for all cardiovascular diseases because of the small number of cases in the age category $\geq$ 70 years.

* Exclusion of persons with coronary heart disease at baseline based on self-report or a diagnosis date before baseline in the registry ( $n=330$ in the HDR-based registry and $n=347$ in the CIS-based registry).

† Defined as incident acute myocardial infarction, unstable angina pectoris, coronary artery bypass grafting (CABG), percutaneous transluminal coronary angioplasty (PTCA), or coronary heart disease as cause of death (ICD-9 codes 410414; ICD-10 codes I20-I25).

‡xclusion of persons with heart failure at baseline based on a diagnosis date before baseline in the registry $(n=1$ in the HDR-based registry and $n=7$ in the CIS-based registry).

$\S$ Refers to a history of coronary heart disease or heart failure prior to the diagnosis of sudden cardiac arrest in the registry. 


\section{References}

1. Kesteloot H, Sans S, Kromhout D. Dynamics of cardiovascular and all-cause mortality in Western and Eastern Europe between 1970 and 2000. Eur Heart J. 2006 Jan;27(1):107-13.

2. Menotti A, Lanti M, Kromhout D, Blackburn H, Nissinen A, Dontas A, et al. Forty-year coronary mortality trends and changes in major risk factors in the first 10 years of follow-up in the seven countries study. Eur J Epidemiol. 2007;22(11):747-54.

3. McGovern PG, Jacobs DR, Jr., Shahar E, Arnett DK, Folsom AR, Blackburn H, et al. Trends in acute coronary heart disease mortality, morbidity, and medical care from 1985 through 1997: the Minnesota heart survey. Circulation. $2001 \mathrm{Jul}$ 3;104(1):19-24.

4. Reitsma JB, Dalstra JA, Bonsel GJ, van der Meulen JH, Koster RW, Gunning-Schepers LJ, et al. Cardiovascular disease in the Netherlands, 1975 to 1995: decline in mortality, but increasing numbers of patients with chronic conditions. Heart. 1999 Jul;82(1):52-6.

5. Kennedy GT, Stern MP, Crawford MH. Miscoding of hospital discharges as acute myocardial infarction: implications for surveillance programs aimed at elucidating trends in coronary artery disease. Am J Cardiol. 1984 Apr 1;53(8):1000-2.

6. Mahonen M, Salomaa V, Keskimaki I, Moltchanov V. The feasibility of routine mortality and morbidity register data linkage to study the occurrence of acute coronary heart disease events in Finland. The Finnish Cardiovascular Diseases Registers (CVDR) Project. Eur J Epidemiol. 2000;16(8):701-11.

7. Koek HL, de Bruin A, Gast A, Gevers E, Kardaun JW, Reitsma JB, et al. Incidence of first acute myocardial infarction in the Netherlands. Neth J Med. 2007 Dec;65(11):434-41.

8. Madsen M, Davidsen M, Rasmussen S, Abildstrom SZ, Osler M. The validity of the diagnosis of acute myocardial infarction in routine statistics: a comparison of mortality and hospital discharge data with the Danish MONICA registry. J Clin Epidemiol. 2003 Feb;56(2):124-30.

9. Pajunen $P$, Koukkunen $H$, Ketonen $M$, Jerkkola $T$, Immonen-Raiha $P$, Karja-Koskenkari $P$, et al. The validity of the Finnish Hospital Discharge Register and Causes of Death Register data on coronary heart disease. Eur J Cardiovasc Prev Rehabil. 2005 Apr;12(2):132-7.

10. Hammar N, Nerbrand C, Ahlmark G, Tibblin G, Tsipogianni A, Johansson S, et al. Identification of cases of myocardial infarction: hospital discharge data and mortality data compared to myocardial infarction community registers. Int J Epidemiol. 1991 Mar;20(1):114-20.

11. Boyle CA, Dobson AJ. The accuracy of hospital records and death certificates for acute myocardial infarction. Aust N Z J Med. 1995 Aug;25(4):316-23.

12. Mahonen M, Salomaa V, Brommels M, Molarius A, Miettinen H, Pyorala K, et al. The validity of hospital discharge register data on coronary heart disease in Finland. Eur J Epidemiol. 1997 Jun;13(4):403-15.

13. Rapola JM, Virtamo J, Korhonen P, Haapakoski J, Hartman AM, Edwards BK, et al. Validity of diagnoses of major coronary events in national registers of hospital diagnoses and deaths in Finland. Eur J Epidemiol. 1997 Feb;13(2):133-8.

14. De Henauw S, de Smet P, Aelvoet W, Kornitzer M, De Backer G. Misclassification of coronary heart disease in mortality statistics. Evidence from the WHO-MONICA Ghent-Charleroi Study in Belgium. J Epidemiol Community Health. 1998 Aug;52(8):513-9.

15. Mahonen M, Salomaa V, Torppa J, Miettinen H, Pyorala K, Immonen-Raiha P, et al. The validity of the routine mortality statistics on coronary heart disease in Finland: comparison with the FINMONICA MI register data for the years 1983-1992. Finnish multinational MONItoring of trends and determinants in CArdiovascular disease. J Clin Epidemiol. 1999 Feb;52(2):157-66.

16. Ingelsson E, Arnlov J, Sundstrom J, Lind L. The validity of a diagnosis of heart failure in a hospital discharge register. Eur J Heart Fail. 2005 Aug;7(5):787-91.

17. Khand AU, Shaw M, Gemmel I, Cleland JG. Do discharge codes underestimate hospitalisation due to heart failure? Validation study of hospital discharge coding for heart failure. Eur J Heart Fail. 2005 Aug;7(5):792-7.

18. Van Leer EM, Seidell JC, Kromhout D. Dietary calcium, potassium, magnesium and blood pressure in the Netherlands. Int J Epidemiol. 1995 Dec;24(6):1117-23.

19. Lean ME, Han TS, Seidell JC. Impairment of health and quality of life in people with large waist circumference. Lancet. 1998 Mar 21;351(9106):853-6.

20. Van den Brandt PA, Schouten LJ, Goldbohm RA, Dorant E, Hunen PM. Development of a record linkage protocol for use in the Dutch Cancer Registry for Epidemiological Research. Int J Epidemiol. 1990 Sep;19(3):553-8. 
21. Gorgels AP, Gijsbers C, de Vreede-Swagemakers J, Lousberg A, Wellens HJ. Out-of-hospital cardiac arrest--the relevance of heart failure. The Maastricht Circulatory Arrest Registry. Eur Heart J. 2003 Jul;24(13):1204-9.

22. Mackenbach JP, van Duyne WM. [Registration and coding of various causes of death in the Netherlands and other EEC countries]. Ned Tijdschr Geneeskd. 1984 Jan 7;128(1):13-8.

23. Mackenbach JP, Van Duyne WM, Kelson MC. Certification and coding of two underlying causes of death in The Netherlands and other countries of the European Community. J Epidemiol Community Health. 1987 Jun;41(2):156-60.

24. Alpert JS, Thygesen K, Antman E, Bassand JP. Myocardial infarction redefined--a consensus document of The Joint European Society of Cardiology/American College of Cardiology Committee for the redefinition of myocardial infarction. J Am Coll Cardiol. 2000 Sep;36(3):959-69.

25. Roedig A. Acuut hartinfarct 2001-2004: ziekenhuisopnamen, per GGD-regio, gecorrigeerd voor leeftijd en geslacht. The National Public Health Compass 2006 [cited 2008 June 5]. Available from: http://www.rivm.nl/vtv/object_map/o1626n25675.html

26. Lindblad U, Rastam L, Ranstam J, Peterson M. Validity of register data on acute myocardial infarction and acute stroke: the Skaraborg Hypertension Project. Scand J Soc Med. 1993 Mar;21(1):3-9.

27. Heliovaara M, Reunanen A, Aromaa A, Knekt P, Aho K, Suhonen O. Validity of hospital discharge data in a prospective epidemiological study on stroke and myocardial infarction. Acta Med Scand. 1984;216(3):309-15.

28. Pladevall M, Goff DC, Nichaman MZ, Chan F, Ramsey D, Ortiz C, et al. An assessment of the validity of ICD Code 410 to identify hospital admissions for myocardial infarction: The Corpus Christi Heart Project. Int J Epidemiol. 1996 Oct;25(5):948-52.

29. Guidelines for the diagnosis of heart failure. The Task Force on Heart Failure of the European Society of Cardiology. Eur Heart J. 1995 Jun;16(6):741-51. 



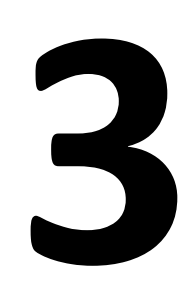

\section{Co-occurrence of metabolic factors and the risk of coronary heart disease: a pro- spective cohort study in the Netherlands}

Audrey H.H. Merry

Petra M.G. Erkens Jolanda M.A. Boer Leo J. Schouten Edith J.M. Feskens W.M. Monique Verschuren Anton P.M. Gorgels Piet A. van den Brandt

International Journal of Cardiology (accepted for publication) 


\section{Abstract}

Background: Prevalence of metabolic factors such as diabetes, hypertension, obesity, $\mathrm{HDL}$ and total cholesterol that are associated with an increased risk of coronary heart disease (CHD) is increasing worldwide. However, less is known about combinations of these factors that are associated with the highest CHD risk. Therefore, the associations between combinations of these metabolic factors and the incidence of CHD, acute myocardial infarction (AMI), and unstable angina pectoris (UAP) were studied in the Cardiovascular Registry Maastricht (CAREMA) cohort study.

Methods: The CAREMA study consists of 21,148 participants, born in 1927-1977 and randomly sampled from Maastricht and surrounding communities in 1987-1997. At baseline, all participants completed a self-administered questionnaire. Height, weight, blood pressure, total and HDL cholesterol levels were measured during a physical examination. After follow-up of maximally 16.9 years, $780 \mathrm{CHD}, 437 \mathrm{AMI}$, and 286 UAP cases of first occurrence were registered. Incidence rate ratios (RRs) were estimated using Cox proportional hazards models adjusted for age, sex, smoking, and alcohol consumption.

Results: Compared with subjects without any of the metabolic factors, the RRs of CHD were $2.37,4.34$, and 7.36 for subjects with 1,2 , or $\geq 3$ metabolic factors, respectively. These RRs were higher for AMI but lower for UAP. Especially combinations of metabolic factors that included diabetes or both a low HDL $(\leq 0.9 \mathrm{mmol} / \mathrm{L}$ in $\mathrm{men} ; \leq 1.0$ $\mathrm{mmol} / \mathrm{L}$ in women) and high total cholesterol $(\geq 6.21 \mathrm{mmol} / \mathrm{L})$ were associated with increased risks.

Conclusion: The risk of total CHD, AMI, and UAP varies considerably between different combinations of metabolic factors. 


\section{Introduction}

Several factors have been established as risk factors for coronary heart disease (CHD) among which are the metabolic factors diabetes, hypertension, dyslipidaemia, and obesity. These metabolic factors tend to co-occur in an individual more often than expected by chance (1-3). The prevalence of metabolic risk factors is increasing worldwide (4-6). This will lead to an increase in the disease burden of CHD caused by these factors. Therefore, it is important to know which persons are at the highest risk of developing CHD.

Several studies found that an increasing number of metabolic factors present within a person are associated with an increasing mortality and/or incidence of CHD (7-19). However, these studies focused only on the risk of total CHD. As specific coronary diseases such as acute myocardial infarction (AMI) and unstable angina pectoris (UAP) differ in their clinical presentation and prognosis $(20,21)$, they may also differ in the strength of their associations with etiological factors. To our knowledge, no studies investigated the association between the number of metabolic factors and the risks of these diseases separately. Furthermore, only four studies investigated the risks associated with different combinations of metabolic factors to identify the combinations that convey the highest risk of cardiovascular disease $(10,22)$ or $\operatorname{CHD}(8,17)$. In addition, none of these studies considered the effects on the risk of AMI or UAP separately.

Therefore, the goals of the present study are to investigate the influence of 1) the individual metabolic factors diabetes, hypertension, obesity, low HDL and high total cholesterol, 2) the co-occurrence of these metabolic factors within a person, and 3) the different specific combinations of these five factors on the risk of AMI and UAP in the Cardiovascular Registry Maastricht (CAREMA) Cohort Study. In addition, the influences of these factors were also investigated on the risk of total CHD.

\section{Materials and Methods}

\section{Study population}

The CAREMA study consists of participants, living in the Maastricht region, of two large monitoring projects in the Netherlands: the Monitoring Project on Cardiovascular Risk Factors (PPHVZ) 1987-1991 (23) and the Monitoring Project on Chronic Disease Risk Factors (MORGEN) 1993-1997 (24), including the transition year (1992) between these projects. Each year, a random sample of people aged 20-59 years was selected from municipality registries of Maastricht and surrounding communities, i.e. Eijsden, Meerssen, Margraten, and Valkenburg aan de Geul. Between 1987 and 1997, 21,662 men and women, born between 1927 and 1977, were included in this study, of whom 21,148 participants $(97.6 \%)$ had given informed consent to retrieve information from Municipal Population Registries and from their general practitioner and specialist. 


\section{Baseline measurements}

At baseline, all participants completed a self-administered questionnaire on demographic characteristics, medical history, family history of myocardial infarction, and lifestyle habits such as smoking, alcohol consumption, usual dietary intake, and physical activity. In addition, a medical examination was performed at the Municipal Health Service to measure blood pressure, height, and weight. All measurements were carried out by trained staff members who were instructed by the same physician.

Blood pressure was measured on the left upper arm with the participant in a sitting position using a Random Zero Sphygmomanometer. Systolic blood pressure was recorded at the appearance of rhythmic sounds (first-phase Korotkoff) and diastolic blood pressure at the disappearance of sounds (fifth-phase Korotkoff). A second blood pressure measurement was performed after measuring the heart rate for thirty seconds. The average of these two measurements was used in the analyses.

Height was recorded to the nearest $0.1 \mathrm{~cm}$ while the participant stood upright against the wall with the feet at a $45^{\circ}$ angle. Weight was recorded to the nearest $0.1 \mathrm{~kg}$ with participants wearing light clothing with empty pockets and without shoes. Body Mass Index (BMI) was calculated as weight $(\mathrm{kg})$ divided by height squared $\left(\mathrm{m}^{2}\right)$.

Non-fasting blood samples were taken for the determination of cholesterol levels. Plasma total and HDL cholesterol were enzymatically determined in EDTA-plasma using a Boehringer test kit (25). HDL cholesterol was determined after precipitation of apo Bcontaining lipoproteins with magnesium phosphotungstate (26).

\section{Definition of metabolic factors}

The metabolic factors studied in this paper are diabetes, hypertension, obesity, low HDL and high total cholesterol. Diabetes (yes/no) was defined according to selfreported data of the participants in the baseline questionnaire. Hypertension, obesity, and low HDL cholesterol were defined according to the definitions of the World Health Organization (WHO) $(27,28)$. Hypertension was defined as systolic blood pressure $\geq 140 \mathrm{mmHg}$, diastolic blood pressure $\geq 90 \mathrm{mmHg}$, or use of blood pressure lowering medication. Obesity was defined as $\mathrm{BMI} \geq 30 \mathrm{~kg} / \mathrm{m}^{2}$, whereas the cut-off points for a low $\mathrm{HDL}$ cholesterol level were $\leq 0.9 \mathrm{mmol} / \mathrm{L}$ in men and $\leq 1.0 \mathrm{mmol} / \mathrm{L}$ in women. For total cholesterol, a cut-off point $\geq 6.21 \mathrm{mmol} / \mathrm{L}$ was used according to the guidelines of the National Cholesterol Education Program Panel (NCEP) (29).

Based on these definitions, a variable was created according to the number of metabolic factors present in a person ranging from 0 to $\geq 3$ metabolic factors. In addition, all possible combinations of the five metabolic factors were studied to identify the combinations with the highest CHD risk. However, combinations that included diabetes were taken together because of small numbers of cases within these groups. 


\section{Follow-up}

A migration and mortality follow-up was performed by record linkage of the cohort to the Municipal Population Registries. For participants who died, the cause of death was obtained from the causes of death registry of Statistics Netherlands. During follow-up until 31 December 2003, 2,106 persons (10.0\%) had migrated to a municipality outside the Maastricht region, 621 persons (2.9\%) had emigrated, 791 persons (3.7\%) had died, and 12 persons (0.1\%) were lost to follow-up.

In addition, a cardiologic follow-up was performed by record linkage of the cohort to the Cardiology Information System (CIS) of the University Hospital Maastricht (UHM). The medical history of the 4,694 participants who were linked to the CIS was abstracted and coded by trained registrars under guidance of a cardiologist (AG). Further details on the cardiologic follow-up have been described in a previous publication (30). Incident cases of CHD (defined as incident acute myocardial infarction, unstable angina pectoris, Coronary Artery Bypass Grafting, or Percutaneous Transluminal Coronary Angioplasty), AMI, and UAP were identified in two ways, 1) based on the first recorded clinical diagnosis of $\mathrm{CHD}$ in $\mathrm{CIS}$, and 2) based on the primary or secondary cause of death according to Statistics Netherlands using the following ICD-codes: ICD-9 410-414 and ICD-10 I20-I25 for CHD; ICD-9 410 and ICD-10 I21-I22 for AMI; and ICD-9 413 and ICD-10 120 for UAP.

Person-time at risk was calculated from baseline until end of follow-up, i.e. clinical diagnosis in CIS, migration to a municipality outside the Maastricht region, emigration, death, or censoring at 31 December 2003, whichever occurred first.

\section{Statistical analyses}

Because of their widespread acceptance as confounders for CHD, all risk estimates were adjusted for age at baseline (yrs), sex, smoking status (never, ex, or current smoker), and alcohol consumption (glasses/day). In addition, all models were adjusted for baseline cohort (PPHVZ or MORGEN). Other potential confounders were only considered if they changed the risk estimates with more than $10 \%$ after adjustment. However, none of the following factors changed the risk estimates with more than $10 \%$ and were therefore not included in the models: occupational and non-occupational physical activity (none to light vs. moderate to heavy), family history of myocardial infarction (yes/no), and the consumption (g/day) of fruits, vegetables, fish, fiber, saturated and unsaturated fatty acids. Furthermore, age, sex, and smoking status were tested as possible effect modifiers of the association between the metabolic factors and coronary disease risk by using Wald chi-square tests.

In the analyses, participants with CHD at baseline $(n=347)$, those who were lost to follow-up ( $n=12)$ or migrated to a municipality outside the Maastricht region before baseline $(n=26)$, and those with missing data on at least one metabolic factor $(n=337)$ or on the confounders ( $n=385)$ were excluded leaving 20,041 cohort members for statistical analyses including 780 incident CHD cases. Among them there were 437 cases with incident $\mathrm{AMI}$ and 286 cases with incident UAP. 
Incidence rate ratios (RRs) and corresponding 95\% confidence intervals $(95 \% \mathrm{Cl}$ ) were calculated by Cox proportional hazards models using the Stata statistical software package 9.2 (Stata corporation, College Station, TX, USA). The proportional hazards assumption was tested using the scaled Schoenfeld residuals (31) and by checking the log-log curves. The assumption was found not to be violated by either one of the metabolic factors. Time-varying covariates were entered into models in case of violation of the assumption by one of the confounders. Ordinal variables were fitted as continuous terms in the models to obtain p-values for dose-response trends. Population attributable risks (PAR) were calculated by combining the RR and the prevalence of the (combinations of) metabolic factors in the study population. Two-sided $p$-values are reported throughout this paper. A $p$-value $<0.05$ is considered as statistically significant.

\section{Results}

Subjects with at least one metabolic factor were older at baseline and were more often male compared with subjects with no metabolic factors (table 1). In addition, participants of the PPHVZ-project more often had at least one metabolic factor compared with participants of the MORGEN-project. As expected, BMI, blood pressure, and total cholesterol increased, while HDL cholesterol decreased with increasing number of metabolic factors. Table 1 also shows higher percentages of current smokers among subjects with at least one metabolic factor, while they consumed alcoholic beverages less often compared with subjects with no metabolic factors.

In table 2, the multivariable adjusted RRs are shown for each of the metabolic factors. All five metabolic factors were found to be independent risk factors for total CHD, AMI, and UAP, except for diabetes and obesity which were not statistically significantly associated with the risk of UAP. The highest CHD risk was found for diabetes (RR 2.81; 95\% Cl 1.94-4.07), while the lowest risk was found for obesity (RR 1.34; 95\% Cl 1.101.64). For AMI a similar pattern was found. The highest UAP risk was found for high total cholesterol. Diabetes and low HDL cholesterol seemed to be stronger risk factors for AMI than for UAP. The impact on the different endpoints was quite similar for the other metabolic factors.

In the total cohort, subjects without any of the five metabolic factors were the most common (56.0\%), $29.4 \%$ had only one factor, $11.2 \%$ had two factors, and $3.5 \%$ of the subjects had $\geq 3$ metabolic factors. These prevalences increased with age. In participants aged $50-60$ years at baseline, $7.1 \%$ had $\geq 3$ metabolic factors compared with $0.5 \%$ in participants aged $20-29$ years at baseline. 
Table 1 Baseline characteristics of the CAREMA cohort, 1987-1997

\begin{tabular}{|c|c|c|c|c|}
\hline & & Number of $\mathrm{m}$ & abolic factors & \\
\hline & $\begin{array}{l}\text { No metabolic } \\
\text { factors } \\
(n=11,218)\end{array}$ & $\begin{array}{l}\text { Only } 1 \text { meta- } \\
\text { bolic factor } \\
(n=5,887)\end{array}$ & $\begin{array}{l}2 \text { metabolic } \\
\text { factors } \\
(n=2,245)\end{array}$ & $\begin{array}{l}\geq 3 \text { metabolic } \\
\text { factors } \\
(n=691)\end{array}$ \\
\hline Demographics & & & & \\
\hline & mean (SD) & mean (SD) & mean (SD) & mean (SD) \\
\hline Age at baseline (years) & $37.9(10.4)$ & $43.6(10.5)$ & $47.4(8.9)$ & $48.8(8.2)$ \\
\hline Sex & $\mathrm{n}(\%)$ & $\mathrm{n}(\%)$ & $\mathrm{n}(\%)$ & $\mathrm{n}(\%)$ \\
\hline Men & $4,660(41.5)$ & $3,070(52.1)$ & $1,239(55.2)$ & $410(59.3)$ \\
\hline Women & $6,558(58.5)$ & $2,817(47.9)$ & $1,006(44.8)$ & $281(40.7)$ \\
\hline Baseline cohort* & & & & \\
\hline PPHVZ (1987-1992) & $7,522(67.1)$ & $4,219(71.7)$ & $1,656(73.8)$ & $521(75.4)$ \\
\hline MORGEN (1993-1997) & $3,696(32.9)$ & $1,668(28.3)$ & $589(26.2)$ & $170(24.6)$ \\
\hline Metabolic factors & & & & \\
\hline & mean (SD) & mean (SD) & mean (SD) & mean (SD) \\
\hline Body Mass Index $\left(\mathrm{kg} / \mathrm{m}^{2}\right)$ & $23.3(2.7)$ & $25.4(3.6)$ & $28.2(4.4)$ & $31.5(4.5)$ \\
\hline Total cholesterol (mmol/L) & $4.9(0.7)$ & $5.8(1.2)$ & $6.3(1.2)$ & $6.6(1.2)$ \\
\hline HDL cholesterol (mmol/L) & $1.4(0.3)$ & $1.2(0.4)$ & $1.1(0.3)$ & $0.9(0.3)$ \\
\hline Systolic blood pressure & $114.2(10.2)$ & $122.0(14.8)$ & $130.9(16.8)$ & $138.0(15.2)$ \\
\hline Diastolic blood pressure & $73.1(7.4)$ & $78.2(9.6)$ & $84.1(10.3)$ & $88.8(9.9)$ \\
\hline & $\mathrm{n}(\%)$ & $\mathrm{n}(\%)$ & n (\%) & $\mathrm{n}(\%)$ \\
\hline $\begin{array}{l}\text { Blood pressure lowering } \\
\text { medication }\end{array}$ & $0(-)$ & $306(5.2)$ & $367(16.3)$ & $209(30.2)$ \\
\hline Diabetes & $0(-)$ & $54(0.9)$ & $61(2.7)$ & $60(8.7)$ \\
\hline Confounding factors & & & & \\
\hline Current smoking & $4,229(37.7)$ & $2,536(43.1)$ & $948(42.2)$ & $282(40.8)$ \\
\hline Regular alcohol use & $7,115(63.4)$ & $3,665(62.3)$ & $1,349(60.1)$ & $404(58.5)$ \\
\hline & median (range) & median (range) & median (range) & median (range) \\
\hline $\begin{array}{l}\text { Number of glasses/day among } \\
\text { regular consumers only }\end{array}$ & $1.3(0.1-17.9)$ & $1.4(0.1-21.4)$ & $1.4(0.1-11.6)$ & $1.4(0.1-30.0)$ \\
\hline
\end{tabular}

n, number; SD, standard deviation.

* Refers to the Monitoring Project on Cardiovascular Risk Factors (PPHVZ) and the Monitoring Project on Chronic Disease Risk Factors (MORGEN). 
Table 2 Multivariable adjusted rate ratios of $\mathrm{CHD}, \mathrm{AMI}$, and UAP for individual metabolic factors in the CAREMA cohort, 1987-2003

\begin{tabular}{|c|c|c|c|c|c|c|}
\hline & \multicolumn{2}{|c|}{ Coronary heart disease } & \multicolumn{2}{|c|}{$\begin{array}{l}\text { Acute myocardial infarc- } \\
\text { tion }\end{array}$} & \multicolumn{2}{|c|}{ Unstable angina pectoris } \\
\hline & $\begin{array}{c}\text { Cases I } \\
\text { person- } \\
\text { years at } \\
\text { risk }\end{array}$ & $\begin{array}{c}\text { RR } \\
(95 \% \mathrm{Cl})\end{array}$ & $\begin{array}{c}\text { Cases I } \\
\text { person- } \\
\text { years at } \\
\text { risk }\end{array}$ & $\begin{array}{c}\text { RR } \\
(95 \% \text { Cl })\end{array}$ & $\begin{array}{c}\text { Cases I } \\
\text { person- } \\
\text { years at } \\
\text { risk }\end{array}$ & $\begin{array}{c}\text { RR } \\
(95 \% \mathrm{Cl})\end{array}$ \\
\hline \multicolumn{7}{|c|}{ Diabetes } \\
\hline No & $\begin{array}{c}750 / \\
216,340\end{array}$ & $\begin{array}{c}1 \\
\text { (reference) }\end{array}$ & $\begin{array}{c}417 / \\
216,340\end{array}$ & $\begin{array}{c}1 \\
\text { (reference) }\end{array}$ & $\begin{array}{c}278 / \\
216,340\end{array}$ & $\begin{array}{c}1 \\
\text { (reference) }\end{array}$ \\
\hline Yes & $\begin{array}{c}30 / \\
1,724\end{array}$ & $\begin{array}{c}2.81 \\
(1.94-4.07)\end{array}$ & $\begin{array}{c}20 / \\
1,724\end{array}$ & $\begin{array}{c}3.41 \\
(2.16-5.38)\end{array}$ & $\begin{array}{c}8 / \\
1,724\end{array}$ & $\begin{array}{c}2.02 \\
(0.99-4.10)\end{array}$ \\
\hline \multicolumn{7}{|c|}{ Hypertension } \\
\hline No & $\begin{array}{c}488 / \\
185,555\end{array}$ & $\begin{array}{c}1 \\
\text { (reference) }\end{array}$ & $\begin{array}{c}275 / \\
185,555\end{array}$ & $\begin{array}{c}1 \\
\text { (reference) }\end{array}$ & $\begin{array}{c}178 / \\
185,555\end{array}$ & $\begin{array}{c}1 \\
\text { (reference) }\end{array}$ \\
\hline Yes & $\begin{array}{c}292 / \\
32,509\end{array}$ & $\begin{array}{c}1.77 \\
(1.52-2.06)\end{array}$ & $\begin{array}{c}162 / \\
32,509\end{array}$ & $\begin{array}{c}1.76 \\
(1.43-2.16)\end{array}$ & $\begin{array}{c}108 / \\
32,509\end{array}$ & $\begin{array}{c}1.78 \\
(1.38-2.29)\end{array}$ \\
\hline \multicolumn{7}{|c|}{ HDL cholesterol* } \\
\hline High & $\begin{array}{c}496 / \\
183,358\end{array}$ & $\begin{array}{c}1 \\
\text { (reference) }\end{array}$ & $\begin{array}{c}259 / \\
183,358\end{array}$ & $\begin{array}{c}1 \\
\text { (reference) }\end{array}$ & $\begin{array}{c}201 / \\
183,358\end{array}$ & $\begin{array}{c}1 \\
\text { (reference) }\end{array}$ \\
\hline Low & $\begin{array}{c}284 \text { / } \\
34,705\end{array}$ & $\begin{array}{c}1.88 \\
(1.61-2.19)\end{array}$ & $\begin{array}{c}178 / \\
34,705\end{array}$ & $\begin{array}{c}2.06 \\
(1.69-2.52)\end{array}$ & $\begin{array}{c}85 / \\
34,705\end{array}$ & $\begin{array}{c}1.52 \\
(1.16-1.98)\end{array}$ \\
\hline \multicolumn{7}{|c|}{ Total cholesterolt ${ }^{\dagger}$} \\
\hline Low & $\begin{array}{c}364 / \\
169,417\end{array}$ & $\begin{array}{c}1 \\
\text { (reference) }\end{array}$ & $\begin{array}{c}206 / \\
169,417\end{array}$ & $\begin{array}{c}1 \\
\text { (reference) }\end{array}$ & $\begin{array}{c}131 / \\
169,417\end{array}$ & $\begin{array}{c}1 \\
\text { (reference) }\end{array}$ \\
\hline High & $\begin{array}{c}416 / \\
48,646\end{array}$ & $\begin{array}{c}2.47 \\
(2.14-2.85)\end{array}$ & $\begin{array}{c}231 / \\
48,646\end{array}$ & $\begin{array}{c}2.50 \\
(2.06-3.03)\end{array}$ & $\begin{array}{c}155 / \\
48,646\end{array}$ & $\begin{array}{c}2.48 \\
(1.95-3.15)\end{array}$ \\
\hline \multicolumn{7}{|c|}{ Obesity } \\
\hline No & $\begin{array}{c}654 / \\
198,813\end{array}$ & $\begin{array}{c}1 \\
\text { (reference) }\end{array}$ & $\begin{array}{c}365 / \\
198,813\end{array}$ & $\begin{array}{c}1 \\
\text { (reference) }\end{array}$ & $\begin{array}{c}240 / \\
198,813\end{array}$ & $\begin{array}{c}1 \\
\text { (reference) }\end{array}$ \\
\hline Yes & $\begin{array}{c}126 / \\
19,250\end{array}$ & $\begin{array}{c}1.34 \\
(1.10-1.64)\end{array}$ & $\begin{array}{c}72 / \\
19,250\end{array}$ & $\begin{array}{c}1.41 \\
(1.08-1.83)\end{array}$ & $\begin{array}{c}46 / \\
19,250\end{array}$ & $\begin{array}{c}1.32 \\
(0.95-1.83)\end{array}$ \\
\hline
\end{tabular}

$\mathrm{RR}$, rate ratio; $\mathrm{Cl}$, confidence interval. RRs were mutually adjusted and adjusted for age (years), sex, baseline cohort (PPHVZ or MORGEN), smoking status (never, ex, or current smoker), and alcohol consumption (glasses/day).

${ }^{*}$ Cut-off point $0.9 \mathrm{mmol} / \mathrm{L}$ for men and $1.0 \mathrm{mmol} / \mathrm{L}$ for women.

† Cut-off point $6.21 \mathrm{mmol} / \mathrm{L}$ for both men and women.

The multivariable adjusted RRs associated with the number of metabolic factors are shown in figure 1. A significant positive trend was found with an increasing number of metabolic factors and the risk of total CHD, AMI, and UAP ( $p$ trends $<0.001$ ). Subjects with $\geq 3$ metabolic factors had a 7.4 times higher risk of CHD, a 9.3 times higher risk of AMI, and a 5.3 times higher risk of UAP compared with subjects with no metabolic factors. The proportion of CHD cases that could be attributed to having 1,2 , or $\geq 3$ metabolic factors were $29 \%, 27 \%$, and $18 \%$, respectively. These proportions were $36 \%$, $29 \%$, and $22 \%$ for AMI cases and $23 \%, 26 \%$, and $13 \%$ for UAP cases, respectively. 


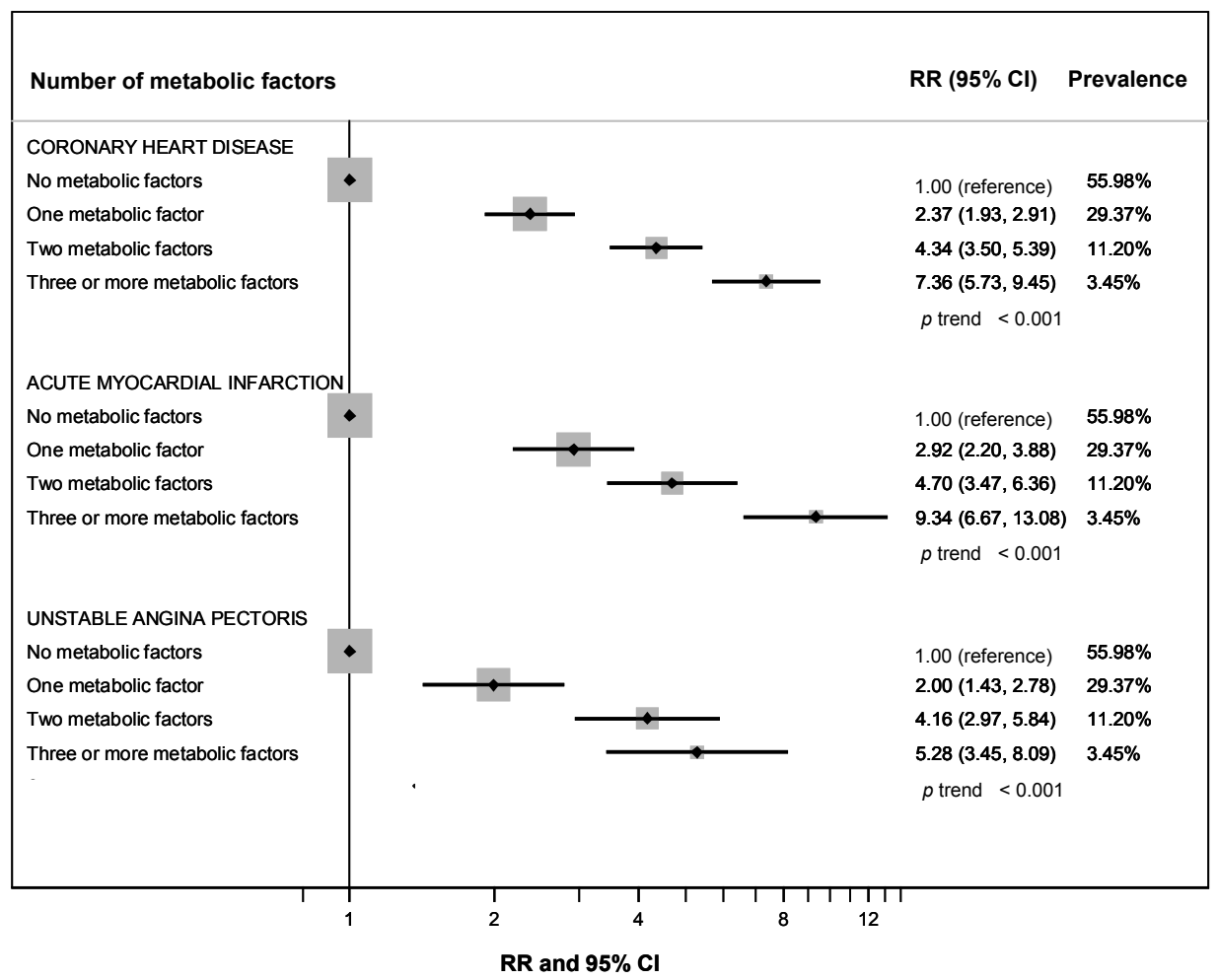

Figure 1 Multivariable adjusted RRs of $\mathrm{CHD}, \mathrm{AMI}$ and UAP by co-occurrence of metabolic factors in the CAREMA cohort, 1987-2003.

$\mathrm{RR}$, rate ratio; $\mathrm{Cl}$, confidence interval. RRs were adjusted for age (yrs), sex, baseline cohort (PPHVZ or MORGEN), smoking status (never, ex, or current smoker), and alcohol consumption (glasses/day). The prevalence, indicated by the size of the gray boxes, refers to the proportion of the total cohort exposed to the specific number of metabolic factors.

Age at baseline was found to be a statistically significant effect modifier on a multiplicative scale in the association of hypertension, total cholesterol, and the number of metabolic factors with the risk of total CHD and AMI ( $p$ values ranging from $<0.001$ to 0.03 ). Stratified analyses showed that these associations became weaker in the older age category ( $\geq 50$ years) compared with the younger age category ( $<50$ years). Compared with subjects with no metabolic factors, the RRs $(95 \% \mathrm{Cl}$ ) of $\mathrm{CHD}$ for having $\geq 3$ metabolic factors was 5.5 (4.0-7.6) in the older age category and $9.8(6.6-14.6)$ in the younger age category.

Table 3 shows the multivariable adjusted RRs and PARs for all possible combinations of the five metabolic factors. Although obesity was found to be an independent risk factor for $\mathrm{CHD}$ and $\mathrm{AMI}$ in multivariable analysis, subjects with obesity as the only metabolic factor did not have a significantly increased risk. Regardless of which metabolic factor, having an additional metabolic factor led to a relatively large increase in the risks of total CHD, AMI, and UAP. Relatively high risks were found for combinations including diabetes or both a low HDL and a high total cholesterol level. 


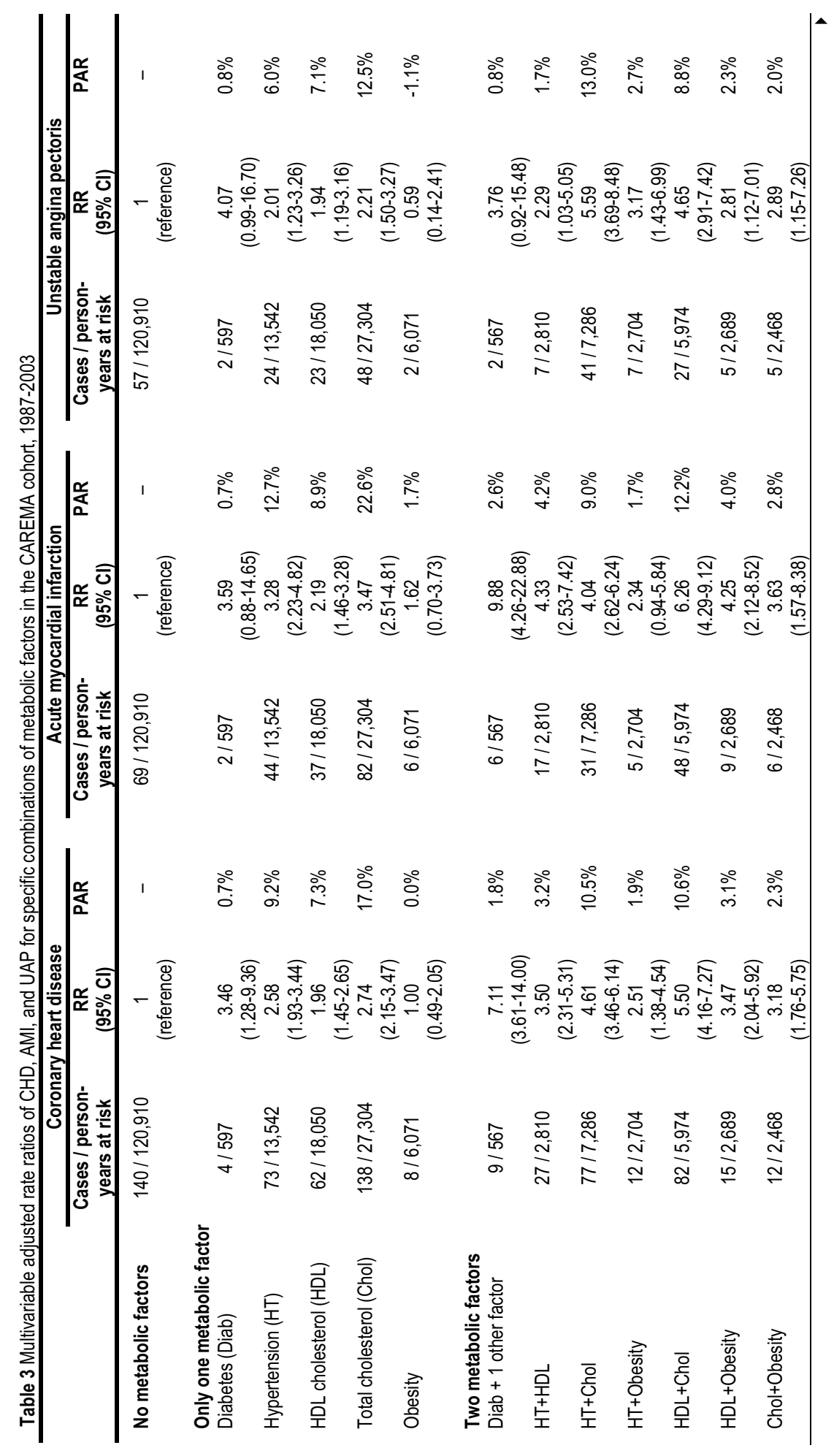




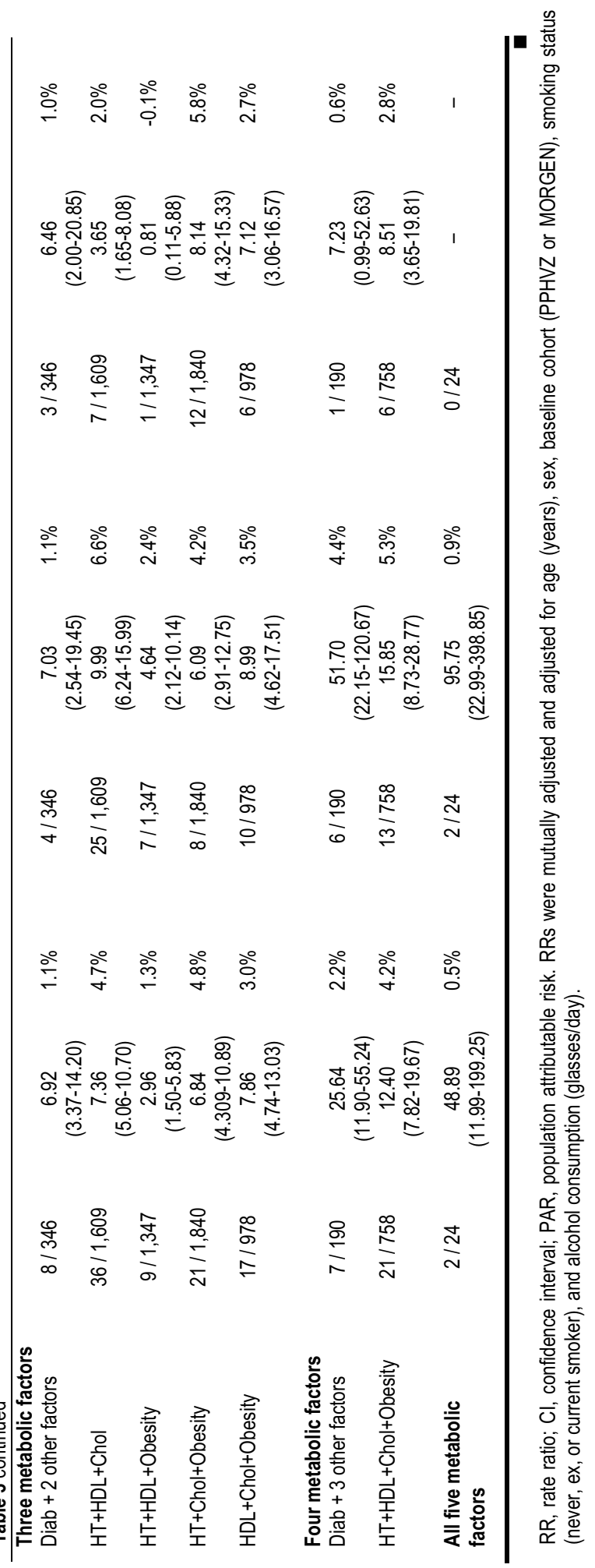


However, only for the combinations including both cholesterol levels relatively high PARs were found. The low PARs for combinations of metabolic factors including diabetes can be explained by the low prevalence of subjects with diabetes in our study population. Furthermore, the PAR was also relatively high for subjects with both hypertension and a high total cholesterol level. Compared with persons with no metabolic factors, persons with all five factors present had a 48.9 (95\% Cl 12.0-199.3) times higher risk of $\mathrm{CHD}$ and an 95.8 (95\% $\mathrm{Cl} 23.0-398.9)$ times higher risk of $\mathrm{AMI}$, though these estimates were based on small numbers of cases.

\section{Discussion}

Of all possible combinations of the five metabolic factors (diabetes, hypertension, obesity, low HDL and high total cholesterol) especially combinations that included diabetes or both a low HDL and high total cholesterol level were associated with elevated risks of the coronary diseases. Although numbers were very small, the highest risks were found for persons with all five metabolic factors present compared with persons without any metabolic factor. All metabolic factors were independent risk factors for developing CHD and AMI, whereas diabetes and obesity were not independently associated with UAP. Furthermore, a clear dose-response trend was found with an increasing number of metabolic factors and the risk of all three endpoints.

In this study, separate analyses were performed for AMI and UAP. The results show that especially the co-occurrence of three or more metabolic factors is associated with higher risks of AMI compared with UAP. For several specific combinations of the five metabolic factors, relatively large differences between the risks of AMI and UAP were found, although some of these risk estimates were based on a small number of cases. The clinical presentation with AMI or UAP depends on the degree of occlusion of a coronary artery by a thrombus after plaque disruption $(32,33)$. Therefore, differences between these two diseases in the strength of their associations with etiological factors may be linked to thrombotic and fibrinolytic processes. Previous studies have found that metabolic factors such as diabetes, hypertension, and hyperlipidemia are associated with decreased fibrinolytic activity (34-36). For that reason, the metabolic factors may be stronger related to the occurrence of AMI compared to the occurrence of UAP. These differences between the two coronary diseases remain undetected in studies where only total CHD or AMI was investigated.

In this prospective cohort study with a maximum follow-up of 16.9 years, only twelve participants $(0.1 \%)$ were lost to follow-up. Therefore, it is unlikely that exposurerelated loss to follow-up has influenced the results. Furthermore, the cardiologic follow-up is expected to be nearly complete, because of the unique and central position of the single hospital, the UHM, in the study region. In addition, emigration or migration out of the Maastricht region was defined as end of follow-up. The cardiologic data were retrieved from the Cardiology Information System (CIS) which contains all infor- 
mation about people that visited the department of Cardiology of the UHM. The clinical diagnoses retrieved from the CIS were based on the diagnosis made by a cardiologist including the additional information in the registry such as ECG findings, enzyme levels, and catheterization results. This has led to a more accurate case identification compared to using data from hospital discharge registers (30).

In this study, only non-fasting instead of fasting plasma levels for HDL and total cholesterol were available. In the study by Craig et al. only small differences were found between the fasting and non-fasting levels of total cholesterol, while no differences were found in the fasting and non-fasting levels of HDL cholesterol (37). Therefore, the use of non-fasting plasma cholesterol levels has probably not biased our results. However, because no data were available on the triglycerides levels in our study, it was not possible to investigate the effect of a high triglycerides level on the risk of total CHD, AMI, and UAP.

The positive trend between an increasing number of metabolic factors and the CHD risk, found in our study, was relatively strong compared with other studies (7-19). In those other studies, which focused on the metabolic syndrome, cut-off points for the metabolic syndrome were used. In our study, cut-off points as defined by the WHO $(27,28)$ were used which are accepted values in the definition of these metabolic risk factors. However, these cut-off points are higher than those for the metabolic syndrome. Therefore, our subjects with metabolic risk factors may represent a more severe population. As a result, the associations between the metabolic factors and the $\mathrm{CHD}$ risk are stronger while the prevalences of subjects with one, two, and three or more metabolic factors are lower compared with other studies. Additionally, the lower prevalence and lower risk can also be explained by the younger age distribution of our study population.

In our study, age was a significant effect modifier on a multiplicative scale in the association of hypertension, total cholesterol, and the number of metabolic factors with the risk of both CHD and AMI. Stratified analyses according to age at baseline showed that the associations of these factors with the risk of CHD and AMI became weaker in the older age category ( $\geq 50$ years) compared with the younger age category $(<50$ years), which was also found in the study by Yusuf et al. (19). This might be explained by a higher baseline risk of people at an older age. Because the risk of CHD increases with age, the differences in absolute risks for people with and without the metabolic factors become relatively smaller at an older age which results in a lower rate ratio. For this reason, the RRs may be lower in the older age category compared with the younger age category, while the absolute risks will still be higher in the older age category.

Although several studies investigated the association with the number of metabolic factors, only two studies looked at specific combinations of metabolic factors to identify the combinations that were associated with the highest CHD risk $(8,17)$. Despite differences in the metabolic factors studied, they also found the highest CHD risk with combinations that included a high plasma glucose level or a low HDL cholesterol level. 
Furthermore, Hong et al. found the highest CHD risk when all five metabolic factors were present, as was seen in our study, although our RRs were substantially higher (6.2 vs. 48.9 , respectively). However, in the study by Hong et al., the number of cases in this category was much higher compared with our study. In addition, their subjects were older at baseline (45-64 years) compared with our subjects (20-59 years).

Besides the advantage of knowing which specific combinations of metabolic risk factors convey the highest risk, changes in the prevalence of each of these factors may help reducing the risk of developing CHD. Several studies have investigated the effects of metabolic factors on the risk of dying from or developing $\operatorname{CHD}(7-9,12-15,17,19)$. Two studies also found that diabetes or an elevated fasting glucose was associated with the highest risk, while (central) obesity was associated with the lowest CHD risk $(8,19)$. Although these two studies and the present study found that all metabolic factors were independent risk factors for $\mathrm{CHD}$, this was not seen in the other studies. However, these inconsistent results between studies may be explained by differences in the number of cases, in the study population, i.e. the in- or exclusion of subjects with diabetes, and in the definition of CHD.

In conclusion, a significantly positive trend was found between an increasing number of metabolic factors and the risks of total CHD, AMI, and UAP. Of all possible combinations of the five metabolic factors, combinations that included diabetes or both a low HDL with a high total cholesterol level conveyed the highest risks. In our population, $29 \%, 27 \%$, and $18 \%$ of the CHD events could be attributed to having 1,2 , or $\geq 3$ metabolic factors, respectively. This means that a relatively large number of CHD cases can be prevented by lowering the prevalences of the metabolic factors in the population. Therefore, focusing on these metabolic factors, and especially on their co-occurrence in people, could play an important role in the primary prevention of $\mathrm{CHD}$, especially because the prevalence of these metabolic factors is increasing worldwide (4-6). 


\section{References}

1. Eckel RH, Grundy SM, Zimmet PZ. The metabolic syndrome. Lancet. 2005 Apr 16-22;365(9468):1415-28.

2. Aizawa $Y$, Kamimura N, Watanabe H, Aizawa $Y$, Makiyama $Y$, Usuda $Y$, et al. Cardiovascular risk factors are really linked in the metabolic syndrome: this phenomenon suggests clustering rather than coincidence. Int J Cardiol. 2006 May 10;109(2):213-8.

3. Schmidt MI, Watson RL, Duncan BB, Metcalf $P$, Brancati FL, Sharrett AR, et al. Clustering of dyslipidemia, hyperuricemia, diabetes, and hypertension and its association with fasting insulin and central and overall obesity in a general population. Atherosclerosis Risk in Communities Study Investigators. Metabolism. 1996 Jun;45(6):699-706.

4. Ford ES, Giles WH, Mokdad AH. Increasing prevalence of the metabolic syndrome among u.s. Adults. Diabetes Care. 2004 Oct;27(10):2444-9.

5. Hu G, Lindstrom J, Jousilahti P, Peltonen M, Sjoberg L, Kaaja R, et al. The increasing prevalence of metabolic syndrome among Finnish men and women over a decade. J Clin Endocrinol Metab. 2008 Mar;93(3):832-6.

6. Desroches $S$, Lamarche B. The evolving definitions and increasing prevalence of the metabolic syndrome. Appl Physiol Nutr Metab. 2007 Feb;32(1):23-32.

7. Ford ES. The metabolic syndrome and mortality from cardiovascular disease and all-causes: findings from the National Health and Nutrition Examination Survey II Mortality Study. Atherosclerosis. 2004 Apr;173(2):309-14.

8. Hong $Y$, Jin X, Mo J, Lin HM, Duan Y, Pu M, et al. Metabolic syndrome, its preeminent clusters, incident coronary heart disease and all-cause mortality--results of prospective analysis for the Atherosclerosis Risk in Communities study. J Intern Med. 2007 Jul;262(1):113-22.

9. Iso $\mathrm{H}$, Sato S, Kitamura A, Imano H, Kiyama M, Yamagishi K, et al. Metabolic syndrome and the risk of ischemic heart disease and stroke among Japanese men and women. Stroke. 2007 Jun;38(6):1744-51.

10. Liu J, Grundy SM, Wang W, Smith SC, Jr., Vega GL, Wu Z, et al. Ten-year risk of cardiovascular incidence related to diabetes, prediabetes, and the metabolic syndrome. Am Heart J. 2007 Apr;153(4):552-8.

11. Malik S, Wong ND, Franklin SS, Kamath TV, L'Italien GJ, Pio JR, et al. Impact of the metabolic syndrome on mortality from coronary heart disease, cardiovascular disease, and all causes in United States adults. Circulation. 2004 Sep 7;110(10):1245-50.

12. McNeill AM, Katz R, Girman CJ, Rosamond WD, Wagenknecht LE, Barzilay Jl, et al. Metabolic syndrome and cardiovascular disease in older people: The cardiovascular health study. J Am Geriatr Soc. 2006 Sep;54(9):1317-24.

13. McNeill AM, Rosamond WD, Girman CJ, Golden SH, Schmidt MI, East HE, et al. The metabolic syndrome and 11-year risk of incident cardiovascular disease in the atherosclerosis risk in communities study. Diabetes Care. 2005 Feb;28(2):385-90.

14. Sattar N, Gaw A, Scherbakova O, Ford I, O'Reilly DS, Haffner SM, et al. Metabolic syndrome with and without C-reactive protein as a predictor of coronary heart disease and diabetes in the West of Scotland Coronary Prevention Study. Circulation. 2003 Jul 29;108(4):414-9.

15. Sone H, Mizuno S, Fujii H, Yoshimura Y, Yamasaki $Y$, Ishibashi S, et al. Is the diagnosis of metabolic syndrome useful for predicting cardiovascular disease in asian diabetic patients? Analysis from the Japan Diabetes Complications Study. Diabetes Care. 2005 Jun;28(6):1463-71.

16. Trevisan M, Liu J, Bahsas FB, Menotti A. Syndrome $X$ and mortality: a population-based study. Risk Factor and Life Expectancy Research Group. Am J Epidemiol. 1998 Nov 15;148(10):958-66.

17. Wilson PW, D'Agostino RB, Parise H, Sullivan L, Meigs JB. Metabolic syndrome as a precursor of cardiovascular disease and type 2 diabetes mellitus. Circulation. 2005 Nov 15;112(20):3066-72.

18. Wilson PW, Kannel WB, Silbershatz H, D'Agostino RB. Clustering of metabolic factors and coronary heart disease. Arch Intern Med. 1999 May 24;159(10):1104-9.

19. Yusuf HR, Giles WH, Croft JB, Anda RF, Casper ML. Impact of multiple risk factor profiles on determining cardiovascular disease risk. Prev Med. 1998 Jan-Feb;27(1):1-9.

20. Maddox TM, Reid KJ, Rumsfeld JS, Spertus JA. One-year health status outcomes of unstable angina versus myocardial infarction: a prospective, observational cohort study of ACS survivors. BMC Cardiovasc Disord. 2007;7:28.

21. Hoshida S, Hayashi T, Kanamasa K, Ishikawa K, Naka M, Kawarabayashi T, et al. Comparison of risk factors in acute myocardial infarction and unstable angina pectoris in patients $<$ or $=66$ versus $>66$ years of age. Am J Cardiol. 2004 Mar 1;93(5):608-10. 
22. Saito I, Iso H, Kokubo $\mathrm{Y}$, Inoue M, Tsugane S. Metabolic syndrome and all-cause and cardiovascular disease mortality: Japan Public Health Center-based Prospective (JPHC) Study. Circ J. 2009 May;73(5):878-84.

23. Van Leer EM, Seidell JC, Kromhout D. Dietary calcium, potassium, magnesium and blood pressure in the Netherlands. Int J Epidemiol. 1995 Dec;24(6):1117-23.

24. Lean ME, Han TS, Seidell JC. Impairment of health and quality of life in people with large waist circumference. Lancet. 1998 Mar 21;351(9106):853-6.

25. Kattermann R, Jaworek D, Moller G, Assmann G, Bjorkhem I, Svensson L, et al. Multicentre study of a new enzymatic method of cholesterol determination. J Clin Chem Clin Biochem. 1984 Mar;22(3):24551.

26. Lopes-Virella MF, Stone P, Ellis S, Colwell JA. Cholesterol determination in high-density lipoproteins separated by three different methods. Clin Chem. 1977 May;23(5):882-4.

27. World Health Organization. Definition, diagnosis and classification of diabetes mellitus and its complications. Report of a WHO Consultation. Part 1: diagnosis and classification of diabetes mellitus. Geneva; 1999.

28. Balkau B, Charles MA. Comment on the provisional report from the WHO consultation. European Group for the Study of Insulin Resistance (EGIR). Diabet Med. 1999 May;16(5):442-3.

29. Third Report of the National Cholesterol Education Program (NCEP) Expert Panel on Detection, Evaluation, and Treatment of High Blood Cholesterol in Adults (Adult Treatment Panel III) final report. Circulation. 2002 Dec 17;106(25):3143-421.

30. Merry AH, Boer JM, Schouten LJ, Feskens EJ, Verschuren WM, Gorgels AP, et al. Validity of coronary heart diseases and heart failure based on hospital discharge and mortality data in the Netherlands using the cardiovascular registry Maastricht cohort study. Eur J Epidemiol. 2009;24(5):237-47.

31. Schoenfeld D. Partial residuals for the proportional hazards regression model. Biometrika. 1982;69:239-41.

32. Fuster V, Badimon L, Badimon JJ, Chesebro JH. The pathogenesis of coronary artery disease and the acute coronary syndromes (2). N Engl J Med. 1992 Jan 30;326(5):310-8.

33. Fuster V, Badimon L, Badimon JJ, Chesebro JH. The pathogenesis of coronary artery disease and the acute coronary syndromes (1). N Engl J Med. 1992 Jan 23;326(4):242-50.

34. Andersen P. Hypercoagulability and reduced fibrinolysis in hyperlipidemia: relationship to the metabolic cardiovascular syndrome. J Cardiovasc Pharmacol. 1992;20 Suppl 8:S29-31.

35. Lip GY. Hypertension and the prothrombotic state. J Hum Hypertens. 2000 Oct-Nov;14(10-11):687-90.

36. McGill JB, Schneider DJ, Arfken CL, Lucore CL, Sobel BE. Factors responsible for impaired fibrinolysis in obese subjects and NIDDM patients. Diabetes. 1994 Jan;43(1):104-9.

37. Craig SR, Amin RV, Russell DW, Paradise NF. Blood cholesterol screening influence of fasting state on cholesterol results and management decisions. J Gen Intern Med. 2000 Jun;15(6):395-9.

38. Coats AJ. Ethical authorship and publishing. Int J Cardiol. 2009 Jan 9;131(2):149-50. 


\title{
4
}

Do smoking, alcohol consumption, physical activity, and family history have different effects on the risks of acute myocardial infarction and unstable angina pectoris? A prospective cohort study

\author{
Audrey H.H. Merry \\ Jolanda M.A. Boer \\ Leo J. Schouten \\ Edith J.M. Feskens \\ W.M. Monique Verschuren \\ Anton P.M. Gorgels \\ Piet A. van den Brandt
}




\section{Abstract}

Background: Few studies investigated the association between smoking, alcohol consumption, or physical activity and the risk of unstable angina pectoris (UAP), while the strength of these associations may differ compared to other coronary diseases such as acute myocardial infarction (AMI). Therefore, we investigated whether the associations of these lifestyle factors with UAP differed from those with AMI. Additionally, we investigated whether these effects differed between subjects with and without a family history of myocardial infarction (MI).

Methods: The CAREMA study consists of 21,148 persons, aged 20-59 years at baseline and randomly sampled from the Maastricht region in 1987-1997. At baseline, all participants completed a self-administered questionnaire. After follow-up of maximally 16.9 years, $420 \mathrm{AMI}$ and 274 UAP incident cases were registered. Incidence rate ratios (RRs) were estimated using Cox proportional hazards models.

Results: For both diseases, smoking increased the risk while alcohol consumption was associated with a protective effect. Associations with both risk factors were stronger for AMI than UAP, although this difference was only statistically significant for smoking. In men, an inverse association was found with physical activity during leisure time which seemed to be stronger for the risk of UAP than of AMI. On the contrary, physical activity during leisure time was associated with an increased risk of both AMI and UAP in women which seemed to be weaker for UAP than for AMI. Except for occupational physical activity in women, no significant interactions on a multiplicative scale were found between the lifestyle factors and family history of MI. Nevertheless, the highest risks were found in subjects with both a positive family history and the most unfavourable level of the lifestyle factors.

Conclusions: Changes in the prevalences of these lifestyle factors may benefit the primary prevention of both AMI and UAP. 


\section{Background}

Lifestyle factors such as smoking, physical inactivity, and alcohol consumption play an important role in the aetiology of coronary heart disease (CHD) (1). Although these factors are well-known risk factors for CHD, only few studies investigated the associations between the risk of (unstable) angina pectoris and smoking status (2, 3), alcohol consumption (4-8), or physical inactivity (9-11). In contrast, the influence of these lifestyle factors on the risk of total CHD or acute myocardial infarction (AMI) is thoroughly investigated (12-27). Although patients with unstable angina pectoris (UAP) have better survival rates than patients with AMI, their cardiac rehospitalisation rates and quality of life scores are similar or even worse (28). In addition, cases with UAP are more often female and are older compared with AMI cases (29-31). The clinical presentation with AMI or UAP depends on the degree of occlusion of the coronary artery. Thrombotic and fibrinolytic processes may play a role in this difference in pathophysiology. Studies have shown that lifestyle factors are associated with haemostatic disturbances affecting these processes (32-34), which suggests that the strength of the associations with etiological factors may be different for AMI and UAP.

In several studies, family history of premature CHD or myocardial infarction (MI) was found to be an independent risk factor for coronary diseases (35-40). Because subjects with a positive family history may be more susceptible to other risk factors, the associations between lifestyle factors and the risk of coronary diseases may be different in subjects with and without a positive family history. However, only few studies investigated a possible synergistic effect between family history and other risk factors for CHD $(39,41-44)$.

To elucidate further the associations between lifestyle factors and the risk of UAP and to see whether these associations indeed differ in strength between AMI and UAP, the objective of this study was to investigate the effects of smoking, alcohol consumption, and physical inactivity on the risks of AMI and UAP as separate endpoints. A second objective was to study the association between family history of $\mathrm{Ml}$ and the risks of these coronary endpoints. In addition, we investigated whether the associations between the lifestyle factors and the risks of AMI and UAP differed for people with and without a family history of premature MI.

\section{Methods}

\section{CAREMA study}

The study participants, living in the Maastricht region, were derived from two large monitoring projects in the Netherlands: the Monitoring Project on Cardiovascular Risk Factors (PPHVZ) (45) and the Monitoring Project on Chronic Disease Risk Factors (MORGEN) (46). Between 1987 and 1997, a new random sample of people aged 20-59 years was selected each year from the population registries of Maastricht and sur- 
rounding municipalities, i.e. Eijsden, Margraten, Meerssen, and Valkenburg aan de Geul. These samples were stratified according to sex and 5-year age groups to obtain equal numbers in each age category. From 1987 until 1997, 21,662 men and women were included in this study (response rate 43\%). The monitoring studies were approved by the Medical Ethics Committee of Leiden University and the Dutch Organization for Applied Research (TNO).

\section{Baseline data}

At baseline, all participants $(n=21,662)$ filled in a self-administered questionnaire on demographics, medical history, family history of $\mathrm{MI}$, and lifestyle factors such as smoking, alcohol consumption, and physical activity. Furthermore, their blood pressure, height, and weight were measured during a medical examination by trained staff members who were instructed by the same physician. Non-fasting blood samples were taken for the determination of total and HDL cholesterol levels.

For smoking, data was collected about the subject's smoking status (never, ex, or current), frequency (number of cigarettes/day) and duration (number of years of smoking). For ex-smokers, time since quitting was calculated using information about the starting age and duration of smoking.

For alcohol consumption, subjects were asked to report their drinking frequency: never, ex, occasional ( $<1$ glass/week), or regular ( $\geq 1$ glass/week). In addition, regular drinkers were asked about the number of glasses of beer, wine including fortified wines, and liquor they consumed per week. Furthermore, subjects reported their amount of physical activity during work, if applicable, and during leisure time.

For family history of $\mathrm{MI}$, participants reported whether their father or mother ever had an $\mathrm{Ml}$ including the age at diagnosis. A premature $\mathrm{Ml}$ was defined as a diagnosis $\leq 60$ years for the father and $\leq 65$ years for the mother (47). Based on these data, three variables were created for family history of MI: number of parents affected, parental history of premature $\mathrm{MI}$, and a combined variable based on the previous two variables.

\section{Follow-up}

A migration and mortality follow-up was performed by record linkage of the cohort to the Municipal Population Registries. Of the 21,662 persons that were included in this study, 21,148 subjects (97.6\%) had given written informed consent to retrieve information from Municipal Population Registries and their general practitioner or specialist. During follow-up until 31 December 2003, 2,106 participants (10.0\%) had migrated out of the Maastricht region, 621 participants (2.9\%) had emigrated abroad, 791 participants (3.7\%) had died, and 12 participants $(0.1 \%)$ were lost to follow-up.

Incident cases of AMI and UAP were identified in two ways, 1) by linkage to the Cardiologic Information System (CIS) of the University Hospital Maastricht (UHM), and 2) by linkage to the causes of death registry of Statistics Netherlands. Using the CIS, incident cases with AMI or UAP were based on the first recorded clinical diagnosis during follow-up. This clinical diagnosis was mostly mentioned in the report to the general prac- 
titioner and was validated using the additional information in CIS including ECG findings, enzyme levels, and catheterization results. From the causes of death registry of Statistics Netherlands, all incident cases were identified using the following International Classification of Diseases (ICD) codes: ICD-9 410 and ICD-10 I21-I22 for AMI; ICD-9 413 and ICD-10 I20 for UAP. Statistics Netherlands receives the death certificate including a certificate with the cause of death for all Dutch inhabitants who deceased. This certificate is filled in by the physician who declares a person's death. The encoding of these cause of death certificates by Statistics Netherlands occurs according to the guidelines of the World Health Organization using the International Classification of Diseases. In case of indistinct or incomplete data, the concerning physician is contacted for more clarity. To guarantee the quality of these data, quality controls and corrections are made by Statistics Netherlands for all of the primary causes of death and, to a lesser extent, for the secondary causes of death. Linkage to the CIS was approved by the Medical Ethics Committee of the UHM.

End of follow-up was determined by a clinical diagnosis of AMI, UAP, a coronary bypass artery grafting, or a percutaneous coronary intervention, migration out of the Maastricht region, emigration, death, or censoring at 31 December 2003, whichever occurred first. Person-time at risk was calculated from baseline until end of follow-up. More details about the study and follow-up are described in a previous publication (48).

\section{Statistical analyses}

Incidence rate ratios (RR) and 95\% confidence intervals $(\mathrm{Cl})$ were estimated in Cox proportional hazards models using the Stata statistical software package 9.2 (Stata Corporation, College Station, TX, USA), after testing of the proportional hazards assumption using the scaled Schoenfeld residuals and by checking the log-log survival curves. For both AMI and UAP, this assumption was not violated by the main variables, except for time since quitting and the UAP risk. However, stratified analyses according to follow-up period were not possible because of the small number of UAP cases in the categories for time since quitting. Two-sided $p$ values are reported throughout this paper. To obtain $p$ values for dose-response trends, ordinal variables were fitted as continuous terms in the models.

All risk estimates were adjusted for age at baseline (years), sex, baseline cohort (PPHVZ or MORGEN), smoking status, frequency, and duration (except for the models on smoking), and total alcohol consumption in glasses/day (except for the models on alcohol). Furthermore, the models for smoking, alcohol consumption, and physical activity were additionally adjusted for educational level (primary school/junior vocational education, secondary vocational education, or vocational college/university) and family history of premature MI (yes, no). Other potential confounders such as diastolic blood pressure $(\mathrm{mmHg})$ and the consumption (g/day) of fruits, vegetables, fish, fibre, saturated, and unsaturated fatty acids were not included in the models, because they did not change the risk estimates with more than $10 \%$ after adjustment. Furthermore, 
separate models were performed with and without adjustments for predefined intermediate variables, i.e. total and $\mathrm{HDL}$ cholesterol $(\mathrm{mmol} / \mathrm{L})$, systolic blood pressure $(\mathrm{mmHg})$, diabetes mellitus (yes, no), and body mass index $\left(\mathrm{kg} / \mathrm{m}^{2}\right)$ depending on the determinant under investigation.

Tests for heterogeneity were performed to evaluate differences between the two coronary diseases (AMI versus UAP) using the competing risks procedure in Stata. However, the standard error for the difference of the log-RRs from this procedure assumes independence of both estimated RRs which would overestimate the standard error and thus overestimate the $p$ values for their difference. Therefore, these $p$ values and the associated confidence intervals were estimated based on a bootstrapping method. The log-RRs were obtained from the bootstrap samples using Stata's competing risks procedure and recalculated for each bootstrap-replication. The confidence interval and $p$ value of the differences in RR between AMI and UAP were then calculated from the replicated statistics using the accelerated bias corrected method in Stata. Each bootstrap analysis was based on 1,000 replications.

Participants with CHD at baseline $(n=347)$ and those who were lost to follow-up $(n=12)$ or migrated out of the Maastricht region before baseline $(n=26)$ were excluded from the analyses. In addition, participants with missing or inconsistent data on the main variables $(n=1,286)$ or confounders $(n=381)$ were excluded, leaving 19,096 participants for statistical analyses.

\section{Results}

During a mean follow-up of 11.1 years, 420 participants developed incident AMI and 274 participants developed incident UAP. Compared with the total cohort, both types of cases had less favourable distributions of the lifestyle factors and other risk factors for coronary disease (table 1). Besides slightly higher percentages of never drinkers among the cases, no differences were found in the median amount of alcoholic beverages consumed.

Compared with AMI cases, UAP cases were more often female (table 1) and slightly older at the time of diagnosis (table 2). Furthermore, table 2 shows that UAP cases more often suffered from two or three vessel disease although this observation might be biased by the higher percentage of AMI cases with unknown catheterization results. Increased risks of both UAP and AMI were found in current and ex-smokers (table 3). A clear dose-response trend with smoking frequency was observed ( $p$ trend $<0.001$ for AMI; 0.01 for UAP). The risks also increased with an increasing number of years smoked, although the dose-response trends were less obvious and only statistically significant for AMI. For all associations, RRs were higher for AMI than for UAP. All risks associated with smoking, except for the smoking duration, attenuated after adjustment for possible intermediate variables, but almost all remained highly significant. 
Table 1 Baseline characteristics of the CAREMA cohort in the Netherlands, 1987-1997

\begin{tabular}{|c|c|c|c|}
\hline & $\begin{array}{l}\text { Total cohort } \\
(n=19,096)\end{array}$ & $\begin{array}{l}\text { AMl cases } \\
(n=420)\end{array}$ & $\begin{array}{l}\text { UAP cases } \\
(n=274)\end{array}$ \\
\hline \multicolumn{4}{|l|}{ Demographics } \\
\hline Age at baseline (years) & $\begin{array}{l}\text { mean (SD) } \\
40.9(10.9)\end{array}$ & $\begin{array}{l}\text { mean (SD) } \\
48.8(7.6)\end{array}$ & $\begin{array}{l}\text { mean (SD) } \\
50.1(7.0)\end{array}$ \\
\hline $\begin{array}{l}\text { Sex } \\
\text { Men } \\
\text { Women }\end{array}$ & $\begin{array}{c}\mathbf{n}(\%) \\
8,956(46.9) \\
10,140(53.1)\end{array}$ & $\begin{array}{c}\mathbf{n}(\%) \\
328(78.1) \\
92(21.9)\end{array}$ & $\begin{array}{c}\mathbf{n}(\%) \\
190(69.3) \\
84(30.7)\end{array}$ \\
\hline $\begin{array}{l}\text { Baseline cohort } \\
\text { PPHVZ (1987-1992) } \\
\text { MORGEN (1993-1997) }\end{array}$ & $\begin{array}{l}13,674(71.6) \\
5,422(28.4)\end{array}$ & $\begin{array}{c}366(87.1) \\
54(12.9)\end{array}$ & $\begin{array}{c}237(86.5) \\
37(13.5)\end{array}$ \\
\hline \multicolumn{4}{|l|}{ Lifestyle factors } \\
\hline $\begin{array}{l}\text { Smoking } \\
\text { Never } \\
\text { Ex } \\
\text { Current }\end{array}$ & $\begin{array}{l}6,598(34.6) \\
4,960(26.0) \\
7,538(39.5)\end{array}$ & $\begin{array}{c}57(13.6) \\
93(22.1) \\
270(64.3)\end{array}$ & $\begin{array}{c}55(20.1) \\
86(31.4) \\
133(48.5)\end{array}$ \\
\hline $\begin{array}{l}\text { Number of cigarettes/day } \\
\text { among current smokers }\end{array}$ & $\begin{array}{c}\operatorname{mean}(\mathrm{SD}) \\
15.7(8.8)\end{array}$ & $\begin{array}{c}\text { mean }(\mathrm{SD}) \\
18.8(8.0)\end{array}$ & $\begin{array}{c}\text { mean (SD) } \\
17.4(7.9)\end{array}$ \\
\hline $\begin{array}{l}\text { Number of years of smoking } \\
\text { among current smokers }\end{array}$ & $22.7(10.5)$ & $30.4(8.8)$ & $30.7(9.1)$ \\
\hline $\begin{array}{l}\text { Alcohol consumption } \\
\text { Never } \\
\text { Ex-drinker } \\
\text { Occasionally (<1 glass/week) } \\
\text { Regular ( } \geq 1 \text { glasses/week) }\end{array}$ & $\begin{array}{c}\mathbf{n}(\%) \\
2,391(12.5) \\
257(1.3) \\
4,468(23.4) \\
11,980(62.7)\end{array}$ & $\begin{array}{c}\mathbf{n}(\%) \\
63(15.0) \\
13(3.1) \\
77(18.3) \\
267(63.6)\end{array}$ & $\begin{array}{c}\mathbf{n}(\%) \\
40(14.6) \\
7(2.6) \\
57(20.8) \\
170(62.0)\end{array}$ \\
\hline $\begin{array}{l}\text { Number of glasses/day among } \\
\text { regular drinkers }\end{array}$ & $\begin{array}{c}\text { median }\left(5^{\text {th }}-95^{\text {th }} \text { perc }\right) \\
1.4(0.3-5.0)\end{array}$ & $\begin{array}{c}\text { median }\left(5^{\text {th }}-95^{\text {th }} \text { perc }\right) \\
1.4(0.3-5.7)\end{array}$ & $\begin{array}{c}\text { median }\left(5^{\text {th }}-95^{\text {th }} \text { perc }\right) \\
1.4(0.3-6.1)\end{array}$ \\
\hline $\begin{array}{l}\text { Occupational activity } \\
\text { None to light } \\
\text { Moderate to heavy }\end{array}$ & $\begin{array}{c}\mathbf{n}(\%) \\
13,849(72.5) \\
3,327(17.4)\end{array}$ & $\begin{array}{c}\mathbf{n}(\%) \\
304(72.4) \\
86(20.5)\end{array}$ & $\begin{array}{c}\mathbf{n}(\%) \\
207(75.5) \\
48(17.5)\end{array}$ \\
\hline $\begin{array}{l}\text { Non-occupational activity } \\
\text { None to light } \\
\text { Moderate to heavy }\end{array}$ & $\begin{array}{c}8,264(43.3) \\
10,828(56.7)\end{array}$ & $\begin{array}{l}171(40.7) \\
249(59.3)\end{array}$ & $\begin{array}{l}115(42.0) \\
159(58.0)\end{array}$ \\
\hline $\begin{array}{l}\text { Family history of premature } \mathbf{M} \\
\text { No } \\
\text { Yes }\end{array}$ & $\begin{array}{c}15,980(83.7) \\
3,116(16.3)\end{array}$ & $\begin{array}{l}331(78.8) \\
89(21.2)\end{array}$ & $\begin{array}{c}216(78.8) \\
58(21.2)\end{array}$ \\
\hline \multicolumn{4}{|c|}{ Confounding/intermediate factors } \\
\hline $\begin{array}{l}\text { Level of education } \\
\text { Primary school/junior voca- } \\
\text { tional education }\end{array}$ & $11,251(58.9)$ & $316(75.2)$ & $208(75.9)$ \\
\hline $\begin{array}{l}\text { Secondary vocational educa- } \\
\text { tion }\end{array}$ & $4,398(23.0)$ & 64 (15.2) & $40(14.6)$ \\
\hline Vocational college/university & 3,447 (18.1) & $40(9.5)$ & $26(9.5)$ \\
\hline Diabetes mellitus & $164(0.9)$ & $20(4.8)$ & $7(2.6)$ \\
\hline $\begin{array}{l}\text { Systolic blood pressure } \\
(\mathrm{mmHg})\end{array}$ & $\begin{array}{l}\text { mean (SD) } \\
119.2(14.3)\end{array}$ & $\begin{array}{c}\text { mean (SD) } \\
128.1(16.6)\end{array}$ & $\begin{array}{l}\text { mean (SD) } \\
130.3(17.1)\end{array}$ \\
\hline $\begin{array}{l}\text { Total cholesterol }(\mathrm{mmol} / \mathrm{L}) \\
\text { HDL cholesterol }(\mathrm{mmol} / \mathrm{L}) \\
\text { Body Mass Index }\left(\mathrm{kg} / \mathrm{m}^{2}\right)\end{array}$ & $\begin{array}{l}5.4(1.1) \\
1.3(0.3) \\
24.7(3.9)\end{array}$ & $\begin{array}{l}6.3(1.2) \\
1.0(0.2) \\
26.7(4.0)\end{array}$ & $\begin{array}{c}6.3(1.1) \\
1.1(0.3) \\
26.4(3.9)\end{array}$ \\
\hline
\end{tabular}

AMI, acute myocardial infarction; MI, myocardial infarction; MORGEN, Monitoring Project on Chronic Disease Risk Factors; n, number; perc, percentile; PPHVZ, Monitoring Project on Cardiovascular Risk Factors; SD, standard deviation; UAP, unstable angina pectoris.

${ }^{*}$ Numbers may not add up to the total number of subjects because of missing values. 


\begin{tabular}{|c|c|c|}
\hline & $\begin{array}{l}\text { AMI cases } \\
(n=420)\end{array}$ & $\begin{array}{l}\text { UAP cases } \\
(n=274)\end{array}$ \\
\hline & mean (SD) & mean (SD) \\
\hline Age at diagnosis (years) & $56.5(7.7)$ & $58.4(7.4)$ \\
\hline Time at risk (years) & $7.2(4.2)$ & $7.9(3.9)$ \\
\hline Coronary angiography & $\mathrm{n}(\%)$ & $\mathrm{n}(\%)$ \\
\hline No abnormalities & $5(1.2)$ & $2(0.7)$ \\
\hline 1-Vessel disease & $107(25.5)$ & $84(30.7)$ \\
\hline 2-Vessel disease & $77(18.3)^{\prime}$ & $55(20.1)$ \\
\hline 3-Vessel disease & $61(14.5)$ & $62(22.6)$ \\
\hline Left main stem stenosis & $9(2.1)$ & $16(5.8)$ \\
\hline Unknown* & $161(38.3)$ & $55(20.1)$ \\
\hline \multicolumn{3}{|l|}{ Follow-up } \\
\hline Revascularisation within 60 days after & $174(41.4)$ & $137(50.0)$ \\
\hline & median $\left(5^{\text {th }}-95^{\text {th }}\right.$ perc $)$ & median $\left(5^{\text {th }}-95^{\text {th }}\right.$ perc $)$ \\
\hline Time to death (years) & $2.9(0.0-14.5)^{\ddagger}$ & $2.4(0.0-14.2)$ \\
\hline
\end{tabular}

AMI, acute myocardial infarction; n, number; SD, standard deviation; UAP, unstable angina pectoris.

* No coronary angiography performed or findings not reported.

† Exclusion of cases with a diagnosis of UAP (for the AMI cases) or AMI (for the UAP cases) within these 60 days and preceding the revascularization.

$\ddagger$ Restricted to cases with incident AMI who were not identified as case by the causes of death registry of Statistics Netherlands $(n=66)$.

The risk of AMI and UAP decreased the longer ago subjects quitted smoking (table 3). Ex-smokers who quitted more than five years ago had about the same risk as never smokers. For ex-smokers who stopped less than two years ago, the risk of AMI was lower than for current smokers, whereas the risk of UAP did not differ considerably for current smokers and ex-smokers who quitted less than five years ago.

Regular alcohol consumption decreased the risk of AMI and UAP, although this association with AMI was stronger than with UAP (table 4). While the risk of AMI decreased with the number of glasses consumed per day, the risk of UAP did not decrease further when more than four glasses were consumed per day. The protective effect of alcohol persisted after adjustment for intermediate variables. Furthermore, the effect was found for all types of alcoholic beverages consumed (table 4).

For both occupational and non-occupational physical activity in relation to CHD, sex was found to be a significant effect modifier. In men, occupational activity seemed to be a risk factor for both endpoints (table 5). In women, however, moderate to heavy activity was associated with a lower risk of AMI and UAP, although these estimates were based on small numbers of cases. Non-occupational activity seemed to be protective in men, which attenuated after adjustment for intermediate variables. In women, however, non-occupational activity was found to be a risk factor. This association became stronger after adjustment for intermediate variables, but was only statistically significant for AMI.

Compared with subjects with no parents affected, the highest risks of both coronary endpoints were found for subjects with both parents affected, especially when they 
were diagnosed at younger age (table 6). Both these trends were stronger for UAP than for AMI. Clear dose-response trends in risk were found for the combination of the number of parents affected with their age at diagnosis, except for the last category and the risk of AMI which may be due to the very low number of cases in this category (table 6).

On a multiplicative scale, none of the interactions between family history of premature $\mathrm{MI}$ and the lifestyle factors were statistically significant for both coronary diseases, except for occupational physical activity and the AMI risk in women. Compared with never smokers without a family history, the highest risks of AMI and UAP were found in current smokers with a positive family history (table 7). For AMI, the risk for current smokers without a family history was higher compared with ex-smokers with a family history, while the risk of UAP was higher for ex-smokers with a family history. For alcohol consumption, the largest protective effect was found for regular drinkers without a family history. In subjects with a positive family history, the protective effect of alcohol consumption is stronger for AMI than UAP.

For occupational physical activity, the highest risks of AMI and UAP were found in subjects with a positive family history and a moderate to heavy activity level, although these risks were only statistically significant in men (table 7). In women, the effect of occupational activity on the risk of AMI differed between subjects with and without a family history ( $p$ interaction 0.03 ), although this interaction was based on a very low number of cases in the moderate to heavy activity category. In men, no differences in the effect of non-occupational activity were seen between subjects with and subjects without a family history for both coronary diseases. In women, however, there seemed to be a synergistic effect between non-occupational activity and family history for the risk of AMI with the highest risk for women with a positive family history and a moderate to heavy physical activity level, although this interaction was not statistically significant. 


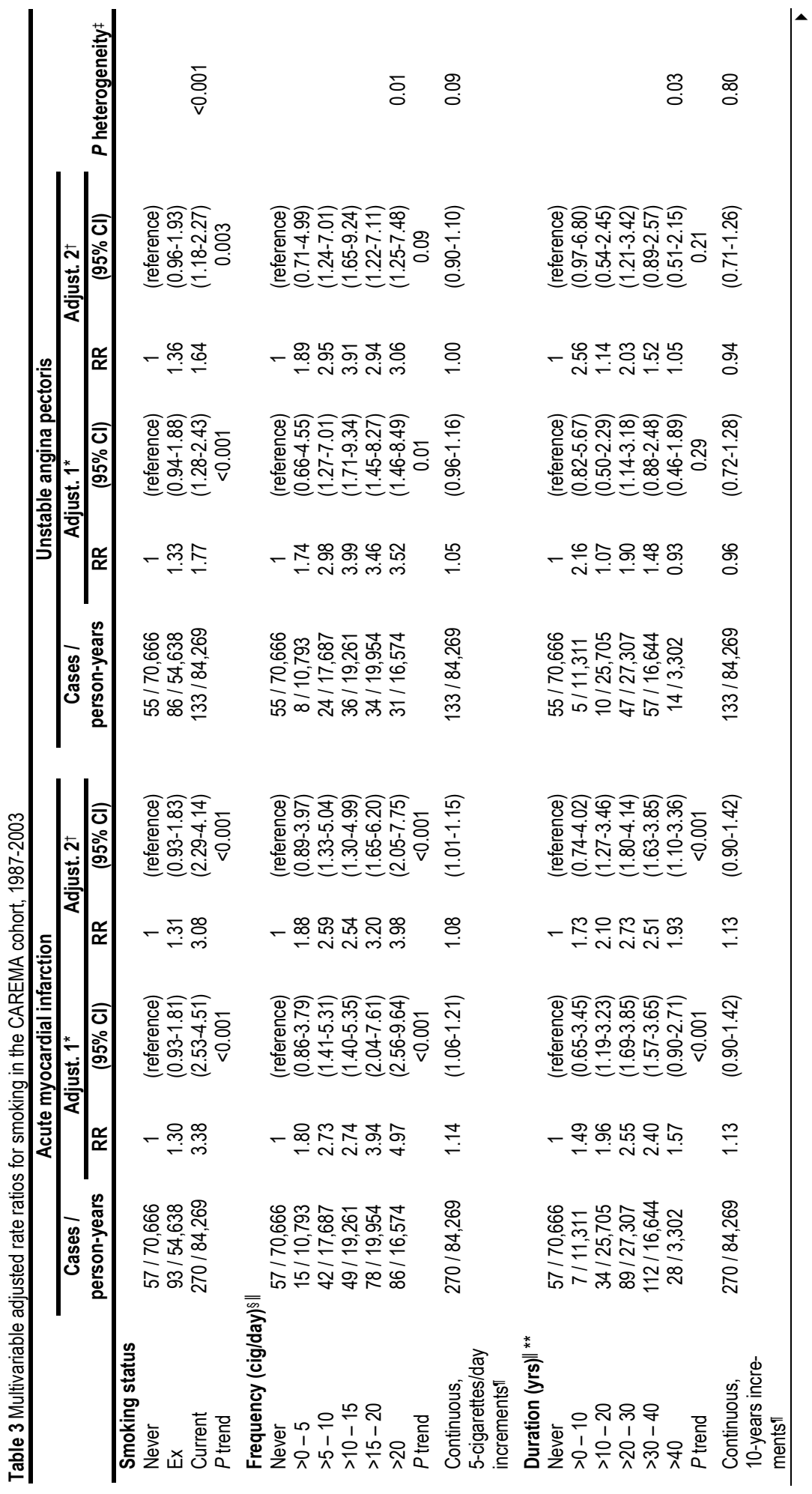




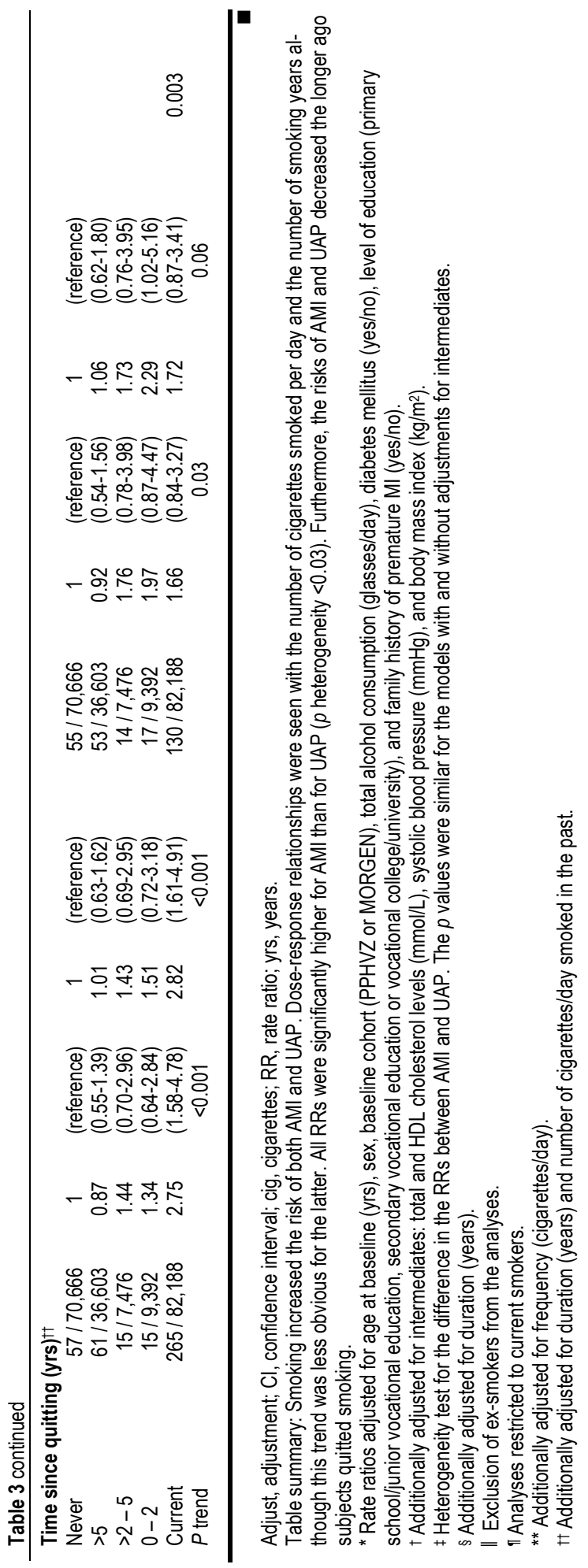




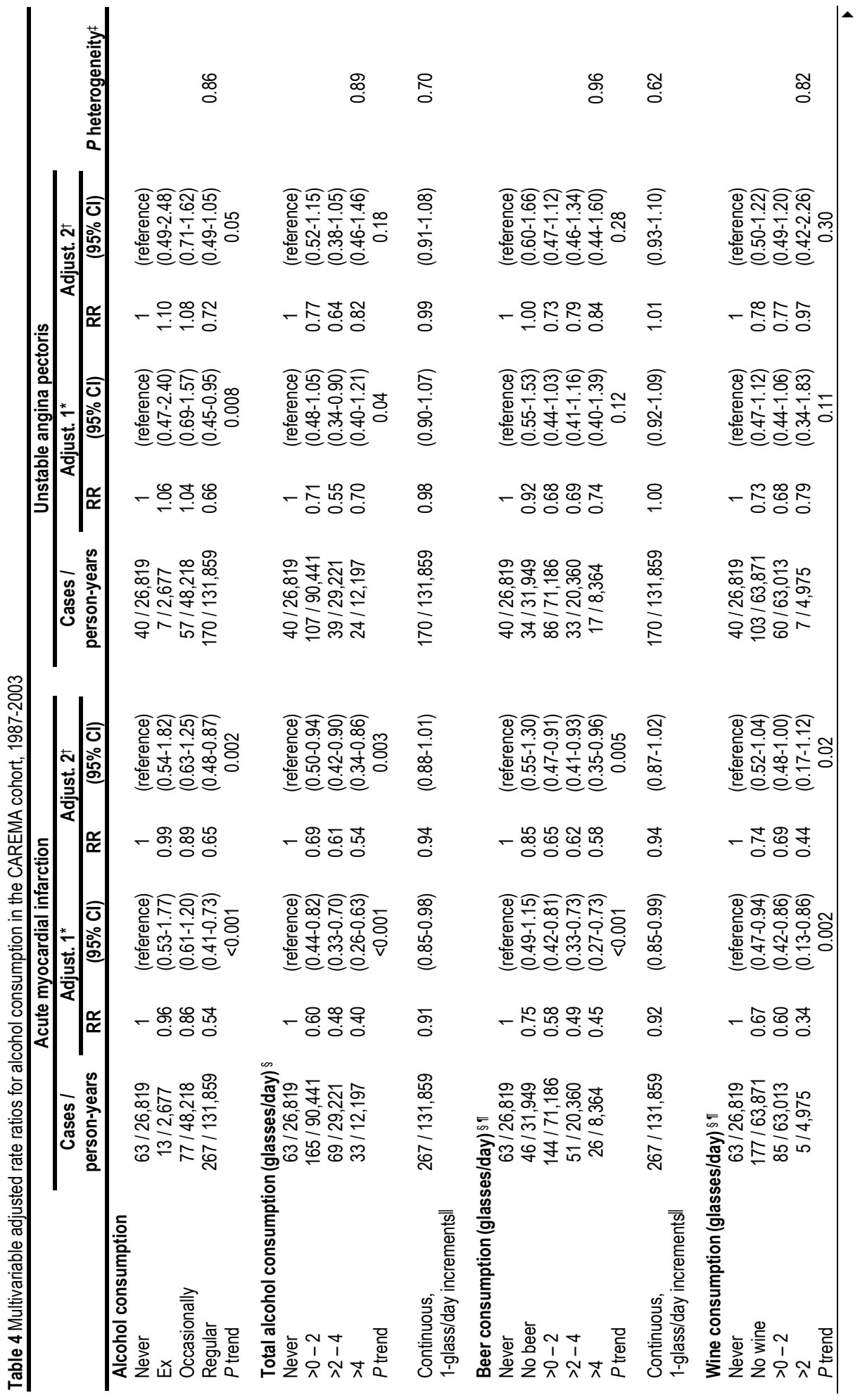




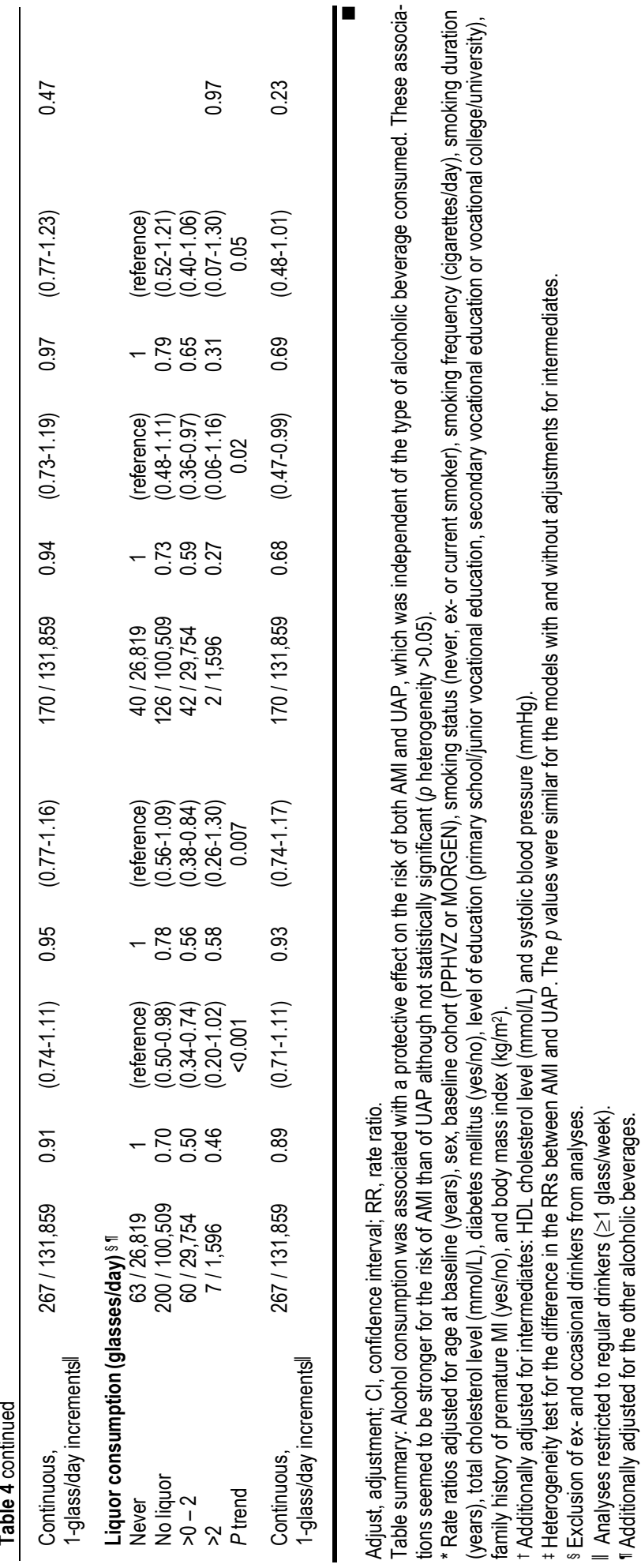




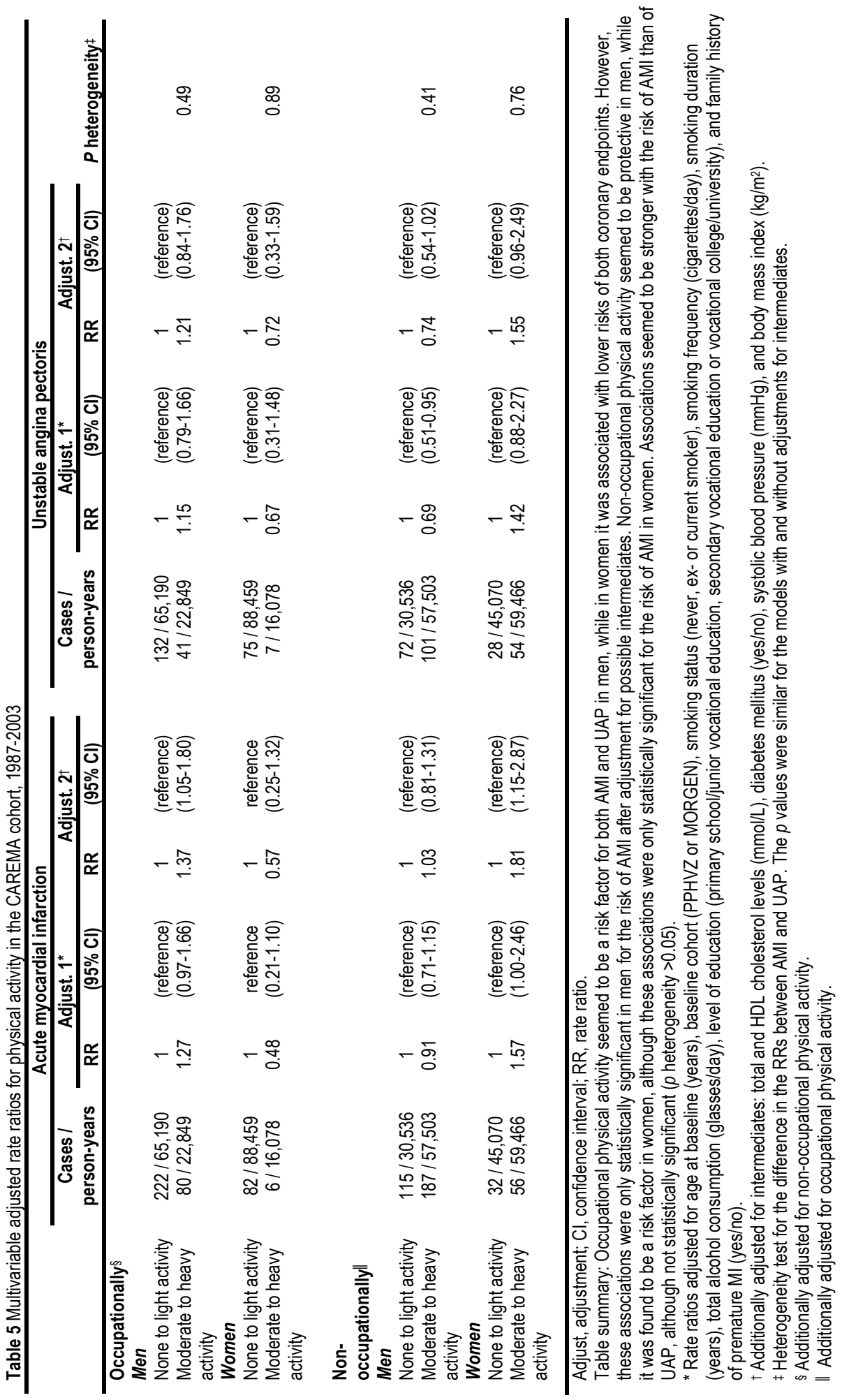


Table 6 Multivariable adjusted rate ratios for family history in the CAREMA cohort, 1987-2003

\begin{tabular}{|c|c|c|c|c|c|c|c|}
\hline & \multicolumn{3}{|c|}{ Acute myocardial infarction } & \multicolumn{3}{|c|}{ Unstable angina pectoris } & \multirow[b]{2}{*}{$\begin{array}{l}P \text { hetero- } \\
\text { geneity }\end{array}$} \\
\hline & $\begin{array}{c}\text { Cases I } \\
\text { person- } \\
\text { years }\end{array}$ & $\mathbf{R R}$ & $(95 \% \mathrm{Cl})$ & $\begin{array}{c}\text { Cases I } \\
\text { person- } \\
\text { years }\end{array}$ & RR & $(95 \% \mathrm{Cl})$ & \\
\hline \multicolumn{8}{|c|}{ Number of parents affected } \\
\hline No parents affected & $\begin{array}{l}253 / \\
147,248\end{array}$ & 1 & (reference) & $\begin{array}{l}148 / \\
147,248\end{array}$ & 1 & (reference) & \\
\hline One parent affected & $\begin{array}{l}144 / \\
56,391\end{array}$ & 1.34 & $(1.09-1.65)$ & $\begin{array}{l}106 / \\
56,391\end{array}$ & 1.70 & $(1.32-2.18)$ & \\
\hline Both parents affected & $\begin{array}{l}25 / \\
6,000\end{array}$ & 1.79 & $(1.18-2.71)$ & $\begin{array}{l}19 / \\
6,000\end{array}$ & 2.22 & $(1.37-3.59)$ & 0.33 \\
\hline$P$ trend & & & $<0.001$ & & & $<0.001$ & \\
\hline \multicolumn{8}{|c|}{ Age at diagnosis of parents } \\
\hline No parents affected & $\begin{array}{l}253 / \\
147,248\end{array}$ & 1 & (reference) & $\begin{array}{l}148 / \\
147,248\end{array}$ & 1 & (reference) & \\
\hline Non-premature MI & $\begin{array}{l}80 / \\
29,244\end{array}$ & 1.16 & $(0.90-1.50)$ & $\begin{array}{l}68 / \\
29,244\end{array}$ & 1.62 & $(1.21-2.16)$ & \\
\hline Premature $\mathrm{Ml}^{\dagger}$ & $\begin{array}{l}89 / \\
33,146\end{array}$ & 1.70 & $(1.33-2.17)$ & $\begin{array}{l}57 / \\
33,146\end{array}$ & 1.97 & $(1.44-2.69)$ & 0.16 \\
\hline$P$ trend & & & $<0.001$ & & & $<0.001$ & \\
\hline \multicolumn{8}{|c|}{ Number of parents affected including age at diagnosis } \\
\hline No parents affected & $\begin{array}{l}253 / \\
147,248\end{array}$ & 1 & (reference) & $\begin{array}{l}148 / \\
147,248\end{array}$ & 1 & (reference) & \\
\hline $\begin{array}{l}\text { One parent affected, } \\
\text { non-premature MI }\end{array}$ & $\begin{array}{l}74 / \\
27,105\end{array}$ & 1.18 & $(0.91-1.53)$ & $\begin{array}{l}61 / \\
27,105\end{array}$ & 1.60 & $(1.18-2.16)$ & \\
\hline $\begin{array}{l}\text { Both parents affected, } \\
\text { both non-premature MI }\end{array}$ & $\begin{array}{l}6 / \\
2,139\end{array}$ & 1.03 & $(0.46-2.33)$ & $\begin{array}{l}7 / \\
2,139\end{array}$ & 1.79 & $(0.83-3.83)$ & \\
\hline $\begin{array}{l}\text { One parent affected, } \\
\text { premature MI }\end{array}$ & $\begin{array}{l}70 / \\
29,285\end{array}$ & 1.58 & $(1.21-2.06)$ & $\begin{array}{l}45 / \\
29,285\end{array}$ & 1.85 & $(1.32-2.60)$ & \\
\hline $\begin{array}{l}\text { Both parents affected, } \\
\text { one premature Ml }\end{array}$ & $\begin{array}{l}17 / \\
2,279\end{array}$ & 3.04 & $(1.85-4.99)$ & $\begin{array}{l}8 / \\
2,279\end{array}$ & 2.42 & $(1.19-4.96)$ & \\
\hline $\begin{array}{l}\text { Both parents affected, } \\
\text { both premature MI }\end{array}$ & $\begin{array}{l}2 / \\
1,582\end{array}$ & 0.78 & $(0.19-3.13)$ & $\begin{array}{l}4 / \\
1,582\end{array}$ & 2.94 & $(1.08-7.99)$ & 0.51 \\
\hline$P$ trend & & & $<0.001$ & & & $<0.001$ & \\
\hline
\end{tabular}

$\mathrm{Cl}$, confidence interval; Ml, myocardial infarction; RR, rate ratio; yrs, years. Rate ratios adjusted for age at baseline (years), sex, baseline cohort (PPHVZ or MORGEN), smoking status (never, ex or current), smoking frequency (cigarettes/day), smoking duration (years), total alcohol consumption (glasses/day), total and HDL cholesterol levels (mmol/L), diabetes mellitus (yes/no), systolic blood pressure $(\mathrm{mmHg})$, and body mass index $(\mathrm{kg} / \mathrm{m} 2)$.

Table summary: A positive family history is associated with increased risks of both AMI and UAP, especially when both parents are affected or when they are diagnosed at a younger age (premature MI). These associations seemed to be stronger for the risk of UAP than of AMI but the differences were not statistically significant ( $p$ heterogeneity $>0.05$ ).

${ }^{*}$ Heterogeneity test for the difference in the RRs between AMI and UAP.

+ Defined as age at diagnosis of $\mathrm{MI} \leq 60$ years for the father and $\leq 65$ years for the mother. If both parents were affected, at least one parent had a premature MI. 


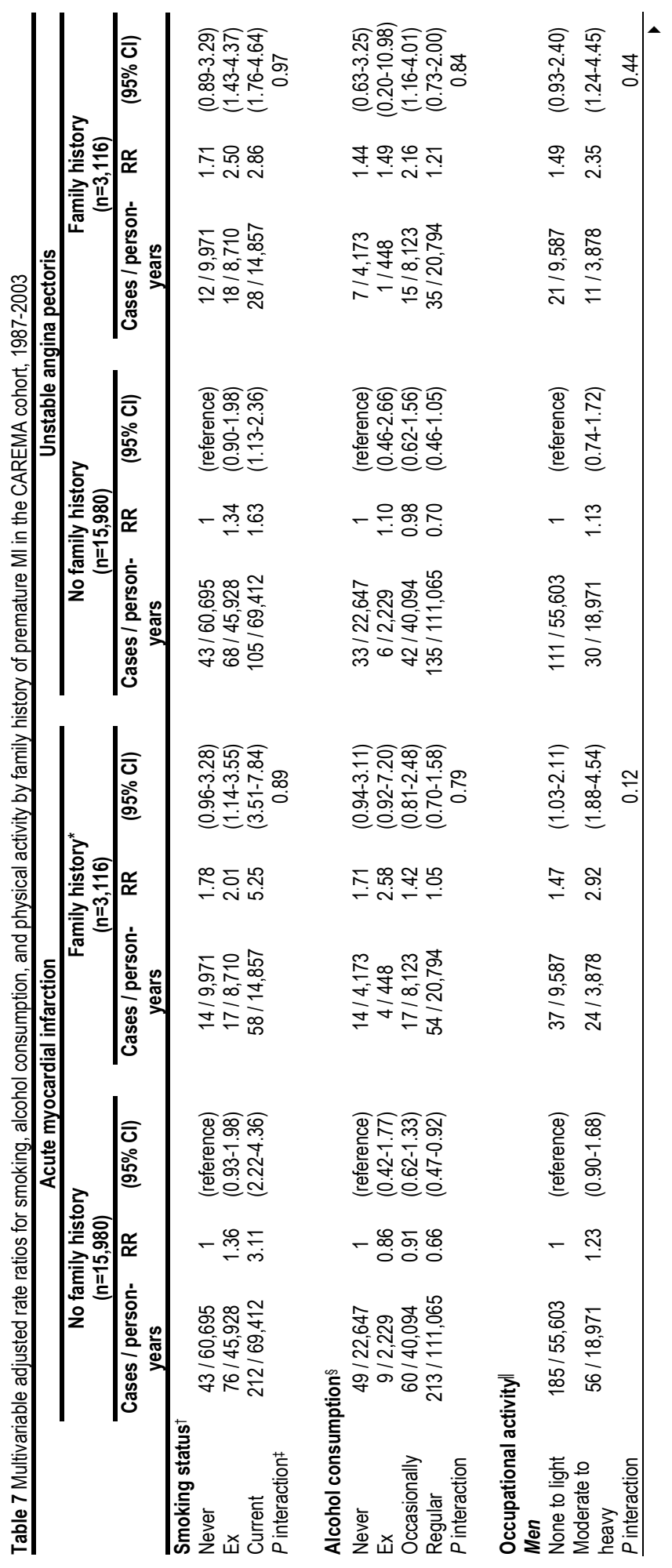




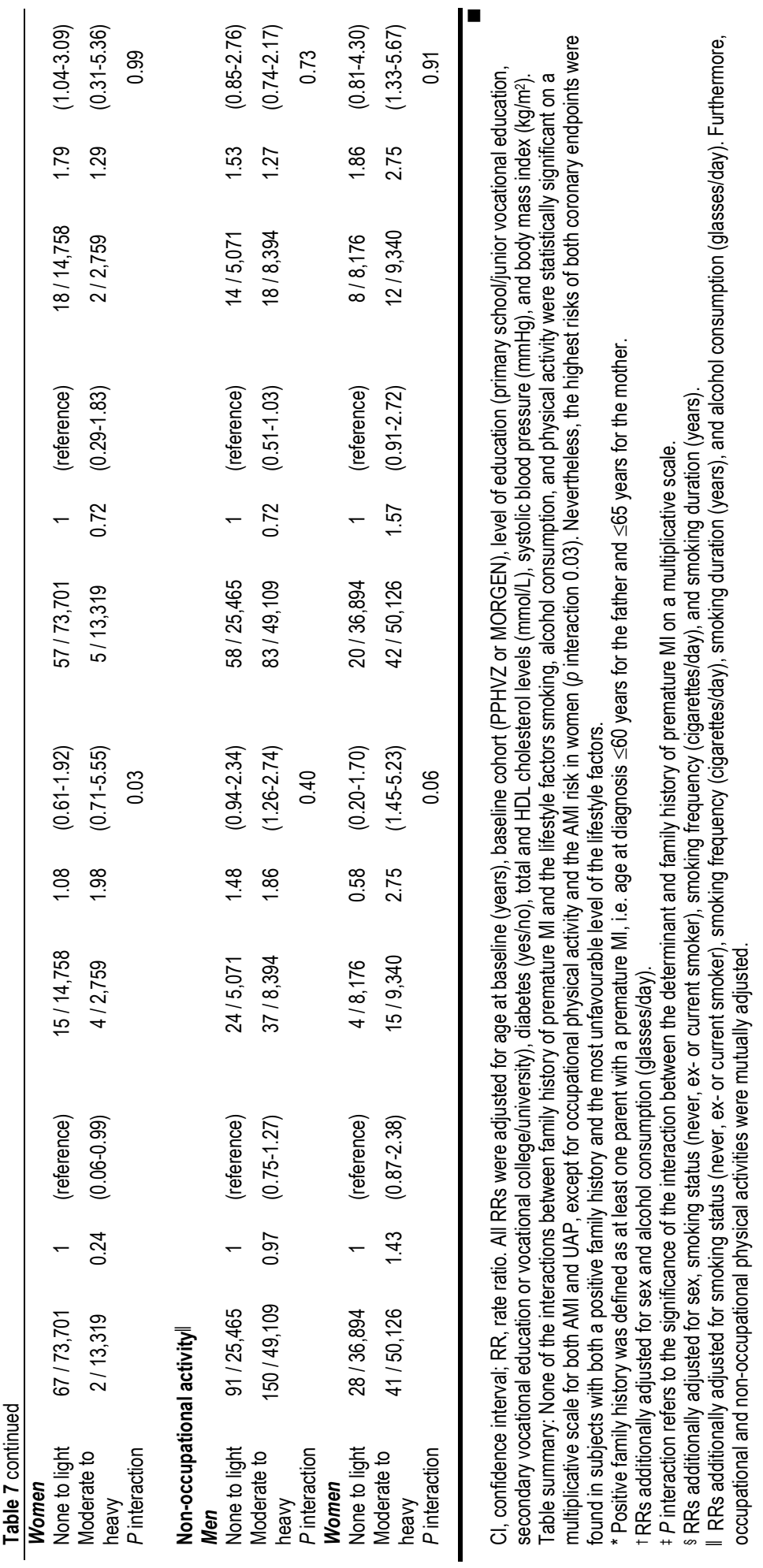




\section{Discussion}

In this prospective study, the effects of smoking, alcohol consumption, and physical activity pointed in the same direction for AMI and UAP. The effects, however, were nearly always stronger for AMI than UAP, although these differences in risks between the two coronary diseases were only statistically significant for the associations with smoking. For both coronary diseases, positive trends in risk were found with the number of cigarettes smoked. These trends were also observed for the number of years smoked, although less obvious. For alcohol consumption, a decreasing trend in risk was found for both coronary diseases. This trend was independent of the type of alcoholic beverage consumed. For occupational and non-occupational physical activity, opposite effects on the risks of AMI and UAP were found between men and women.

Clear positive trends in risk were found for both the number of parents affected with an $\mathrm{Ml}$ and for the age at diagnosis of the parents. The highest risk was found for subjects with both parents affected of whom at least one parent had a premature MI. As opposed to the lifestyle factors, the associations with family history seemed to be stronger for UAP than AMI, although the differences in risks were not statistically significant. Furthermore, similar effects of the lifestyle factors were found for subjects with and subjects without a family history of premature MI.

The results in this prospective study are probably not influenced by selection or information bias. During follow-up, only twelve participants $(0.1 \%)$ were lost. Therefore, exposure-related loss to follow-up is unlikely. The cardiologic follow-up is also expected to be nearly complete because of the central and unique position of the UHM in the study region. Furthermore, the cardiologic data were collected in an extensive manner which is probably less susceptible to misclassification (48).

During follow-up, more sensitive screening tests became available for the diagnosis of AMI which may have led to misclassification of the outcome. However, as mentioned above, the way in which the AMI and UAP cases were identified is probably more accurate than using data from other registries such as hospital discharge registries (48). Furthermore, this misclassification would have attenuated the differences in effects between AMI and UAP.

According to the redefinition of AMI by the European Society of Cardiology and the American College of Cardiology (49), ST elevation myocardial infarctions (STEMI) and non-ST elevation myocardial infarctions (non-STEMI) can be considered as separate pathophysiological entities. This may suggest that the associations with the lifestyle factors may differ between STEMI and non-STEMI. As no sufficient data on ECG abnormalities was available at the time of the statistical analyses to distinct between STEMI and non-STEMI, separate analyses for these subtypes of AMI could not be performed within this study.

In this cohort study, family history and the lifestyle factors were self-reported by the participants, which may have led to exposure misclassification. However, several studies have shown that self-reported data can be used quite accurately to define family 
history (50-52) and smoking status (53). In addition, Pols et al. have shown that the questions on physical activity in the MORGEN study were suitable for ranking the participants according to their physical activity level (54). Because the exposure measurements took place before the occurrence of the disease, the misclassification is probably non-differential (55). Therefore, the use of self-reported data has probably not biased our results to a great extent. However, two validation studies within subsamples of our study population found that the amount of alcohol consumption was underestimated by the food frequency questionnaire $(56,57)$. This misclassification may have resulted in an underestimation of the effect of alcohol consumption in our study.

The participants included in this study were relatively young at baseline (20-59 years). Consequently, both the AMI and UAP cases were diagnosed at a relatively young age. This may have affected the RRs. As the risks of these coronary diseases increase with an increasing age, the difference in absolute risks between the exposed and unexposed participants becomes relatively smaller at an older age, resulting in a lower RR. Therefore, the RRs in our study may be higher compared to other studies in which the study population and cases are relatively older.

Many studies investigated the associations between smoking, alcohol consumption, and physical activity and the risk of coronary diseases, part of which are summarized in several reviews/meta-analyses, e.g. $(9,12,13,16,18,21-27,58-67)$. However, these studies did not discern between the risk of AMI and UAP and will, therefore, not be discussed any further.

To our knowledge, two studies investigated the effect of smoking status on UAP risk (2, 3 ). In a case-control study by Sagastagoitia et al. (2), smoking was found to be independently associated with the presence of UAP (OR 3.42, 95\% CI 1.77-6.58). This OR is considerably higher than the RR of 1.6 found in the present prospective study which may be due to differences in study design. Kennon et al. (3) found that smokers were at higher risk to be discharged with a diagnosis of AMI than of UAP (OR $1.49,95 \% \mathrm{CI}$ 1.09-2.03) which suggest that the association with smoking is stronger for AMI than UAP as was found in the present study. No studies investigated the effects of smoking frequency or duration on the UAP risk.

Five studies found an inverse association between alcohol consumption and the risk of angina pectoris (4-8), although they did not specifically look at UAP. In the present study, the association seemed to be stronger for AMI than UAP which was also found in the study by Marques-Vidal et al. for angina pectoris (8), while the other studies found no great differences between the two coronary diseases. However, comparison between the studies should be done with caution because of differences in disease definition and in average alcohol consumption.

The results of studies that investigated the association between occupational or nonoccupational physical activity and the risk of angina pectoris are still inconclusive (911). In a meta-analysis by Berlin et al. (9), occupational activity was found to be a significant protective factor for angina but only when the group with the highest activity 
was compared with the moderately active group (RR $0.6,95 \% \mathrm{Cl} 0.4-0.9$ ). Contrary to our expectations, occupational activity seemed to increase the UAP risk in this study, but only in men. Although not completely clear, this finding may be due to residual confounding, the limited contrast in the activity level between the comparison groups or chance. For non-occupational activity, no association was found with the risk of angina by Berlin et al. (9), while Wagner et al. (11) found a significant positive association (RR 1.07, 95\% Cl 1.02-1.12). However, these studies differed in the categorizing of physical activity into comparison groups which complicates their comparison. In the present study, the inclusion of subjects with a light activity level in the reference group may be the reason for not finding a protective effect of higher activity levels on the coronary disease risk.

To our knowledge, only three studies investigated the association between family history and the risk of angina $(44,68,69)$ of which one study specifically looked at UAP (44). In line with the present study, two studies $(44,68)$ also found higher risks for angina than for AMI in subjects with a positive family history, while the other study (69) found no differences in risks. However, in all these studies, different definitions of family history were used which complicates their comparison.

In this study, only a statistically significant interaction on a multiplicative scale was found between occupational physical activity and family history of a premature $\mathrm{MI}$ for the risk of AMI in women. Five studies also investigated a possible synergistic effect between smoking and family history $(39,41-44)$. One study $(43)$ also found no synergistic effect, while in two other studies this interaction was only significant in women although these studies assessed the interaction on an additive scale $(39,41)$. In addition, these two studies also found no synergistic effect between physical inactivity and family history $(39,41)$ as was found in this study for non-occupational physical activity and occupational activity in men. Nevertheless, subjects with a positive family history and the most unfavourable level of lifestyle factors had the highest risks in all of these studies, including our study.

This study and other studies have shown that lifestyle factors such as smoking, physical inactivity, and alcohol consumption play an important role in the aetiology of coronary diseases (1). Therefore, changing the prevalences of these factors plays a role in the primary prevention of CHD. In current risk scores, however, smoking frequency and duration are mostly not included while some studies, including this study, found a clear dose-response relationship between the number of cigarettes smoked and the risk of cardiovascular disease $(1,13,14,58)$. In addition, alcohol consumption is mostly even neglected in these risk scores, whereas physical activity is only included in the risk score of the ARIC study (70). Although family history of premature CHD or MI was found to be an independent risk factor for coronary diseases in several studies (35-40), this factor is only included in part of the current risk scores (71-76). However, although these factors have been found to be strong independent risk factors for CHD, this does not mean that they have an added value to the risk prediction of CHD. Some studies which took these factors into consideration did not include them in the final algorithm 
because of limited availability (77) or limited predictive ability (72). Still, focusing on these factors in both low- and high-risk subjects may help to prevent CHD.

\section{Conclusions}

In this prospective cohort study, smoking, alcohol consumption, and physical activity affected the risk of both AMI and UAP. However, the strength of these associations seemed to differ between these two coronary diseases in which they were mostly stronger for AMI, although the differences in risks were only statistically significant for smoking. Opposed to this, the association with family history of MI seemed to be stronger for UAP. Nevertheless, more research is needed to elucidate these associations, especially for the risk of UAP. Although no synergistic effects on a multiplicative scale were found between the lifestyle factors and family history, the highest risks were found in subjects with both a positive family history and the most unfavourable level of the lifestyle factors. Therefore, future studies should evaluate whether changes in the prevalences of these lifestyle factors result in lower incidence rates of $\mathrm{AMI}$ and UAP and thus benefit the primary prevention of both coronary diseases, especially in subjects with a positive family history. 


\section{References}

1. Yusuf S, Hawken S, Ounpuu S, Dans T, Avezum A, Lanas F, et al. Effect of potentially modifiable risk factors associated with myocardial infarction in 52 countries (the INTERHEART study): case-control study. Lancet. 2004 Sep 11-17;364(9438):937-52.

2. Sagastagoitia JD, Saez Y, Vacas M, Narvaez I, de Lafuente JP, Molinero E, et al. Acute versus chronic myocardial ischemia: a differential biological profile study. Pathophysiol Haemost Thromb. 2008;36(2):91-7.

3. Kennon S, Suliman A, MacCallum PK, Ranjadayalan K, Wilkinson P, Timmis AD. Clinical characteristics determining the mode of presentation in patients with acute coronary syndromes. J Am Coll Cardiol. 1998 Dec;32(7):2018-22.

4. Camargo CA, Jr., Stampfer MJ, Glynn RJ, Grodstein F, Gaziano JM, Manson JE, et al. Moderate alcohol consumption and risk for angina pectoris or myocardial infarction in U.S. male physicians. Ann Intern Med. 1997 Mar 1;126(5):372-5.

5. Gordon T, Doyle JT. Drinking and coronary heart disease: the Albany Study. Am Heart J. 1985 Aug;110(2):331-4.

6. Kitamura A, Iso H, Sankai T, Naito Y, Sato S, Kiyama M, et al. Alcohol intake and premature coronary heart disease in urban Japanese men. Am J Epidemiol. 1998 Jan 1;147(1):59-65.

7. Kittner SJ, Garcia-Palmieri MR, Costas R, Jr., Cruz-Vidal M, Abbott RD, Havlik RJ. Alcohol and coronary heart disease in Puerto Rico. Am J Epidemiol. 1983 May;117(5):538-50.

8. Marques-Vidal P, Montaye M, Arveiler D, Evans A, Bingham A, Ruidavets JB, et al. Alcohol consumption and cardiovascular disease: differential effects in France and Northern Ireland. The PRIME study. Eur J Cardiovasc Prev Rehabil. 2004 Aug;11(4):336-43.

9. Berlin JA, Colditz GA. A meta-analysis of physical activity in the prevention of coronary heart disease. Am J Epidemiol. 1990 Oct;132(4):612-28.

10. Hagman $\mathrm{M}$, Wilhelmsen L, Wedel H, Pennert K. Risk factors for angina pectoris in a population study of Swedish men. J Chronic Dis. 1987;40(3):265-75.

11. Wagner A, Simon C, Evans A, Ferrieres J, Montaye M, Ducimetiere P, et al. Physical activity and coronary event incidence in Northern Ireland and France: the Prospective Epidemiological Study of Myocardial Infarction (PRIME). Circulation. 2002 May 14;105(19):2247-52.

12. Taylor B, Rehm J. When risk factors combine: the interaction between alcohol and smoking for aerodigestive cancer, coronary heart disease, and traffic and fire injury. Addict Behav. 2006 Sep;31(9):152235.

13. Woodward M, Lam TH, Barzi F, Patel A, Gu D, Rodgers A, et al. Smoking, quitting, and the risk of cardiovascular disease among women and men in the Asia-Pacific region. Int J Epidemiol. 2005 Oct;34(5):1036-45.

14. Al-Delaimy WK, Manson JE, Solomon CG, Kawachi I, Stampfer MJ, Willett WC, et al. Smoking and risk of coronary heart disease among women with type 2 diabetes mellitus. Arch Intern Med. 2002 Feb 11;162(3):273-9.

15. Willett WC, Green A, Stampfer MJ, Speizer FE, Colditz GA, Rosner B, et al. Relative and absolute excess risks of coronary heart disease among women who smoke cigarettes. N Engl J Med. 1987 Nov 19;317(21):1303-9.

16. Biyik I, Ergene O. Alcohol and acute myocardial infarction. J Int Med Res. 2007 Jan-Feb;35(1):46-51.

17. Emberson JR, Bennett DA. Effect of alcohol on risk of coronary heart disease and stroke: causality, bias, or a bit of both? Vasc Health Risk Manag. 2006;2(3):239-49.

18. Di Castelnuovo A, Rotondo S, lacoviello L, Donati MB, De Gaetano G. Meta-analysis of wine and beer consumption in relation to vascular risk. Circulation. 2002 Jun 18;105(24):2836-44.

19. Mukamal KJ, Conigrave KM, Mittleman MA, Camargo CA, Jr., Stampfer MJ, Willett WC, et al. Roles of drinking pattern and type of alcohol consumed in coronary heart disease in men. N Engl J Med. 2003 Jan 9;348(2):109-18.

20. Mukamal KJ, Jensen MK, Gronbaek M, Stampfer MJ, Manson JE, Pischon T, et al. Drinking frequency, mediating biomarkers, and risk of myocardial infarction in women and men. Circulation. 2005 Sep 6;112(10):1406-13.

21. Corrao G, Rubbiati L, Bagnardi V, Zambon A, Poikolainen K. Alcohol and coronary heart disease: a metaanalysis. Addiction. 2000 Oct;95(10):1505-23.

22. Cleophas TJ. Wine, beer and spirits and the risk of myocardial infarction: a systematic review. Biomed Pharmacother. 1999 Oct;53(9):417-23. 
23. Rimm EB, Klatsky A, Grobbee D, Stampfer MJ. Review of moderate alcohol consumption and reduced risk of coronary heart disease: is the effect due to beer, wine, or spirits. Bmj. 1996 Mar 23;312(7033):731-6.

24. Batty GD. Physical activity and coronary heart disease in older adults. A systematic review of epidemiological studies. Eur J Public Health. 2002 Sep;12(3):171-6.

25. Eaton CB. Relation of physical activity and cardiovascular fitness to coronary heart disease, Part I: A meta-analysis of the independent relation of physical activity and coronary heart disease. J Am Board Fam Pract. 1992 Jan-Feb;5(1):31-42.

26. Kohl HW, 3rd. Physical activity and cardiovascular disease: evidence for a dose response. Med Sci Sports Exerc. 2001 Jun;33(6 Suppl):S472-83; discussion S93-4.

27. Oguma $Y$, Shinoda-Tagawa T. Physical activity decreases cardiovascular disease risk in women: review and meta-analysis. Am J Prev Med. 2004 Jun;26(5):407-18.

28. Maddox TM, Reid KJ, Rumsfeld JS, Spertus JA. One-year health status outcomes of unstable angina versus myocardial infarction: a prospective, observational cohort study of ACS survivors. BMC Cardiovasc Disord. 2007;7:28.

29. Hoshida S, Hayashi T, Kanamasa K, Ishikawa K, Naka M, Kawarabayashi T, et al. Comparison of risk factors in acute myocardial infarction and unstable angina pectoris in patients $<$ or $=66$ versus $>66$ years of age. Am J Cardiol. 2004 Mar 1;93(5):608-10.

30. Goldberg R, Goff D, Cooper L, Luepker R, Zapka J, Bittner V, et al. Age and sex differences in presentation of symptoms among patients with acute coronary disease: the REACT Trial. Rapid Early Action for Coronary Treatment. Coron Artery Dis. 2000 Jul;11(5):399-407.

31. Steg PG, Goldberg RJ, Gore JM, Fox KA, Eagle KA, Flather MD, et al. Baseline characteristics, management practices, and in-hospital outcomes of patients hospitalized with acute coronary syndromes in the Global Registry of Acute Coronary Events (GRACE). Am J Cardiol. 2002 Aug 15;90(4):358-63.

32. Ambrose JA, Barua RS. The pathophysiology of cigarette smoking and cardiovascular disease: an update. J Am Coll Cardiol. 2004 May 19;43(10):1731-7.

33. Meade TW, Chakrabarti R, Haines AP, North WR, Stirling Y. Characteristics affecting fibrinolytic activity and plasma fibrinogen concentrations. Br Med J. 1979 Jan 20;1(6157):153-6.

34. Rimm EB, Williams P, Fosher K, Criqui M, Stampfer MJ. Moderate alcohol intake and lower risk of coronary heart disease: meta-analysis of effects on lipids and haemostatic factors. Bmj. 1999 Dec 11;319(7224):1523-8.

35. Andresdottir MB, Sigurdsson G, Sigvaldason H, Gudnason V. Fifteen percent of myocardial infarctions and coronary revascularizations explained by family history unrelated to conventional risk factors. The Reykjavik Cohort Study. Eur Heart J. 2002 Nov;23(21):1655-63.

36. Bertuzzi M, Negri E, Tavani A, La Vecchia C. Family history of ischemic heart disease and risk of acute myocardial infarction. Prev Med. 2003 Sep;37(3):183-7.

37. Friedlander $Y$, Kark JD, Stein Y. Family history of myocardial infarction as an independent risk factor for coronary heart disease. Br Heart J. 1985 Apr;53(4):382-7.

38. Jousilahti P, Puska P, Vartiainen E, Pekkanen J, Tuomilehto J. Parental history of premature coronary heart disease: an independent risk factor of myocardial infarction. J Clin Epidemiol. 1996 May;49(5):497-503.

39. Leander K, Hallqvist J, Reuterwall C, Ahlbom A, de Faire U. Family history of coronary heart disease, a strong risk factor for myocardial infarction interacting with other cardiovascular risk factors: results from the Stockholm Heart Epidemiology Program (SHEEP). Epidemiology. 2001 Mar;12(2):215-21.

40. Pohjola-Sintonen S, Rissanen A, Liskola P, Luomanmaki K. Family history as a risk factor of coronary heart disease in patients under 60 years of age. Eur Heart J. 1998 Feb;19(2):235-9.

41. Boer JM, Feskens EJ, Verschuren WM, Seidell JC, Kromhout D. The joint impact of family history of myocardial infarction and other risk factors on 12-year coronary heart disease mortality. Epidemiology. 1999 Nov;10(6):767-70.

42. Khaw KT, Barrett-Connor E. Family history of heart attack: a modifiable risk factor? Circulation. 1986 Aug;74(2):239-44.

43. Myers RH, Kiely DK, Cupples LA, Kannel WB. Parental history is an independent risk factor for coronary artery disease: the Framingham Study. Am Heart J. 1990 Oct;120(4):963-9.

44. Vitullo F, Marchioli R, Di Mascio R, Cavasinni L, Pasquale AD, Tognoni G. Family history and socioeconomic factors as predictors of myocardial infarction, unstable angina and stroke in an Italian population. PROGETTO 3A Investigators. Eur J Epidemiol. 1996 Apr;12(2):177-85.

45. Van Leer EM, Seidell JC, Kromhout D. Dietary calcium, potassium, magnesium and blood pressure in the Netherlands. Int J Epidemiol. 1995 Dec;24(6):1117-23. 
46. Lean ME, Han TS, Seidell JC. Impairment of health and quality of life in people with large waist circumference. Lancet. 1998 Mar 21;351(9106):853-6.

47. Boer JM, Feskens EJ, Kuivenhoven JA, Schouten EG, Havekes LM, Kastelein JJ, et al. Parental history of myocardial infarction: lipid traits, gene polymorphisms and lifestyle. Atherosclerosis. 2001 Mar;155(1):149-56.

48. Merry AH, Boer JM, Schouten LJ, Feskens EJ, Verschuren WM, Gorgels AP, et al. Validity of coronary heart diseases and heart failure based on hospital discharge and mortality data in the Netherlands using the cardiovascular registry Maastricht cohort study. Eur J Epidemiol. 2009;24(5):237-47.

49. Alpert JS, Thygesen K, Antman E, Bassand JP. Myocardial infarction redefined--a consensus document of The Joint European Society of Cardiology/American College of Cardiology Committee for the redefinition of myocardial infarction. J Am Coll Cardiol. 2000 Sep;36(3):959-69.

50. Bensen JT, Liese AD, Rushing JT, Province M, Folsom AR, Rich SS, et al. Accuracy of proband reported family history: the NHLBI Family Heart Study (FHS). Genet Epidemiol. 1999;17(2):141-50.

51. Kee F, Tiret L, Robo JY, Nicaud V, McCrum E, Evans A, et al. Reliability of reported family history of myocardial infarction. Bmj. 1993 Dec 11;307(6918):1528-30.

52. Silberberg J, Wlodarczyk J, Hensley M, Ray C, Alexander H, Basta M, et al. Accuracy of reported family history of heart disease: the impact of 'don't know' responses. Aust N Z J Med. 1994 Aug;24(4):386-9.

53. Patrick DL, Cheadle A, Thompson DC, Diehr P, Koepsell T, Kinne S. The validity of self-reported smoking: a review and meta-analysis. Am J Public Health. 1994 Jul;84(7):1086-93.

54. Pols MA, Peeters PH, Ocke MC, Slimani N, Bueno-de-Mesquita HB, Collette HJ. Estimation of reproducibility and relative validity of the questions included in the EPIC Physical Activity Questionnaire. Int J Epidemiol. 1997;26 Suppl 1:S181-9.

55. White E, Hunt JR, Casso D. Exposure measurement in cohort studies: the challenges of prospective data collection. Epidemiol Rev. 1998;20(1):43-56.

56. Bloemberg BPM, Kromhout D, Jansen AM, Goddijn HE. Reproducibility and validity of a short selfadministered semi-quantitative food frequency questionnaire. Thesis B Bloemberg. 1993:45-63.

57. Ocke MC, Bueno-de-Mesquita HB, Goddijn HE, Jansen A, Pols MA, van Staveren WA, et al. The Dutch EPIC food frequency questionnaire. I. Description of the questionnaire, and relative validity and reproducibility for food groups. Int J Epidemiol. 1997;26 Suppl 1:S37-48.

58. Mukamal KJ. The effects of smoking and drinking on cardiovascular disease and risk factors. Alcohol Res Health. 2006;29(3):199-202.

59. Corrao G, Bagnardi V, Zambon A, La Vecchia C. A meta-analysis of alcohol consumption and the risk of 15 diseases. Prev Med. 2004 May;38(5):613-9.

60. Kloner RA, Rezkalla SH. To drink or not to drink? That is the question. Circulation. 2007 Sep 11;116(11):1306-17.

61. Fuchs FD, Chambless LE. Is the cardioprotective effect of alcohol real? Alcohol. 2007 Sep;41(6):399-402.

62. De Gaetano G, Di Castelnuovo A, Rotondo S, lacoviello L, Donati MB. A meta-analysis of studies on wine and beer and cardiovascular disease. Pathophysiol Haemost Thromb. 2002 Sep-Dec;32(5-6):353-5.

63. Wannamethee SG, Shaper AG. Physical activity in the prevention of cardiovascular disease: an epidemiological perspective. Sports Med. 2001 Feb;31(2):101-14.

64. Williams PT. Physical fitness and activity as separate heart disease risk factors: a meta-analysis. Med Sci Sports Exerc. 2001 May;33(5):754-61.

65. Marmot MG. Alcohol and coronary heart disease. Int J Epidemiol. 2001 Aug;30(4):724-9.

66. Sofi F, Capalbo A, Cesari F, Abbate R, Gensini GF. Physical activity during leisure time and primary prevention of coronary heart disease: an updated meta-analysis of cohort studies. Eur J Cardiovasc Prev Rehabil. 2008 Jun;15(3):247-57.

67. Zheng H, Orsini N, Amin J, Wolk A, Nguyen VT, Ehrlich F. Quantifying the dose-response of walking in reducing coronary heart disease risk: meta-analysis. Eur J Epidemiol. 2009;24(4):181-92.

68. Colditz GA, Stampfer MJ, Willett WC, Rosner B, Speizer FE, Hennekens CH. A prospective study of parental history of myocardial infarction and coronary heart disease in women. Am J Epidemiol. 1986 Jan;123(1):48-58.

69. Yarnell J, Yu S, Patterson C, Cambien F, Arveiler D, Amouyel P, et al. Family history, longevity, and risk of coronary heart disease: the PRIME Study. Int J Epidemiol. 2003 Feb;32(1):71-7.

70. Chambless LE, Folsom AR, Sharrett AR, Sorlie P, Couper D, Szklo M, et al. Coronary heart disease risk prediction in the Atherosclerosis Risk in Communities (ARIC) study. J Clin Epidemiol. 2003 Sep;56(9):880-90. 
71. Assmann G, Cullen P, Schulte H. Simple scoring scheme for calculating the risk of acute coronary events based on the 10-year follow-up of the prospective cardiovascular Munster (PROCAM) study. Circulation. 2002 Jan 22;105(3):310-5.

72. Ridker PM, Buring JE, Rifai N, Cook NR. Development and validation of improved algorithms for the assessment of global cardiovascular risk in women: the Reynolds Risk Score. Jama. 2007 Feb 14;297(6):611-9.

73. Woodward M, Brindle P, Tunstall-Pedoe H. Adding social deprivation and family history to cardiovascular risk assessment: the ASSIGN score from the Scottish Heart Health Extended Cohort (SHHEC). Heart. 2007 Feb;93(2):172-6.

74. Hippisley-Cox J, Coupland C, Vinogradova Y, Robson J, May M, Brindle P. Derivation and validation of QRISK, a new cardiovascular disease risk score for the United Kingdom: prospective open cohort study. Bmj. 2007 Jul 21;335(7611):136.

75. Hippisley-Cox J, Coupland C, Vinogradova Y, Robson J, Minhas R, Sheikh A, et al. Predicting cardiovascular risk in England and Wales: prospective derivation and validation of QRISK2. Bmj. 2008 Jun 28;336(7659):1475-82.

76. Thomsen TF, Davidsen M, Ibsen H, Jorgensen T, Jensen G, Borch-Johnsen K. A new method for CHD prediction and prevention based on regional risk scores and randomized clinical trials; PRECARD and the Copenhagen Risk Score. J Cardiovasc Risk. 2001 Oct;8(5):291-7.

77. Wilson PW, D'Agostino RB, Levy D, Belanger AM, Silbershatz H, Kannel WB. Prediction of coronary heart disease using risk factor categories. Circulation. 1998 May 12;97(18):1837-47. 



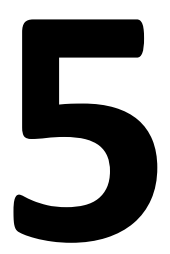

\title{
Risk prediction of incident coronary heart disease in the Netherlands:
} recalibration and improvement of the SCORE risk function

\author{
Audrey H.H. Merry \\ Jolanda M.A. Boer \\ Leo J. Schouten \\ Ton Ambergen \\ Ewout W. Steyerberg \\ Edith J.M. Feskens \\ W.M. Monique Verschuren \\ Anton P.M. Gorgels \\ Piet A. van den Brandt
}




\section{Abstract}

Aims: To recalibrate the SCORE risk function using individual data on risk factors and coronary heart disease (CHD) incidence from the Dutch Cardiovascular Registry Maastricht (CAREMA) population-based cohort study; to evaluate changes that may improve risk prediction after recalibration; and to compare the performance of the resulting CAREMA risk function with that of existing risk scores.

Methods and Results: The cohort consisted of 21,148 participants, born in 1927-1977 and randomly sampled from the Maastricht region in 1987-1997. After follow-up (median 10.9 years), 783 incident CHD cases occurred. Model performance was assessed by discrimination and calibration. The additional value of including other risk factors or current risk factors in a different manner was evaluated using the net reclassification index (NRI).

The $\mathrm{c}$ statistic of the recalibrated SCORE model was 0.799 (95\% Cl 0.782-0.816). Separating the total/HDL cholesterol ratio into total and $\mathrm{HDL}$ cholesterol levels did not improve the $c$ statistic $(p=0.22)$, but reclassified $6.0 \%$ of the participants into a more appropriate risk category $(p<0.001)$ compared with the recalibrated model. The resulting CAREMA function reclassified $28 \%$ of the participants into a more appropriate risk category than the Framingham score. Compared with the SCORE functions for highand low-risk regions, the NRIs were $28 \%$ and $35 \%$, respectively, which can largely be explained by the difference in disease outcome (CHD incidence versus cardiovascular mortality).

Conclusion: In this Dutch population, a recalibrated SCORE function with total and HDL cholesterol levels instead of the cholesterol ratio can be used for the risk prediction of CHD incidence. 


\section{Introduction}

Coronary heart disease (CHD) is a multifactorial disease caused by several risk factors which may also interact to increase risk. Therefore, the risk of CHD based on the combined effect of risk factors is more meaningful than the risk based on a single risk factor. Consequently, risk functions have been developed for cardiovascular disease (CVD) (1-5) or CHD (6-12) that estimate the risk in time taking into account the cumulative effect of risk factors. Such risk scores can be useful in the primary prevention of CVD/CHD by identifying persons at high risk of developing the disease.

In most European countries including the Netherlands, the SCORE function is often used in the primary prevention of $\operatorname{CVD}(13,14)$. Separate risk functions have been developed for high- and low-risk regions. These functions estimate the 10-year risk of fatal CVD using the following predictors: age, sex, current smoking, total/HDL cholesterol ratio, and systolic blood pressure (4). Some studies have found that applying these formulas to their own population overestimated absolute risks (15-18). Therefore, several countries including the Netherlands have recalibrated the SCORE function using national estimates of incidence rates and mean risk factor levels. However, the problem with such ecological data is that the risk factor and disease status are not measured at an individual level. Thus, it would be better to use observed individual data from prospective cohort studies for recalibration. Additionally, the SCORE functions estimate the risk of CVD mortality only, while for clinical practice the prediction of both fatal and non-fatal events is more relevant.

Furthermore, some established risk factors such as physical inactivity and body mass index are mostly not included in current risk scores. Many studies investigated whether the inclusion of additional risk factors resulted in an improvement of the risk prediction (19-27). They found that adding predictors resulted in only small improvements in the predictive ability of risk scores using the discriminative ability (determined as the area under the ROC curve) as the criterion. However, adding these factors may still improve risk prediction when evaluated by reclassification of subjects to a more appropriate risk category (28).

Therefore, the goals of this study were 1 ) to recalibrate the SCORE risk function using individual data on risk factors and both fatal and non-fatal CHD incidence from the Cardiovascular Registry Maastricht (CAREMA) cohort study in the Netherlands; and 2) to evaluate whether including additional risk factors or current risk factors in a different manner into this recalibrated function improves risk prediction. A third goal was to compare the risk prediction of CHD incidence by the recalibrated and extended risk function from the CAREMA cohort study with the risk predicted by functions of the SCORE project (4) for high-risk (SCORE-high) and low-risk regions (SCORE-low) and the Framingham risk score (10). 


\section{Methods}

\section{Study population}

The study participants, living in the Maastricht region, were derived from two large monitoring projects in the Netherlands: the Monitoring Project on Cardiovascular Disease Risk Factors (PPHVZ) 1987-1992 (29) and the Monitoring Project on Chronic Disease Risk Factors (MORGEN) 1993-1997 (30). Each year, a random sample of people aged 20-59 years was selected from municipal registries of Maastricht and surrounding communities, i.e. Eijsden, Margraten, Meerssen, and Valkenburg aan de Geul. Between 1987 and 1997, 21,662 participants, born between 1927 and 1977, were included in this study.

\section{Baseline data}

At baseline, all participants completed a self-administered questionnaire on demographic characteristics, medical history, parental history of myocardial infarction, and lifestyle factors such as smoking, alcohol consumption, usual dietary intake, and physical activity. In addition, all participants underwent a physical examination at the Municipal Health Service to measure their height, weight, and blood pressure $(29,30)$. All measurements were carried out by trained staff members who were instructed by the same physician. Non-fasting blood samples were taken for the determination of total and HDL cholesterol levels.

\section{Follow-up}

Of the 21,662 participants, $21,148(97.6 \%)$ had given written informed consent to retrieve information from the Municipal Population Registries and their general practitioner or specialist. A migration and mortality follow-up was performed by record linkage of the cohort to the Municipal Population Registries. During follow-up until 31 December 2003, 791 participants (3.7\%) died, 621 (2.9\%) emigrated, 2,106 (10.0\%) migrated to a municipality outside the Maastricht region, and $12(0.1 \%)$ were lost to follow-up.

Cardiologic follow-up was performed by record linkage to the Cardiology Information System (CIS) of the University Hospital Maastricht and to the causes of death registry of Statistics Netherlands. Incident CHD was defined as a clinical diagnosis of an acute myocardial infarction, unstable angina pectoris, a percutaneous transluminal coronary angioplasty or coronary artery bypass grafting according to the CIS or CHD as primary or secondary cause of death according to Statistics Netherlands (ICD-9 410-414 or ICD10 120-125).

Person-time at risk was calculated from baseline until end of follow-up, i.e. a clinical diagnosis of CHD, death, emigration, migration outside the Maastricht region, or censoring at 31 December 2003, whichever occurred first. Participants with CHD at baseline $(n=347)$, those who migrated to a municipality outside the Maastricht region be- 
fore baseline $(n=26)$ or who were lost to follow-up $(n=12)$ were excluded from the analyses.

\section{Statistical analyses \\ Recalibration}

Weibull proportional hazards models with age as time variable were used for the development of the prediction models, similar as in the SCORE project (4). Separate baseline survival functions were obtained for men and women while the coefficients for the predictors were obtained from the total cohort. Continuous predictors were centred and linearity was checked using restricted cubic spline analyses.

The proportional hazard assumption was tested by checking the log-log curves. To see whether the assumptions about the underlying survival functions made by the Weibull model influenced the risk prediction, the Weibull model was cross-checked with a Cox regression model. Based on previous risk functions, interaction terms were tested between total/HDL cholesterol ratio and sex (31), and between systolic blood pressure and use of blood pressure lowering medication (32).

For the recalibration the same predictors were included as in the SCORE risk function, i.e. age in years (time variable), sex (strata), current smoking (yes/no), systolic blood pressure $(\mathrm{mmHg})$, and total/HDL cholesterol ratio. Because of the low number of missing values and negligible impact on the regression coefficients, participants with missing data on at least one predictor $(n=619)$ were excluded from the analysis. In addition, participants with inconsistent data on smoking or alcohol consumption $(n=89)$ were excluded, leaving 20,055 participants including 783 incident CHD cases.

\section{Model performance}

Model performance was evaluated in the study population of 40 years and older at baseline. Discrimination was evaluated using the c statistic which is the probability of the model to distinguish between those who developed CHD during the follow-up period and those who did not, taking into account censored follow-up times. Calibration was used to assess the agreement between observed and predicted risks. The 10year predicted risk of incident CHD was calculated as described in the Appendix. In each decile of predicted risk, the observed 10-year risk was calculated from the 10 year Kaplan-Meier estimate and the ratio between predicted and observed risk was calculated. A calibration plot was made by plotting the observed risk against the predicted risk. The calibration slope and intercept were calculated using a linear regression model with the observed risk as the outcome variable and the predicted risk as the only independent variable. In case of perfect agreement, these estimates are one and zero, respectively. Because the interpretation of the intercept is difficult when the slope is unequal to one, the intercept was calculated with the slope fixed at one. Model performance was assessed in the same population as in which the model was developed. Formal internal validation of the model by bootstrapping was not consid- 
ered indicated, because of the very favourable ratio of events per variable (783/8) (33, 34).

\section{Evaluating improvements in risk prediction}

Several changes to the recalibrated SCORE function were investigated to assess their contribution to risk prediction (table 2). Besides discrimination and calibration, the prediction models were compared using the net reclassification index (NRI) taking into account persons with incomplete 10 -year follow-up $(28,35)$. This estimate refers to the percentage of subjects shifting to a more appropriate risk category (to a higher risk category for cases, to a lower risk category for non-cases) when using the new risk function compared with the original function. According to the predicted risks, subjects were divided in the following risk categories: $0-<2 \%, 2-<5 \%, 5-<10 \%$, and $\geq 10 \%$. The final model from these analyses is referred to as the CAREMA risk function.

The performance of the CAREMA risk function to predict CHD incidence was compared to the performance of SCORE-high and SCORE-low (4), as these risk functions are mostly used for primary prevention of CVD in Europe, including the Netherlands. However, because the SCORE functions predict CVD mortality instead of CHD incidence, the CAREMA risk function was also compared to the Framingham risk function which predicts the same endpoint (10). For these comparisons, the original formulas and regression coefficients of these risk functions were applied to the population of the CAREMA cohort study.

All analyses were performed using the Stata statistical software package 9.2 (Stata corporation, College Station, TX, USA). Two-sided $\mathrm{p}$ values are reported throughout this paper, with $\mathrm{p}<0.05$ considered statistically significant.

\section{Results}

During follow-up of maximally 16.9 years, 783 participants developed incident CHD (573 men, 210 women). Mean age at diagnosis was slightly lower for men than for women (57.0 and 58.7 years, respectively). Besides alcohol consumption, no large differences in risk factor levels were found between men and women at baseline (table 1).

Our recalibrated SCORE risk function had a c statistic of 0.799 (95\% Cl 0.782-0.816) (table 2). The calibration slope and intercept were 1.06 and $0.09 \%$, respectively. The model performance significantly decreased after including age as predictor instead of as time variable or using linear transformations for the continuous predictors (data not shown). Although the $c$ statistic increased to 0.806 when parental history of myocardial infarction was added to the model, none of the changes significantly increased the c statistic (table 2). Based on the NRI, however, replacement of the total/HDL cholesterol ratio by total and HDL cholesterol separately (table 2, model $3 \mathrm{~A}$ and $3 \mathrm{~B}$ ) improved model performance of the recalibrated SCORE function $(p<0.001)$. 


\begin{tabular}{|c|c|c|}
\hline & $\begin{array}{c}\text { Men } \\
(n=9,380)\end{array}$ & $\begin{array}{c}\text { Women } \\
(n=10,675)\end{array}$ \\
\hline Age at baseline (y) & $41.1(10.8)$ & $40.9(11.0)$ \\
\hline \multicolumn{3}{|l|}{ Baseline cohort } \\
\hline PPHVZ & $70.0 \%(6,568)$ & $68.8 \%(7,342)$ \\
\hline MORGEN & $30.0 \%(2,812)$ & $31.2 \%(3,333)$ \\
\hline Current smoking & $38.7 \%(3,630)$ & $40.8 \%(4,355)$ \\
\hline No. of cigarettes/day* & $16.5(9.2)$ & $15.0(8.5)$ \\
\hline Total cholesterol (mmol/L) & $5.4(1.1)$ & $5.4(1.1)$ \\
\hline HDL cholesterol (mmol/L) & $1.1(0.3)$ & $1.4(0.3)$ \\
\hline Total/HDL cholesterol ratio & $4.9(3.9-6.1)$ & $3.8(3.1-4.7)$ \\
\hline Systolic blood pressure $(\mathrm{mmHg})$ & $121(113-130)$ & $113(106-123)$ \\
\hline Diastolic blood pressure (mmHg) & $78.6(9.5)$ & $74.4(9.2)$ \\
\hline Pulse pressure $(\mathrm{mmHg})$ & $44.3(9.8)$ & $41.5(9.3)$ \\
\hline Parental history of Ml & $29.2 \%(2,742)$ & $30.7 \%(3,278)$ \\
\hline Father ever Ml & $23.1 \%(2,167)$ & $23.1 \%(2,470)$ \\
\hline Age at diagnosis father $(\mathrm{y})$ & $60.3(10.8)$ & $60.5(10.8)$ \\
\hline Mother ever Ml & $8.7 \%(820)$ & $10.9 \%(1,164)$ \\
\hline Age at diagnosis mother $(\mathrm{y})$ & $65.4(10.8)$ & $64.7(11.3)$ \\
\hline Body Mass Index (kg/m2) & $24.9(22.8-27.2)$ & $23.6(21.5-26.3)$ \\
\hline Diabetes $(\%)$ & $1.0 \%(93)$ & $0.8 \%(82)$ \\
\hline \multicolumn{3}{|l|}{ Physical activity during leisure time } \\
\hline None to light activity & $40.6 \%(3,809)$ & $46.5 \%(4,969)$ \\
\hline Moderate to heavy activity & $59.3 \%(5,567)$ & $53.4 \%(5,702)$ \\
\hline Regular alcohol intake ( $\geq 1$ glass/week) & $78.9 \%(7,403)$ & $47.7 \%(5,094)$ \\
\hline No. of glasses consumed per day ${ }^{\dagger}$ & $1.7(0.9-2.9)$ & $0.9(0.6-1.4)$ \\
\hline
\end{tabular}

Furthermore, this change resulted in slightly better calibration compared with the recalibrated SCORE function (model 1 ). Including an interaction term between HDL cholesterol and sex (model $3 \mathrm{~B}$ ) did not improve the predictive value significantly compared with model $3 \mathrm{~A}$. Therefore, the simplest model is preferred. Thus, the CAREMA risk function consists of the following predictors: age in years (time variable), sex (strata), current smoking (yes/no), systolic blood pressure (continuous), total cholesterol (continuous), and HDL cholesterol (continuous). This risk function had a good discriminative ability (c statistic $0.802,95 \% \mathrm{Cl} 0.785-0.819$ ) and calibration (slope 1.00, intercept $0.07 \%$ ). In figure 1 , the calibration plot and the ratio predicted/observed risk for the CAREMA risk function are shown.

Using the CAREMA risk function instead of SCORE-high or SCORE-low, the NRIs were $28 \%$ and $35 \%$, respectively $(p<0.001$ ) (table 3 ). Both SCORE-high and SCORE-low underestimated the 10-year absolute risks of incident CHD in the CAREMA study population, as expected given the fact that the SCORE risk functions were developed to predict the 10-year risk of fatal CVD, and not of non-fatal CHD. More details about the differences between the CAREMA and SCORE risk functions are given in the Appendix. The Framingham risk score, however, which predicts the 10-year risk of both fatal and non-fatal CHD, overestimated the absolute risks in this study population. Using the CAREMA risk function instead of the Framingham score resulted in an NRI of $28 \%$ ( $p$ $<0.001$ ). 


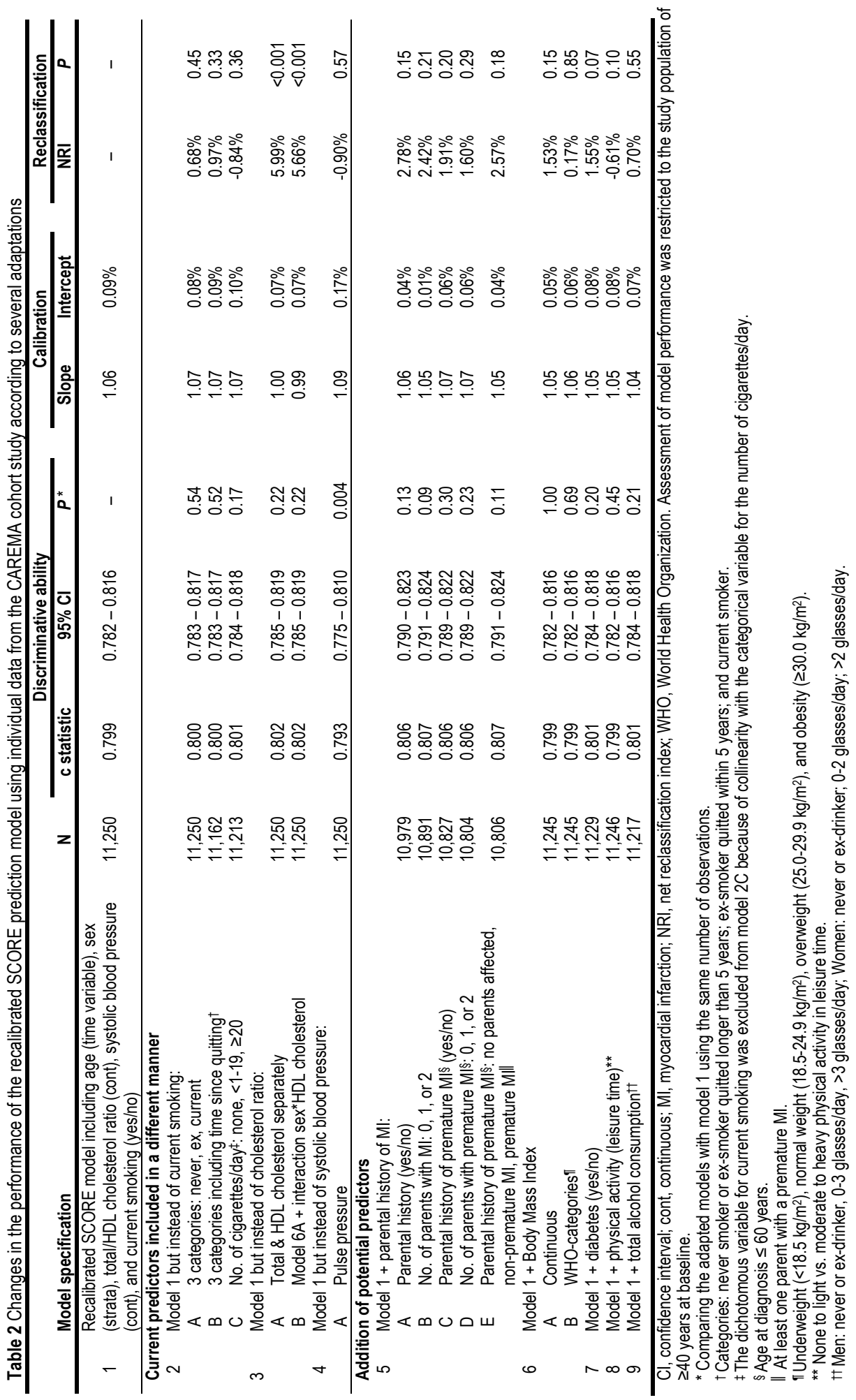




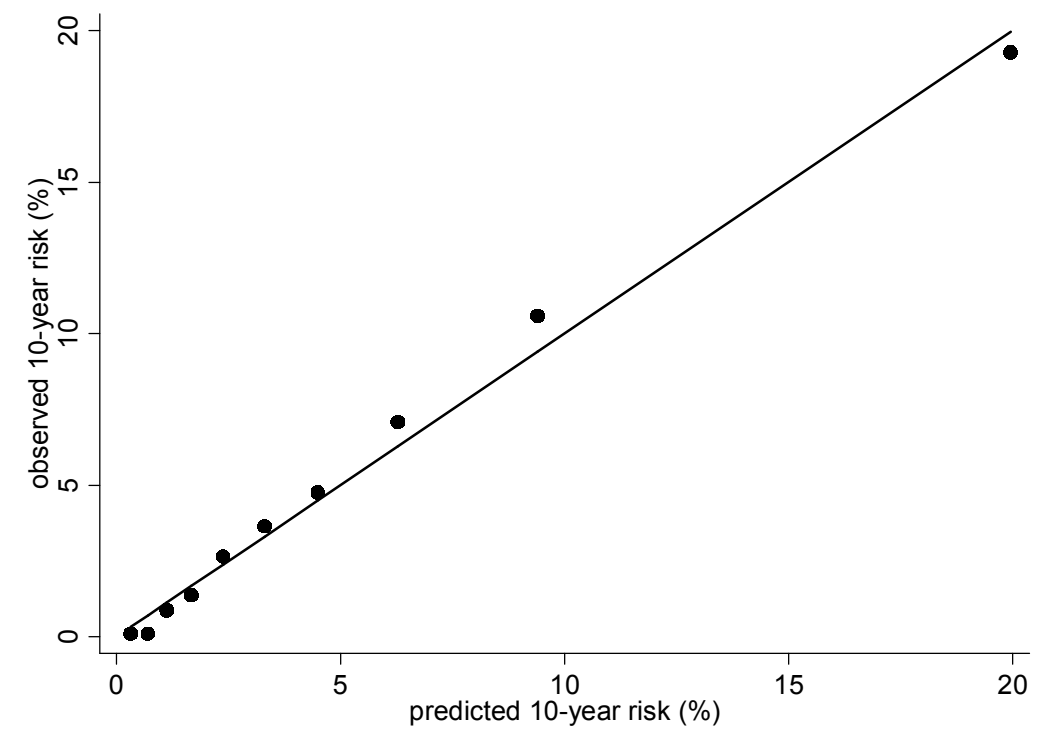

\begin{tabular}{lcccccccccc}
\hline & \multicolumn{10}{c}{ Risk decile } \\
\hline & $\mathbf{1}$ & $\mathbf{2}$ & $\mathbf{3}$ & $\mathbf{4}$ & $\mathbf{5}$ & $\mathbf{6}$ & $\mathbf{7}$ & $\mathbf{8}$ & $\mathbf{9}$ & $\mathbf{1 0}$ \\
\hline Mean predicted risk & 0.003 & 0.007 & 0.011 & 0.017 & 0.024 & 0.033 & 0.045 & 0.063 & 0.094 & 0.200 \\
Observed risk & 0.001 & 0.001 & 0.009 & 0.014 & 0.026 & 0.036 & 0.048 & 0.071 & 0.106 & 0.193 \\
Predicted/observed ratio & 3.48 & 7.73 & 1.29 & 1.23 & 0.90 & 0.91 & 0.95 & 0.89 & 0.89 & 1.04 \\
\hline
\end{tabular}

Figure 1 Calibration plot of the CAREMA risk function (slope 1.00; intercept $0.07 \%$ ), including an overview of the predicted/observed risk ratio. Restricted to the study population of $\geq 40$ years at baseline.

Table 3 Comparison of the performance to predict $\mathrm{CHD}$ incidence between the CAREMA risk function and existing risk scores in the CAREMA study population

\begin{tabular}{|c|c|c|c|c|c|c|c|}
\hline \multirow[b]{2}{*}{ Risk Score } & \multicolumn{3}{|c|}{ Discriminative ability } & \multicolumn{2}{|c|}{ Calibration } & \multicolumn{2}{|c|}{ Reclassification } \\
\hline & $\begin{array}{l}\text { C statis- } \\
\text { tic }\end{array}$ & $95 \% \mathrm{Cl}$ & $P^{*}$ & Slope & Intercept & NRI & $P$ \\
\hline CAREMA & 0.802 & $0.785-0.819$ & - & 1.00 & $0.07 \%$ & - & - \\
\hline SCORE-high (4) & 0.789 & $0.771-0.807$ & $<0.001$ & 2.32 & $3.29 \%$ & $-27.91 \%$ & $<0.001$ \\
\hline SCORE-low (4) & 0.789 & $0.771-0.807$ & $<0.001$ & 4.63 & $4.19 \%$ & $-34.63 \%$ & $<0.001$ \\
\hline $\begin{array}{l}\text { Framingham } \\
\text { study (10) }\end{array}$ & 0.792 & $0.774-0.810$ & 0.01 & 0.82 & $-4.14 \%$ & $-28.05 \%$ & $<0.001$ \\
\hline
\end{tabular}

$\mathrm{Cl}$, confidence interval; NRI, net reclassification index.

Assessment of model performance was restricted to the study population of $\geq 40$ years at baseline.

* Compared to the CAREMA risk function using the same number of observations. 


\section{Discussion}

After recalibration of the SCORE risk function using individual data on risk factor levels and CHD incidence from the CAREMA cohort study, risk prediction of CHD incidence can be improved by separating the total/HDL cholesterol ratio into total and HDL cholesterol levels. The resulting CAREMA risk function classified $28 \%$ of the participants into a more appropriate risk category for CHD incidence compared with the Framingham risk score. Compared with SCORE-high and SCORE-low, the NRIs were $28 \%$ and $35 \%$, respectively, which can largely be explained by the difference in disease outcome.

The SCORE risk function calculates the 10-year risk of CVD mortality only (4). In practice, however, there is at least equal interest in the prevention of non-fatal CVD. Therefore, the endpoint of the SCORE function was extended to include also incident non-fatal CHD cases in this study. In the CAREMA cohort study, hospital-based data on non-fatal CHD events were collected in an extensive manner. So the cardiologic followup is expected to be nearly complete and misclassification of the disease is expected to be low (36). On the other hand, the endpoint definition had to be restricted to the incidence of CHD instead of CVD, as accurate data on other CVD events such as stroke were not available from the cardiology register. Nevertheless, this difference in endpoint has contributed to the high percentages of both cases and non-cases shifting to a higher risk category when the CAREMA function was used instead of SCORE-high or SCORE-low, while none of the participants were reclassified into a lower risk category (Appendix). For CHD incidence, however, these higher predicted risks are more appropriate. In addition, higher cut-off points for risk stratification are used in the prevention of CVD incidence than of CVD mortality (14).

Among previous risk scores studies, only three $(1,2,11)$ evaluated blood pressure lowering medication as potential predictor, of which two studies actually included it in their risk function $(1,11)$. In the present study, systolic blood pressure predicted the CHD risk similarly in participants with and without blood pressure lowering medication ( $p$ interaction $=0.07$ ). Because medication use may prevent or postpone the occurrence of $\mathrm{CHD}$, inclusion of participants using medication may have led to an underestimation of the predicted risk (37). However, only a small proportion of the study population reported the use of medication for high blood pressure (4.5\%) and/or high cholesterol level $(0.5 \%)$ at baseline. Therefore, this will not have influenced the results of our study to a great extent.

Many studies found that adding risk factors to current risk scores resulted in no or only small improvements in risk prediction as assessed by the area under the ROC curve (equivalent to the c statistic) (19-27). This estimate, however, may be insensitive to detect clinically relevant improvements in risk prediction when the traditional risk factors are already included $(28,38)$. Therefore, in addition to the c statistic, the NRI can be estimated which is probably better qualified for this purpose (28). Most changes evaluated in this study did not significantly improve risk prediction, regardless 
whether the c statistic or NRI was used. However, based on the NRI, separating the cholesterol ratio into total and HDL cholesterol levels resulted in a small but significant improvement in risk prediction by the recalibrated SCORE function (NRI 6.0\%). This was also reported in a recent publication by the SCORE investigators (39), although they found a lower NRI (3.8\%).

In primary practice in the Netherlands, the Framingham risk score has been used for CVD prevention in the past, while it is nowadays replaced by the SCORE-risk charts. In the present study population, the Framingham risk score overestimated the 10-year absolute risk of CHD, as was also found in other studies (40). This can be explained by the higher CHD incidence and mortality and the higher prevalence of risk factors at the time the Framingham risk score was developed. Because of this, the SCORE project developed risk functions for high- and low-risk regions based on European data, but predicted the 10-risk of fatal CVD instead of total CVD. Although SCORE-low can be used quite well to predict the risk of CVD mortality in the Netherlands (41), the results of our study show that both SCORE-high as SCORE-low are inappropriate to predict the 10-year risk of CHD incidence. As expected, the CAREMA risk function performed better as it is especially developed to predict this endpoint. Nevertheless, the CAREMA function also performed better than the Framingham risk score which predicts the same endpoint. The CAREMA function, however, has a home-advantage as its performance is evaluated in the population in which the function is developed. Although the CAREMA function may be a useful tool to predict the 10-year risk of CHD incidence in the Netherlands, its performance has first to be validated externally as well.

In conclusion, a recalibrated SCORE risk function with total and HDL cholesterol separately instead of the cholesterol ratio can be used for the risk prediction of CHD incidence in this Dutch population. Although the CAREMA risk function which includes these changes performed better than the SCORE or Framingham risk function in this study population, external validation of the function is necessary before use in practice. 


\section{Appendix}

\section{Estimating the 10-year predicted risk}

The 10-year predicted risk of incident CHD from the CAREMA risk function can be calculated using the formulas as published in the article of the SCORE project (4) but with adapted model parameters and regression coefficients from the CAREMA cohort study, as follows:

1. Calculate the baseline survival $\left(S_{0}\right)$ of $\mathrm{CHD}$ for the person's age now and for their age in ten years time:

For men:

$\mathrm{S}_{0}$ (age) $=\exp \left\{-(\exp (-14.95)) *(\text { age }-20)^{\exp (1.22)}\right\}$

$\mathrm{S}_{0}($ age +10$)=\exp \left\{-(\exp (-14.95)) *(\text { age }-10)^{\exp (1.22)}\right\}$

For women:

$\mathrm{S}_{0}$ (age) $=\exp \left\{-(\exp (-16.30)) *(\text { age }-20)^{\exp (1.26)}\right\}$

$\mathrm{S}_{0}($ age +10$)=\exp \left\{-(\exp (-16.30)) *(\text { age }-10)^{\exp (1.26)}\right\}$

2. Calculate the weighted sum ( $w$ ) of the risk factors total cholesterol (mmol/L), HDL cholesterol $(\mathrm{mmol} / \mathrm{L})$, systolic blood pressure $(\mathrm{mmHg})$, and current smoking (yes/no):

$\mathrm{w}=0.353 *($ total cholesterol -6$)-1.816 *(\mathrm{HDL}$ cholesterol -1$)+0.0178 *$ (systolic blood pressure -120$)+0.657 *$ current smoking

3. Combine the underlying baseline survival for CHD, at the person's age now and at their age ten years from now, with the cumulative effect of a person's risk factors to calculate the probability of survival at each age for each cause:

$\mathrm{S}($ age $)=\left\{\mathrm{S}_{0}(\text { age })\right\}^{\exp (\mathrm{w})}$

$S($ age +10$)=\left\{S_{0}(\text { age }+10)\right\}^{\exp (w)}$

4. Calculate the 10-year survival probability based on the survival probability for the person's current age and their age in ten years time:

$\mathrm{S}_{10}($ age $)=\mathrm{S}($ age +10$) / \mathrm{S}($ age $)$

5. Calculate the 10 -year risk of CHD by:

Risk $_{10}=1-\mathrm{S}_{10}$ (age)

\section{Comparison between the CAREMA risk function and the SCORE risk functions}

Compared with SCORE-high, $83 \%$ of the CHD cases were reclassified into a higher risk category by the CAREMA-risk function, while no cases were reclassified into a lower risk category (see table A). Among the non-cases, 55\% were reclassified into a higher and no subjects into a lower risk category. For SCORE-low, these numbers were $92 \%$ and $0 \%$ for the cases and $58 \%$ and $0 \%$ for the non-cases, respectively. 
Compared with the 10-year absolute risks of fatal CVD from the SCORE risk charts including the HDL cholesterol level (39), the risks of developing CHD within the next ten years from the CAREMA risk function were almost twice as high at the age of 65 years, while this difference even increased at younger ages (when HDL cholesterol is fixed at $0.8 \mathrm{mmol} / \mathrm{L}$ ). For example, a male smoker, 65 years old, with a systolic blood pressure of $180 \mathrm{mmHg}$, total cholesterol level of $8 \mathrm{mmol} / \mathrm{L}$, and an HDL cholesterol level of 0.8 $\mathrm{mmol} / \mathrm{L}$ has a risk of $88 \%$ to develop CHD within the next ten years according to the CAREMA risk function, while his risk of dying from CVD within the next ten years according to the SCORE risk charts is $45 \%$ (39). For a 55 -year-old man with the same risk profile these risks are $71 \%$ and $25 \%$, respectively. The differences between the predicted risks by the CAREMA and SCORE functions, however, became smaller at higher levels of HDL cholesterol. When HDL cholesterol is fixed at $1.8 \mathrm{mmol} / \mathrm{L}$, only small differences between the absolute risks were found. For instance, the 65-year-old man from the example above (but with an HDL cholesterol level of $1.8 \mathrm{mmol} / \mathrm{L}$ ) now has a risk of $29 \%$ to develop CHD in the next ten years compared with a $28 \%$ risk of dying from CVD. 
Table A Reclassification of subjects according to the 10-year predicted risk of CHD using the CAREMA risk function instead of SCORE-high and SCORE-low

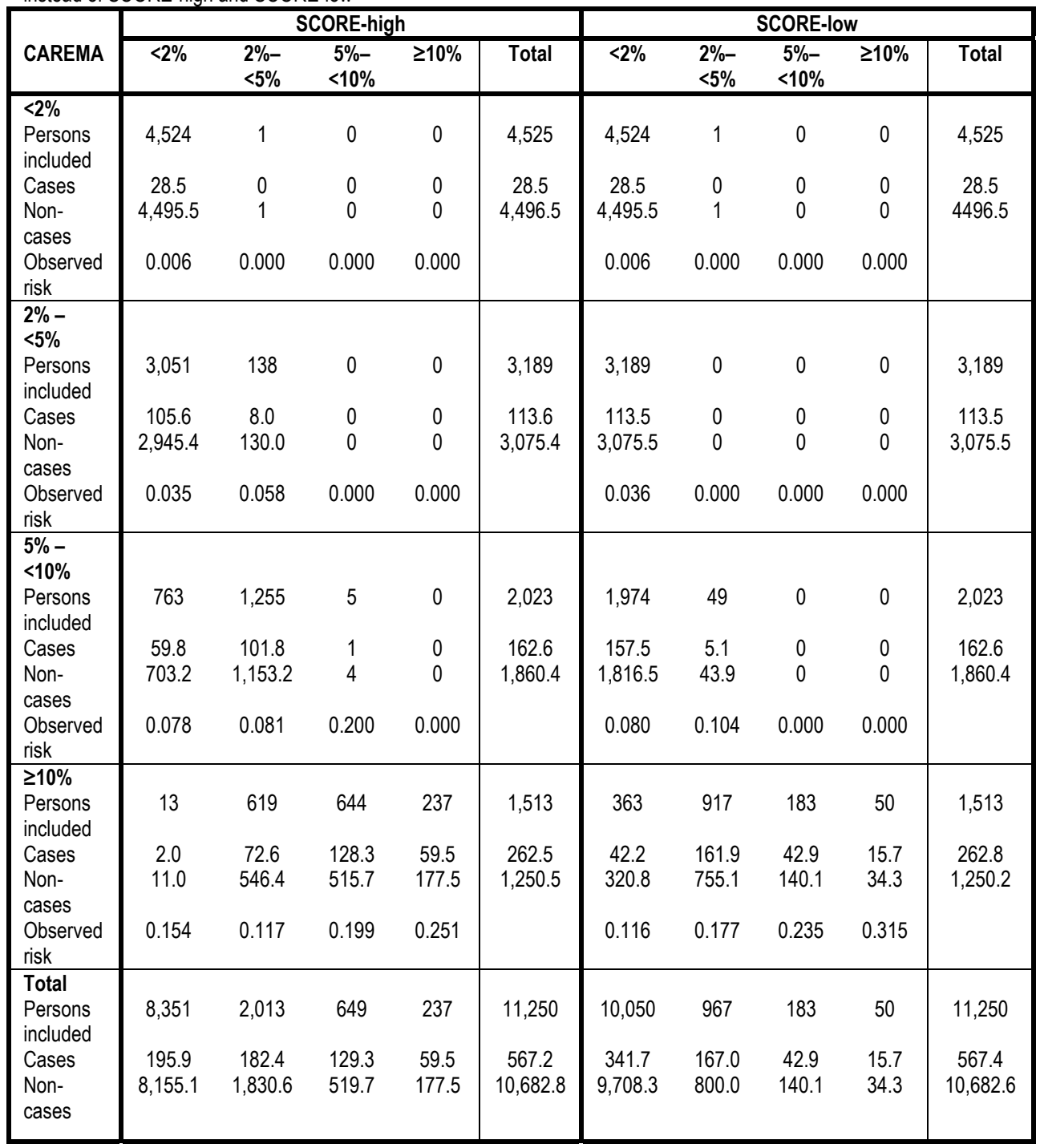




\section{References}

1. Hippisley-Cox J, Coupland C, Vinogradova Y, Robson J, Minhas R, Sheikh A, et al. Predicting cardiovascular risk in England and Wales: prospective derivation and validation of QRISK2. Bmj. 2008 Jun 28;336(7659):1475-82.

2. Ridker PM, Buring JE, Rifai N, Cook NR. Development and validation of improved algorithms for the assessment of global cardiovascular risk in women: the Reynolds Risk Score. Jama. 2007 Feb 14;297(6):611-9.

3. Woodward $\mathrm{M}$, Brindle $\mathrm{P}$, Tunstall-Pedoe $\mathrm{H}$. Adding social deprivation and family history to cardiovascular risk assessment: the ASSIGN score from the Scottish Heart Health Extended Cohort (SHHEC). Heart. 2007 Feb;93(2):172-6.

4. Conroy RM, Pyorala K, Fitzgerald AP, Sans S, Menotti A, De Backer G, et al. Estimation of ten-year risk of fatal cardiovascular disease in Europe: the SCORE project. Eur Heart J. 2003 Jun;24(11):987-1003.

5. Balkau B, Hu G, Qiao Q, Tuomilehto J, Borch-Johnsen K, Pyorala K. Prediction of the risk of cardiovascular mortality using a score that includes glucose as a risk factor. The DECODE Study. Diabetologia. 2004 Dec;47(12):2118-28.

6. Shaper AG, Pocock SJ, Phillips AN, Walker M. Identifying men at high risk of heart attacks: strategy for use in general practice. Br Med J (Clin Res Ed). 1986 Aug 23;293(6545):474-9.

7. Tunstall-Pedoe H. The Dundee coronary risk-disk for management of change in risk factors. Bmj. 1991 Sep 28;303(6805):744-7.

8. Menotti A, Lanti M, Puddu PE, Kromhout D. Coronary heart disease incidence in northern and southern European populations: a reanalysis of the seven countries study for a European coronary risk chart. Heart. 2000 Sep;84(3):238-44.

9. Stevens RJ, Kothari V, Adler Al, Stratton IM. The UKPDS risk engine: a model for the risk of coronary heart disease in Type II diabetes (UKPDS 56). Clin Sci (Lond). 2001 Dec;101(6):671-9.

10. Wilson PW, D'Agostino RB, Levy D, Belanger AM, Silbershatz $H$, Kannel WB. Prediction of coronary heart disease using risk factor categories. Circulation. 1998 May 12;97(18):1837-47.

11. Chambless LE, Folsom AR, Sharrett AR, Sorlie P, Couper D, Szklo M, et al. Coronary heart disease risk prediction in the Atherosclerosis Risk in Communities (ARIC) study. J Clin Epidemiol. 2003 Sep;56(9):880-90.

12. Assmann G, Schulte $H$, Cullen $P$, Seedorf U. Assessing risk of myocardial infarction and stroke: new data from the Prospective Cardiovascular Munster (PROCAM) study. Eur J Clin Invest. 2007 Dec;37(12):92532.

13. Graham I, Atar D, Borch-Johnsen K, Boysen G, Burell G, Cifkova R, et al. European guidelines on cardiovascular disease prevention in clinical practice: executive summary. Eur Heart J. 2007 Oct;28(19):2375414.

14. Smulders YM, Burgers JS, Scheltens T, van Hout BA, Wiersma T, Simoons ML. Clinical practice guideline for cardiovascular risk management in the Netherlands. Neth J Med. 2008 Apr;66(4):169-74.

15. Ulmer H, Kollerits B, Kelleher C, Diem G, Concin H. Predictive accuracy of the SCORE risk function for cardiovascular disease in clinical practice: a prospective evaluation of 44649 Austrian men and women. Eur J Cardiovasc Prev Rehabil. 2005 Oct;12(5):433-41.

16. Neuhauser HK, Ellert U, Kurth BM. A comparison of Framingham and SCORE-based cardiovascular risk estimates in participants of the German National Health Interview and Examination Survey 1998. Eur J Cardiovasc Prev Rehabil. 2005 Oct;12(5):442-50.

17. Bhopal R, Fischbacher C, Vartiainen E, Unwin N, White M, Alberti G. Predicted and observed cardiovascular disease in South Asians: application of FINRISK, Framingham and SCORE models to Newcastle Heart Project data. J Public Health (Oxf). 2005 Mar;27(1):93-100.

18. Lindman AS, Veierod MB, Pedersen JI, Tverdal A, Njolstad I, Selmer R. The ability of the SCORE high-risk model to predict 10-year cardiovascular disease mortality in Norway. Eur J Cardiovasc Prev Rehabil. 2007 Aug;14(4):501-7.

19. Atsma F, van der Schouw YT, Grobbee DE, Hoes AW, Bartelink ML. No added value of age at menopause and the lifetime cumulative number of menstrual cycles for cardiovascular risk prediction in postmenopausal women. Int J Cardiol. 2007 Dec 4.

20. Cooper JA, Miller GJ, Bauer KA, Morrissey JH, Meade TW, Howarth DJ, et al. Comparison of novel hemostatic factors and conventional risk factors for prediction of coronary heart disease. Circulation. 2000 Dec 5;102(23):2816-22. 
21. Lee AJ, Price JF, Russell MJ, Smith FB, van Wijk MC, Fowkes FG. Improved prediction of fatal myocardial infarction using the ankle brachial index in addition to conventional risk factors: the Edinburgh Artery Study. Circulation. 2004 Nov 9;110(19):3075-80.

22. Lloyd-Jones DM, Liu K, Tian L, Greenland P. Narrative review: Assessment of C-reactive protein in risk prediction for cardiovascular disease. Ann Intern Med. 2006 Jul 4;145(1):35-42.

23. Nawrot TS, Staessen JA, Thijs L, Fagard RH, Tikhonoff V, Wang JG, et al. Should pulse pressure become part of the Framingham risk score? J Hum Hypertens. 2004 Apr;18(4):279-86.

24. Van der Steeg WA, Boekholdt SM, Stein EA, El-Harchaoui K, Stroes ES, Sandhu MS, et al. Role of the apolipoprotein B-apolipoprotein A-I ratio in cardiovascular risk assessment: a case-control analysis in EPIC-Norfolk. Ann Intern Med. 2007 May 1;146(9):640-8.

25. Wang TJ, Gona P, Larson MG, Tofler GH, Levy D, Newton-Cheh C, et al. Multiple biomarkers for the prediction of first major cardiovascular events and death. N Engl J Med. 2006 Dec 21;355(25):2631-9.

26. Wilsgaard T, Arnesen E. Body mass index and coronary heart disease risk score: the Tromso study, 1979 to 2001. Ann Epidemiol. 2007 Feb;17(2):100-5.

27. Ridker PM, Paynter NP, Rifai N, Gaziano JM, Cook NR. C-reactive protein and parental history improve global cardiovascular risk prediction: the Reynolds Risk Score for men. Circulation. 2008 Nov 25;118(22):2243-51, 4p following 51.

28. Pencina MJ, D'Agostino RB, Sr., D'Agostino RB, Jr., Vasan RS. Evaluating the added predictive ability of a new marker: from area under the ROC curve to reclassification and beyond. Stat Med. 2008 Jan 30;27(2):157-72; discussion 207-12.

29. Van Leer EM, Seidell JC, Kromhout D. Dietary calcium, potassium, magnesium and blood pressure in the Netherlands. Int J Epidemiol. 1995 Dec;24(6):1117-23.

30. Lean ME, Han TS, Seidell JC. Impairment of health and quality of life in people with large waist circumference. Lancet. 1998 Mar 21;351(9106):853-6.

31. Boland B, Christiaens T, Goderis G, Govaerts F, Philips H, Smeets F, et al. Globaal cardiovasculair risicobeheer. Huisarts Nu. 2007;36(7):339-69.

32. Hippisley-Cox J, Coupland C, Vinogradova Y, Robson J, May M, Brindle P. Derivation and validation of QRISK, a new cardiovascular disease risk score for the United Kingdom: prospective open cohort study. Bmj. 2007 Jul 21;335(7611):136.

33. Steyerberg EW, Eijkemans MJ, Harrell FE, Jr., Habbema JD. Prognostic modeling with logistic regression analysis: in search of a sensible strategy in small data sets. Med Decis Making. 2001 Jan-Feb;21(1):4556.

34. Harrell FE, Jr., Lee KL, Mark DB. Multivariable prognostic models: issues in developing models, evaluating assumptions and adequacy, and measuring and reducing errors. Stat Med. 1996 Feb 28;15(4):36187.

35. Steyerberg EW, Pencina MJ. Reclassification calculations for persons with incomplete follow-up. Ann Intern Med. 2010 Feb 2;152(3):195-6; author reply 6-7.

36. Merry AH, Boer JM, Schouten LJ, Feskens EJ, Verschuren WM, Gorgels AP, et al. Validity of coronary heart diseases and heart failure based on hospital discharge and mortality data in the Netherlands using the cardiovascular registry Maastricht cohort study. Eur J Epidemiol. 2009;24(5):237-47.

37. Liew SM, Glasziou P. QRISK may be less useful. Bmj. 2009;339:b3485.

38. Cook NR. Statistical evaluation of prognostic versus diagnostic models: beyond the ROC curve. Clin Chem. 2008 Jan;54(1):17-23.

39. Cooney MT, Dudina A, De Bacquer D, Fitzgerald A, Conroy R, Sans S, et al. How much does HDL cholesterol add to risk estimation? A report from the SCORE Investigators. Eur J Cardiovasc Prev Rehabil. 2009 Jun;16(3):304-14.

40. Eichler K, Puhan MA, Steurer J, Bachmann LM. Prediction of first coronary events with the Framingham score: a systematic review. Am Heart J. 2007 May;153(5):722-31, 31 e1-8.

41. Van Dis I, Kromhout D, Geleijnse JM, Boer JM, Verschuren WM. Evaluation of cardiovascular risk predicted by different SCORE equations: the Netherlands as an example. Eur J Cardiovasc Prev Rehabil. 2010 Apr;17(2):244-9. 


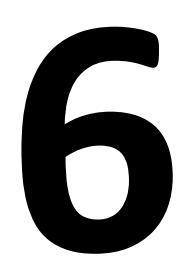

General discussion 
Because of the high disease burden of coronary heart disease (CHD), primary prevention is warranted. A commonly used strategy in primary prevention is the identification of persons at high risk of developing CHD by risk scores (and subsequently reducing the risk by interventions). The main focus of this thesis was to develop a refined risk prediction model in the Dutch study population of the Cardiovascular Registry Maastricht (CAREMA) cohort study and to compare its performance with that of existing risk scores. This chapter will place our findings in the light of the current knowledge. Furthermore, some important issues and considerations regarding risk prediction will be discussed, both from a scientific and practical point of view. Finally, some recommendations for future research will be given.

\section{Main findings}

Using the CAREMA study population, we estimated incidence rates of several heart diseases such as CHD and heart failure. Incidence rates based on hospital discharge data together with mortality data were lower compared with those from the Cardiology Information System (CIS) in combination with mortality data (chapter 2). When these two methods of case identification were compared, relatively high sensitivities and positive predictive values were found for total CHD and acute myocardial infarction (AMI), while these values were considerably lower for unstable angina pectoris (UAP) and heart failure. Furthermore, depending on the type of cardiac disease, $14 \%$ to $47 \%$ of the cases were found only in the CIS-based registry while they were missed or miscoded in the hospital discharge registry (HDR). Therefore, incidence rates based on hospital discharge data in combination with mortality may underestimate the true incidence rates, especially for UAP and heart failure.

Persons with at least one metabolic factor (hypertension, obesity, diabetes, high total or low HDL cholesterol level) were at increased risk of developing CHD compared with persons with no metabolic factors (chapter 3). Additionally, a clear dose-response relationship was seen between the number of metabolic factors and the risk of CHD. Similar results were found for both $\mathrm{AMI}$ and UAP, although the associations were stronger for AMI. Especially combinations including diabetes or a high total with a low HDL cholesterol level were associated with elevated risks of the coronary diseases.

The effects of the lifestyle factors smoking, alcohol consumption, and physical activity were in the same direction for the risk of AMI and UAP, but nearly always stronger for AMI than for UAP (chapter 4). Parental history of myocardial infarction (MI) was also positively associated with the risk of both coronary diseases, although this association was stronger with the risk of UAP than of AMI. Between persons with and without a parental history of $\mathrm{MI}$, no differences were found in the associations with the lifestyle factors. The highest risks for both coronary diseases were found in persons with a positive parental history of $\mathrm{Ml}$ and the most unfavourable level of the lifestyle factors. 
Our recalibrated SCORE risk function, using data on risk factor levels and incident CHD from the CAREMA cohort study, performed well in terms of discrimination and calibration (chapter 5). Based on the net reclassification index, risk prediction by this model was improved by separating the total/HDL cholesterol ratio in total and HDL cholesterol levels. The resulting CAREMA risk function that predicts the 10-year absolute risk of incident CHD consisted of the following predictors: age (time variable), sex (strata), current smoking (yes/no), systolic blood pressure (continuous), total and HDL cholesterol levels (continuous). Compared with the SCORE functions for high- and low-risk regions that predict the 10 -year risk of fatal cardiovascular disease (CVD), high percentages of both cases and non-cases were reclassified to a higher risk category which can mainly be explained by the difference in the predicted outcome. Compared with the Framingham score which predicts the same outcome as the CAREMA risk function, a high percentage of both cases and non-cases were reclassified into a more appropriate risk category of CHD incidence in this Dutch population. Therefore, the CAREMA risk function may be a useful tool for the risk prediction of CHD incidence in the Netherlands and possibly also in other populations, although it first has to be externally validated as well. In the next paragraphs, the results of our studies will be discussed in more detail.

\section{Incidence of coronary heart disease}

\section{Validity of incidence estimates}

In many countries including the Netherlands, a national registry exists containing the causes of death of the deceased inhabitants. Such registries are not only useful to estimate mortality rates but also for the comparison of these rates between populations and for trends in time. However, this may be complicated by differences in the validity of causes of death registries between countries and in time. Unfortunately, national as well as regional registries on CHD incidence are not available in the Netherlands and most other countries. Therefore, data on non-fatal cases are mostly retrieved from registries of general practitioners or hospital discharge data. In several countries, CHD incidence rates are estimated by combining these data with national mortality data. Although this seems to be a useful and accurate method, it has some disadvantages. First, contrary to e.g. Scandinavian countries, it is not allowed in the Netherlands to use the personal identification number (Burger Service Nummer (BSN)), which is unique for every inhabitant, in the linkages between registries. Therefore, registries are linked using a combination of age, sex, and the four numbers of the postal code. To solve the problem that these variables are not unique and may cause the merging of different persons into one, only persons with a unique combination of these factors within the Dutch population registry are used for the record linkage between the HDR and causes of death registry. A pilot study by Reitsma et al. showed that $11 \%$ of the participants in the national HDR could be linked to multiple records 
within the Dutch population registry, while $5 \%$ of the participants could not be linked to any record using sex, date of birth, and the four numbers of the postal code (1). The exclusion of these persons from the incidence estimates would be a problem if the incidence rate of $\mathrm{CHD}$ in these persons differs from that in uniquely linked persons due to differences in their risk profile. Nevertheless, Reitsma et al. found only small differences between uniquely and non-uniquely linked persons according to age, ethnicity, and number of inhabitants in the postal code area (1). However, information on risk factors for CHD (other than age and sex) was not available and differences in these factors can therefore not be excluded. Furthermore, the $5 \%$ of the participants not linked to any record in the population registry may still include eligible cases that could not be linked due to administrative errors in one of the registries. These cases are also not included leading to a possible underestimation of the incidence rates.

Second, the effort and commitment to register the data are the main determinants of the validity of the HDR and causes of death registries. Although the reliability of the Netherlands causes of death registry is reasonably well for major causes of death such as AMI (2), the validity of the data in the national HDR may be problematic for some reasons. People who were admitted with $\mathrm{CHD}$ to a hospital outside the country, for example, or who were diagnosed at the outpatient's clinic will not be registered in the national HDR, although the latter is less relevant for the diagnosis of acute CHD which nearly always warrants hospitalisation. As a result, these cases will be missed in estimating the incidence rate of CHD. Furthermore, the national HDR is a combined registry from the individual HDRs of all Dutch hospitals. In each hospital, one or more registrars are responsible for the registration of the discharge diagnoses in the HDR, which is mostly based on the information reported by the clinicians in the clinical files. Therefore, the validity of the data in the HDR may differ between hospitals.

In this thesis, we used the CIS of the University Hospital Maastricht (UHM) department of Cardiology for the identification of incident CHD cases. In the cardiovascular disease registry of this study, we verified the registered diagnoses using the detailed information in the CIS. The data were abstracted by a limited number of registrars, who were all instructed and guided by the same cardiologist. Therefore, this disease registry is probably less prone to misclassification. When all data from the CIS were entered in the disease registry, several quality controls were performed to check for completeness, possible errors, and inconsistencies in the registered data. Seventy-seven percent of the registered cases with AMI met the diagnostic criteria of the European Society of Cardiology and the American College of Cardiology (3), while the remaining cases had incomplete data to test against these criteria.

Nevertheless, we will have missed cases in our disease registry. The participants were living in the Maastricht region at baseline. Despite the central and unique position of the UHM in the study region, patients with CHD may have been admitted to and followed up in another hospital nearby this region, such as the hospitals in Sittard, Heerlen or in Belgian hospitals close to the Dutch border. However, the percentage of missed cases is expected to be low. Furthermore, we do not expect that these cases 
differ in their risk profile from the cases we did register. Therefore, the fact that we missed cases in our registry probably had a negligible effect on our results.

\section{Generalizability}

Although incidence rates based on similar registries as the disease registry in our study may be more valid compared with data from the HDR, as has been shown in this thesis, a disadvantage is that such disease registries are not available in most hospitals. The incidence rates presented in this thesis are based on our study population from the Maastricht region which is located in the south of the Netherlands. The generalizability of these rates to the Dutch population may be questioned due to regional differences in incidence rates. In the Maastricht region, the hospital admissions rates for both AMI and other CHD were lower compared with the Dutch average in the period 1991-2004 (4). These differences may be due to true differences between regions, but also to differences in the completeness and accuracy of the HDRs on which these estimates are based. Using the CIS-based registry as gold standard we have found that the quality of the HDR in the Maastricht region is quite well (sensitivity $72 \%$; positive predictive value $91 \%$ ), while the quality of the HDRs in other regions has not been investigated. On the contrary, the mortality rate of CHD is higher in the Maastricht region compared with the Dutch average mortality rate (5). Nevertheless, our cardiovascular disease registry based on data from the CIS and causes of death registry will have resulted in qualitatively better estimates of the incidence rates compared with data from the HDR in combination with mortality data. Therefore, the incidence rates from our study population can be generalized to the Dutch population when some attention is given to possible regional differences.

\section{Consequences for trends}

Because cases were missed or miscoded in the HDR, the incidence rates of heart diseases based on these data may underestimate the true incidence rates. Using CIS as gold standard, the miscoding of discharge diagnoses was especially seen for specific coronary diseases such as AMI and UAP and not overall. As these cases were mostly registered with another CHD as discharge diagnosis (mostly ICD-9 413.9 other and unspecified angina and 414.0 coronary atherosclerosis) in the HDR, miscoding will probably have a small influence on the incidence rate of total CHD. Patients diagnosed at the outpatient clinic or in a hospital outside the country, however, will still be missed in the HDR.

If the miscoding of discharge diagnoses in the HDR has been stable over the last decades, this has not influenced the trend in the incidence rates of CHD. Even for diagnoses of AMI and UAP, which are more prone to miscoding, the trend in incidence rates will be unaffected if the miscoding has been stable over time. During the study period, however, more sensitive diagnostic markers have become available such as troponin $T$ being introduced in 1999, allowing a better distinction between the diagnosis of AMI and UAP. This change in clinical decision-making may have influenced the incidence 
rate of these diseases, regardless whether they were based on our cardiovascular disease registry or on the HDR. However, we did not see a difference in the ratio between AMI and UAP in our registry before and after this test became available. Therefore, the introduction of this test probably had a negligible impact on the incidence rates of these coronary diseases in our study population. Based on the national HDR, no clear changes were seen in the hospital admission rates of AMI around the year 1999 while for other (sub)acute CHD (including UAP) the decline in admission rate seemed to level off around 2001 (6). However, it is unclear to what extent this change is due to introduction of the diagnostic markers. Nevertheless, the national HDR can be useful to evaluate the trend in hospital admissions for total CHD but these data should be used with caution for specific coronary diseases such as UAP.

\section{Etiology of coronary heart disease}

The associations between the etiological factors in the CAREMA study and CHD risk were studied in preparation to the development of the risk score. Both the effects of the single risk factors as their combined effect were studied in this thesis.

\section{Metabolic factors}

\section{Single effect of metabolic factors}

Diabetes, hypertension, plasma total and HDL cholesterol concentrations, and obesity were all found to be independent risk factors of CHD in our study. Of these factors, diabetes was associated with the highest risk of CHD (RR 2.8, 95\% Cl 1.9-4.1). In our study population, only few participants had diabetes at baseline (0.9\%). No information was available about the specific type of diabetes (type I or type II), although the age at diagnosis was recorded. From the literature it is known that pre-diabetes, defined as impaired fasting glucose and/or impaired glucose tolerance, is related to a modestly increased cardiovascular risk (7). Information about these markers was also not available in the CAREMA cohort study. It is likely that participants with prediabetes were included in the reference category. Therefore, the CHD risk associated with diabetes may have been underestimated. However, this probably concerns only a small proportion of the study population, and will therefore not have influenced the association with diabetes to a large extent.

Hypertension, as defined by the WHO (8), was also associated with an increased risk in our study. Systolic blood pressure levels were measured during a physical examination by trained staff members. These data are probably less prone to misclassification compared with self-reported data. On the other hand, participants may have had raised blood pressure levels during the measurement, while they usually have normal levels (white-coat hypertension). However, this effect will partly be overcome because the average of two successive measurements was used with a resting period of thirty seconds between the measurements. Although the information is limited, there seems to 
be an increase in the percentage of people with a raised systolic blood pressure in the Netherlands since 1987 (9). These data are partially based on the same population as used in the CAREMA cohort study. Therefore, it can be expected that the number of participants with a raised systolic blood pressure has also increased in our study population after the baseline measurement. However, as these changes probably are nondifferential, it may have resulted in a small underestimation of relative risks in our study.

A high total as well as a low HDL cholesterol level was associated with an elevated CHD risk, especially when both risk factors were present within the same individual resulting in a high total/HDL cholesterol ratio. Based on the same data sources as for blood pressure, the number of people with unfavourable cholesterol levels or using cholesterol lowering medication has decreased between 1987 and 1997 (10). This decline in total cholesterol levels can mainly be attributed to other causes than medication use, for example the change in types of fat used in the food-industry, because the percentage of people using cholesterol lowering medication increased between 1993 and 1997 (11). In the same population, the percentage of people with a low HDL cholesterol ( $<0.9 \mathrm{mmol} / \mathrm{L}$ ) increased in men from 1987-1992 followed by a decreasing trend in 1993-1997 (10). In women, this percentage also decreased in this period after it has been stable between 1987 and 1992 (10). If these trends in cholesterol levels continued during the next years, this may have resulted in a further decrease of the number of study participants with unfavourable cholesterol levels during the follow-up period. However, because the trends are largely unknown after 1997 it is difficult to assess the effect of these changes in cholesterol levels on our risk estimates.

Obesity was associated with a modestly increased CHD risk in multivariable analyses. In addition, we found no association between obesity and the CHD risk when this was the only metabolic risk factor present within an individual ( $R R$ 1.00, 95\% $\mathrm{Cl} 0.49-2.05$ ), as was also found in at least two other studies for the risk of CVD $(12,13)$. A possible explanation is that the effect of an increased body mass index is mediated through its effect on other metabolic factors such as diabetes, blood pressure and cholesterol levels. This explanation is supported by the very low percentage of CHD cases with obesity as the only metabolic factor in the CAREMA cohort (1.0\%). In the last three decades, there has been a substantial increase in the amount of overweight people in the Netherlands and the number of obese persons even doubled (14). Therefore, it is highly plausible that the percentage of study participants with overweight/obesity also increased during the follow-up period. Schuit et al. (15) indeed showed an average increase in BMI of $0.37 \mathrm{~kg} / \mathrm{m}^{2}$ over a period of 5 years (1998-2003) within a random sample of the CAREMA study population (measured within an intervention study which will be discussed in more detail in the section on interventions). As a result, there will have been an increasing number of persons with overweight in the reference category, which were normal-weighted subjects at baseline, leading to attenuated risks. 
Dichotomised definitions of the metabolic factors were used in these analyses. As categorisation of variables is associated with loss of information, it may be better to include these variables as continuous predictors in prediction models, except for diabetes.

\section{Cumulative effect of metabolic factors}

In line with previous studies, we have found a strong dose-response relationship between the number of metabolic factors and the risk of CHD. As these risk factors tend to co-occur within an individual more often than expected by chance (16-18), it could be suggested that a cluster variable summarising the number of metabolic factors is more relevant in risk prediction than including the metabolic factors separately. On the other hand, we have found that the CHD risk varies considerably according to the combination of metabolic factors within these clusters, as was also found in other studies $(19,20)$. When only the number of metabolic factors present within an individual is included in risk prediction models, high-risk combinations would have the same effect as combinations associated with a modestly elevated CHD risk. However, including all possible combinations of the metabolic risk factors as separate categories in the risk prediction model would limit the accuracy of the model as the number of participants would be small in some categories. Furthermore, this approach would complicate the use of the prediction model in primary practice as the general practitioner first has to determine to which specific category the individual belongs. Taking these considerations into account, it is preferred to include the metabolic factors as separate predictors into the prediction model. In this way, each metabolic factor constitutes its own effect while their cumulative effect is taken into account in the predicted absolute risk resulting from the risk function.

\section{Lifestyle factors}

Current smokers had a significantly increased risk of CHD compared with never smokers. Furthermore, we found a dose-response relationship with the number of cigarettes smoked per day and the number of smoking years, which was also found in other studies $(21,22)$. As we also had information about the age at which ex-smokers quitted smoking, we were able to investigate the effect of time since quitting. Comparable to the results of our study, several studies found that the risk of CHD starts to decline very rapidly after smoking cessation leading to similar risks compared with never smokers after three to five years of cessation $(23,24)$. During our follow-up period, participants may have decided to quit smoking. In the same random sample of our study population as described for obesity, a significant number of participants (6.2\%) quitted smoking between 1998 and 2003 (25). On the other hand, 2.2\% of the participants within this random sample started smoking in this period. Consequently, the exact impact of changes in the smoking behaviour of our study results is unknown. 
The inverse association between alcohol consumption and the risk of CHD was independent of the type of alcoholic beverage consumed, which was also found by other studies (26-28). However, including alcohol consumption into prediction models is controversial. As this factor is associated with a protective effect, physicians may then be inclined to advice persons to start alcoholic drinking or to drink more glasses of alcoholic beverages per day in order to reduce the person's risk of CHD. This situation is not preferable in clinical practice because of the adverse effects of alcohol consumption on the risk of several other diseases such as cancer and liver cirrhosis (29). Therefore, including alcohol consumption into risk scores should only be done if adding this factor results in a substantial improvement in risk prediction of CHD and after careful consideration of the benefits and adverse effects on overall disease risk.

Although physical activity has been found to be protective against the risk of CHD (3033), a non-significantly protective effect was only found in men in our study. The questionnaires of the two monitoring projects from which the study population was derived differed in their measurement of physical activity. In the Monitoring Project on Cardiovascular Risk Factors (1987-1992), physical activity was measured less extensively as in the Monitoring Project on Chronic Disease Risk Factors (1993-1997). As our participants were derived from both projects, we used the more restricted definition of physical activity, consisting of only two categories (none to light versus moderate to heavy activity). This restricted definition may explain why we found no protective effect of physical activity as in other studies. Nevertheless, a physician probably prefers to use a simple definition for assessing the physical activity level of an individual. Furthermore, physical activity during leisure time may be more important for risk prediction than work-related physical activity as the latter is less modifiable.

\section{Family history}

A positive relationship was found between parental history of $\mathrm{MI}$ and the risk of CHD. In addition, risk increased when both parents were affected and when they were diagnosed with premature $\mathrm{Ml}$ (father $\leq 60$ years, mother $\leq 65$ years). In addition to parental history, a positive sibling history was found to be an even stronger risk factor for CHD (34). In our study, however, no information was available about CHD events in brothers or sisters of the study participants. As our study population is relatively young, the number of participants with an affected sibling may be low and, therefore, its effect may be limited in our study.

\section{Synergistic effect between family history and lifestyle factors}

No interaction on a multiplicative scale was found between family history and the lifestyle factors. Nevertheless, the highest risks of CHD were found in participants with a positive family history and unfavourable levels of the lifestyle factors. Myers et al. also found no interaction between parental history of CHD and established risk factors of CHD such as smoking, systolic blood pressure, and serum cholesterol levels (35). In other studies, synergistic effects were found between family history and other risk 
factors for CHD such as smoking, high LDL/HDL cholesterol ratio, and diabetes (36-38). These results suggest that separate risk factor coefficients for persons with and without a positive family history may be used in prediction models in addition to the inclusion of family history as predictor. It is unknown whether this approach would result in better risk prediction, as the cumulative effect of family history of CHD and the other risk factors will still be taken into account in the predicted risk when they are included as single predictors. Nevertheless, this approach may be beneficial in case of a strong interaction on a multiplicative scale between family history and the other risk factors in the prediction model.

\section{Interventions}

During the follow-up period of the CAREMA cohort study, several planned or unforeseen interventions have occurred that may have influenced our results. First, the study participants were informed about their blood pressure and cholesterol levels which were measured during their physical examination at baseline. In case of raised levels, they were advised to contact their general practitioner. Although we do not have information about the exact numbers, part of the study participants has probably followed this advice. In case the general practitioner also found raised levels, persons may have started to use blood pressure lowering and/or cholesterol-lowering medication. Many studies found that using these medications significantly reduces the risk of developing $\operatorname{CHD}(23,24)$. As a result, we may have underestimated the CHD risk associated with hypertension, high total or low HDL cholesterol.

Second, in 1998 Hartslag Limburg was initiated in the Maastricht region which is a community-based cardiovascular disease prevention program promoting a healthy lifestyle (39). As a result of this program, individual changes in risk factor levels have occurred as measured within a random sample of the population from the two monitoring projects of the National Institute of Public Health and the Environment from which the CAREMA study population was derived $(15,25)$. After 5 years of intervention, no difference was found in the percentage of participants who quitted smoking between the intervention area and a reference area in which no intervention program was undertaken (25). In addition, no difference was seen in the percentage of participants who started smoking between the two populations (25). For physical activity, a significantly smaller decrease in the total amount of physical activities in leisure time and in the time spent on walking was found in the intervention area for women but not for men (25). No differences between the two regions were found for the change in other physical activities such as bicycling and sports in both sexes. Furthermore, none of these activities significantly changed within the Maastricht area.

Regarding the metabolic factors, the intervention area showed a smaller increase in $\mathrm{BMI}$ and both the systolic and diastolic blood pressure compared with the control area (15). Nevertheless, the levels of these factors increased during the study period from 1998 to 2003. In this period, total cholesterol levels declined in men from the intervention area as well as the control area $(-0.15$ and $-0.16 \mathrm{mmol} / \mathrm{L}$, respectively) and in 
women from the control area $(-0.08 \mathrm{mmol} / \mathrm{L})$. In women from the intervention area a small increase was seen $(0.04 \mathrm{mmol} / \mathrm{L})(15)$. HDL cholesterol levels increased in both areas with changes ranging from 0.02 to $0.05 \mathrm{mmol} / \mathrm{L}$.

These studies showed that the risk factor levels in the Maastricht region changed differently from those in the control region, likely due to the intervention program. They also showed that changes did occur in these risk factors during our follow-up period. With the exception of the cholesterol levels, unfavourable changes occurred in the other lifestyle and metabolic factors as described above, although less pronounced as in the reference area. Assuming that these changes within the random sample are representative for the whole population in the Maastricht region, this may have biased the associations between these factors and the CHD risk in the CAREMA cohort study. In case of favourable changes in risk factor levels, for example in the cholesterol levels, the risks associated with these factors may have been underestimated in this thesis. On the contrary, unfavourable changes in risk factors may have resulted in overestimated risks. However, the changes in risk factor levels within our study population were relatively small, and therefore these changes probably had a limited impact on our risk estimates.

Third, apart from these study-related activities and intervention programs, participants may have been diagnosed with increased blood pressure or cholesterol levels by their general practitioner or other specialists during the follow-up period because of which they started to use medications. Houterman et al., for example, found an increase in the reported use of cholesterol lowering medication at baseline between 1993 and 1997 in the MORGEN study, especially in men (11). Although use of these medications has been related to considerable reductions in the $\operatorname{CHD}$ risk $(23,24)$, persons with normal blood pressure or cholesterol levels thanks to their medications may still be at increased risk compared with healthy subjects having normal levels without medication. Therefore, the increasing use of medications may have biased the effect of blood pressure and total cholesterol on the CHD risk, but probably to a limited extent.

\section{AMI versus UAP}

In our study, associations with the metabolic and lifestyle factors were practically always stronger for AMI than UAP. This may be explained by the effect of these risk factors on atherosclerotic and thrombotic processes. As described in chapter 1, the clinical manifestation of AMI or UAP depends largely on the degree of occlusion of the coronary artery $(40,41)$. Several studies have shown that smoking is associated with an increased activity and adhesion of platelets, higher fibrinogen levels, and decreased fibrinolytic activity (42). These changes may accelerate the thrombus formation after plaque disruption. The decreased fibrinolytic activity found in smokers compared with non-smokers may favour a complete and persistent occlusion of a coronary artery by a thrombus. On the contrary, moderate alcohol consumption, which is a protective factor for $\mathrm{CHD}$, has been associated with reduced levels of fibrinogen and a thrombolytic profile $(43,44)$ favouring the occurrence of incomplete or temporarily occlusion by a 
labile thrombus. Increased levels of the metabolic factors have been associated with an increased activity of platelets and the coagulation system, and an impaired fibrinolytic activity (45-49). These haemostatic disturbances may accelerate the atherosclerotic process but impair the fibrinolysis of the thrombus after plaque disruption. Especially the decrease in the fibrinolytic activity in persons with unfavourable levels of risk factors may explain the stronger associations of these factors with AMI than with UAP. In contrast, the effect of family history was stronger for UAP than for AMI. Colditz et al. also found that parental history of $\mathrm{MI}$ was stronger related to angina (not specifically UAP) than to non-fatal MI (50). They suggested that physicians may be more likely to examine persons with chest pain that have a positive family history of CHD. As a result, angina pectoris may be more frequently detected in patients with than in patients without a positive family history leading to higher risk estimates. This explanation, however, is less plausible for acute events such as UAP in which further examination is mostly indicated. On the other hand, the stronger association of family history with UAP may also be a chance-finding or due to residual confounding factors. In summary, no clear explanation can be given for the stronger association of family history with the risk of UAP than of AMI.

Based on our results that the strength of the associations with risk factors differed between the two coronary diseases, it may be suggested to develop separate risk functions for these coronary diseases that may then be combined in the next step to predict the risk of total CHD. However, it is questionable whether the difference in the strength of the associations is large enough to have an impact on risk prediction. Furthermore, making separate formulas for AMI and UAP that are then combined into a risk function for total CHD would result in a decreased power of the analyses as they would be based on a smaller number of cases leading to more uncertainties.

\section{Risk prediction of coronary heart disease}

\section{Methods and considerations in model development}

Several choices have to be made in the development of a risk score for example about the statistical model, the (number of) candidate predictors, and how to deal with missing values. In the development of the CAREMA risk function, Weibull proportional hazards models were used which models the baseline survival function and estimates regression coefficients for the effect of the predictors. An advantage of the parametric Weibull model is that the risk function can be written as a formula (51). Furthermore, risk estimates at the end of follow-up are more stable with parametric models such as the Weibull model than with non-parametric approaches such as the Cox regression model (52). For this reason, a parametric model might be preferable for long-term predictions of disease probabilities (53). On the other hand, parametric models are less flexible according to the shape of the underlying survival function. Nevertheless, Weibull and Cox regression models mostly give similar results if the data follow a 
Weibull distribution $(54,55)$. In this study, we also found no differences between the Weibull and Cox regression model which suggests that the assumptions about the baseline survival function by the Weibull model have not influenced our risk predictions.

Another decision in model development concerns the number of candidate predictors in relation to the number of cases. Many factors have been found to be independent risk factors for $\mathrm{CHD}$ as described before. Although these factors are all candidate predictors, a restriction in the number of predictors should be made to prevent overfitting, especially in small study populations. In the development of the CAREMA risk function, we used a predefined set of predictors based on the factors included in the SCORE risk function. Because of the large sample size including the relative large number of CHD cases, we were able to investigate the inclusion of additional predictors into the prediction model without the risk of overfitting.

Several approaches are available to deal with missing values such as complete or available case analysis, and single and multiple imputation methods. In our analyses, we used the available case approach. Only a limited number of study participants (3.0\%) had a missing value on one or more of the predefined predictors. When we compared the levels of the other predictors between persons with and without a missing value, small differences were found in sex, smoking status, and mean systolic blood pressure between persons with and without a missing value for total/HDL cholesterol ratio. Nevertheless, only very small differences were seen in the regression coefficients of the other predictors between models with and without participants with a missing value of the cholesterol ratio. Therefore, it is very unlikely that the exclusion of participants with missing values on the determinants has influenced our risk predictions.

\section{Endpoint definition}

Several risk functions have been developed in the last decades to estimate the absolute risk of CVD or CHD in time (for a comprehensive overview see table 1, chapter 1). These functions differ amongst other things in their predicted endpoints. The first developed risk functions, such as the Framingham risk score, mostly predict the absolute risk of CHD incidence. As atherosclerosis can also occur in other parts of the body, risk scores developed in the more recent years changed to predict total CVD including cerebrovascular events, peripheral artery disease, and heart failure. In addition to CHD, cerebrovascular diseases, heart failure, and other heart diseases such as arrhythmias also contribute considerably to the mortality and hospital admission rate of CVD (56). Therefore, physicians are probably more interested in the prediction of total CVD than in the prediction of CHD only. However, specific cardiovascular diseases such as $\mathrm{CHD}$ and stroke may differ in their risk factor profile or in the importance of specific risk factors for the disease incidence. As a result, the SCORE risk function consists of separate formulas for $\mathrm{CHD}$ and non-CHD mortality which are then combined to calculate the risk of total CVD mortality. 
The CAREMA risk function, however, is restricted to the prediction of CHD. Our identification of incident CHD cases was largely based on accurate and extensive data from the CIS. Because such data were not completely available for other CVD events such as stroke and heart failure, these events were not yet included in our endpoint definition. Persons at high risk of developing CHD, however, will also have a high risk of developing CVD, while people at very low risk of developing CHD will have at the most a small to modest risk of CVD. However, people at intermediate risk of developing CHD may be in the high-risk category of developing CVD. By using a risk score that only predicts $\mathrm{CHD}$, the advice given to these people may not be the most optimal advice. On the other hand, the endpoint definition in the CAREMA risk function is based on data of high quality as mentioned before. Therefore, risk predictions based on these data will be more accurate than when we would use data from the HDR in combination with mortality data.

Other differences in the endpoint between existing risk scores concerns the inclusion of non-fatal events, although most risk scores predicted the risk of both fatal and nonfatal events (see table 1 , chapter 1 ). Only three risk scores are restricted to the prediction of CVD mortality including the SCORE risk function $(51,57,58)$. An argument given in favour of predicting only fatal events is the more standardised coding and ascertainment of the endpoint within and across countries (59). Nevertheless, studies have shown that substantial differences exist in the validity of the national causes of death registries between countries (60-62). In addition, the contribution of non-fatal events to the total CHD incidence has been growing during the last decades as described in chapter 1 . Non-fatal events are associated with an increasing prevalence of chronic heart diseases, higher health care costs and other economic consequences compared with fatal events. Therefore, the prediction of non-fatal events in addition to fatal events has become more important nowadays.

\section{Medication use}

In clinical practice, risk functions are meant to be used to predict the absolute disease risk in a healthy population without symptoms of the disease. Based on the level of the predicted risk, the general practitioner can decide to recommend lifestyle modifications or drug therapy (63). This implies that persons who already use medications should be excluded from the development of prediction models. In the CAREMA study, only a small proportion of the population reported the use of medications for high blood pressure (4.5\%) and/or high cholesterol level $(0.5 \%)$ at baseline. Nevertheless, part of the study population may have started using medications for high blood pressure or cholesterol levels during the follow period. Because medication use may lead to an underestimation of the predicted risk (64), a sensitivity analysis was performed in which the absolute risk predictions were compared between a model with and without participants who used blood pressure or cholesterol lowering medication at baseline. Using the risk categories $0-<5 \%, 5-<10 \%$, and $\geq 10 \%$, only 20 participants $(0.1 \%)$ moved one category upwards, while 110 participants (0.6\%) moved one category downwards 
when participants who used blood pressure or cholesterol lowering medication at baseline were excluded. These participants, however, had a predicted risk around the boundaries of the categories. Therefore, we expect that the inclusion of participants that used medication at baseline into the prediction model only had a very small influence on the risk predictions.

\section{Methods and considerations in assessing improvement of risk prediction}

The added value of including additional factors into existing risk scores can be assessed by several methods. A method frequently used in the literature is the change in the area under the ROC curve (AUC, equivalent to the $c$ statistic). The fact that the AUC is already high when the traditional risk factors are included in the prediction model limits the ability of additional predictors to improve this estimate (59). Another disadvantage of this estimate is that it only refers to the concordance between pairs (do cases have a higher probability to develop the disease than non-cases) independent of the size of the difference in risk estimates between cases and non-cases (65). The added value of predictors should therefore be evaluated by other estimates in addition to the AUC, for example by the net reclassification index (NRI). Nonetheless, this estimate also has some disadvantages $(66,67)$. Firstly, this estimate depends on the number and the boundaries of the risk categories in which the study population is divided. More subjects will move to another risk category in case of more and smaller categories which may lead to a higher or lower NRI depending on the direction of the movements. Therefore, carefully chosen risk categories with a link to clinical practice should be chosen when using the NRI. Secondly, every movement of a subject to a more appropriate risk category has the same value in the NRI, irrespective of the size of the movement. For example, cases moving from a low to a high risk category add the same value to the NRI as cases moving from a low to an intermediate category. Appropriate changes within risk categories are also not counted, though these as well depend on the width of the chosen risk categories. In case of very broad categories, for example, subjects moving from the lower to the upper boundary are not taken into account in the NRI.

In prospective studies with a long follow-up period, there will be participants with an incomplete follow-up (censored). These participants are mostly excluded from the calculation of the NRI. Recently, Steyerberg et al. introduced an alternative method using the Kaplan-Meier estimate so that subjects with incomplete follow-up can be included in the calculation of the NRI (68). We used this method, and found that risk prediction was not improved by including parental history of MI. However, when we excluded subjects who were censored within 10 years of follow-up, including parental history of $\mathrm{Ml}$ into the prediction model did result in a significant reclassification of subjects. This shows that exclusion of subjects with incomplete follow-up should be done with caution when calculating the NRI as this may bias the results. 


\section{Validation}

It is well-known that prediction models perform at best in populations in which they were developed $(65,69)$. Therefore, it is important to validate the prediction model internally to assess its performance within the study population as well as externally to assess its performance in other populations.

\section{Internal validation}

Several methods exist for the internal validation of prediction models such as split-half validation, cross-validation, and bootstrap validation. These methods can be used to quantify the over-optimism of the prediction model which is the difference between the true performance in the underlying population and the apparent performance in the derivation population $(70,71)$. Internal validation is especially important in small datasets with a low number of cases and many possible predictors leading to more uncertainty in the model development. In the CAREMA study, a large sample size including a large number of CHD cases was available for the development of the risk function. Furthermore, we used a predefined set of candidate predictors instead of testing all possible predictors. The large number of cases and the limited number of predictors included into the model resulted in a very favourable ratio of events per predictor, because of which overfitting and over-optimism is less likely $(65,72)$. Therefore, internal validation of the CAREMA risk function was not considered indicated. Nevertheless, risk scores will still perform better in internal validation cohorts (from the above described validation methods) because these cohorts are similar in the prevalence of risk factors, incidence rates of the disease and the definition and measurement of the endpoint as the derivation cohort.

\section{External validation}

Before use in practice, prediction models should be externally validated to evaluate their performance in other populations than the derivation cohort. Physicians want to know whether the risk function is applicable to their own population. Validation studies have been performed for the Framingham and SCORE risk functions and to a lesser extent for other risk functions such as the QRISK and PROCAM functions (table 1). Overall, these studies found that the existing risk scores performed quite well in populations comparable to the derivation population. Their performance in other populations was however more limited which could be explained, amongst other things, by differences in risk factor prevalences and disease incidence. The poor performance of risk scores in these populations may be solved by recalibration of the scores using national data on risk factor levels and incidence rates of the disease, as described by Conroy et al. (51). Although this is a useful solution, it is better to recalibrate a risk score using individual data as is done in this thesis for the SCORE risk function instead of such ecological data, because individual data makes it possible to link the risk factor level to the disease status in every person. Nevertheless, the next step must be the 
external validation of the CAREMA risk function to assess its performance in other (Dutch) study populations.

Several issues that may reduce the performance of the CAREMA risk function have to be considered when externally validating it in the general Dutch and other European populations. As mentioned before, the endpoint definition in our study is largely based on accurate and extensive data from the CIS. Such cardiology registries are mostly not available, and therefore, most validation studies will use hospital discharge and mortality registries for their case identification. The results described in chapter 2 showed that the incidence rate of $\mathrm{CHD}$ based on these registries was lower than the incidence rate from the CIS-based registry, because some cases were missed or miscoded in the HDR. Due to this incomplete and relatively inaccurate case identification, the CAREMA risk function will seem to overestimate the absolute CHD risk in studies that use hospital discharge and mortality data for their case identification.

Additionally, regional differences in CHD incidence within the Netherlands may affect the performance of the CAREMA risk function in other Dutch populations. In the Maastricht region, the hospital admission rate for CHD is lower compared with the Dutch average while the mortality rate is higher $(4,5)$. If this is a true difference, it may be necessary to recalibrate our risk function to the general Dutch population. The CAREMA study population originates from two monitoring projects that are also carried out in two other Dutch cities, i.e. Doetinchem and Amsterdam. Although we only had extensive clinical data available for Maastricht, linkage to the causes of death registry and national HDR was available for all three cities. When we compared the three cities with each other, the number of participants who developed a fatal or nonfatal CHD event was found to be similar in the populations from Maastricht (5\%), Doetinchem (5\%), and Amsterdam (6\%). Furthermore, regional differences in prevalence and levels of risk factors may also affect the performance of the CAREMA function in the Dutch population. However, only very small differences in risk factor levels were found when the baseline characteristics from the Doetinchem and Amsterdam cohort were compared with those from the CAREMA population in 1987-1991. In Maastricht, the percentage of smokers (42\%) was slightly higher than in Amsterdam (41\%) and Doetinchem (36\%), while the mean systolic blood pressure was slightly lower (119 $\mathrm{mmHg}$ in Maastricht versus 120 and $122 \mathrm{mmHg}$ in Amsterdam and Doetinchem, respectively). In the MORGEN project (1993-1997), the baseline characteristics of the CAREMA population were also comparable to those from the Amsterdam and Doetinchem cohort. Because no large differences were found between the CAREMA study population and these other Dutch populations, it is to be expected that the performance of the CAREMA risk function in the Dutch population will hardly be affected by differences in risk factor levels. 


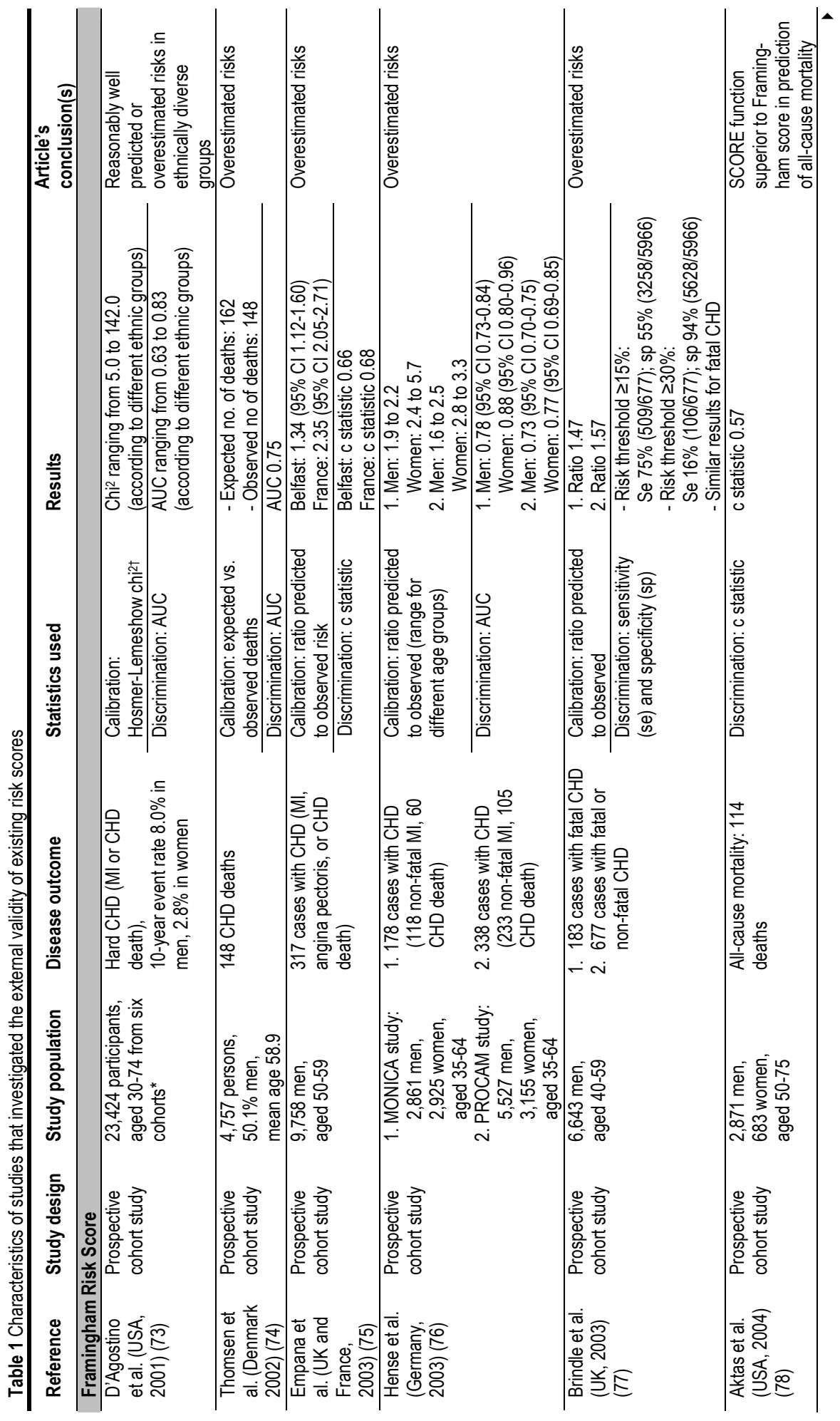




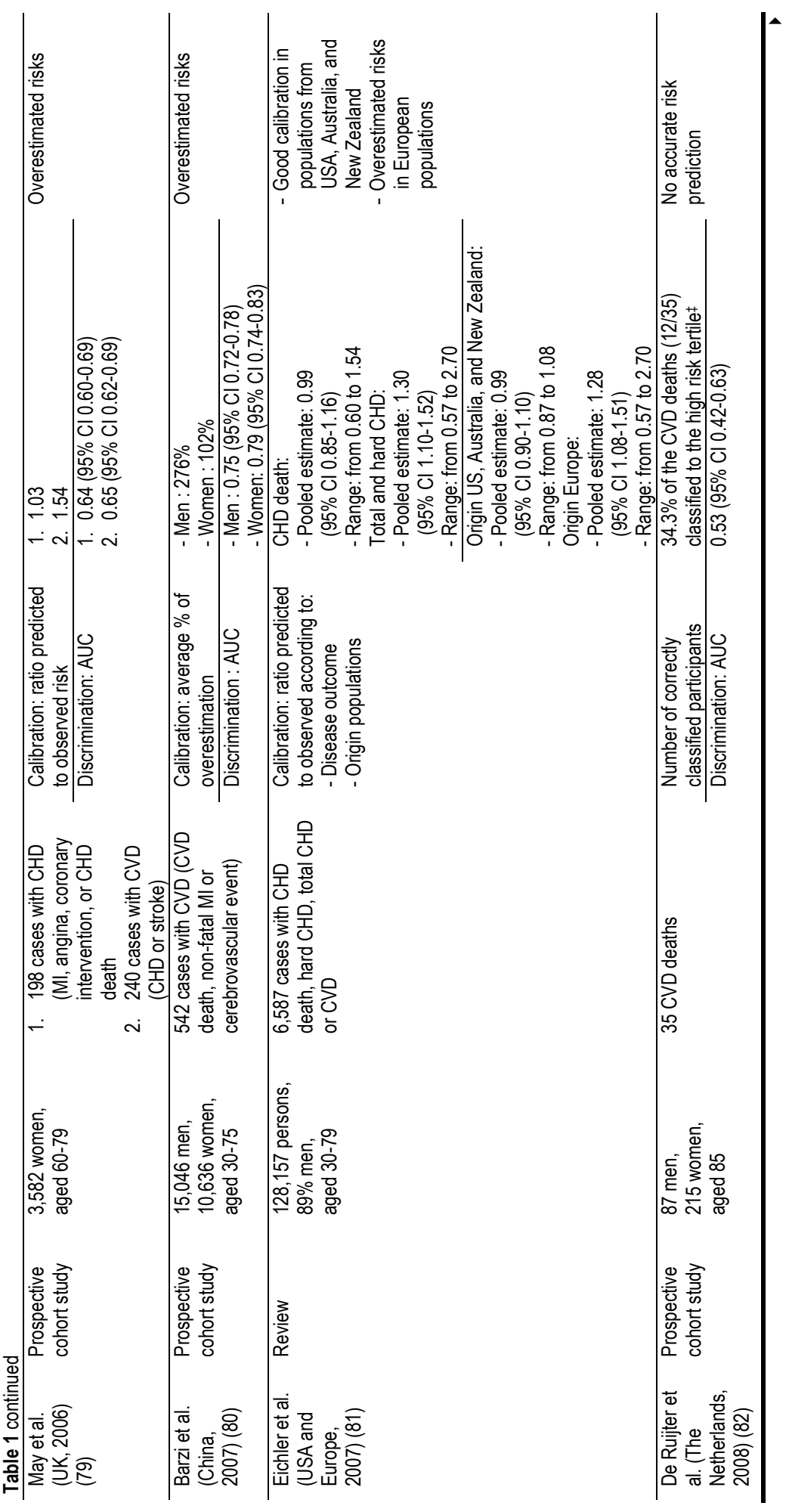




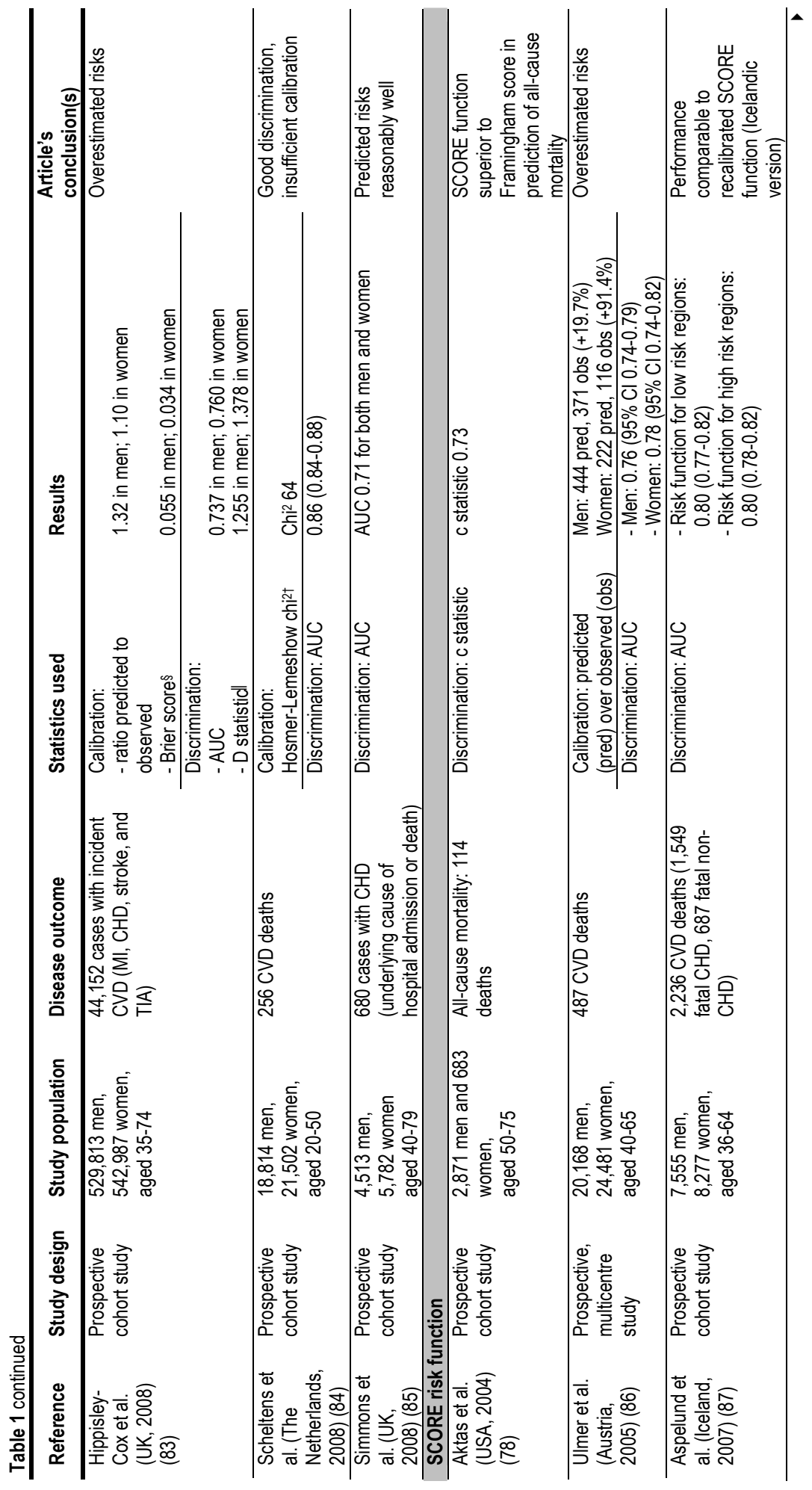




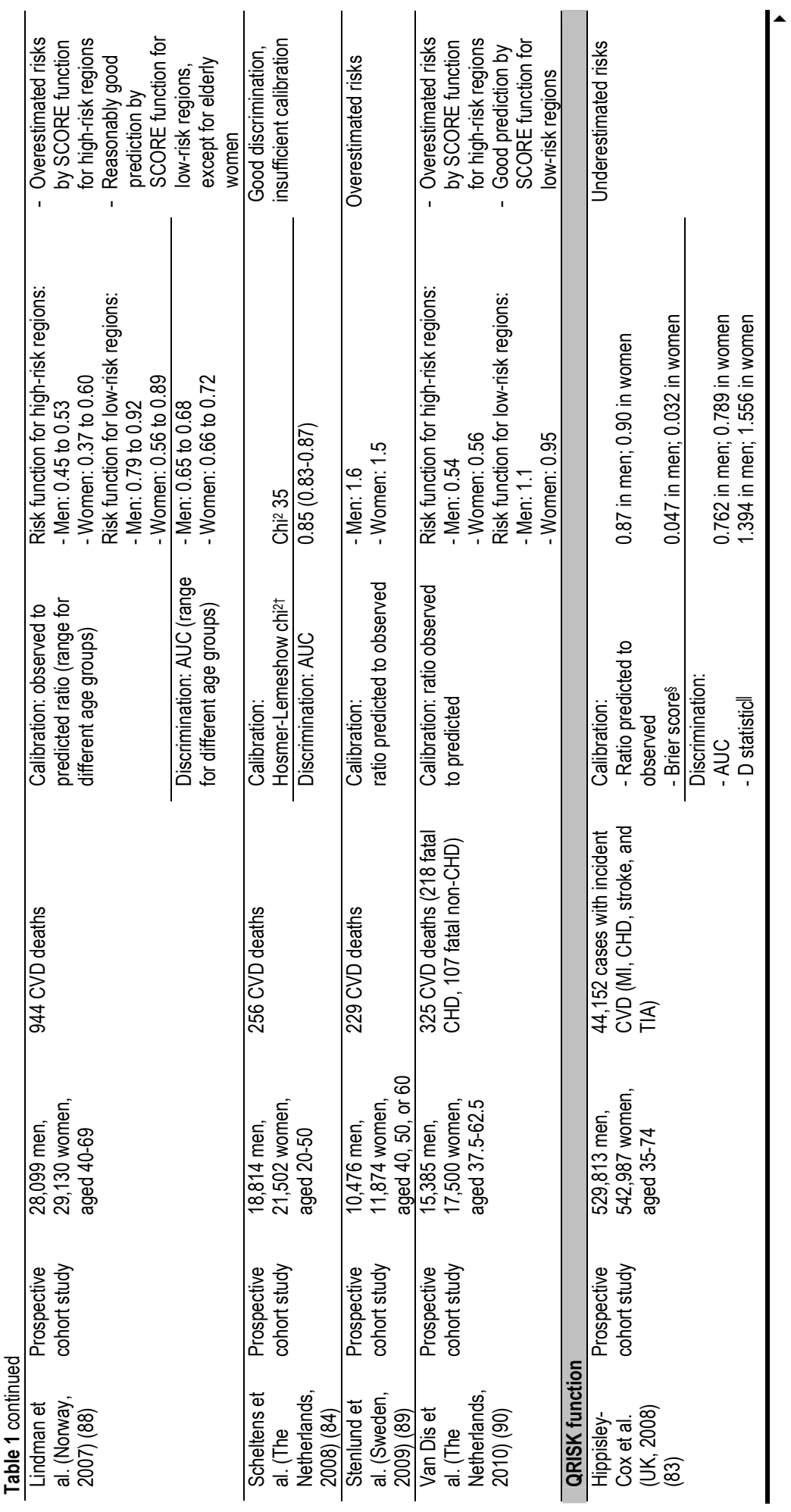




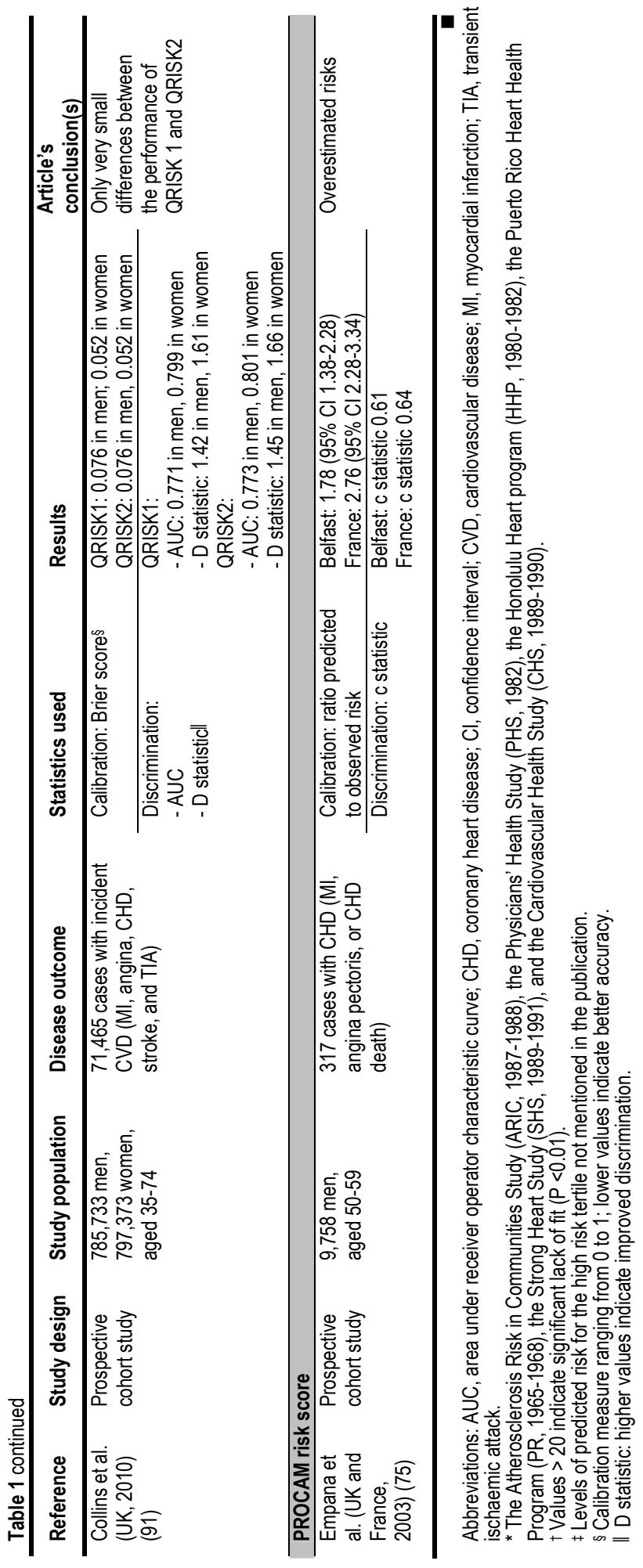


Besides geographical considerations, the performance of the CAREMA risk function may also be affected by temporal changes. During the study period 1987-2003, the mortality from CHD has declined in the Netherlands (6). This trend is partly due to a decreased case-fatality rate of CHD caused by a better treatment and care of patients. The contribution of fatal cases to the CHD incidence in our study is, however, considerably smaller than that from non-fatal cases. About $30 \%$ of the cases with CHD as primary or secondary cause of death according to the causes of death registry were also registered with $\mathrm{CHD}$ in the $\mathrm{CIS}$, while $10 \%$ of the $\mathrm{CHD}$ cases were only found in the causes of death registry. Because of this, the influence of the declining trend in CHD mortality may be limited. On the other hand, an increasing trend was seen in the use of blood pressure and cholesterol lowering medications during the study period, as discussed before. In current populations, the percentage of participants using blood pressure or cholesterol lowering medications will be higher than in the CAREMA study population. As a result of these temporal changes, the CAREMA risk function may overestimate the 10-year absolute risk of CHD nowadays. However, the exact impact of all these changes should be evaluated in a validation study.

\section{Comparison with existing risk scores}

The traditional risk factors of CHD such as age, smoking, systolic blood pressure, and cholesterol levels were included in almost all of the existing risk scores including the CAREMA risk score. Furthermore, most risk scores were developed in both men and women using sex as predictor or generating separate baseline survival functions and/or regression coefficients for men and women (strata). However, the scores differ in the manner in which they included some of the predictors. Cholesterol levels were mostly included only as the total cholesterol level, while some other risk scores also added HDL cholesterol or used the total/HDL cholesterol ratio. The results of our study have shown that using total and HDL cholesterol separately instead of the total/HDL cholesterol ratio significantly improved risk prediction of incident CHD. This may be explained by the fact that unfavourable levels of each of these factors are now taken in to account individually, while a high cholesterol ratio may be due to a high total, a low HDL cholesterol level or a combination of these levels.

Smoking was mostly included as a yes/no variable according to the (current) smoking status, while some studies used the number of cigarettes smoked per day (92-95). We found no improved risk prediction by including an extra category for ex-smoking, including time since smoking cessation, or adding the number of cigarettes per day, as was also found in two other risk scores $(94,96)$. This may be explained by the rapid decline in CHD risk after smoking cessation independent of the amount or duration of smoking $(23,24)$, which suggests that the status is more important for the CHD risk than the number of cigarettes smoked or years of smoking.

BMI was evaluated in the development of almost all risk scores, but was actually included in only a few scores (97-100). We also found no added value for BMI, regardless whether BMI was included continuously or when using the WHO categories. As it is 
hypothesized that the effect of BMI on the CHD risk is mediated by its effect on other metabolic factors such as diabetes, cholesterol and blood pressure levels, the added value of BMI may be limited when these factors are already included in the prediction model. This may also be true for the added value of physical activity to risk prediction. Only two studies evaluated this factor as a potential predictor, but only the ARIC study found an added value of physical activity $(101,102)$. In our study, physical activity showed no added value to the risk prediction of CHD incidence.

Diabetes was a strong risk factor for CHD but did not improve risk prediction in the CAREMA cohort study. In the study population, only $0.9 \%$ of the participants reported to have diabetes at baseline. Nevertheless, they were responsible for $3.8 \%$ of the CHD cases. The prevalence of diabetes in the study population was probably too low to have a significant impact on risk prediction. Several risk scores which did include diabetes had somewhat higher prevalences of diabetes in their derivation population, ranging from $1.4 \%$ to $7 \%$. Furthermore, they mostly included diabetes in the prediction model as predefined predictor or based on its significance in multivariable analyses. Persons with diabetes were even excluded in the development of two other risk scores $(98,103)$. In the Dutch guideline on cardiovascular risk management, it is stated that the estimation of the 10-year absolute risk is not necessary in persons with diabetes as these persons are already at increased risk of developing CVD (63). As already special care is given to patients with diabetes in the Netherlands, including this factor in the prediction model would not be necessary regarding prevention strategies to reduce the CHD risk.

Another risk factor for CHD is a positive family history of CHD but it is included in only part of the existing risk scores (94, 98-101, 103-107). We did not find an added value of including parental history of $\mathrm{MI}$, regardless of the definition we used (only yes/no, the number of parents affected, and/or the age at diagnosis of the parents). Nevertheless, $2.8 \%$ of the participants were reclassified to a more appropriate risk category when parental history of $\mathrm{Ml}$ was added as a yes/no variable to the prediction model $(p=0.15)$. Therefore, including family history into risk scores may be useful and its effect may even become stronger when this factor includes both parental and sibling history. In the Dutch guideline, a positive family history is also taken into account in the recommendations on the preventive strategy. Young individuals ( $<50$ years) or persons at intermediate risk $(<10 \%)$ with a positive family history of premature CVD ( $<60$ years in a parent or sibling) are still candidates for drug therapy according to the guideline (63).

Several other risk factors of CHD (table 2) have been evaluated whether they improve risk prediction, such as inflammatory markers (C-reactive protein), hemostatic factors, and atherosclerotic markers. Because we had no information about such factors in the CAREMA study, we were not able to investigate their additional value to risk prediction. Based on the results of the previous studies (table 2), however, it can be expected that these factors would not improve our risk prediction model or only to a very limited extent. Although many risk factors of CHD seem to have the potential to improve 
risk prediction, most factors do not have an additional value when the traditional factors are already included in the prediction model as assessed by the discriminative ability (AUC or c statistic) (108). Furthermore, we have to keep in mind that more not always means better. A very extensive risk prediction model including a large number of predictors would limit its use in practice. Such a model would be very time consuming and expensive because every predictor has to be measured before a physician is able to estimate the predicted risk (59). Therefore, the choice of adding predictors to existing risk score models should be well-considered taking into account the consequences and should therefore only be done when they have a significant added value to risk prediction. 


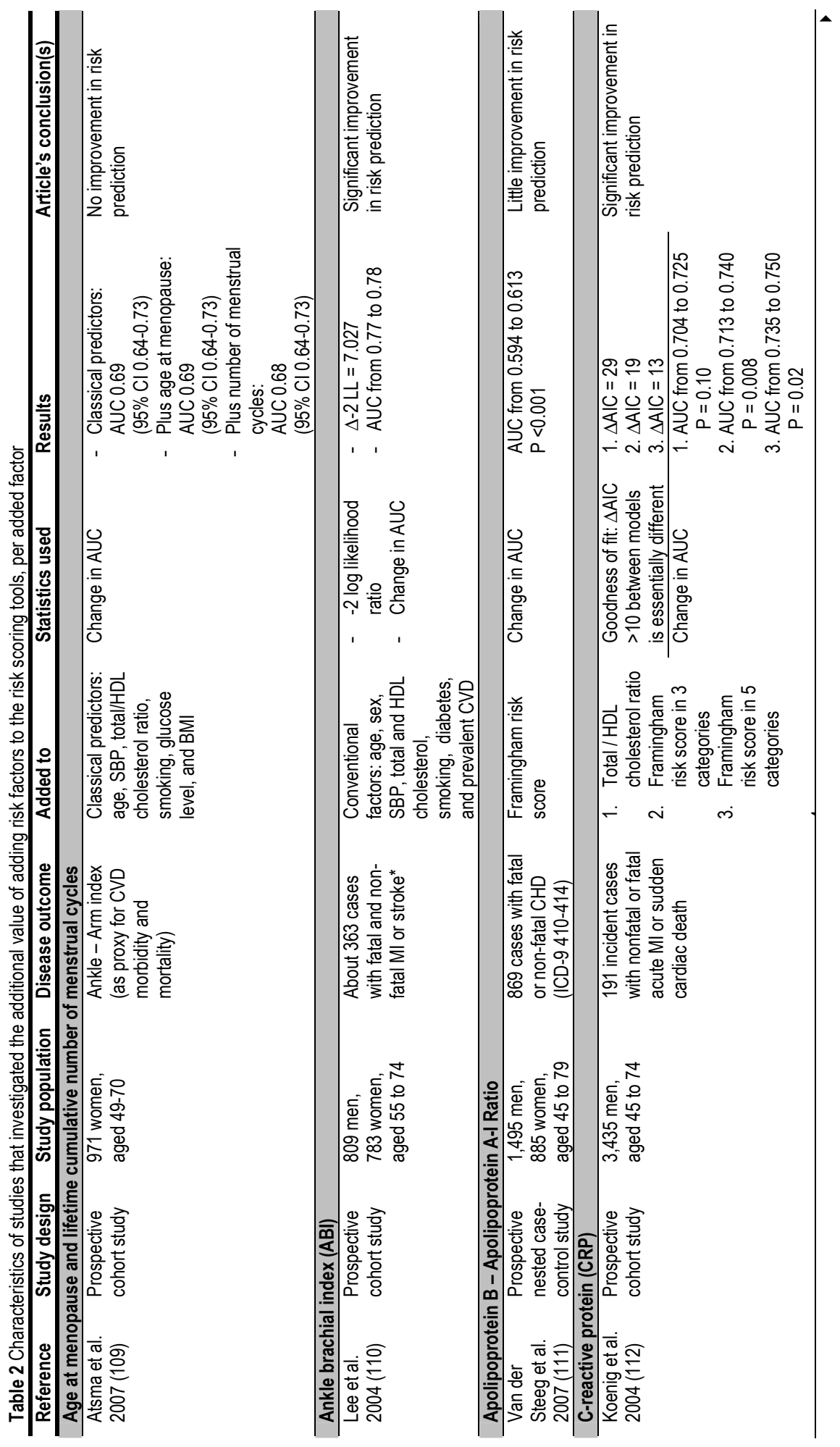




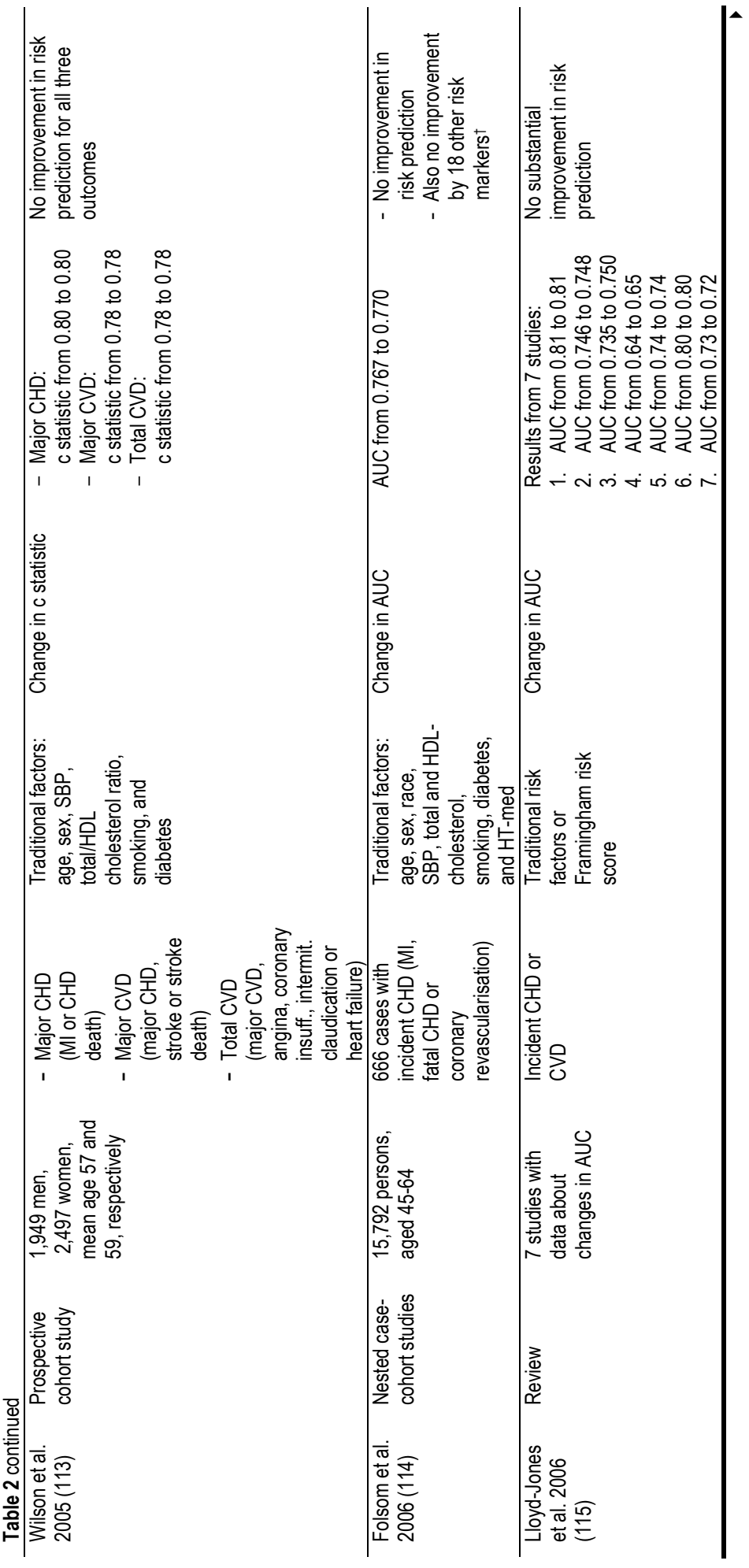




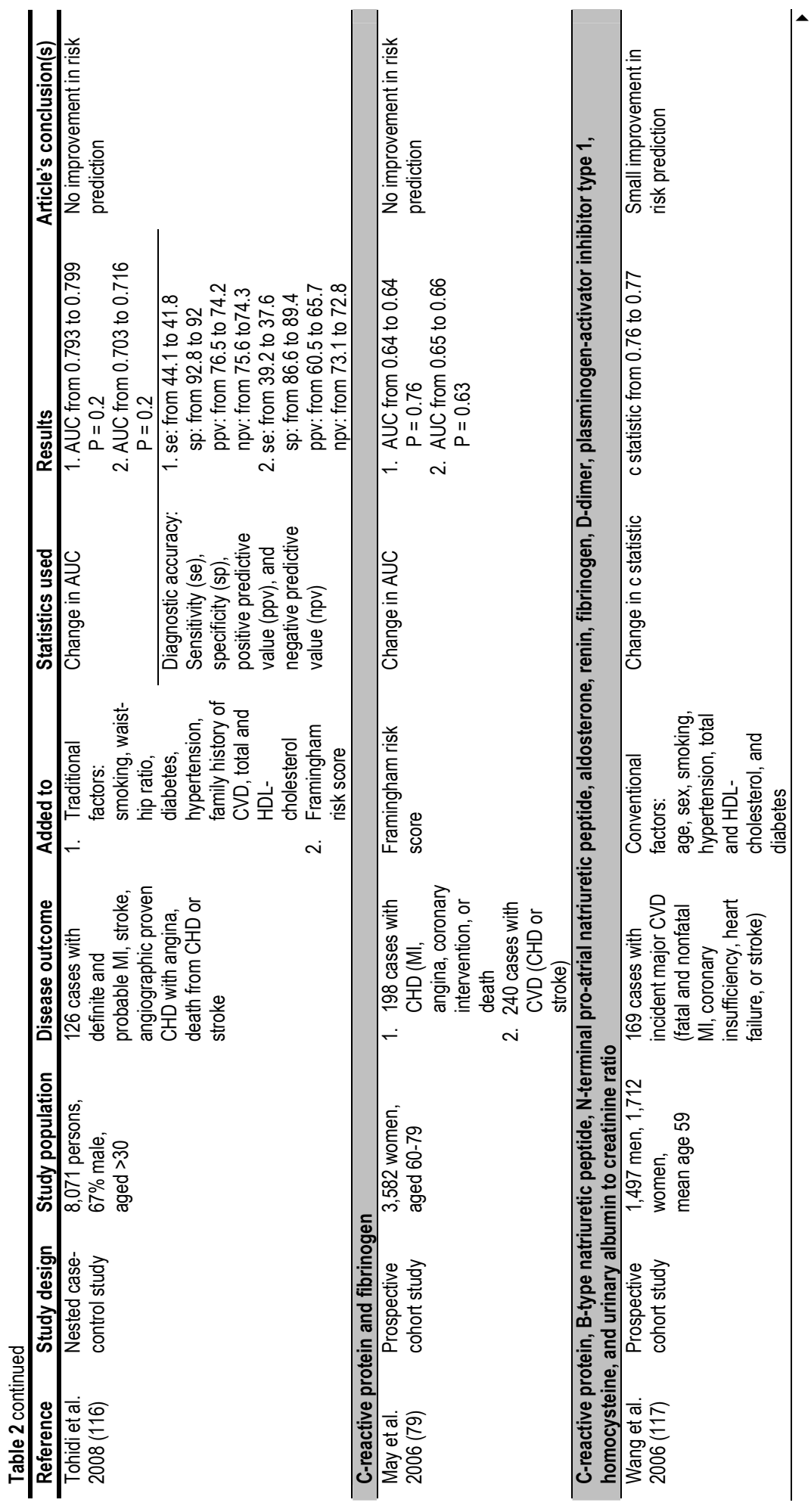




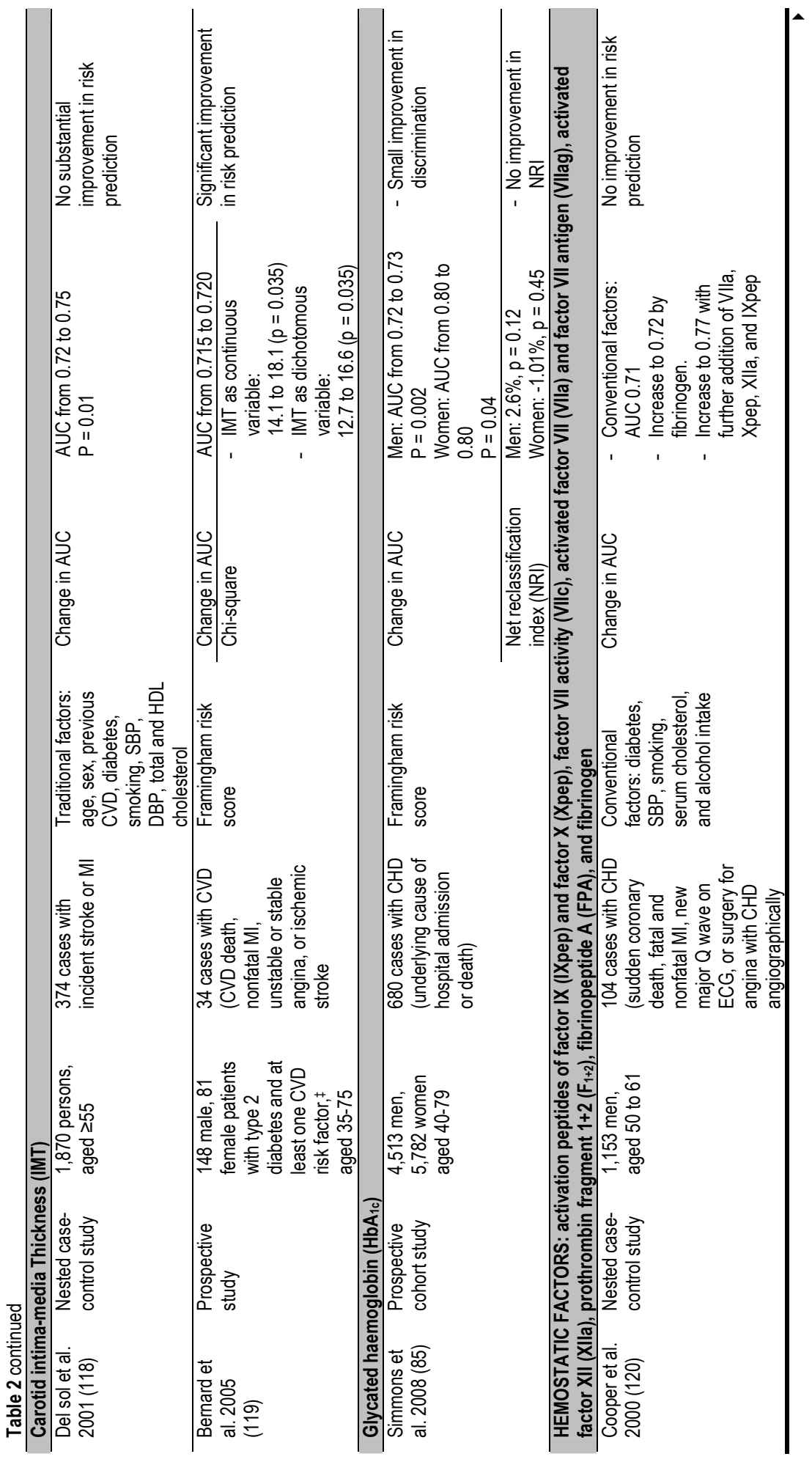




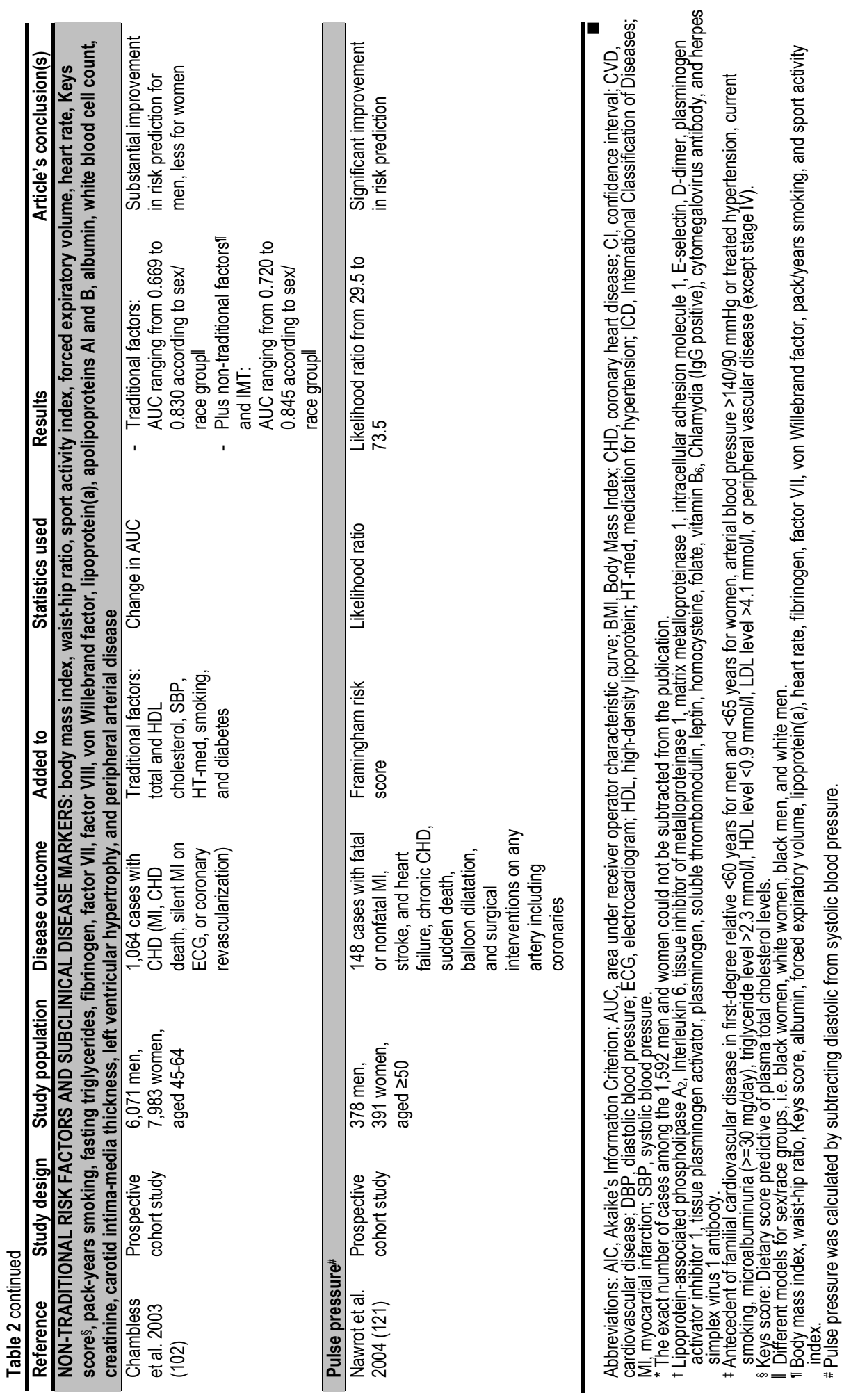




\section{Considerations about use in practice}

In practice, the goal of risk prediction is to identify individuals at high risk of developing CVD or CHD who can then be provided with strategies to reduce their risk. In the Dutch guideline, the SCORE risk tables, recalibrated to the Dutch situation using aggregate data, are used to predict the 10-year risk of fatal CVD. As physicians are also interested in the prediction of non-fatal events, modified risk tables for both mortality and morbidity are presented in an appendix of the Dutch guideline (63). These risk estimates for CVD morbidity are calculated using a conversion rate from mortality to morbidity based on assumptions about life expectancy and chances to develop first and subsequent CVD events. To my knowledge, no information is available about the accuracy of these estimates. As these estimates are subject to two modifications (recalibration of the SCORE risk tables and conversion to predict both mortality and morbidity), there may be a substantial bias in the predicted risk. For clinical practice, this is especially problematic at the boundaries of the risk categories as persons may be categorised to another risk category than where they belong to. Therefore, it should be better to use data from prospective studies in which the disease risk can be calculated using actual data to estimate the predicted risks of morbidity and mortality as is done in the CAREMA cohort study for CHD.

Switching from mortality to morbidity also has consequences for the cut-off points for intervention. In the current Dutch guideline, persons with a risk between $5 \%$ and $10 \%$ of dying from CVD within the next ten years are eligible for lifestyle modifications, while drug treatment is recommended in case of a $\geq 10 \%$ risk (63). The cut-off point for pharmaceutical treatment is based on a cost-effectiveness evaluation taking into account the health care capacity (63). Taking the same aspects into consideration, these cut-off points should be considerably higher for CVD incidence. In a previous Dutch guideline on hypercholesterolemia, the recommended threshold for drug treatment was a $20 \%$ risk of fatal and non-fatal CVD within the next ten years, which corresponds to the threshold of $10 \%$ for CVD mortality in the current guideline (63). The European task force also recommended that a $20 \% 10$-year risk of CHD incidence (fatal and nonfatal events) should be the threshold for drug treatment (122). Several aspects must be taken into account when determining these cut-off points such as the number needed to treat, side effects of treatment, health care costs and capacity, and the danger of overtreatment (90).

The existing risk scores including the CAREMA risk score are meant to be used in a healthy population without symptoms or even prevalent CHD. Every person that visits the general practitioner can be eligible for the determination of the absolute 10-year CVD risk. Symptoms, a positive family history, visible overweight, or specific request from the patient may trigger the general practitioner to assess his or her smoking behaviour, systolic blood pressure, and cholesterol levels (63). In addition, the Dutch guideline states that calculation of the predicted risk is indicated in persons who have elevated risk factors, i.e. persons with a systolic blood pressure $\geq 140 \mathrm{mmHg}$, or total cholesterol level of $\geq 4.5 \mathrm{mmol} / \mathrm{L}$, or male smokers $\geq 50$ years, or female smokers $\geq 55$ 
years. Based on the level of the predicted 10-year risk, the general practitioner can decide that the person is eligible for lifestyle intervention or medication as described above. This suggests that risk prediction is not indicated in persons who already use blood pressure or cholesterol lowering medications. Nevertheless, Smulders et al. stated that the blood pressure and cholesterol values presented in the risk tables are also appropriate for persons using these medications (63). Therefore, determination of the absolute risk is also indicated in persons using these medications.

In addition to these practical considerations, prediction models are only useful when they are actually used in clinical practice and when the recommendations according to the predicted risk are followed and lead to the prevention of events. Although Dutch general practitioners recognize the usefulness of the national guidelines, it has been reported that they use them only to a certain extent or even not at all in clinical practice (123). A possible explanation may be a lack of time and facilities to implement the guidelines in the right way. By keeping prediction models as simple as possible, it will take less time to calculate the predicted risk. Some studies investigated whether simple prediction models based on data that are easy to assess are as accurate as more complicated models. Mainous et al. compared the performance of a model based on patient self-reported data with that of the Framingham and SCORE risk functions (124). In men, a model based on age, self-reported diabetes, history of hypertension, history of hypercholesterolemia, smoking, physical activity, and parental history of $\mathrm{Ml}<50$ years performed significantly poorer than the Framingham score but similar as the SCORE function in the prediction of CHD. In women, the same set of variables with BMI instead of physical activity and family history performed similar to the Framingham score but better than the SCORE function (124). However, the performance of the SCORE function may be underestimated in this study as they used this model for CHD incidence instead of CVD mortality. In addition, two studies evaluated whether a nonlaboratory-based model with BMI instead of cholesterol levels performed as well as a laboratory-based model using cholesterol levels $(125,126)$. Gaziano et al. (125) found no differences between the performances of the two models in the prediction of CVD, while the laboratory-based model performed significantly better than the nonlaboratory model in the study by D'Agostino et al. (126). All these studies generated risk functions using predictors that can easily be measured by the physician in only one visit. Although there seems to be a potential for such simplified prediction models, their performance has to be externally validated as well.

\section{Risk prediction in younger adults}

Younger adults (aged $\leq 50$ years) are almost never at increased risk within 10 years according to the existing risk scores, including the CAREMA risk score, even when they have very unfavourable levels of CHD risk factors. Nevertheless, they may be at increased risk of developing CHD later in life. As a result, several approaches have been suggested for risk stratification in younger persons such as the life time risk, risk at age 60 , and relative risk. Both the life time risk and risk at age 60 extrapolates the absolute 
risk to the age 60 or the expected lifetime based on the current risk factor levels of the person $(127,128)$. The relative risk calculates how many times the absolute risk of the person is higher compared with an individual of the same age but with optimal levels of the risk factors (129). Some studies have found that persons with low short-term risks (10 years) may have considerable life time risks according to the level of their risk factors $(130,131)$. In addition, a higher life time risk or risk at age 60 in young adults has been associated with higher levels of subclinical atherosclerosis like the carotid intima-media thickness, coronary artery calcium, or pulse wave velocity $(131,132)$. According to the study by Stamatelopoulos et al., the pattern of the association between risk at age 60 and surrogate CVD markers was similar in young adults (<40 years) and older adults (40-60 years) (132).

As the development of CHD starts already early in life, prevention should start as early as possible. The above-mentioned approaches seem to have the potential to identify persons already at young age who are at increased risk of developing CHD later in life. Consequently, a large number of relatively young people would be eligible for drug treatment according to such approaches (63) introducing the risk of overtreatment. As the long-term use of medications may also have considerable side-effects, early prevention by drug treatment should only be recommended if it indeed results in a better prognosis. Therefore, future studies should focus on the benefit of early prevention in young adults who are at increased risk of developing CHD as assessed by strategies like the life time risk or relative risk. Nevertheless, these approaches can be helpful in the risk communication to young persons with a very unfavourable risk profile as the high life time or relative risk may motivate them for lifestyle interventions.

\section{Risk prediction in the elderly}

The existing risk scores were mostly developed in middle-aged populations in which the maximum age ranged from 59 to 75 years at baseline. In these populations, elderly persons ( $\geq 70$ years) were mostly underrepresented or not included at all. As a result, the risk estimates based on these scores may be unreliable for elderly persons. Studies have shown that the performance of existing risk scores was indeed lower in older populations $(82,133)$. This may be explained by the fact that risk factors are associated with lower relative risks at older age, counterbalanced however by higher absolute risks $(134,135)$. The beta coefficients of the existing risk scores are therefore less suitable for the elderly compared with middle-aged populations (59). Therefore, Houterman et al. developed a risk function to predict CHD and CVD mortality in elderly men (aged 65-84 years) from Finland, Italy, and the Netherlands (136). This risk function consisted of most classical risk factors that are also included in the risk scores for middle-aged persons. Although this approach may improve risk prediction in the elderly, such risk functions developed in the elderly first have to be externally validated in other populations before they can be used in clinical practice.

Based on the existing risk scores, elderly persons are almost always at increased risk of CHD because of their age. When the same cut-off points for intervention are used in 
this population, a very large proportion would be eligible for drug treatment leading to medicalisation (63). Therefore, the Dutch guideline recommends that the level of risk factors, general health, life expectancy, and a persons own wishes should be taken into account when deciding on drug treatment for primary prevention in the elderly (63). Another point that should be considered in deciding on drug treatment for primary CHD prevention in the elderly is that these persons often use already a considerable number of medications. Adding more drugs may increase the risk of incorrect use or of dangerous interactions between medications.

\section{Presentation of risk scores}

Several formats can be used to present the predicted absolute risks in an attractive manner such as coloured risk charts, scoring sheets, and website-based calculators. In the Dutch guideline, the SCORE risk function is presented using colour-coded risk charts. These charts are very useful for risk communication as physicians can easily show what the patient's risk is of dying from CVD within the next ten years based on the current levels of risk factors and what this risk can be when these levels change. However, a disadvantage of these charts is that the risk cannot be determined when the level of one or more risk factors outranges the values presented in the risk charts. Furthermore, these charts are suitable for the current number of predictors in the SCORE risk function, but become inefficient when one or more predictors are added. Both the SCORE project (137) as the CAREMA cohort study have found that risk prediction by the SCORE risk function can be improved when the cholesterol ratio is separated in total and HDL cholesterol levels. Because of this extra dimension, the coloured risk chart becomes unusable. Other formats should be considered that include all the information in a useful and illustrative manner. For example, a computer-based programme that can easily be filled in by the general practitioner and that shows the predicted absolute risk based on the current risk factor levels of the patient and after changing one or more risk factor levels.

In current practice in the Netherlands, risk prediction and communication is performed by the general practitioner. An advantage of this approach is that the prevention strategy is applied in a controlled manner by a skilled general practitioner and that immediate action can be undertaken. A disadvantage is, however, that only persons who visit their general practitioner are eligible for risk prediction. An approach to overcome this restriction may be a web-based risk calculator that can be used by the person itself. Although this is an easy and relatively cheap option, it may be doubtful whether the target population is reached by such an approach. Self-management tests are mostly used by people who are concerned about their own health and are more likely to have a healthy lifestyle $(138,139)$. Persons with high risk factor levels who know that they are at increased risk of developing CHD may show evasive behaviour of using such tests. Another disadvantage of a web-based approach is that people do not always know their risk factor levels that are needed to calculate the predicted risk. These missing values will lead to more uncertainty in the risk estimates. Furthermore, it can 
be discussed whether people are able to interpret the results of such self-tests correctly (140). Taking these issues into consideration, the application by the general practitioner is probably the best option, at least for now.

\section{Recommendations for future research}

In this thesis, a risk score has been developed that estimates the absolute risk of an individual to develop CHD within the next ten years. As mentioned before in this chapter, the performance of this score may be limited in other settings due to differences in prevalences and levels of risk factors and in disease rates. Therefore, validation studies should be carried out to assess the performance of the CAREMA risk function in other (Dutch) populations. In these studies, incident CHD cases should be identified using an extensive and accurate method as was done in our study.

Because the CAREMA risk function is limited to the prediction of incident CHD, future prospective studies should also focus on developing risk scores that predict the incidence of other cardiovascular diseases such as stroke. For these diseases, other risk factors may be more relevant for risk prediction than for CHD. The identification of incident cases should be as complete as possible, including both fatal and non-fatal cases. Furthermore, the use of specific cardiovascular disease registries would be preferred in the case identification over the use of more general registries such as the HDR. In the next step, it can be investigated in which way these risk scores for other cardiovascular diseases can be combined with risk scores for CHD incidence such as the CAREMA risk function to be able to predict the absolute risk of total CVD.

In the development of risk scores, special attention may be given to the prediction in younger adults and the elderly. In these groups, other risk factors may be more important compared with a middle-aged population. Therefore, future studies should also focus on an improvement of risk prediction in younger adults and elderly.

Risk scores have been found to be useful for identifying high-risk individuals in the primary prevention of CVD or CHD. Nevertheless, they will only be effective if 1 ) they are actually used in general practice and result in more recommendations on lifestyle or drug treatment, 2) if the advice given by the general practitioner is followed by the individual resulting in a better risk profile, and 3 ) if these changes indeed result in a lower CHD incidence over time. Therefore, we recommend performing an intervention study in which these aspects are evaluated. This study may consist of a short-term evaluation regarding the actual use and recommendations and of a long-term evaluation regarding the effect on risk factor changes and disease incidence over time. 


\section{References}

1. Reitsma JB, Kardaun JW, Gevers E, de Bruin A, van der Wal J, Bonsel GJ. [Possibilities for anonymous follow-up studies of patients in Dutch national medical registrations using the Municipal Population Register: a pilot study]. Ned Tijdschr Geneeskd. 2003 Nov 15;147(46):2286-90.

2. Harteloh P, de Bruin K, Kardaun J. The reliability of cause-of-death coding in The Netherlands. Eur J Epidemiol. 2010 Mar 23.

3. Alpert JS, Thygesen K, Antman E, Bassand JP. Myocardial infarction redefined--a consensus document of The Joint European Society of Cardiology/American College of Cardiology Committee for the redefinition of myocardial infarction. J Am Coll Cardiol. 2000 Sep;36(3):959-69.

4. Roedig A. Acuut hartinfarct 2001-2004. Ziekenhuisopnamen, per GGD-regio, gecorrigeerd voor leeftijd en geslacht. The National Public Health Compass 2006 [cited 2010 May 12]. Available from: http://www.rivm.nl/vtv/object_map/o1626n25675.html

5. Zwakhals SLN, Giesbers H, Deuning CM. Sterfte aan coronaire hartziekten 2005-2008. Per GGD-regio, gecorrigeerd voor leeftijd en geslacht. The National Public Health Compass 2010 [cited 2010 May 12]. Available from: http://www.rivm.nl/vtv/object_map/o3276n21683.html

6. Feskens EJM, Merry AHH, Deckers JW, M.J.J.C. P. Coronaire hartziekten. Neemt het aantal mensen met een coronaire hartziekte toe of af? The National Public Health Compass 2006 [cited 2010 May 5]. Available from: http://www.nationaalkompas.nl/gezondheid-en-ziekte/ziekten-enaandoeningen/hartvaatstelsel/coronaire-hartziekten/trend/

7. Ford ES, Zhao G, Li C. Pre-diabetes and the risk for cardiovascular disease: a systematic review of the evidence. J Am Coll Cardiol. Mar 30;55(13):1310-7.

8. World Health Organization. Definition, diagnosis and classification of diabetes mellitus and its complications. Report of a WHO Consultation. Part 1: diagnosis and classification of diabetes mellitus. Geneva; 1999.

9. Verschuren WMM, Leent-Loenen HMJA. Bloeddruk. Neemt het aantal mensen met een verhoogde bloeddruk toe of af? The National Public Health Compass 2008 [cited 2010 May 16]. Available from: http://www.nationaalkompas.nl/gezondheidsdeterminanten/persoonsgebonden/bloeddruk/trend/

10. Verschuren WMM. Serumcholesterol. Neemt het aantal mensen met een ongunstig cholesterol toe of af? The National Public Health Compass 2008 [cited 2010 May 16]. Available from: http://www.nationaalkompas.nl/gezondheidsdeterminanten/persoonsgebonden/serumcholesterol/tre nd/

11. Houterman S, Verschuren WM, Oomen CM, Boersma-Cobbaert CM, Kromhout D. Trends in total and high density lipoprotein cholesterol and their determinants in The Netherlands between 1993 and 1997. Int J Epidemiol. 2001 Oct;30(5):1063-70.

12. Liu J, Grundy SM, Wang W, Smith SC, Jr., Vega GL, Wu Z, et al. Ten-year risk of cardiovascular incidence related to diabetes, prediabetes, and the metabolic syndrome. Am Heart J. 2007 Apr;153(4):552-8.

13. Saito I, Iso H, Kokubo $\mathrm{Y}$, Inoue M, Tsugane S. Metabolic syndrome and all-cause and cardiovascular disease mortality: Japan Public Health Center-based Prospective (JPHC) Study. Circ J. 2009 May;73(5):878-84.

14. Bakel AM, Zantinge EM. Lichaamsgewicht. Neemt het aantal mensen met overgewicht of ondergewicht toe of af? The National Public Health Compass 2010 [cited 2010 May 16]. Available from: http://www.nationaalkompas.nl/gezondheidsdeterminanten/persoonsgebonden/lichaamsgewicht/tre nd/

15. Schuit AJ, Wendel-Vos GC, Verschuren WM, Ronckers ET, Ament A, Van Assema P, et al. Effect of 5-year community intervention Hartslag Limburg on cardiovascular risk factors. Am J Prev Med. 2006 Mar;30(3):237-42.

16. Aizawa Y, Kamimura N, Watanabe H, Aizawa Y, Makiyama Y, Usuda Y, et al. Cardiovascular risk factors are really linked in the metabolic syndrome: this phenomenon suggests clustering rather than coincidence. Int J Cardiol. 2006 May 10;109(2):213-8.

17. Eckel RH, Grundy SM, Zimmet PZ. The metabolic syndrome. Lancet. 2005 Apr 16-22;365(9468):1415-28.

18. Schmidt MI, Watson RL, Duncan BB, Metcalf P, Brancati FL, Sharrett AR, et al. Clustering of dyslipidemia, hyperuricemia, diabetes, and hypertension and its association with fasting insulin and central and overall obesity in a general population. Atherosclerosis Risk in Communities Study Investigators. Metabolism. 1996 Jun;45(6):699-706. 
19. Hong $Y$, Jin X, Mo J, Lin HM, Duan Y, Pu M, et al. Metabolic syndrome, its preeminent clusters, incident coronary heart disease and all-cause mortality--results of prospective analysis for the Atherosclerosis Risk in Communities study. J Intern Med. 2007 Jul;262(1):113-22.

20. Wilson PW, D'Agostino RB, Parise H, Sullivan L, Meigs JB. Metabolic syndrome as a precursor of cardiovascular disease and type 2 diabetes mellitus. Circulation. 2005 Nov 15;112(20):3066-72.

21. Woodward M, Lam TH, Barzi F, Patel A, Gu D, Rodgers A, et al. Smoking, quitting, and the risk of cardiovascular disease among women and men in the Asia-Pacific region. Int J Epidemiol. 2005 Oct;34(5):1036-45.

22. Willett WC, Green A, Stampfer MJ, Speizer FE, Colditz GA, Rosner B, et al. Relative and absolute excess risks of coronary heart disease among women who smoke cigarettes. N Engl J Med. 1987 Nov 19;317(21):1303-9.

23. Manson JE, Tosteson H, Ridker PM, Satterfield S, Hebert P, O'Connor GT, et al. The primary prevention of myocardial infarction. N Engl J Med. 1992 May 21;326(21):1406-16.

24. Rich-Edwards JW, Manson JE, Hennekens $\mathrm{CH}$, Buring JE. The primary prevention of coronary heart disease in women. N Engl J Med. 1995 Jun 29;332(26):1758-66.

25. Wendel-Vos GC, Dutman AE, Verschuren WM, Ronckers ET, Ament A, van Assema P, et al. Lifestyle factors of a five-year community-intervention program: the Hartslag Limburg intervention. Am J Prev Med. 2009 Jul;37(1):50-6.

26. Rimm EB, Klatsky A, Grobbee D, Stampfer MJ. Review of moderate alcohol consumption and reduced risk of coronary heart disease: is the effect due to beer, wine, or spirits. Bmj. 1996 Mar 23;312(7033):731-6.

27. Mukamal KJ, Conigrave KM, Mittleman MA, Camargo CA, Jr., Stampfer MJ, Willett WC, et al. Roles of drinking pattern and type of alcohol consumed in coronary heart disease in men. N Engl J Med. 2003 Jan 9;348(2):109-18.

28. Di Castelnuovo A, Rotondo S, lacoviello L, Donati MB, De Gaetano G. Meta-analysis of wine and beer consumption in relation to vascular risk. Circulation. 2002 Jun 18;105(24):2836-44.

29. Corrao G, Bagnardi V, Zambon A, La Vecchia C. A meta-analysis of alcohol consumption and the risk of 15 diseases. Prev Med. 2004 May;38(5):613-9.

30. Sofi F, Capalbo A, Cesari F, Abbate R, Gensini GF. Physical activity during leisure time and primary prevention of coronary heart disease: an updated meta-analysis of cohort studies. Eur J Cardiovasc Prev Rehabil. 2008 Jun;15(3):247-57.

31. Oguma Y, Shinoda-Tagawa T. Physical activity decreases cardiovascular disease risk in women: review and meta-analysis. Am J Prev Med. 2004 Jun;26(5):407-18.

32. Batty GD. Physical activity and coronary heart disease in older adults. A systematic review of epidemiological studies. Eur J Public Health. 2002 Sep;12(3):171-6.

33. Kohl HW, 3rd. Physical activity and cardiovascular disease: evidence for a dose response. Med Sci Sports Exerc. 2001 Jun;33(6 Suppl):S472-83; discussion S93-4.

34. Nasir K, Michos ED, Rumberger JA, Braunstein JB, Post WS, Budoff MJ, et al. Coronary artery calcification and family history of premature coronary heart disease: sibling history is more strongly associated than parental history. Circulation. 2004 Oct 12;110(15):2150-6.

35. Myers RH, Kiely DK, Cupples LA, Kannel WB. Parental history is an independent risk factor for coronary artery disease: the Framingham Study. Am Heart J. 1990 Oct;120(4):963-9.

36. Boer JM, Feskens EJ, Verschuren WM, Seidell JC, Kromhout D. The joint impact of family history of myocardial infarction and other risk factors on 12-year coronary heart disease mortality. Epidemiology. 1999 Nov;10(6):767-70.

37. Khaw KT, Barrett-Connor E. Family history of heart attack: a modifiable risk factor? Circulation. 1986 Aug;74(2):239-44.

38. Leander K, Hallqvist J, Reuterwall C, Ahlbom A, de Faire U. Family history of coronary heart disease, a strong risk factor for myocardial infarction interacting with other cardiovascular risk factors: results from the Stockholm Heart Epidemiology Program (SHEEP). Epidemiology. 2001 Mar;12(2):215-21.

39. Ronda G, Van Assema P, Ruland E, Steenbakkers M, Brug J. The Dutch Heart Health Community Intervention 'Hartslag Limburg': design and results of a process study. Health Educ Res. 2004 Oct;19(5):596607.

40. Fuster V, Badimon L, Badimon JJ, Chesebro JH. The pathogenesis of coronary artery disease and the acute coronary syndromes (2). N Engl J Med. 1992 Jan 30;326(5):310-8.

41. Fuster V, Badimon L, Badimon JJ, Chesebro JH. The pathogenesis of coronary artery disease and the acute coronary syndromes (1). N Engl J Med. 1992 Jan 23;326(4):242-50. 
42. Ambrose JA, Barua RS. The pathophysiology of cigarette smoking and cardiovascular disease: an update. J Am Coll Cardiol. 2004 May 19;43(10):1731-7.

43. Rimm EB, Williams P, Fosher K, Criqui M, Stampfer MJ. Moderate alcohol intake and lower risk of coronary heart disease: meta-analysis of effects on lipids and haemostatic factors. Bmj. 1999 Dec 11;319(7224):1523-8

44. Meade TW, Chakrabarti R, Haines AP, North WR, Stirling Y. Characteristics affecting fibrinolytic activity and plasma fibrinogen concentrations. Br Med J. 1979 Jan 20;1(6157):153-6.

45. Sobel BE, Schneider DJ. Platelet function, coagulopathy, and impaired fibrinolysis in diabetes. Cardiol Clin. 2004 Nov;22(4):511-26.

46. Alessi MC, Juhan-Vague I. Metabolic syndrome, haemostasis and thrombosis. Thromb Haemost. 2008 Jun;99(6):995-1000.

47. Poli KA, Tofler GH, Larson MG, Evans JC, Sutherland PA, Lipinska I, et al. Association of blood pressure with fibrinolytic potential in the Framingham offspring population. Circulation. 2000 Jan 25;101(3):2649.

48. Nieuwdorp M, Stroes ES, Meijers JC, Buller H. Hypercoagulability in the metabolic syndrome. Curr Opin Pharmacol. 2005 Apr;5(2):155-9.

49. Rosito GA, D'Agostino RB, Massaro J, Lipinska I, Mittleman MA, Sutherland P, et al. Association between obesity and a prothrombotic state: the Framingham Offspring Study. Thromb Haemost. 2004 Apr;91(4):683-9.

50. Colditz GA, Stampfer MJ, Willett WC, Rosner B, Speizer FE, Hennekens CH. A prospective study of parental history of myocardial infarction and coronary heart disease in women. Am J Epidemiol. 1986 Jan;123(1):48-58.

51. Conroy RM, Pyorala K, Fitzgerald AP, Sans S, Menotti A, De Backer G, et al. Estimation of ten-year risk of fatal cardiovascular disease in Europe: the SCORE project. Eur Heart J. 2003 Jun;24(11):987-1003.

52. Steyerberg EW. Clinical Prediction Models: A Practical Approach to Development, Validation, and Updating. New York: Springer Science+Business Media; 2009. Chapter 4, Statistical Models for Prediction; p.53-82.

53. Steyerberg EW. Clinical Prediction Models: A Practical Approach to Development, Validation, and Updating. New York: Springer Science+Business Media; 2009. Chapter 23, Case Study on Survival Analysis: Prediction of Secondary Cardiovascular Events; p.427-46.

54. Carroll KJ. On the use and utility of the Weibull model in the analysis of survival data. Control Clin Trials. 2003 Dec;24(6):682-701.

55. Odell PM, Anderson KM, Kannel WB. New models for predicting cardiovascular events. J Clin Epidemiol. 1994 Jun;47(6):583-92.

56. Vaartjes I, Van Dis SJ, Visseren FLJ, Bots ML. Hart- en vaatziekten in Nederland. In: Visseren FLJ, Van Dis SJ, Bots ML, Vaartjes I (red.). Hart- en vaatziekten in Nederland 2009, cijfers over leefstijl- en risicofactoren, ziekte en sterfte. Den Haag: Nederlandse Hartstichting; 2009: p.7-23.

57. Balkau B, Hu G, Qiao Q, Tuomilehto J, Borch-Johnsen K, Pyorala K. Prediction of the risk of cardiovascular mortality using a score that includes glucose as a risk factor. The DECODE Study. Diabetologia. 2004 Dec;47(12):2118-28.

58. Pocock SJ, McCormack V, Gueyffier F, Boutitie F, Fagard RH, Boissel JP. A score for predicting risk of death from cardiovascular disease in adults with raised blood pressure, based on individual patient data from randomised controlled trials. Bmj. $2001 \mathrm{Jul}$ 14;323(7304):75-81.

59. Cooney MT, Dudina AL, Graham IM. Value and limitations of existing scores for the assessment of cardiovascular risk: a review for clinicians. J Am Coll Cardiol. 2009 Sep 29;54(14):1209-27.

60. Mackenbach JP, Van Duyne WM, Kelson MC. Certification and coding of two underlying causes of death in The Netherlands and other countries of the European Community. J Epidemiol Community Health. 1987 Jun;41(2):156-60.

61. Maudsley G, Williams EM. "Inaccuracy' in death certification--where are we now? J Public Health Med. 1996 Mar;18(1):59-66.

62. Jougla E, Pavillon G, Rossollin F, De Smedt M, Bonte J. Improvement of the quality and comparability of causes-of-death statistics inside the European Community. EUROSTAT Task Force on "causes of death statistics". Rev Epidemiol Sante Publique. 1998 Dec;46(6):447-56.

63. Smulders YM, Burgers JS, Scheltens T, van Hout BA, Wiersma T, Simoons ML. Clinical practice guideline for cardiovascular risk management in the Netherlands. Neth J Med. 2008 Apr;66(4):169-74.

64. Liew SM, Glasziou P. QRISK may be less useful. Bmj. 2009;339:b3485. 
65. Harrell FE, Jr., Lee KL, Mark DB. Multivariable prognostic models: issues in developing models, evaluating assumptions and adequacy, and measuring and reducing errors. Stat Med. 1996 Feb 28;15(4):36187.

66. Cook NR. Comments on 'Evaluating the added predictive ability of a new marker: From area under the ROC curve to reclassification and beyond' by M. J. Pencina et al., Statistics in Medicine (DOI: 10.1002/sim.2929). Stat Med. 2008 Jan 30;27(2):191-5.

67. Pepe MS, Feng Z, Gu JW. Comments on 'Evaluating the added predictive ability of a new marker: From area under the ROC curve to reclassification and beyond' by M. J. Pencina et al., Statistics in Medicine (DOI: 10.1002/sim.2929). Stat Med. 2008 Jan 30;27(2):173-81.

68. Steyerberg EW, Pencina MJ. Reclassification calculations for persons with incomplete follow-up. Ann Intern Med. 2010 Feb 2;152(3):195-6; author reply 6-7.

69. Van Houwelingen JC, Le Cessie S. Predictive value of statistical models. Stat Med. 1990 Nov;9(11):130325.

70. Schumacher M, Hollander N, Sauerbrei W. Resampling and cross-validation techniques: a tool to reduce bias caused by model building? Stat Med. 1997 Dec 30;16(24):2813-27.

71. Steyerberg EW. Clinical Prediction Models: A Practical Approach to Development, Validation, and Updating. New York: Springer Science+Business Media; 2009. Chapter 5, Overfitting and Optimism in Prediction Models; p.83-100.

72. Steyerberg EW, Eijkemans MJ, Harrell FE, Jr., Habbema JD. Prognostic modeling with logistic regression analysis: in search of a sensible strategy in small data sets. Med Decis Making. 2001 Jan-Feb;21(1):4556.

73. D'Agostino RB, Sr., Grundy S, Sullivan LM, Wilson P. Validation of the Framingham coronary heart disease prediction scores: results of a multiple ethnic groups investigation. Jama. 2001 Jul 11;286(2):180-7.

74. Thomsen TF, McGee D, Davidsen M, Jorgensen T. A cross-validation of risk-scores for coronary heart disease mortality based on data from the Glostrup Population Studies and Framingham Heart Study. Int J Epidemiol. 2002 Aug;31(4):817-22.

75. Empana JP, Ducimetiere P, Arveiler D, Ferrieres J, Evans A, Ruidavets JB, et al. Are the Framingham and PROCAM coronary heart disease risk functions applicable to different European populations? The PRIME Study. Eur Heart J. 2003 Nov;24(21):1903-11.

76. Hense HW, Schulte $H$, Lowel H, Assmann G, Keil U. Framingham risk function overestimates risk of coronary heart disease in men and women from Germany--results from the MONICA Augsburg and the PROCAM cohorts. Eur Heart J. 2003 May;24(10):937-45.

77. Brindle P, Emberson J, Lampe F, Walker M, Whincup P, Fahey T, et al. Predictive accuracy of the Framingham coronary risk score in British men: prospective cohort study. Bmj. 2003 Nov 29;327(7426):1267.

78. Aktas MK, Ozduran V, Pothier CE, Lang R, Lauer MS. Global risk scores and exercise testing for predicting all-cause mortality in a preventive medicine program. Jama. 2004 Sep 22;292(12):1462-8.

79. May M, Lawlor DA, Brindle P, Patel R, Ebrahim S. Cardiovascular disease risk assessment in older women: can we improve on Framingham? British Women's Heart and Health prospective cohort study. Heart. 2006 Oct;92(10):1396-401.

80. Barzi F, Patel A, Gu D, Sritara P, Lam TH, Rodgers A, et al. Cardiovascular risk prediction tools for populations in Asia. J Epidemiol Community Health. 2007 Feb;61(2):115-21.

81. Eichler K, Puhan MA, Steurer J, Bachmann LM. Prediction of first coronary events with the Framingham score: a systematic review. Am Heart J. 2007 May;153(5):722-31, 31 e1-8.

82. de Ruijter W, Westendorp RG, Assendelft WJ, den Elzen WP, de Craen AJ, le Cessie S, et al. Use of Framingham risk score and new biomarkers to predict cardiovascular mortality in older people: population based observational cohort study. Bmj. 2009;338:a3083.

83. Hippisley-Cox J, Coupland C, Vinogradova Y, Robson J, Brindle P. Performance of the QRISK cardiovascular risk prediction algorithm in an independent UK sample of patients from general practice: a validation study. Heart. 2008 Jan;94(1):34-9.

84. Scheltens T, Verschuren WM, Boshuizen HC, Hoes AW, Zuithoff NP, Bots ML, et al. Estimation of cardiovascular risk: a comparison between the Framingham and the SCORE model in people under 60 years of age. Eur J Cardiovasc Prev Rehabil. 2008 Oct;15(5):562-6.

85. Simmons RK, Sharp S, Boekholdt SM, Sargeant LA, Khaw KT, Wareham NJ, et al. Evaluation of the Framingham risk score in the European Prospective Investigation of Cancer-Norfolk cohort: does adding glycated hemoglobin improve the prediction of coronary heart disease events? Arch Intern Med. 2008 Jun 9;168(11):1209-16. 
86. Ulmer H, Kollerits B, Kelleher C, Diem G, Concin H. Predictive accuracy of the SCORE risk function for cardiovascular disease in clinical practice: a prospective evaluation of 44649 Austrian men and women. Eur J Cardiovasc Prev Rehabil. 2005 Oct;12(5):433-41.

87. Aspelund T, Thorgeirsson G, Sigurdsson G, Gudnason V. Estimation of 10-year risk of fatal cardiovascular disease and coronary heart disease in Iceland with results comparable with those of the Systematic Coronary Risk Evaluation project. Eur J Cardiovasc Prev Rehabil. 2007 Dec;14(6):761-8.

88. Lindman AS, Veierod MB, Pedersen JI, Tverdal A, Njolstad I, Selmer R. The ability of the SCORE high-risk model to predict 10-year cardiovascular disease mortality in Norway. Eur J Cardiovasc Prev Rehabil. 2007 Aug;14(4):501-7.

89. Stenlund $H$, Lonnberg $G$, Jenkins $P$, Norberg $M$, Persson $M$, Messner $T$, et al. Fewer deaths from cardiovascular disease than expected from the Systematic Coronary Risk Evaluation chart in a Swedish population. Eur J Cardiovasc Prev Rehabil. 2009 Jun;16(3):321-4.

90. van Dis I, Kromhout D, Geleijnse JM, Boer JM, Verschuren WM. Evaluation of cardiovascular risk predicted by different SCORE equations: the Netherlands as an example. Eur J Cardiovasc Prev Rehabil. 2010 Apr;17(2):244-9.

91. Collins GS, Altman DG. An independent and external validation of QRISK2 cardiovascular disease risk score: a prospective open cohort study. Bmj.340:c2442.

92. Tunstall-Pedoe $\mathrm{H}$. The Dundee coronary risk-disk for management of change in risk factors. Bmj. 1991 Sep 28;303(6805):744-7.

93. Menotti A, Puddu PE, Lanti M. Comparison of the Framingham risk function-based coronary chart with risk function from an Italian population study. Eur Heart J. 2000 Mar;21(5):365-70.

94. Woodward M, Brindle P, Tunstall-Pedoe H. Adding social deprivation and family history to cardiovascular risk assessment: the ASSIGN score from the Scottish Heart Health Extended Cohort (SHHEC). Heart. 2007 Feb;93(2):172-6.

95. Thorsen RD, Jacobs DR, Jr., Grimm RH, Jr., Keys A, Taylor H, Blackburn H. Preventive cardiology in practice: a device for risk estimation and counseling in coronary disease. Prev Med. 1979 Sep;8(5):54856.

96. Stevens RJ, Kothari V, Adler Al, Stratton IM. The UKPDS risk engine: a model for the risk of coronary heart disease in Type II diabetes (UKPDS 56). Clin Sci (Lond). 2001 Dec;101(6):671-9.

97. Zhang XF, Attia J, D'Este C, Yu XH, Wu XG. A risk score predicted coronary heart disease and stroke in a Chinese cohort. J Clin Epidemiol. 2005 Sep;58(9):951-8.

98. Hippisley-Cox J, Coupland C, Vinogradova Y, Robson J, May M, Brindle P. Derivation and validation of QRISK, a new cardiovascular disease risk score for the United Kingdom: prospective open cohort study. Bmj. 2007 Jul 21;335(7611):136.

99. Hippisley-Cox J, Coupland C, Vinogradova Y, Robson J, Minhas R, Sheikh A, et al. Predicting cardiovascular risk in England and Wales: prospective derivation and validation of QRISK2. Bmj. 2008 Jun 28;336(7659):1475-82.

100. Thomsen TF, Davidsen M, Ibsen H, Jorgensen T, Jensen G, Borch-Johnsen K. A new method for CHD prediction and prevention based on regional risk scores and randomized clinical trials; PRECARD and the Copenhagen Risk Score. J Cardiovasc Risk. 2001 Oct;8(5):291-7.

101. Ridker PM, Buring JE, Rifai N, Cook NR. Development and validation of improved algorithms for the assessment of global cardiovascular risk in women: the Reynolds Risk Score. Jama. 2007 Feb 14;297(6):611-9.

102. Chambless LE, Folsom AR, Sharrett AR, Sorlie P, Couper D, Szklo M, et al. Coronary heart disease risk prediction in the Atherosclerosis Risk in Communities (ARIC) study. J Clin Epidemiol. 2003 Sep;56(9):880-90.

103. Ridker PM, Paynter NP, Rifai N, Gaziano JM, Cook NR. C-reactive protein and parental history improve global cardiovascular risk prediction: the Reynolds Risk Score for men. Circulation. 2008 Nov 25;118(22):2243-51, 4p following 51.

104. Assmann G, Cullen P, Schulte H. Simple scoring scheme for calculating the risk of acute coronary events based on the 10-year follow-up of the prospective cardiovascular Munster (PROCAM) study. Circulation. 2002 Jan 22;105(3):310-5.

105. Assmann G, Schulte H, Cullen $P$, Seedorf U. Assessing risk of myocardial infarction and stroke: new data from the Prospective Cardiovascular Munster (PROCAM) study. Eur J Clin Invest. 2007 Dec;37(12):92532.

106. Ferrario M, Chiodini P, Chambless LE, Cesana G, Vanuzzo D, Panico S, et al. Prediction of coronary events in a low incidence population. Assessing accuracy of the CUORE Cohort Study prediction equation. Int J Epidemiol. 2005 Apr;34(2):413-21. 
107. Shaper AG, Pocock SJ, Phillips AN, Walker M. Identifying men at high risk of heart attacks: strategy for use in general practice. Br Med J (Clin Res Ed). 1986 Aug 23;293(6545):474-9.

108. Pencina MJ, D'Agostino RB, Sr., D'Agostino RB, Jr., Vasan RS. Evaluating the added predictive ability of a new marker: from area under the ROC curve to reclassification and beyond. Stat Med. 2008 Jan 30;27(2):157-72; discussion 207-12.

109. Atsma F, van der Schouw YT, Grobbee DE, Hoes AW, Bartelink ML. No added value of age at menopause and the lifetime cumulative number of menstrual cycles for cardiovascular risk prediction in postmenopausal women. Int J Cardiol. 2007 Dec 4.

110. Lee AJ, Price JF, Russell MJ, Smith FB, van Wijk MC, Fowkes FG. Improved prediction of fatal myocardial infarction using the ankle brachial index in addition to conventional risk factors: the Edinburgh Artery Study. Circulation. 2004 Nov 9;110(19):3075-80.

111. van der Steeg WA, Boekholdt SM, Stein EA, El-Harchaoui K, Stroes ES, Sandhu MS, et al. Role of the apolipoprotein B-apolipoprotein A-I ratio in cardiovascular risk assessment: a case-control analysis in EPIC-Norfolk. Ann Intern Med. 2007 May 1;146(9):640-8.

112. Koenig W, Lowel H, Baumert J, Meisinger C. C-reactive protein modulates risk prediction based on the Framingham Score: implications for future risk assessment: results from a large cohort study in southern Germany. Circulation. 2004 Mar 23;109(11):1349-53.

113. Wilson PW, Nam BH, Pencina M, D'Agostino RB, Sr., Benjamin EJ, O'Donnell CJ. C-reactive protein and risk of cardiovascular disease in men and women from the Framingham Heart Study. Arch Intern Med. 2005 Nov 28;165(21):2473-8.

114. Folsom AR, Chambless LE, Ballantyne CM, Coresh J, Heiss G, Wu KK, et al. An assessment of incremental coronary risk prediction using $\mathrm{C}$-reactive protein and other novel risk markers: the atherosclerosis risk in communities study. Arch Intern Med. $2006 \mathrm{Jul}$ 10;166(13):1368-73.

115. Lloyd-Jones DM, Liu K, Tian L, Greenland P. Narrative review: Assessment of C-reactive protein in risk prediction for cardiovascular disease. Ann Intern Med. $2006 \mathrm{Jul}$ 4;145(1):35-42.

116. Tohidi M, Hadaegh F, Harati H, Azizi F. C-reactive protein in risk prediction of cardiovascular outcomes: Tehran Lipid and Glucose Study. Int J Cardiol. 2008 Jan 31.

117. Wang TJ, Gona P, Larson MG, Tofler GH, Levy D, Newton-Cheh C, et al. Multiple biomarkers for the prediction of first major cardiovascular events and death. N Engl J Med. 2006 Dec 21;355(25):2631-9.

118. del Sol Al, Moons KG, Hollander M, Hofman A, Koudstaal PJ, Grobbee DE, et al. Is carotid intima-media thickness useful in cardiovascular disease risk assessment? The Rotterdam Study. Stroke. 2001 Jul;32(7):1532-8.

119. Bernard S, Serusclat A, Targe F, Charriere S, Roth O, Beaune J, et al. Incremental predictive value of carotid ultrasonography in the assessment of coronary risk in a cohort of asymptomatic type 2 diabetic subjects. Diabetes Care. 2005 May;28(5):1158-62.

120. Cooper JA, Miller GJ, Bauer KA, Morrissey JH, Meade TW, Howarth DJ, et al. Comparison of novel hemostatic factors and conventional risk factors for prediction of coronary heart disease. Circulation. 2000 Dec 5;102(23):2816-22.

121. Nawrot TS, Staessen JA, Thijs L, Fagard RH, Tikhonoff V, Wang JG, et al. Should pulse pressure become part of the Framingham risk score? J Hum Hypertens. 2004 Apr;18(4):279-86.

122. Wood D, De Backer G, Faergeman O, Graham I, Mancia G, Pyorala K. Prevention of coronary heart disease in clinical practice: recommendations of the Second Joint Task Force of European and other Societies on Coronary Prevention. Atherosclerosis. 1998 Oct;140(2):199-270.

123. Fleuren $\mathrm{MAH}$. Waarom worden standaarden in de praktijk niet gevolgd en wat valt eraan te doen? Huisarts Wet. 1998;41:511-4.

124. Mainous AG, 3rd, Koopman RJ, Diaz VA, Everett CJ, Wilson PW, Tilley BC. A coronary heart disease risk score based on patient-reported information. Am J Cardiol. 2007 May 1;99(9):1236-41.

125. Gaziano TA, Young CR, Fitzmaurice G, Atwood S, Gaziano JM. Laboratory-based versus non-laboratorybased method for assessment of cardiovascular disease risk: the NHANES I Follow-up Study cohort. Lancet. 2008 Mar 15;371(9616):923-31.

126. D'Agostino RB, Sr., Vasan RS, Pencina MJ, Wolf PA, Cobain M, Massaro JM, et al. General cardiovascular risk profile for use in primary care: the Framingham Heart Study. Circulation. 2008 Feb 12;117(6):74353.

127. Lloyd-Jones DM, Larson MG, Beiser A, Levy D. Lifetime risk of developing coronary heart disease. Lancet. 1999 Jan 9;353(9147):89-92.

128. De Backer G, Ambrosioni E, Borch-Johnsen K, Brotons C, Cifkova R, Dallongeville J, et al. European guidelines on cardiovascular disease prevention in clinical practice: third joint task force of European 
and other societies on cardiovascular disease prevention in clinical practice (constituted by representatives of eight societies and by invited experts). Eur J Cardiovasc Prev Rehabil. 2003 Aug;10(4):S1-S10.

129. Graham I, Atar D, Borch-Johnsen K, Boysen G, Burell G, Cifkova R, et al. European guidelines on cardiovascular disease prevention in clinical practice: full text. Fourth Joint Task Force of the European Society of Cardiology and other societies on cardiovascular disease prevention in clinical practice (constituted by representatives of nine societies and by invited experts). Eur J Cardiovasc Prev Rehabil. 2007 Sep;14 Suppl 2:S1-113.

130. Lloyd-Jones DM, Leip EP, Larson MG, D'Agostino RB, Beiser A, Wilson PW, et al. Prediction of lifetime risk for cardiovascular disease by risk factor burden at 50 years of age. Circulation. 2006 Feb 14;113(6):791-8.

131. Berry JD, Liu K, Folsom AR, Lewis CE, Carr JJ, Polak JF, et al. Prevalence and progression of subclinical atherosclerosis in younger adults with low short-term but high lifetime estimated risk for cardiovascular disease: the coronary artery risk development in young adults study and multi-ethnic study of atherosclerosis. Circulation. 2009 Jan 27;119(3):382-9.

132. Stamatelopoulos KS, Papamichael CM, Zacharoulis A, Papaioannou T, Kollias GE, Kyrkou K, et al. Heartscore calculated in individuals younger than 40 years is related to vascular markers of early atherosclerosis. Eur J Cardiovasc Prev Rehabil. 2008 Dec;15(6):619-24.

133. Stork S, Feelders RA, van den Beld AW, Steyerberg EW, Savelkoul HF, Lamberts SW, et al. Prediction of mortality risk in the elderly. Am J Med. 2006 Jun;119(6):519-25.

134. Kannel WB. Coronary heart disease risk factors in the elderly. Am J Geriatr Cardiol. 2002 MarApr;11(2):101-7.

135. Kannel WB, D'Agostino RB. The Importance of Cardiovascular Risk Factors in the Elderly. Am J Geriatr Cardiol. 1995 Mar;4(2):10-23.

136. Houterman S, Boshuizen HC, Verschuren WM, Giampaoli S, Nissinen A, Menotti A, et al. Predicting cardiovascular risk in the elderly in different European countries. Eur Heart J. 2002 Feb;23(4):294-300.

137. Cooney MT, Dudina A, De Bacquer D, Fitzgerald A, Conroy R, Sans S, et al. How much does HDL cholesterol add to risk estimation? A report from the SCORE Investigators. Eur J Cardiovasc Prev Rehabil. 2009 Jun;16(3):304-14.

138. Deutekom M, Aziz Y, van Dis I, Stronks K, Bossuyt PM. [The Dutch National Colesterol Test: participants mainly healthy]. Ned Tijdschr Geneeskd. 2008 Nov 1;152(44):2425-9.

139. Ronda G, Portegijs P, Dinant GJ, Buntinx F, Norg R, van der Weijden T. Use of diagnostic self-tests on body materials among Internet users in the Netherlands: prevalence and correlates of use. BMC Public Health. 2009;9:100.

140. Deutekom M, Bossuyt PM. [The increased availability of self-tests for medical analyses]. Ned Tijdschr Geneeskd. 2007 Apr 21;151(16):901-4. 
Summary 
Coronary heart disease (CHD) is associated with a high disease burden in the Netherlands with large consequences for the individual patient as well as for society (see chapter 1). Therefore, the focus has been on the primary prevention of CHD, identifying persons at high risk of the disease but without symptoms yet. In the last decades, several attempts have been made to predict the absolute risk of an individual to develop CHD in the next years, based on the cumulative effect of the person's risk factors. Consequently, several risk scores have been developed for different cardiovascular endpoints, of which the Framingham risk score is probably the best-known. Although these risk scores performed reasonably well within their own and similar populations, different levels and trends in risk factors and disease rates diminish their performance in other populations. Subsequently, methods were developed to recalibrate risk scores.

However, several limitations exist regarding the current and recalibrated risk scores. Firstly, national data on mean risk factor levels and disease incidence were used for recalibration, while it would be better to recalibrate the existing risk scores using individual data on risk factors and disease rates from prospective studies in which the risk factor level can be linked to the disease status in every person. Secondly, because of the high disease burden of non-fatal CHD, the prediction of both fatal and non-fatal events is more relevant than the prediction of fatal events only. Therefore, we developed a recalibrated and adjusted risk score for total (fatal and non-fatal) CHD in the Dutch population, using data from the population-based prospective Cardiovascular Registry Maastricht (CAREMA) cohort study.

The CAREMA cohort study consists of 21,148 participants, aged 20-59 years at baseline and living in the Maastricht region, the Netherlands. They were derived from two monitoring projects of the National Institute for Public Health and the Environment: the Monitoring Project on Cardiovascular Disease Risk Factors (PPHVZ) in 1987-1992 and the Monitoring Project on Chronic Disease Risk factors (MORGEN) in 1993-1997. Baseline data were available on demographic characteristics, medical history, parental history of myocardial infarction, anthropometric data, blood pressure and cholesterol levels, lifestyle habits, and usual dietary intake.

A migration and mortality follow-up was performed by record linkage of the cohort to the Municipal Population Registries. For participants who died, the cause of death was retrieved from the causes of death registry of Statistics Netherlands. Cardiologic follow-up was performed by linkage to the Cardiology Information System (CIS) of the department of Cardiology, University Hospital Maastricht (UHM). The CIS is a unique registry that contains the cardiologic information of all persons who visited the UHM department of Cardiology. Using information from the CIS and the causes of death registry of Statistics Netherlands, both fatal and non-fatal incident cases of CHD were identified during follow-up until 31 December 2003. 
In chapter $\mathbf{2}$ we estimated the incidence rates of $\mathrm{CHD}$, acute myocardial infarction (AMI), unstable angina pectoris (UAP), heart failure, and sudden cardiac arrest based on the case identification from the CIS in combination with the causes of death registry (CIS-based method). The incidence rates per 100,000 persons-years were 362.2 for CHD, 212.2 for AMI, 171.8 for UAP, 66.4 for heart failure, and 65.4 for sudden cardiac arrest. Because cardiovascular disease registries are lacking in most countries including the Netherlands, record linkage with national hospital discharge and mortality data is often used to estimate the incidence rates of CHD and other heart diseases. The validity of these estimates, however, depends on the completeness and accuracy of the data in the national registers and the accuracy of the linkage. Therefore, we compared the incidence rates of the CIS-based method with the incidence rates based on hospital discharge and mortality data to assess the completeness and validity of the latter. Using the CIS-based method as gold standard, high sensitivities and positive predictive values were found for $\mathrm{CHD}$ and $\mathrm{AMI}$, while these values were substantially lower for UAP and heart failure. High percentages of cases (ranging from $14.2 \%$ for AMI to $47.5 \%$ for heart failure) were found in the CIS-based registry only, while these cases were missed or classified otherwise in the hospital discharge registry. As a result, the incidence rates based on hospital discharge and mortality data were considerably lower than the incidence rates from the CIS-based registry, especially for UAP and heart failure. Using hospital discharge diagnoses and mortality data may therefore underestimate true incidence rates.

The prevalence of metabolic factors such as diabetes, hypertension, obesity, low HDL and high total cholesterol levels that are associated with an increased risk of CHD is increasing worldwide. However, less is known about combinations of these factors that are associated with the highest CHD risk. Chapter 3 describes the results of our study on the associations between combinations of metabolic factors and the risk of total CHD, AMI, and UAP. Diabetes, hypertension, obesity, low HDL and high total cholesterol levels were all independent risk factors for total CHD and AMI. Diabetes and obesity were not independently associated with the risk of UAP. Furthermore, a clear dose-response relationship was found for an increasing number of metabolic factors. Compared with subjects without any metabolic risk factor, the incidence rate ratio (RR) for subjects with three or more metabolic factors was 7.36 (95\% confidence interval (Cl) 5.73-9.45) for total CHD, 9.34 (95\% Cl 6.67-13.08) for AMI, and 5.28 (95\% Cl 3.458.09) for UAP. Of all possible combinations of the five metabolic factors, especially those combinations with diabetes or both a low HDL and high total cholesterol level were associated with elevated risks for all three coronary endpoints.

Few studies investigated the association between lifestyle factors and the risk of UAP, while the strength of these associations may differ compared to other coronary diseases such as AMI. Therefore, we studied the effects of smoking, alcohol consumption, physical activity, and parental history of myocardial infarction on the risks of AMI and 
UAP as separate endpoints. The results are presented in chapter 4. Smoking increased the risks of both AMI and UAP. Furthermore, dose-response relationships were found with the number of cigarettes smoked per day and the number of years smoked, although the trend was less obvious for the latter. Alcohol consumption was associated with a protective effect on both coronary endpoints, which was independent of the type of alcoholic beverage consumed. In men, occupational physical activity seemed to be a risk factor for both coronary endpoints, while it was associated with lower risks of both AMI and UAP in women. On the contrary, non-occupational activity was associated with a non-significantly protective effect in men, while it was found to be a risk factor in women. Although the associations with the lifestyle factors seemed to be stronger for AMI than UAP, the differences in RRs were only statistically significant for the smoking variables. Parental history of myocardial infarction was associated with increased risks of AMI and UAP, especially when both parents were affected or when they were diagnosed at a younger age. Although these associations seemed to be stronger for UAP than for AMI, the differences were not statistically significant. Because subjects with a positive family history may be more susceptible to other risk factors, the associations between lifestyle factors and the risk of CHD may differ between subjects with and without a positive family history. No clear interactions on a multiplicative scale were found between the lifestyle factors and parental history of premature myocardial infarction (diagnosis date $\leq 60$ years for the father and $\leq 65$ years for the mother). Nevertheless, the highest risks were found in subjects with both a positive parental history and the most unfavourable level of the lifestyle factors.

As described in chapter 5, we recalibrated the SCORE risk function, which is used nowadays in the Dutch clinical practice guideline on cardiovascular risk management, using individual data on risk factor levels and CHD incidence. The discriminative ability, which is the probability of the risk function to distinguish between those who developed CHD during the follow-up period and those who did not, was assessed by the $c$ statistic (equivalent to the area under the ROC curve). The c statistic of the recalibrated risk function was $0.799(95 \% \mathrm{Cl}$ 0.782-0.816). Furthermore, we investigated whether including additional risk factors (e.g. body mass index, diabetes, and family history of myocardial infarction) or current risk factors in a different manner improved the recalibrated risk function. None of these changes improved the $c$ statistic. Nevertheless, separating the total/HDL cholesterol ratio into total and HDL cholesterol levels reclassified $6.0 \%$ of the participants into a more appropriate risk category compared with the recalibrated model ( $p<0.001$ ). The final CAREMA risk score consisted of the following predictors: age in years (time variable), sex (strata), current smoking (yes/no), systolic blood pressure in $\mathrm{mmHg}$ (continuous), and total and $\mathrm{HDL}$ cholesterol levels in $\mathrm{mmol} / \mathrm{L}$ (both continuous). Compared with the SCORE functions for high- and low-risk regions that predict the 10-year risk of fatal CVD, high percentages of both cases and non-cases were reclassified into a higher risk category. This is mainly due to the different outcome used. Compared with the Framingham score which also predicts 
the 10-year risk of total CHD, the CAREMA risk score reclassified a high percentage of both cases and non-cases into a more appropriate risk category for CHD incidence within our study population.

In chapter 6, the main findings from our studies are summarized and discussed in the context of current knowledge and practice about cardiovascular disease. The data in our study were derived from a unique registry containing the cardiologic information of all persons who visited the UHM department of Cardiology. Furthermore, the data were extracted in an extensive manner by a limited number of registrars under guidance of a cardiologist. Therefore, we believe that our disease registry resulted in qualitatively better estimates of the incidence rates compared with data on hospital discharge diagnoses.

In this thesis, a strong dose response relationship was found between the number of metabolic factors and the risk of CHD. Therefore, it could be suggested that a cluster variable regarding the number of metabolic factors is more relevant in risk prediction than including the metabolic factors separately. However, because the CHD risk varies considerably according to the combination of metabolic factors within these clusters, it is preferred to include the metabolic factors as separate predictors into the prediction model. Furthermore, as no clear interactions were found between the lifestyle factors and parental history of myocardial infarction, using separate risk factor coefficients for persons with and without a positive family history is not indicated based on the results of our study. No large differences were found in the strength of the associations between the risk factors and the risks of AMI and UAP. Therefore, it is not necessary to develop separate risk functions for these coronary diseases that could then be combined to predict the risk of total CHD.

In addition, chapter 6 addresses some important issues regarding risk prediction such as considerations in model development and in assessing improvements in prediction models. It is well-known that prediction models perform at best in populations in which they were developed. Therefore, it is important to validate the prediction model internally as well as externally. Because of the large number of cases and the limited number of predictors included into the model, internal validation of the CAREMA risk score was not considered indicated. Before use in practice, however, the CAREMA risk score should be validated externally to assess its performance in other populations. For an accurate external validation, however, identification of incident CHD cases should be as accurate as in our study.

Future studies should also focus on developing risk scores to predict the incidence of other cardiovascular diseases, such as stroke. Furthermore, special attention should be given to an improvement of risk prediction in younger adults and the elderly, as other risk factors may be more important in these groups compared with a middle-aged population. In practice, however, risk scores will only be effective when they are addressed properly and when their use indeed results in a lower CHD incidence over time. 

Samenvatting 
Coronaire hartziekten (CHD) gaan gepaard met een hoge ziektelast in Nederland. Deze aandoening heeft grote gevolgen zowel voor de individuele patiënt als voor de maatschappij (hoofdstuk 1). Daarom is er veel aandacht voor de primaire preventie van CHD waarbij de identificatie van personen zonder symptomen maar met een hoog risico op de ziekte van nut kan zijn. In de laatste decennia zijn verscheidene pogingen ondernomen om op basis van het cumulatieve effect van de risicofactoren van een persoon zijn of haar absolute risico op het ontwikkelen van CHD in de komende jaren te voorspellen. Als gevolg hiervan zijn er verschillende risicoscores ontwikkeld voor verschillende cardiologische eindpunten, waarvan de Framingham risicoscore waarschijnlijk het meest bekend is. Hoewel deze scores het risico redelijk goed voorspellen binnen hun eigen en soortgelijke populaties, wordt hun functioneren in andere populaties beperkt door verschillen in niveaus en trends van zowel de risicofactoren als de ziekte. Als oplossing voor dit probleem zijn er methodes ontwikkeld voor het herberekenen van een risicoscore.

Zowel de bestaande als de herberekende risicoscores hebben echter een aantal beperkingen. Ten eerste worden voor de herberekening gemiddelde waarden voor de risicofactoren en de ziekte gebruikt van de populatie waarin de risicoscore toegepast zal worden. Het zou echter beter zijn om deze herberekening te baseren op gegevens die op een individueel niveau gemeten zijn, bij voorkeur binnen een prospectief onderzoek. Ten tweede, vanwege de hoge ziektelast van CHD met een niet-fatale afloop is de voorspelling van zowel patiënten met een fatale als met een niet-fatale afloop van de ziekte van groter belang dan de voorspelling van alleen sterfte. Daarom hebben wij een risicoscore ontwikkeld voor de Nederlandse populatie die het risico voorspelt op het ontwikkelen van coronaire hartaandoeningen met zowel een fatale als een nietfatale afloop. Hiervoor hebben we gegevens gebruikt uit de prospectieve Cardiovasculaire Registratie Maastricht (CAREMA) cohortstudie waarvan de onderzoekspopulatie afkomstig is uit de algemene bevolking.

De CAREMA cohortstudie bestaat uit 21.148 deelnemers in de leeftijd van 20-59 jaar bij aanvang van de studie en woonachtig in de regio Maastricht. De deelnemers zijn afkomstig uit twee monitoringsprojecten van het Rijksinstituut voor Volksgezondheid en Milieu (RIVM): het Peilstationsproject Hart- en Vaatziekten (PPHVZ) in 1987-1992 en het project Monitoring van Risicofactoren en Gezondheid in Nederland (MORGEN) in 1993-1997. Bij aanvang van de studie waren de volgende gegevens van de deelnemers beschikbaar: demografische kenmerken zoals leeftijd en geslacht, medische voorgeschiedenis, voorgeschiedenis van de ouders betreffende een hartinfarct, lengte en gewicht, bloeddruk en cholesterolgehaltes, informatie over leefstijlfactoren en hun gebruikelijke voedselinname.

Vervolgens hebben we de deelnemers tot en met 31 december 2003 gevolgd. Door middel van een koppeling van het cohort aan de Gemeentelijke Basisadministratie werden eventuele verhuizingen en de vitale status van de deelnemers bijgehouden. Voor deelnemers die overleden bleken te zijn, werd de doodsoorzaak verkregen uit de 
doodsoorzakenregistratie van het Centraal Bureau voor de Statistiek (CBS). Door middel van een koppeling aan het Cardiologisch Informatiesysteem (CIS) van de afdeling Cardiologie van het academisch ziekenhuis Maastricht (azM) werd nagegaan welke deelnemers een cardiologische aandoening hebben ontwikkeld. Het CIS is een unieke registratie die cardiologische informatie bevat van alle personen die de afdeling Cardiologie van het azM hebben bezocht. Gedurende de follow-up periode werden zowel incidente patiënten met een fatale als met een niet-fatale afloop van hun coronaire aandoening geïdentificeerd op basis van de gegevens uit het CIS en de doodsoorzakenregistratie van het $\mathrm{CBS}$.

In hoofdstuk 2 hebben we incidentiecijfers berekend voor CHD, het acuut hartinfarct, instabiele angina pectoris, hartfalen en plotse hartdood op basis van het CIS in combinatie met de doodsoorzakenregistratie (CIS-gebaseerde methode). Het incidentiecijfer per 100.000 persoonsjaren bedroeg 362,2 voor CHD, 212,2 voor het acuut hartinfarct, 171,8 voor instabiele angina pectoris, 66,4 voor hartfalen en 65,4 voor plotse hartdood. In de meeste landen, waaronder Nederland, zijn geen ziekteregistraties voor hart- en vaatziekten voorhanden. Daarom worden de incidentiecijfers voor CHD en andere hartaandoeningen vaak berekend aan de hand van gegevens over ziekenhuisontslagdiagnoses en doodsoorzaken. De validiteit van deze cijfers is echter afhankelijk van de volledigheid en nauwkeurigheid van de gegevens in deze registraties. Ook is het van belang dat de juiste persoon aan de juiste gegevens in deze registraties wordt gekoppeld. Daarom hebben we de incidentiecijfers op basis van het CIS en de doodsoorzakenregistratie vergeleken met incidentiecijfers op basis van ziekenhuisontslagdiagnoses en doodsoorzaken om de compleetheid en validiteit van de laatstgenoemde methode te bepalen.

Indien de incidentiecijfers op basis van het CIS als gouden standaard werden beschouwd, vonden we hoge waarden voor de sensitiviteit en positief voorspellende waarde voor CHD en het acuut hartinfarct. Deze waarden waren aanzienlijk lager voor instabiele angina pectoris en hartfalen. Een groot aantal patiënten (variërend van $14,2 \%$ voor het acuut hartinfarct tot $47,5 \%$ voor hartfalen) werd alleen gevonden in het CIS maar werd gemist of was anders gecodeerd in de ziekenhuisontslagregistratie. Hierdoor waren de incidentiecijfers op basis van de ziekenhuisontslagdiagnoses en doodsoorzaken aanzienlijk lager dan de incidentiecijfers op basis van de CISgebaseerde methode. Dit was met name het geval voor instabiele angina pectoris en hartfalen. Incidentiecijfers op basis van ziekenhuisontslagdiagnoses en doodsoorzaken kunnen dus de werkelijke incidentiecijfers van deze hartaandoeningen onderschatten.

Metabole factoren zoals diabetes, hypertensie, obesitas, een laag HDL en hoog totaal cholesterolgehalte, die geassocieerd zijn met een verhoogd risico op CHD, komen wereldwijd steeds vaker voor. Er is echter weinig bekend over de specifieke combinaties van deze factoren die geassocieerd zijn met het hoogste risico op CHD. Hoofdstuk 3 beschrijft de resultaten van onze studie naar de verbanden tussen me- 
tabole factoren en het risico op totaal CHD, het acuut hartinfarct en instabiele angina pectoris. Diabetes, hypertensie, obesitas, een laag HDL en een hoog totaal cholesterolgehalte waren allemaal onafhankelijke risicofactoren voor totaal CHD en het acuut hartinfarct. Van deze metabole factoren vertoonden diabetes en obesitas echter geen onafhankelijk verband met het risico op instabiele angina pectoris. Daarnaast vonden we een duidelijke dosis-respons relatie met een toenemend aantal metabole factoren. Het relatieve risico (RR) voor personen met drie of meer metabole factoren was 7,36 (95\% betrouwbaarheidsinterval (BI) 5,73-9,45) voor totaal CHD, 9,34 (95\% BI 6,67$13,08)$ voor het acuut hartinfarct en 5,28 (95\% BI 3,45-8,09) voor instabiele angina pectoris vergeleken met personen met geen enkele metabole risicofactor. Van alle mogelijke combinaties tussen de vijf metabole factoren waren vooral combinaties met diabetes of met zowel een laag HDL als een hoog totaal cholesterolgehalte geassocieerd met de hoogste risico's op de drie coronaire aandoeningen.

Slechts enkele studies hebben het verband tussen leefstijlfactoren en het risico op instabiele angina pectoris onderzocht, terwijl de sterkte van deze verbanden kunnen verschillen ten opzichte van andere hartaandoeningen zoals het acuut hartinfarct. Daarom hebben wij de relaties onderzocht tussen roken, alcoholconsumptie, lichamelijke activiteit, een familiaire belasting voor CHD en het risico op een acuut hartinfarct en op instabiele angina pectoris als aparte eindpunten. De resultaten van deze studie staan weergegeven in hoofdstuk 4. Roken verhoogde zowel het risico op een acuut hartinfarct als op instabiele angina pectoris. Bovendien nam het risico toe met een toenemend aantal gerookte sigaretten per dag en een toenemend aantal rookjaren, hoewel deze trend minder duidelijk aanwezig was voor de laatstgenoemde factor. Verder hadden personen die regelmatig alcohol dronken, een lager risico op het ontwikkelen van een acuut hartinfarct of instabiele angina pectoris dan personen die nooit alcohol dronken. Dit verband was onafhankelijk van het type alcoholische drank (bier, wijn of sterke drank). Voor mannen was lichamelijke activiteit gedurende het werk een risicofactor voor beide coronaire aandoeningen, terwijl deze factor bij vrouwen met een lager risico op zowel een acuut hartinfarct als instabiele angina pectoris geassocieerd was. Lichamelijke activiteit gedurende vrije tijd daarentegen was geassocieerd met een niet-significant beschermend effect bij mannen, terwijl het een risicofactor bleek te zijn voor vrouwen. Hoewel de verbanden met de leefstijlfactoren sterker leken te zijn voor het acuut hartinfarct dan voor instabiele angina pectoris, waren de verschillen alleen statistisch significant voor de rookvariabelen.

Het hebben van ouder(s) die een hartinfarct hebben doorgemaakt, was geassocieerd met een verhoogd risico op een acuut hartinfarct en instabiele angina pectoris. Dit risico was vooral verhoogd wanneer beide ouders een hartinfarct hadden doorgemaakt of wanneer zij het infarct op jongere leeftijd hadden doorgemaakt. Hoewel deze verbanden sterker leken te zijn voor instabiele angina pectoris dan voor het acuut hartinfarct, waren de verschillen niet statistisch significant. Personen met een familiaire belasting zijn mogelijk gevoeliger voor het schadelijke effect van andere risico- 
factoren. Daarom hebben we tevens onderzocht of de verbanden tussen de leefstijlfactoren en het risico op beide coronaire aandoeningen verschilden tussen personen met en zonder een familiaire belasting. We vonden we geen duidelijke verschillen in deze verbanden tussen personen met en zonder ouder(s) die een prematuur hartinfarct (op de leeftijd van 60 jaar of jonger voor de vader en 65 jaar of jonger voor de moeder) hebben doorgemaakt. Desalniettemin vonden we de hoogste risico's bij personen met een familiaire belasting en het meest ongunstige niveau van de leefstijlfactoren.

Hoofdstuk 5 beschrijft de eigenlijke ontwikkeling van de risicoscore. Hiervoor hebben we de zogenaamde SCORE risicofunctie, die momenteel wordt toegepast in de Nederlandse huisartsenrichtlijn 'Cardiovasculair risicomanagement', als uitgangspunt genomen. Deze risicofunctie hebben we herberekend (gerecalibreerd) aan de hand van gegevens over het niveau van de risicofactoren en de incidentiecijfers voor CHD uit de CAREMA cohortstudie. Het discriminerend vermogen van een risicoscore beschrijft hoe goed de score personen die de ziekte ontwikkeld hebben tijdens de follow-up periode, kan onderscheiden van personen zonder de ziekte. Dit discriminerend vermogen kan gemeten worden met de c statistic (een toetsingsgrootheid die vergelijkbaar is met de oppervlakte onder de ROC-curve). Voor de gerecalibreerde risicoscore bedroeg de $c$ statistic 0,799 (95\% BI 0,782-0,816). Het toevoegen van extra risicofactoren (o.a. quetelet index, diabetes of familiaire belasting) verbeterde de risicovoorspelling door de gerecalibreerde risicoscore niet. Het opsplitsen van de totaal/HDL cholesterolratio in totaal en HDL cholesterolgehaltes leidde niet tot een verbetering in de c statistic maar hergroepeerde wel 6,0\% van de onderzoekspersonen in een meer van toepassing zijnde risicocategorie vergeleken met de oorspronkelijke gerecalibreerde risicoscore $(p$ $<0.001$ ). Daarom bestaat de uiteindelijke CAREMA risicoscore uit de volgende voorspellende factoren: leeftijd in jaren (tijdsvariabele), geslacht (strata), huidige roker (ja/nee), systolische bloeddruk in $\mathrm{mmHg}$ (continue variabele), en het totaal en HDL cholesterolgehalte in $\mathrm{mmol} / \mathrm{L}$ (allebei continue variabelen). Vergeleken met twee SCORE risicofuncties - één voor landen waar CHD relatief vaak voorkomt en één voor landen waar CHD minder vaak voorkomt - werd een groot aantal onderzoekspersonen, zowel personen met als zonder CHD, door de CAREMA risicoscore ingedeeld in een hogere risicocategorie. Dit resultaat kan met name verklaard worden doordat de SCORE risicofunctie alleen het risico op sterfte aan hart- en vaatzieken voorspelt, terwijl de CAREMA risicoscore het risico op CHD met zowel een fatale (sterfte) als een niet-fatale afloop in de komende tien jaar voorspelt. De Framingham risicoscore daarentegen voorspelt dezelfde uitkomstmaat als de CAREMA risicoscore. Vergeleken met deze score hergroepeerde de CAREMA risicoscore nog steeds een groot aantal onderzoekspersonen in een risicocategorie, die beter paste bij het daadwerkelijke risico van de persoon. 
In hoofdstuk 6 zijn de belangrijkste bevindingen uit onze studies samengevat en bediscussieerd in het licht van de huidige kennis en praktijk over hart- en vaatziekten. In deze studies zijn de gegevens over het optreden van cardiologische aandoeningen afkomstig uit een unieke registratie die de cardiologische informatie bevat van alle personen die ooit de afdeling Cardiologie van het azM hebben bezocht. Deze gegevens zijn op een zorgvuldige manier verzameld door slechts een beperkt aantal onderzoeksmedewerkers onder begeleiding van een cardioloog. Daarom zullen de incidentiecijfers die berekend zijn op basis van onze studiegegevens, kwalitatief beter zijn dan de incidentiecijfers op basis van ziekenhuisontslagdiagnoses.

In onze studie hebben we een sterke dosis-respons relatie gevonden tussen het aantal metabole factoren en het risico van CHD. Daarom is een clustervariabele op basis van het aantal metabole factoren mogelijk relevanter voor het voorspellen van het risico op CHD dan de individuele factoren. Maar we hebben ook gevonden dat het risico op CHD binnen deze clusters afhankelijk is van de specifieke combinaties van factoren. Daarom is het beter de metabole factoren als individuele voorspellers in de risicofuncties op te nemen. Omdat wij verder geen duidelijke verschillen hebben gevonden in het effect van de leefstijlfactoren tussen personen met en zonder een familiaire belasting, is het niet nodig aparte effectschattingen van de risicofactoren te gebruiken voor deze twee groepen. Daarnaast hebben we geen grote verschillen gevonden in de sterkte van de verbanden tussen de risicofactoren en het risico op een acuut hartinfarct en op instabiele angina pectoris. Daarom is het ook niet nodig aparte risicofuncties te ontwikkelen voor deze twee aandoeningen die dan gecombineerd zouden worden om het risico op totaal CHD te voorspellen.

Verder worden in hoofdstuk 6 enkele belangrijke punten betreffende risicovoorspelling besproken zoals overwegingen bij de modelontwikkeling en bij het meten van verbeteringen in predictiemodellen. Het is alom bekend dat predictiemodellen het beste voorspellen in populaties waarin zij ontwikkeld zijn. Daarom is het belangrijk een predictiemodel zowel intern (binnen de onderzoekspopulatie) als extern (in andere populaties) te valideren. Vanwege het grote aantal patiënten met CHD en het beperkte aantal predictoren in het model was interne validatie van de CAREMA risicoscore niet noodzakelijk. Maar de CAREMA risicoscore dient wel extern gevalideerd te worden om zijn functioneren in andere populaties te testen, alvorens de score in de praktijk toegepast kan worden. Bij externe validatie van de CAREMA risicoscore is het belangrijk dat de identificatie van personen met de aandoening in deze studies even zorgvuldig gebeurt als in de CAREMA studie. 
Toekomstige studies zouden zich verder ook moeten richten op de ontwikkeling van risicoscores voor de voorspelling van andere hartaandoeningen, zoals een beroerte.

Omdat bij jongvolwassenen en personen op oudere leeftijd andere risicofactoren van belang kunnen zijn dan bij personen van middelbare leeftijd, zou men ook extra aandacht moeten geven aan de verbetering van risicovoorspellingen in deze groepen. In de praktijk zijn risicoscores echter alleen effectief wanneer zij op een juiste manier toegepast worden en wanneer het gebruik van deze scores daadwerkelijk leidt tot een afname in het aantal patiënten in de tijd. 

Dankwoord 
Zo, nu zijn we aangekomen bij misschien wel het meest gelezen hoofdstuk van het proefschrift. Dit boekje is er gekomen door de hulp en steun van vele anderen. Ik wil dan ook iedereen hartelijk bedanken die op wat voor manier dan ook heeft bijgedragen aan de totstandkoming van dit boekje! Verder wil ik op deze pagina's een aantal personen in het bijzonder bedanken.

Allereerst wil ik mijn copromotoren en promotoren bedanken.

Leo, als dagelijkse begeleider hebben we heel wat tijd samen doorgebracht. Wat ik ontzettend waardeer in jouw begeleiding is je betrokkenheid. Onze afspraken begonnen altijd met een persoonlijke noot om daarna allerlei zaken rondom het promotieproject te bespreken. Maar ook buiten onze afspraken stond je deur altijd open om mij over allerlei uiteenlopende zaken advies te geven. Je bent een geweldige begeleider! Ik vind het dan ook leuk om te merken dat ik in mijn eigen begeleiding van stagiaires verschillende dingen van jou heb overgenomen.

Jolanda, hoewel de afstand tussen ons letterlijk gezien wat groter was (jij in Bilthoven en ik in Maastricht) was de afstand in je begeleiding juist heel klein. Ik kon altijd bij jou terecht met vragen en hoe lang mijn e-mails soms ook waren, ik kreeg altijd snel een antwoord van je terug. Daarnaast wil ik je ook bedanken voor je kritische blik op de data-analyses en artikelen. Hoewel ik soms een beetje schrok van de omvang, kon ik je uitgebreide opmerkingen en suggesties voor de artikelen altijd zeer waarderen en hier heb ik ook veel van geleerd!

Piet, bedankt voor je goede begeleiding. Jij wist het overzicht altijd goed te bewaren. Het nauwkeurig in de gaten houden van de tijdsplanning, je efficiënte werkwijze en je concrete beslissingen hebben mij vaak geholpen. Verder heb jij me geleerd dingen in een breder perspectief te plaatsen.

Ton, bedankt voor de fijne begeleiding. Ik heb veel geleerd van uw blik op de onderwerpen vanuit de cardiologische kant. Onze besprekingen tijdens de dataverzameling van de cardiologische gegevens heb ik als zeer prettig ervaren. Ook nadat alle gegevens verzameld waren, was $u$ altijd bereid om mij verder wegwijs te maken in de bijzondere wereld van de cardiologie.

Ook wil ik graag Edith Feskens bedanken die altijd nauw betrokken is geweest bij het project. Edith, jouw kennis over de epidemiologie van hart- en vaatziekten heeft mij vaak geholpen bij het schrijven van de artikelen. Ondanks je drukke werkzaamheden wist je altijd wel tijd vrij te maken op mij verder op weg te helpen. Bedankt!

Verscheidene personen hebben bijgedragen aan de opzet dan wel uitvoer van het onderzoek die ik hiervoor graag wil bedanken.

Monique Verschuren, bedankt voor het kritisch becommentariëren van de artikelen. Ik vind het jammer dat we ons op het congres in Stockholm zijn misgelopen en elkaar dus niet in levenden lijve hebben kunnen ontmoeten. 
Ton Ambergen, ik wil u graag bedanken voor uw hulp en suggesties bij het doorgronden van de statistische aspecten bij de ontwikkeling van de risicoscore. Bedankt dat ik altijd op korte termijn bij u terecht kon.

Ewout Steyerberg, uw boek heeft mij goed geholpen bij het opzetten van een plan voor de ontwikkeling van de risicoscore. Via de e-mail heb ik mijn vragen persoonlijk aan $u$ kunnen stellen die $u$ vervolgens op een zeer vriendelijke en openhartige manier beantwoord hebt. Ik vind het dan ook een hele eer dat $u$ coauteur bent op het artikel over de risicopredictie.

Petra Erkens, met veel plezier denk ik terug aan onze zeer prettige samenwerking. Dat jij na je hulp bij de data-invoer van de cardiologische gegevens bij mij en Leo stage kwam lopen voor je master thesis Epidemiologie, vond ik heel bijzonder. Jouw werkzaamheden hebben een grote bijdrage geleverd aan dit onderzoek, bedankt hiervoor! Ook Ann Hilton, Violet Visser en Suzanne Philippens wil ik graag bedanken voor hun hulp bij het invoeren van de cardiologische gegevens van de meer dan 4000 onderzoekspersonen in het CIS. Ook de overige personen die betrokken zijn geweest bij de klinische dataverzameling wil ik hiervoor graag hartelijk bedanken.

Sacha van de Crommert, bedankt voor je goede hulp bij het opzetten en uitvoeren van de kwaliteitscontroles nadat alle gegevens verzameld en ingevoerd waren.

Dr. Fitzgerald en dr. Cooney van het SCORE-project wil ik graag bedanken voor het aanleveren van gedetailleerde informatie over de coëfficiënten in de SCORE risicofuncties.

Verder wil ik graag de coördinatoren en stuurgroep van het Peilstationsproject en het MORGEN-project bedanken, de epidemiologen en veldwerkers van de GGD's in Maastricht, Amsterdam en Doetinchem voor hun bijdrage aan de dataverzameling bij aanvang van de studie en allen die betrokken waren bij de logistieke kanten en het databeheer binnen deze projecten. Natuurlijk wil ik ook de onderzoekspersonen bedanken die zich destijds de moeite hebben genomen om deel te nemen aan de monitoringsprojecten van het RIVM. Zonder hen allen was dit onderzoek niet mogelijk geweest.

Mijn collega's en oud-collega's van de afdeling Epidemiologie wil ik graag bedanken voor de gezellige en collegiale sfeer op de afdeling. De gezellige gesprekken en fijne discussies zorgen ervoor dat ik met plezier op mijn werk rondloop.

Alle mede-promovendi, van wie een deel nu al gepromoveerd is, wil ik graag bedanken voor de gezellige lunches en wandelingen, de lekkere en gezellige diners en de plezierige AiO-uitjes. Vele dingen hebben we wel een keer met elkaar besproken, zowel de pieken en dalen van een promotieproject als de dagelijkse beslommeringen buiten het werk.

Rob de Bie, jou wil ik graag hartelijk bedanken voor de ruimte die je me geboden hebt om mijn proefschrift af te ronden. Ik zie uit naar onze prettige samenwerking in de komende jaren. 
Yvonne en Nathalie, hartelijk dank voor alles wat jullie voor me gedaan hebben. Ik kon altijd bij jullie terecht voor advies of hulp, zelfs voor de kleinste dingen. Bedankt ook voor jullie luisterend oor en jullie interesse in de dagelijkse dingen buiten het werk.

Ook de (ex-)secretaresses van mijn promotor Ton wil ik graag bedanken. Lilian Skiba, Nicoline Nanninga en Nadine Hofman, bedankt voor jullie behulpzaamheid bij het plannen van afspraken en andere zaken. Jullie hebben me altijd goed geholpen bij al mijn vragen en wensen.

Jos en Harry, vaak heb ik jullie hulp nodig gehad als ik weer eens ruzie had met mijn computer. Maar ook voor allerlei andere technische vragen en computerweetjes kon ik altijd bij jullie terecht. Bedankt!

Yvonne, jou wil ik hartelijk bedanken voor de mooie lay-out van mijn proefschrift. Niets was je te veel, zelfs niet als ik weer eens met een kleine wijziging of aanpassing in de teksten kwam. En het eindresultaat is super, bedankt!

Bas, jouw eerste idee voor het ontwerp van de omslag vond ik meteen al super. Nu de kleur ook nog eens helemaal naar wens is, is het eindresultaat werkelijk fantastisch geworden, bedankt!

Lieve paranimfen, Esther en Marlou, ik vind het een hele eer dat jullie tijdens mijn verdediging aan mijn zijde willen staan. Geweldig om te zien hoe enthousiast jullie reageerden op het verzoek om mijn paranimf te zijn.

Esther, mijn kamergenootje, samen hebben we een gezellige tijd gehad op onze kamer. Alles konden we met elkaar bespreken, zowel de perikelen in onze promotieonderzoeken als ook al onze belevenissen buiten het werk. Ik vind het dan ook geweldig dat jij ook bij de laatste etappe van mijn promotieonderzoek aan mijn zij wilt staan.

Marlou, je bent voor mij een echte goede vriendin. Samen kunnen we praten, lachen en huilen, en ik weet dat ik altijd bij jou terecht kan en andersom. Onze vriendschap is voor mij heel belangrijk. Ik vind het dan ook heel bijzonder dat jij tijdens de verdediging van mijn proefschrift naast mij wilt staan.

Lieve familie en vrienden, bedankt voor al jullie interesse in mijn onderzoek gedurende de afgelopen jaren. De gezellige dates, etentjes, feestjes of gewoon het gezellig samenzijn hebben vaak voor de nodige ontspanning gezorgd.

Lieve Roel, vorig jaar ben jij me voor gegaan als dr. Merry en nu is het mijn beurt. Bedankt dat ik altijd met alles bij je terecht kan en dat je altijd voor me klaarstaat. Je adviezen en praktische tips hebben me vaak geholpen. Je bent de beste broer die ik me kan wensen!

Lieve pap en mam, mede dankzij jullie ben ik zover gekomen en is dit boekje tot stand gekomen; het is dan ook voor en van jullie. Bedankt voor alle kansen die jullie me geboden hebben en voor jullie onvoorwaardelijke liefde en steun bij alle stappen in mijn leven! 
Allerliefste Marcel, woorden kunnen niet omschrijven wat jij voor mij betekent. Bedankt voor al je liefde en onvoorwaardelijke steun elke dag in mijn leven, zo ook tijdens de pieken en dalen van mijn promotieonderzoek. Bedankt ook dat je me alle ruimte hebt gegeven voor de afronding van mijn boekje, ook al ging dit vaak ten koste van onze tijd samen. Zonder jou was het me niet gelukt! Lieverd, ik hoop dat we samen nog vele gelukkige jaren tegemoet mogen gaan. 

About the author 
Audrey Merry was born on August 6, 1982 in Sittard, the Netherlands. She completed secondary school (Gymnasium) at the Trevianum Scholengroep Sittard in 2000. In the same year, she started her study Biomedical Sciences at the Radboud University Nijmegen. In 2003, she obtained her Bachelor degree and continued her study with the master of Epidemiology at the same university. During this master, she fulfilled her internship at the Department of Epidemiology of Maastricht University, resulting in the master thesis "Body Mass Index, height and adenocarcinomas of the oesophagus and gastric cardia". After graduating, Audrey started working as a PhD student at the Department of Epidemiology (CAPHRI School for Public Health and Primary Care, Maastricht University) in September 2005 on a research project, entitled "Incidence of cardiac disease and development of a risk score in the Netherlands: a prospective cohort study", resulting in this thesis. Since September 2009, Audrey works as a lecturer at the Department of Epidemiology, Maastricht University.

Audrey is married to Marcel Golsteijn. 